\title{
Endoscopic treatment of obesity and metabolic disorders : basic and clinical studies on the effect of the Duodenal-Jejunal bypass liner
}

Citation for published version (APA):

de Jonge, C. (2014). Endoscopic treatment of obesity and metabolic disorders : basic and clinical studies on the effect of the Duodenal-Jejunal bypass liner. [Doctoral Thesis, Maastricht University]. Maastricht University. https://doi.org/10.26481/dis.20140905cj

Document status and date:

Published: 01/01/2014

DOI:

10.26481/dis.20140905cj

Document Version:

Publisher's PDF, also known as Version of record

Please check the document version of this publication:

- A submitted manuscript is the version of the article upon submission and before peer-review. There can be important differences between the submitted version and the official published version of record.

People interested in the research are advised to contact the author for the final version of the publication, or visit the DOI to the publisher's website.

- The final author version and the galley proof are versions of the publication after peer review.

- The final published version features the final layout of the paper including the volume, issue and page numbers.

Link to publication

\footnotetext{
General rights rights.

- You may freely distribute the URL identifying the publication in the public portal. please follow below link for the End User Agreement:

www.umlib.nl/taverne-license

Take down policy

If you believe that this document breaches copyright please contact us at:

repository@maastrichtuniversity.nl

providing details and we will investigate your claim.
}

Copyright and moral rights for the publications made accessible in the public portal are retained by the authors and/or other copyright owners and it is a condition of accessing publications that users recognise and abide by the legal requirements associated with these

- Users may download and print one copy of any publication from the public portal for the purpose of private study or research.

- You may not further distribute the material or use it for any profit-making activity or commercial gain

If the publication is distributed under the terms of Article $25 \mathrm{fa}$ of the Dutch Copyright Act, indicated by the "Taverne" license above, 


\section{Endoscopic treatment of Obesity and Metabolic disorders}

Basic and Clinical studies on the effect of the

Duodenal-Jejunal Bypass Liner

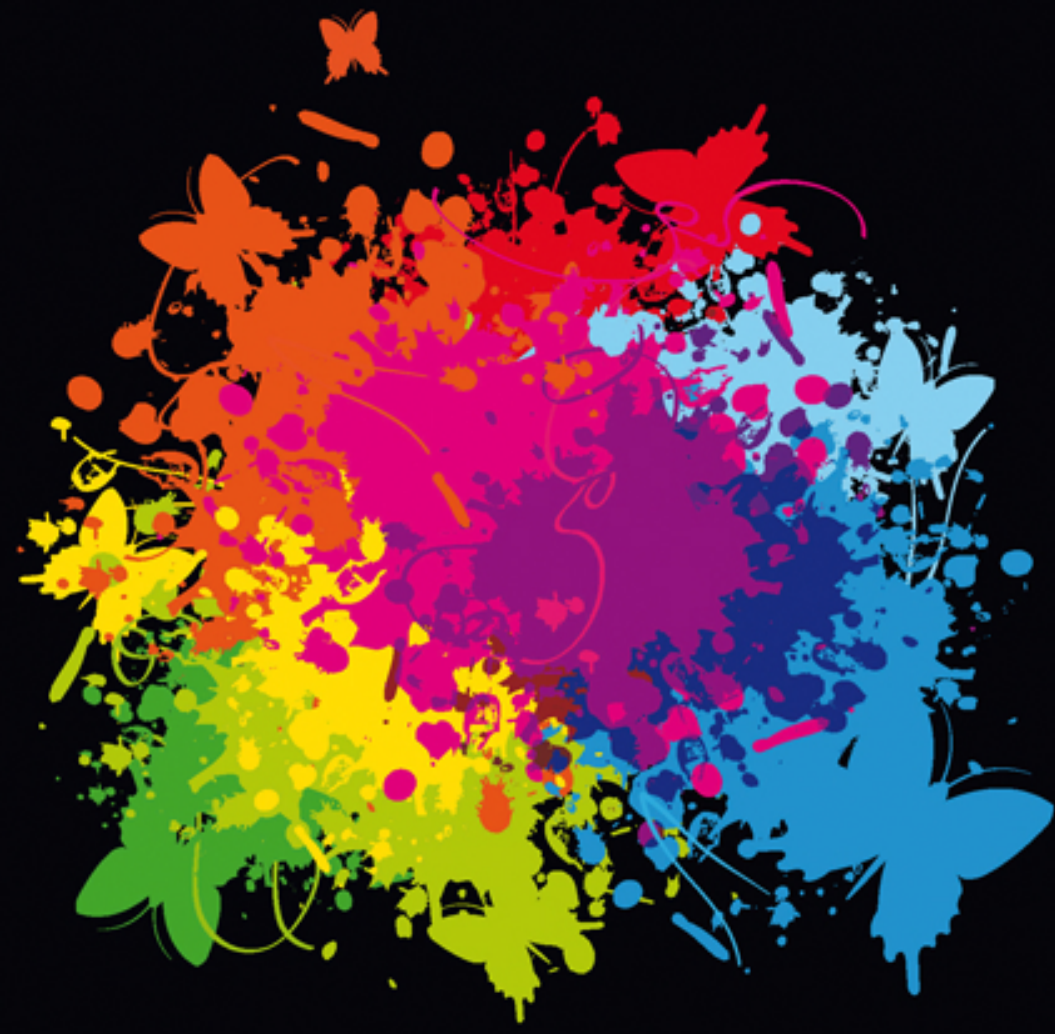

Charlotte de Jonge 



\title{
Endoscopic treatment of Obesity and Metabolic disorders
}

\author{
Basic and Clinical studies on the effect of the \\ Duodenal-Jejunal Bypass Liner
}

\author{
PROEFSCHRIFT \\ ter verkrijging van de graad van doctor \\ aan de Universiteit Maastricht, \\ op het gezag van de Rector Magnificus, \\ Prof. dr. L.L.G. Soete, \\ volgens het besluit van het College van Decanen, \\ in het openbaar te verdedigen \\ op vrijdag 5 september 2014 om 10.00 uur
}

door

Charlotte de Jonge

Geboren op 10 september 1985 te Zierikzee, Nederland 


\section{Promotor}

Prof. dr. W.A. Buurman

\section{Copromotores}

Dr. N.D. Bouvy

Dr. J.W.M. Greve (Atrium Medisch Centrum Parkstad, Heerlen)

Dr. S.S. Rensen

\section{Beoordelingscommissie}

Prof. dr. E. Blaak (voorzitter)

Prof. dr. A. Masclee

Prof. dr. F. Pattou (Hôpital Huriez, Lille, Frankrijk)

Dr. B. van Ramshorst (St. Antonius Ziekenhuis, Nieuwegein)

Prof. dr. C. Stehouwer 
Aan mijn ouders 



\section{CONTENTS}

$\begin{array}{lll}\text { Chapter } 1 & \text { General Introduction } & 9\end{array}$

Chapter 2 The effect of the endoscopic Duodenal-Jejunal Bypass Liner on obesity and type 2 diabetes mellitus, a multi-center randomized controlled trial

Chapter 3 Endoscopic Duodenal-Jejunal Bypass Liner rapidly improves type 2 diabetes

Chapter $4 \quad$ Impact of duodenal-jejunal exclusion on satiety hormones

Chapter $5 \quad$ Endoscopic Duodenal-Jejunal Bypass Liner rapidly improves plasma parameters of Nonalcoholic Fatty Liver Disease in obese subjects

Chapter 6 Human intestinal microbiota composition is associated with 87 local and systemic inflammation in obesity

Chapter 7 Metabolic improvement after duodenal-jejunal exclusion correlates to changes in intestinal microbiota composition

Chapter 8 Six months of treatment with the endoscopic DuodenalJejunal Bypass Liner does not lead to decreased systemic inflammation in obese patients with type 2 diabetes

Chapter 9 General Discussion

Chapter $10 \quad$ Valorization

Chapter $11 \quad$ Nederlandse Samenvatting

Appendix

Dankwoord 

Chapter 1

General Introduction 
Chapter 1 


\section{GENERAL INTRODUCTION}

\section{Overweight and obesity, definitions and epidemiology}

According to the World Health Organization, overweight and obesity are defined as abnormal or excessive fat accumulation that might impair health. A classification has been made based on body mass index (BMI), a simple weight for height index defined as a person's weight in kilograms divided by the square of a person's height in meters (weight/height ${ }^{2}$ ). Subjects with a BMI $\geq 25 \mathrm{~kg} / \mathrm{m}^{2}$ are considered overweight, whereas subjects with a BMI $\geq 30 \mathrm{~kg} / \mathrm{m}^{2}$ are considered obese. Severe or morbid obesity is defined as a $\mathrm{BMI} \geq 40 \mathrm{~kg} / \mathrm{m}^{2,1}$

Worldwide, the prevalence of obesity has increased tremendously over the last decades. ${ }^{1,2}$ Projections made in 2005 predicted the total number of overweight individuals worldwide to be at least 1.35 billion in $2030 .{ }^{3}$ Unfortunately, this number has already been reached. The same holds true for the Netherlands. Obesity among adults has increased dramatically and the prevalence has more than doubled over the last 30 years. To date, in the category 'men over 40 years of age', more than half is overweight and in total more than 6.5 million people are suffering from overweight in our country. In addition, the percentage of people with obesity has increased to around 12 over the last years and this trend seems to continue. $^{4}$

Importantly, overweight is nowadays the fifth leading risk factor for death globally. More than half of the world's population lives in countries where overweight and obesity kill more people than underweight. Notably, once considered a high-income country problem, the prevalence of obesity is now also dramatically on the rise in low-income and middleincome countries. In addition, it is also affecting young adults and even children. In 2011, an estimated 40 million children under the age of five were overweight. ${ }^{1}$

\section{Description and epidemiology of comorbidities of obesity}

A number of diseases have been associated with overweight and obesity. As Hippocrates already wrote: "Corpulence is not only a disease itself, but the harbinger of others". Examples of obesity-related diseases or comorbidities are: type 2 diabetes, cardiovascular diseases, several types of cancer, psychosocial and musculoskeletal problems, obstructive sleep apnea syndrome, nonalcoholic fatty liver disease (NAFLD), and the metabolic syndrome. As a consequence of the obesity epidemic, the prevalence of these comorbidities is also rising. ${ }^{5,6}$ The comorbid conditions of obesity that are the subject of this thesis, type 2 diabetes and NAFLD, and their epidemiology will be described below. 
Type 2 diabetes is the most prevalent obesity-related disease. It is characterized by a combination of insulin resistance, a condition in which the body fails to respond to the normal actions of the hormone insulin, and insufficient insulin secretion by the $\beta$-cells of the pancreas causing high fasting and high postprandial blood glucose levels (hyperglycemia). ${ }^{7}$ When blood glucose levels exceed the reabsorption capacity of the kidneys, glycosuria develops. This is accompanied by a classical triad of symptoms: polyuria (frequent urination), polydipsia (increased thirst), and polyphagia (increased hunger). Long term complications can be divided into macrovascular diseases, like myocardial infarction, stroke, and peripheral arterial vascular disease, and microvascular

diseases such as diabetic nephropathy, retinopathy, and peripheral neuropathy. ${ }^{8,9}$ In parallel to the increased prevalence of obesity, a dramatic rise in the number of people suffering from type 2 diabetes has been observed over the last years and predictions indicate that this number will continue to increase. ${ }^{10}$

Another prevalent comorbid condition strongly associated with obesity is nonalcoholic fatty liver disease or NAFLD. NAFLD comprises a disease spectrum ranging from simple benign steatosis or a fatty liver, to a state of an inflamed steatotic liver referred to as nonalcoholic steatohepatitis (NASH). ${ }^{11,12}$ Hepatic steatosis, the early stage of NAFLD, is defined as at least $5 \%$ fat accumulation in the liver. Progression from a fatty liver to the more advanced stage NASH occurs often. In turn, NASH can evolve to liver fibrosis and cirrhosis, increases the risk of developing hepatocellular carcinoma, and can even result in end-stage liver failure requiring liver transplantation. Presently, NAFLD is the most common chronic liver disease worldwide, affecting approximately $20 \%$ of the general population. Significantly higher disease rates have been reported among obese subjects and the increasing obesity prevalence will thus have important implications for the future. $^{13-15}$

\section{Pathogenesis of obesity and its related diseases}

Obesity basically results from an imbalance between energy intake and energy expenditure. When energy intake is increased and/or energy expenditure is decreased, the energy balance is positive, leading to an increase in body fat. As a consequence, obesity-related comorbidities might develop. Therefore, an unhealthy life style, in which energy intake exceeds energy expenditure, is considered the culprit in the development of obesity and its related diseases. Notably, a positive energy balance of only $1 \%$ of the average daily consumption is enough to elicit a weight gain of one to two kilograms a year. Over the last decades, our environment has become more and more obesogenic. A large variety of highly palatable, relatively inexpensive, energy dense foods is widely available. In addition, physical activity has decreased due to the increasing sedentary nature of many forms of work, changes in modes of transportation, and the increasing urbanization. ${ }^{1,5,16}$ 
However, the pathogenesis of obesity is more complicated and multifactorial; several additional factors such as genetics, metabolic, psychological and endocrine disorders, and certain drugs may contribute to the obese state. ${ }^{17-19}$

An increasing body of evidence furthermore suggests that the intestinal microbiota potentiate the development of obesity and its associated diseases. Both in animals and in human subjects, obesity has been associated with an altered gut microbiota composition, with a decreased ratio between the two most dominant divisions within the gut microbiome, the Bacteroidetes and the Firmicutes. In addition, the 'obese microbiome' has been associated with an increased capacity to extract energy from the diet and with subsequent storage of fat, promoting the development of obesity. ${ }^{20,21}$

Disturbed regulation of hunger and satiety are other factors often put forward as contributors to the development of obesity. Appetite control results from a complex interplay between several hormonal and neuronal networks. ${ }^{22}$ In obesity, various aberrations within this system have been described. For example, obese subjects have been found to be resistant to the satiety effects of the hormone leptin, ${ }^{23}$ but also an impaired postprandial response of peptide $Y Y$, an important gut derived satiety hormone, has been observed. ${ }^{24}$

Eventually, once the interplay of all known and unknown factors involved has led to the development of obesity, fat has accumulated at different sites within the human body. In the affected organs and tissues, increased fat accumulation is associated with inflammation and impaired function. In adipose tissue, accumulation of fat in adipocytes causes hypertrophy. This not only leads to the obese phenotype, but has numerous additional implications. Visceral adipose tissue, in particular, can be considered an 'organ' with important metabolic and immunological functions: it secretes several cytokines, called adipokines. In the normal situation, the secretion of pro-inflammatory and antiinflammatory adipokines is balanced. In the obese state, adipocyte dysfunction occurs: adipokine production is disturbed supporting the local and systemic inflammation typical for obese subjects. ${ }^{25}$ Moreover, excessive amounts of insulin resistance-inducing and atherosclerosis-provoking adipokines are secreted. The secretion of insulin-sensitizing adipokines is impaired. Furthermore, when the fat storage capacity of the adipocyte is exceeded, ectopic fat deposition will occur; lipid 'flows' into organs such as the liver and the pancreas. This phenomenon is often referred to as the 'fat overflow hypothesis' ${ }^{26}$

In the liver, accumulation of fat, especially fatty acids, will lead to the development of steatosis, potentially progressing to NASH when the liver becomes affected by inflammation. ${ }^{27,28}$ Furthermore, evidence suggests that fat accumulation in the liver, next to accumulation of fat in skeletal muscle and adipose tissue, causes insulin resistance. Under normal conditions, insulin suppresses hepatic glucose production, enhances 
glucose uptake by skeletal muscle cells and the liver, and suppresses lipolysis in adipose tissue. In insulin resistance, these functions are compromised and, as a compensatory mechanism, insulin secretion by pancreatic $\beta$-cells markedly increases. Notably, fat infiltration in the pancreas has been suggested to amplify the age-related decline of its capacity to secrete appropriate amounts of insulin. Consequently, when insulin resistance becomes severe, the ability of the pancreas to secrete the required high rates of insulin is no longer sufficient. As a result, glucose is not adequately taken up and stored as glucagon in the insulin sensitive tissues, and lipolysis and hepatic glucose production is no longer effectively inhibited. This leads to hyperglycemia and high plasma levels of fatty acids; a vicious circle is entered, promoting the development of type 2 diabetes and NAFLD. ${ }^{7,26,27}$

\section{Conservative options in the treatment of obesity}

Since obesity and its associated comorbid conditions are the results of a long term multifactorial process, treatment is challenging. As excess fat as a result of the imbalance between energy intake and energy expenditure is fundamental in the development of obesity, the first step in treatment is weight loss through life style interventions. These interventions are based on the 'eat less and exercise more' principle.

In order to reduce caloric intake, a variety of dietary strategies can be applied, from a 'crash' or very low calorie diet, using meal replacement drinks, to diets that are relatively high in proteins to increase satiety, such as the popular so-called Dr. Frank diet. According to the guidelines of the Dutch Institute for Healthcare Improvement, moderate caloric restriction is best recommended to achieve long term weight loss; daily intake should be restricted to a daily energy deficit of around $600 \mathrm{kcal}$ until the intended weight target has been reached. The initial goal should be to reduce body weight by approximately $10 \%$ from baseline. This amount significantly decreases the severity of obesity associated risk factors and is a reasonable goal for most patients. Aggressive dietary regimens can accomplish more rapid and greater weight loss, though they are less feasible and compliance is usually harder to maintain. As a result, weight regain is common. ${ }^{29,30}$

Preferably, not only caloric intake should be restricted; in addition a healthier diet should be acquired. The diet ought to be balanced with a variety of fruit, vegetables, grains, lowfat or nonfat dairy products, fish, poultry, and lean meats. Products high in fats or carbohydrates must be avoided. Moreover, alcohol intake is best limited to two drinks per day for men and one drink per day for women. ${ }^{29-31}$

Next to dietary adaptations, physical activity is an important component in the treatment of obesity. Although increasing activity is not expected to lead to a substantially greater weight loss, regular physical activity has been suggested to be helpful in preventing weight 
regain. ${ }^{29,32}$ Besides, physical activity has been shown to increase insulin sensitivity. ${ }^{33}$ In previously inactive patients, physical activity should be initiated slowly and the intensity should be increased gradually. Ideally the long term goal is set to at least half an hour of moderate intensity physical activity at most, but preferably all days of the week. ${ }^{29}$ Furthermore, patients should be encouraged to increase non-exercise activities such as taking the stairs instead of the elevator. ${ }^{32}$

Additionally, behavioral therapy can support weight loss. It focusses on providing tools to overcome barriers to comply with a healthier lifestyle. Important cognitive strategies with regard to obesity treatment are self-monitoring of eating behavior and physical activity, cognitive restructuring, stimulus control, and social support. ${ }^{30,32}$

Over the last few years, pharmaceutical companies have developed weight losing medication. ${ }^{34}$ Examples are orlistat, rimonabant, sibutramine, and fabuless. Orlistat is a lipase inhibitor preventing fat absorption in the gut, rimonabant is a cannabinoid receptor 1 blocker reducing appetite, and sibutramine is a centrally-acting serotoninnorepinephrine reuptake inhibitor. However, using these drugs has important drawbacks. Side effects of orlistat range from gastrointestinal complaints and headache to liver failure and the main side effects of rimonabant and sibutramine are severe depression and sleeping disorders, respectively. Fabuless is a lipid emulsion consisting of oat oil and palm oil marketed as a functional food ingredient enhancing satiety. ${ }^{35}$ Though, recent reports do not endorse this. ${ }^{36,37}$ As a consequence, in the Netherlands only orlistat is currently registered for the treatment of overweight. It can be bought as an over the counter drug in a low dose, but notably, because of the potentially severe side effects, use of this drug is not supported by the Dutch Health Care Insurance Board and is therefore not recommended. ${ }^{38}$

The conventional strategies as described here and preferably applied in combination, may achieve good results; a significant amount of weight loss can usually be induced. ${ }^{39}$ This positively affects obesity-related comorbidities. For instance, successful lifestyle changes reduce cardiovascular risk factors and improve type 2 diabetes and NAFLD. ${ }^{32}$ Hence, weight loss is also considered the first step in the treatment of the majority of the obesityrelated comorbid conditions. ${ }^{40-42}$ However, if the maximum amount of weight loss obtained by conventional therapy is unsatisfactory, a more agressive approach can be considered.

\section{Types of bariatric surgery and their effectiveness}

Subjects with a $\mathrm{BMI} \geq 40 \mathrm{~kg} / \mathrm{m}^{2}$ or a $\mathrm{BMI} \geq 35 \mathrm{~kg} / \mathrm{m}^{2}$ accompanied by severe comorbidities are considered eligible for weight loss surgery. ${ }^{43}$ Weight loss surgery is usually referred to 
as bariatric surgery, from the Greek words baros meaning 'weight' and iatrikos: 'the art of healing'. Over the last years, the number of surgical bariatric techniques has been expanding. Roughly, the techniques can be described as purely restrictive in nature and as 'malabsorptive' or as a combination of the two. The most commonly performed techniques are described below. ${ }^{44}$

Gastric banding, Figure $1 \mathrm{~A}$, is an example of a restrictive technique. With restrictive techniques, the gastric capacity is restricted to diminish food intake and increase satiety. In case of gastric banding, a small gastric pouch is created by positioning an adjustable silicon band around the upper part of the stomach. Another restrictive technique is the sleeve gastrectomy, which was previously used as the first stage of the more invasive duodenal switch, but has become popular over the last years as a stand-alone procedure. In case of a sleeve gastrectomy, Figure 1B, the stomach is transformed into a gastric sleeve by surgically removing a large portion of the stomach following the outer curvature. As a result, the stomach volume is reduced to about one fourth of its original volume.

A predominantly malabsorptive technique is the biliopancreatic diversion or Scopinaro procedure. This technique combines gastric volume reduction with an intensive malabsorptive component. A large portion of the stomach is surgically removed. The stomach remnant is then connected to the distal part of the small intestine to create an intestinal bypass with a Y-shaped configuration incorporating a digestive limb, a biliopancreatic limb, and a so-called common channel. The common channel is the portion of the small intestine where digestion and uptake occurs when nutrients from the digestive limb mix with bile and pancreatic secretions from the biliopancreatic limb. In case of biliopancreatic diversion, the anastomosis of the limps is created very distally with a common channel of only $50 \mathrm{~cm}$. Digestion and absorption of the nutrients is limited to this very short common channel and as a consequence, this procedure is accompanied by a risk of nutrient deficiencies, the most important long term complication. A modified version of the biliopancreatic diversion is the duodenal switch. This technique combines a sleeve gastrectomy with a more proximal intestinal bypass to create a longer common channel (Fig. 1C).

Restriction and small intestinal exclusion have also been combined in the Roux-en-Y gastric bypass technique (Fig. 1D). With this technique, gastric restriction is realized by creation of a small gastric pouch through transection of the stomach. This pouch is connected to the middle portion of the small intestine, bypassing the remaining stomach and the proximal small intestine (duodenum and proximal jejunum). ${ }^{45,46}$ 
A

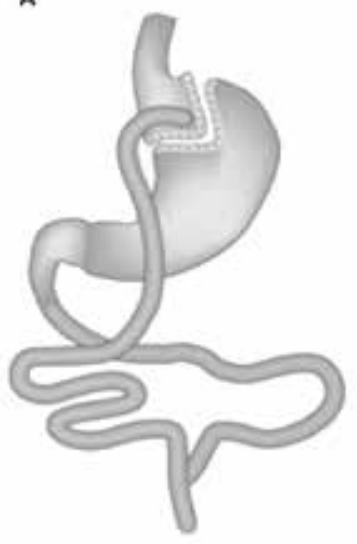

C

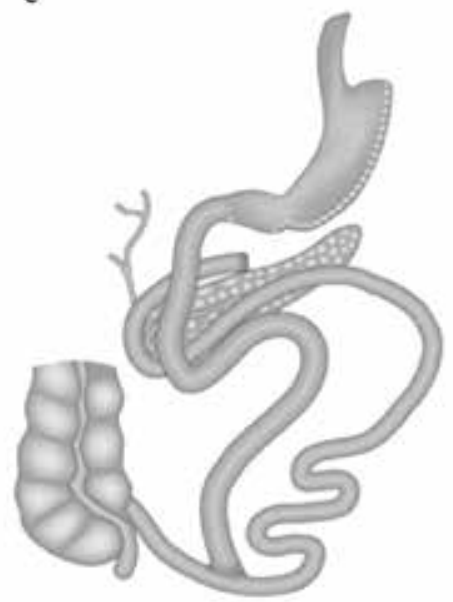

B

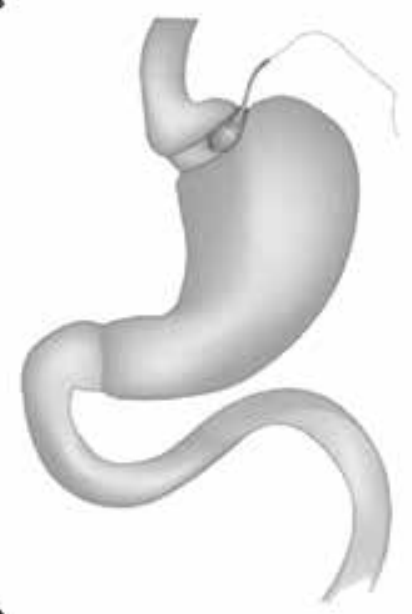

D

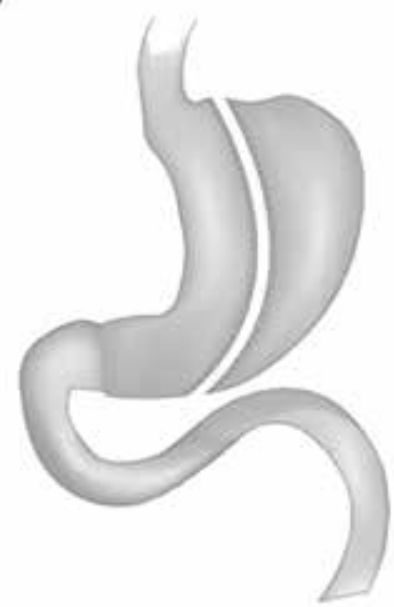

Figure 1. Different types of bariatric surgery. A) Gastric banding. B) Gastric sleeve. C) Biliopancreatic diversion with duodenal switch. D) Roux-en- $Y$ gastric bypass. (derived from: Dixon JB et al. Surgical approaches to the treatment of obesity. Nat Rev Gastroenterol Hepatol. 2011).

Bariatric surgery, applied in combination with life style adaptations, is currently the most effective weight loss therapy. In the largest prospective controlled study conducted in the bariatric field, the Swedish Obese Subjects Study, bariatric surgery was shown to be superiorly effective in achieving long term weight loss when compared to conventional lifestyle based therapy for obesity. Control subjects reached a total weight loss of $1 \%$ after 20 years versus $18 \%$ body weight loss in the surgery group. Part of the success of bariatric surgery might be attributable to increased satiety mediated by positive changes in appetite control hormones such as PYY. ${ }^{47,48}$ Recently, research has also been focused on 
other factors, like changes in intestinal microbiota composition after bariatric surgery, in order to unravel the mechanisms responsible for the effectiveness of bariatric surgery. ${ }^{49}$

Next to extensive weight loss, bariatric surgery is associated with a reduction in overall mortality and decreased incidence of obesity-related comorbidities such as type 2 diabetes, NAFLD, and cardiovascular disorders..$^{50-52}$ These metabolic effects of bariatric surgery were first described in 1995 by Pories et al. in the renowned publication entitled: 'Who would have thought it? An operation proves to be the most effective therapy for adult-onset diabetes mellitus'. ${ }^{53}$ Since then, many studies have supported this statement. ${ }^{51,54-58}$ Therefore, bariatric surgery is more and more considered metabolic surgery.

Interestingly, rapid improvement of type 2 diabetes particularly occurs after procedures that include an intestinal bypass component. ${ }^{59}$ This phenomenon is not yet fully understood and several hypotheses have been put forward to explain it. Two major hypotheses are known as the foregut and the hindgut hypothesis. According to the foregut hypothesis, the improvement of type 2 diabetes after procedures including an intestinal bypass component is caused by the absence of nutrients in the bypassed proximal small intestine. It is proposed that in the obese situation, nutrients trigger the secretion of as yet undefined diabetogenic factors in this part of the small intestine. By the absence of food in the proximal small intestine, this trigger is eliminated and, as a result, type 2 diabetes improves. ${ }^{60,61}$ The hindgut hypothesis, on the other hand, attributes rapid improvement of type 2 diabetes after proximal small intestinal exclusion to impaired digestion of nutrients resulting in the presence of undigested nutrients in the distal small intestine. These undigested nutrients are proposed to initiate the secretion of incretins, gut hormones known to stimulate insulin secretion, thereby improving type 2 diabetes. $^{59,62}$ In this light, purely intestinal bypass techniques have recently been developed, such as the duodenojejunal bypass. Basically, this technique is a Roux-en-Y gastric bypass without the gastric restriction component. Recent reports indicate that this technique is able to rapidly improve type 2 diabetes, even in non-obese patients. ${ }^{63-65}$ On the long term, not the type of the procedure and whether or not it is accompanied by anatomical rearrangement of the gastrointestinal tract, but the weight loss caused by the procedure seems to be the major factor responsible for the improvement of type 2 diabetes. $^{66}$

Despite all beneficial effects, bariatric surgery has some important drawbacks. Perioperative mortality occurs at a low frequency ranging from less than $0.1 \%$ to around 1 $\%$, increasing along with the invasiveness of the procedure and the physical status of the patient. ${ }^{56}$ Additionally, postoperative complications such as leakage, bleeding, thromboembolisms, infections, or pulmonary complications may occur and, at times, reoperations 
are unavoidable. ${ }^{67,68}$ These risks may create a hesitative attitude towards bariatric surgery in some patients and physicians. ${ }^{69}$ Yet, it should be kept in mind that the risks of leaving obesity untreated exceed the risks of bariatric surgery in most patients. Therefore, the use of bariatric surgery finds support in national and international guidelines for the treatment of obesity and its related diseases. ${ }^{15,30,32,43,70-72}$ However, less invasive or even non-surgical bariatric techniques are highly desirable. ${ }^{73}$

\section{Endoluminal bariatric techniques}

The field of bariatric surgery is rapidly evolving. Recently, several endoluminal bariatric techniques have been developed. ${ }^{73,74}$ These techniques can be divided into two major groups similar to conventional bariatric surgery: the gastric restrictive techniques and the intestinal bypass techniques.

The space-filling intragastric balloon is an example of a gastric restrictive technique which has been in use already for years. ${ }^{75,76}$ Whereas the balloons from the eighties failed to induce significant weight loss and were associated with complications, newer balloons can achieve short term weight loss. ${ }^{77}$ In addition, suturing devices enabling endoluminal gastroplasty, such as the transoral gastroplasty or TOGA system ${ }^{78}$ and the Trans-oral Endoscopic Restrictive Implant System or TERIS ${ }^{79}$ have been developed. The TOGA system is an endoscopic full-thickness stapling device that can create a narrow gastric sleeve, thereby mimicking the surgical gastric sleeve technique. Familiari et al. observed significant weight loss after the TOGA procedure. ${ }^{80}$ TERIS is a silicon implant to be anchored in the gastric cardia creating a restrictive pouch with a $10-\mathrm{mm}$ orifice for food entering the stomach, thereby imitating the effect of gastric banding. De Jong et al. have shown significant weight loss using this technique, although in a small number of patients. $^{79}$

On the other hand, intestinal bypass techniques such as the ValenTx gastro-jejunal bypass sleeve ${ }^{81}$ and the EndoBarrier Duodenal-Jejunal Bypass Liner (DJBL) ${ }^{82}$ have been developed. The ValenTx is a $120 \mathrm{~cm}$ long impermeable sleeve which is anchored at the gastroesophageal junction, thereby bypassing the stomach and proximal small intestine. The first data indicate that the ValenTx induces significant weight loss. ${ }^{81}$ However, long term results are lacking. The DJBL was investigated in the current thesis and will be discussed below.

\section{The Duodenal-Jejunal Bypass Liner}

The Duodenal-Jejunal Bypass Liner or DJBL, Figure 2A, is a promising novel, non-surgical bariatric technique. As shown in Figure 2B, it consists of a $60 \mathrm{~cm}$ long impermeable 
fluoropolymer sleeve that extends into the small bowel, and a nitinol anchor, which is used to reversibly affix the device to the wall of the duodenal bulb. The DJBL is open at both ends to allow food passage. Delivery and retrieval of the DJBL is performed endoscopically, so no incisions are needed. Currently, the maximum treatment duration is one year, though studies to extend this period are being performed. Once in place, the DJBL excludes the duodenum and proximal jejunum from contact with ingested food; chyme will pass through the inside of sleeve, while pancreatic enzymes and bile acids pass along the outer wall of the conduit and mix with the chyme only at the end of the sleeve. ${ }^{82}$ In this way, the DJBL mimics the bypass component of the Roux-en-Y gastric bypass and the surgical duodenal-jejunal exclusion procedure. ${ }^{83}$

A

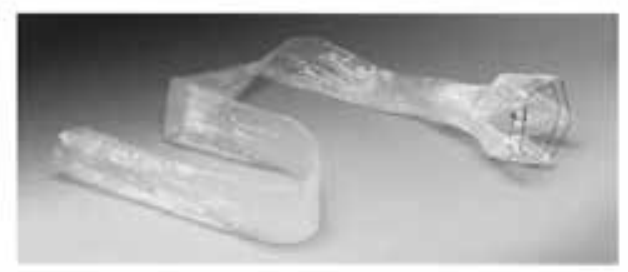

B

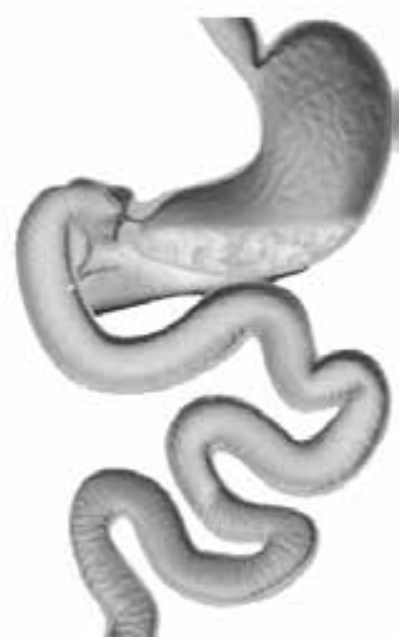

Figure 2. The DJBL. A) Depiction of the DJBL. B) Implanted DJBL.

In 2007, the first human DJBL procedure was reported. Preliminary data of this particular patient showed a total body weight loss of $9 \mathrm{~kg}$ over a three months time period. ${ }^{84}$ Later studies have confirmed the positive effects of DJBL treatment on obesity, with an amount of excess weight loss of up to $47 \%$ after 52 weeks of treatment. In addition, improvement of type 2 diabetes has been observed as fast as within one week after DJBL placement. ${ }^{85-87}$ Randomized trials comparing DJBL treatment to sham or diet control treatment showed superiority of the DJBL in treating obesity and ameliorating type 2 diabetes. ${ }^{82,88-90}$ Initially, the DJBL procedures were performed under general anesthesia. Presently, the first reports on procedures performed under conscious sedation appear. ${ }^{91}$ Furthermore, the device has been tested in type 2 diabetic subjects with a relatively low BMI with promising results. ${ }^{92}$ 
In the future, DJBL treatment might fill in the niche between conservative lifestyle interventions and surgical bariatric techniques in the treatment of obesity. ${ }^{83}$

\section{Aims and outline of this thesis}

The main purpose of the studies described in the current thesis was to investigate the effects of DJBL treatment on obesity and its comorbidities. In Chapter 2, the efficacy of the DJBL in treating obesity and type 2 diabetes is described and compared to dietary intervention. Hormonal changes putatively mediating improvement of type 2 diabetes after DJBL implantation are reported in Chapter 3, and DJBL-induced changes in hormones involved in appetite control are described in Chapter 4. In Chapter 5, the effect of DJBL treatment on NAFLD is described. Additionally, differences in intestinal microbiota composition between lean and obese human subjects are described in Chapter 6 and the effect of DJBL treatment on the composition of gut microbiota is reported in Chapter 7. In Chapter 8 , the effect of the DJBL on low grade systemic inflammation is described. The main findings of these studies as well as their potential future implications are reviewed and discussed in Chapter 9. 


\section{REFERENCES}

1. World Health Organization World Wide Web Media Centre. Obesity and overweight Fact sheet $\mathrm{N}^{\circ} 311$. 2013.

2. Ogden CL, Yanovski SZ, Carroll MD, Flegal KM. The epidemiology of obesity. Gastroenterology. 2007 May;132(6):2087-102.

3. Kelly T, Yang W, Chen CS, Reynolds K, He J. Global burden of obesity in 2005 and projections to 2030. Int J Obes. 2008 Sep;32(9):1431-7.

4. Statistics Netherlands Web Magazine. More people overweight. 2012.

5. Haslam DW, James WP. Obesity. Lancet. 2005 Oct 1;366(9492):1197-209.

6. Must A, Spadano J, Coakley EH, Field AE, Colditz G, Dietz WH. The disease burden associated with overweight and obesity. JAMA. 1999 Oct 27;282(16):1523-9.

7. Stumvoll M, Goldstein BJ, van Haeften TW. Type 2 diabetes: principles of pathogenesis and therapy. Lancet. 2005 Apr 9-15;365(9467):1333-46.

8. UK Prospective Diabetes Study Group. Tight blood pressure control and risk of macrovascular and microvascular complications in type 2 diabetes: UKPDS 38. UK Prospective Diabetes Study Group. BMJ. 1998 Sep 12;317(7160):703-13.

9. World Health Organization World Wide Web Media Centre.Diabetes Fact sheet N³12. 2012.

10. Wild S, Roglic G, Green A, Sicree R, King H. Global prevalence of diabetes: estimates for the year 2000 and projections for 2030. Diabetes Care. 2004 May;27(5):1047-53.

11. Brunt EM. Nonalcoholic steatohepatitis (NASH): further expansion of this clinical entity? Liver. 1999 Aug;19(4):263-4.

12. Kleiner DE, Brunt EM, Van Natta M, Behling C, Contos MJ, Cummings OW, Ferrell LD, Liu YC, Torbenson MS, Unalp-Arida A, et al. Design and validation of a histological scoring system for nonalcoholic fatty liver disease. Hepatology. 2005 Jun;41(6):1313-21.

13. Angulo P. Nonalcoholic fatty liver disease. N Engl J Med. 2002 Apr 18;346(16):1221-31.

14. Lazo M, Clark JM. The epidemiology of nonalcoholic fatty liver disease: a global perspective. Semin Liver Dis. 2008 Nov;28(4):339-50.

15. Chalasani N, Younossi Z, Lavine JE, Diehl AM, Brunt EM, Cusi K, Charlton M, Sanyal AJ. The diagnosis and management of non-alcoholic fatty liver disease: practice Guideline by the American Association for the Study of Liver Diseases, American College of Gastroenterology, and the American Gastroenterological Association. Hepatology. 2012 Jun;55(6):2005-23.

16. Hill JO, Peters JC. Environmental contributions to the obesity epidemic. Science. 1998 May 29;280(5368):1371-4.

17. Keith SW, Redden DT, Katzmarzyk PT, Boggiano MM, Hanlon EC, Benca RM, Ruden D, Pietrobelli A, Barger JL, Fontaine KR, et al. Putative contributors to the secular increase in obesity: exploring the roads less traveled. Int J Obes. 2006 Nov;30(11):1585-94.

18. Campfield LA, Smith FJ. The pathogenesis of obesity. Best practice \& research Clinical endocrinology \& metabolism. 1999 Apr;13(1):13-30.

19. Woods SC, D'Alessio DA. Central control of body weight and appetite. J Clin Endocrinol Metab. 2008 Nov;93(11 Suppl 1):S37-50.

20. Ley RE. Obesity and the human microbiome. Current opinion in gastroenterology. 2010 Jan;26(1):5-11.

21. Diamant M, Blaak EE, de Vos WM. Do nutrient-gut-microbiota interactions play a role in human obesity, insulin resistance and type 2 diabetes? Obes Rev. 2011 Apr;12(4):272-81.

22. Huda MS, Wilding JP, Pinkney JH. Gut peptides and the regulation of appetite. Obes Rev. 2006 May;7(2):163-82.

23. Meier U, Gressner AM. Endocrine regulation of energy metabolism: review of pathobiochemical and clinical chemical aspects of leptin, ghrelin, adiponectin, and resistin. Clin Chem. 2004 Sep;50(9):1511-25. 
24. le Roux CW, Batterham RL, Aylwin SJ, Patterson M, Borg CM, Wynne KJ, Kent A, Vincent RP, Gardiner J, Ghatei MA, et al. Attenuated peptide YY release in obese subjects is associated with reduced satiety. Endocrinology. 2006 Jan;147(1):3-8.

25. Ouchi N, Parker JL, Lugus JJ, Walsh K. Adipokines in inflammation and metabolic disease. Nat Rev Immunol. 2011 Feb;11(2):85-97.

26. Bays H, Mandarino L, DeFronzo RA. Role of the adipocyte, free fatty acids, and ectopic fat in pathogenesis of type 2 diabetes mellitus: peroxisomal proliferator-activated receptor agonists provide a rational therapeutic approach. J Clin Endocrinol Metab. 2004 Feb;89(2):463-78.

27. Verna EC, Berk PD. Role of fatty acids in the pathogenesis of obesity and fatty liver: impact of bariatric surgery. Semin Liver Dis. 2008 Nov;28(4):407-26.

28. Walenbergh SM, Koek GH, Bieghs V, Shiri-Sverdlov R. Non-alcoholic steatohepatitis: The role of oxidized low-density lipoproteins. J Hepatol. 2013 Apr;58(4):801-10.

29. Klein S, Sheard NF, Pi-Sunyer X, Daly A, Wylie-Rosett J, Kulkarni K, Clark NG, American Diabetes A, North American Association for the Study of O, American Society for Clinical N. Weight management through lifestyle modification for the prevention and management of type 2 diabetes: rationale and strategies. A statement of the American Diabetes Association, the North American Association for the Study of Obesity, and the American Society for Clinical Nutrition. The American journal of clinical nutrition. 2004 Aug;80(2):257-63.

30. Centraal BegeleidingsOrgaan Richtlijn. Diagnostiek en behandeling van obesitas bij volwassenen en kinderen. 2008.

31. Health Counseling of the Netherlands. Guidelines for a healthy diet. 2006

32. National Institutes of Health. Clinical Guidelines on the Identification, Evaluation, and Treatment of Overweight and Obesity in Adults--The Evidence Report. National Institutes of Health. Obesity research. 1998 Sep;6 Suppl 2:51S-209S.

33. Mayer-Davis EJ, D'Agostino R, Jr., Karter AJ, Haffner SM, Rewers MJ, Saad M, Bergman RN. Intensity and amount of physical activity in relation to insulin sensitivity: the Insulin Resistance Atherosclerosis Study. JAMA. 1998 Mar 4;279(9):669-74.

34. Kang JG, Park CY. Anti-Obesity Drugs: A Review about Their Effects and Safety. Diabetes \& metabolism journal. 2012 Feb;36(1):13-25.

35. Haenni A, Sundberg B, Yazdanpandah N, Viberg A, Olsson J. Effect of fat emulsion (Fabuless) on orocecal transit time in healthy men. Scandinavian journal of gastroenterology. 2009 44(10):1186-90.

36. Smit HJ, Keenan E, Kovacs EM, Wiseman SA, Mela DJ, Rogers PJ. No appetite efficacy of a commercial structured lipid emulsion in minimally processed drinks. Int J Obes (Lond). 2012 Sep;36(9):1222-8.

37. Smit HJ, Keenan E, Kovacs EM, Wiseman SA, Peters HP, Mela DJ, Rogers PJ. No efficacy of processed Fabuless (Olibra) in suppressing appetite or food intake. European journal of clinical nutrition. 2011 Jan;65(1):81-6.

38. Health Care Insurance Board. Farmacotherapeutisch kompas. 2003.

39. Ryan DH, Johnson WD, Myers VH, Prather TL, McGlone MM, Rood J, Brantley PJ, Bray GA, Gupta AK, Broussard AP, et al. Nonsurgical weight loss for extreme obesity in primary care settings: results of the Louisiana Obese Subjects Study. Archives of internal medicine. 2010 Jan 25;170(2):146-54.

40. Klein S, Sheard NF, Pi-Sunyer X, Daly A, Wylie-Rosett J, Kulkarni K, Clark NG, American Diabetes Association, North American Association for the Study of Obesity, American Society for Clinical Nutrition. Weight management through lifestyle modification for the prevention and management of type 2 diabetes: rationale and strategies: a statement of the American Diabetes Association, the North American Association for the Study of Obesity, and the American Society for Clinical Nutrition. Diabetes Care. 2004 Aug;27(8):2067-73.

41. Thoma C, Day CP, Trenell MI. Lifestyle interventions for the treatment of non-alcoholic fatty liver disease in adults: a systematic review. J Hepatol. 2012 Jan;56(1):255-66.

42. Catapano AL, Reiner Z, De Backer G, Graham I, Taskinen MR, Wiklund O, Agewall S, Alegria E, Chapman $M$, Durrington $P$, et al. ESC/EAS Guidelines for the management of dyslipidaemias The Task Force for the 
management of dyslipidaemias of the European Society of Cardiology (ESC) and the European Atherosclerosis Society (EAS). Atherosclerosis. 2011 Jul;217(1):3-46.

43. Nederlandse Vereniging voor Heelkunde. Richtlijn morbide obesitas. 2011

44. Buchwald H, Oien DM. Metabolic/bariatric surgery worldwide 2011. Obes Surg. 2013 Apr;23(4):427-36.

45. Miller K. Obesity: surgical options. Best practice \& research Clinical gastroenterology. 2004 Dec;18(6):1147-65.

46. Mechanick JI, Kushner RF, Sugerman HJ, Gonzalez-Campoy JM, Collazo-Clavell ML, Spitz AF, Apovian CM, Livingston EH, Brolin R, Sarwer DB, et al. American Association of Clinical Endocrinologists, The Obesity Society, and American Society for Metabolic \& Bariatric Surgery medical guidelines for clinical practice for the perioperative nutritional, metabolic, and nonsurgical support of the bariatric surgery patient. Obesity. 2009 Apr;17 Suppl 1:S1-70.

47. Borg CM, le Roux CW, Ghatei MA, Bloom SR, Patel AG, Aylwin SJ. Progressive rise in gut hormone levels after Roux-en-Y gastric bypass suggests gut adaptation and explains altered satiety. Br J Surg. 2006 Feb;93(2):210-5.

48. le Roux CW, Welbourn R, Werling M, Osborne A, Kokkinos A, Laurenius A, Lonroth H, Fandriks L, Ghatei MA, Bloom SR, et al. Gut hormones as mediators of appetite and weight loss after Roux-en-Y gastric bypass. Ann Surg. 2007 Nov;246(5):780-5.

49. Zhang H, DiBaise JK, Zuccolo A, Kudrna D, Braidotti M, Yu Y, Parameswaran P, Crowell MD, Wing R, Rittmann BE, et al. Human gut microbiota in obesity and after gastric bypass. Proceedings of the National Academy of Sciences of the United States of America. 2009 Feb 17;106(7):2365-70.

50. Sjostrom L. Review of the key results from the Swedish Obese Subjects (SOS) trial - a prospective controlled intervention study of bariatric surgery. Journal of internal medicine. 2013 Mar;273(3):219-34.

51. Buchwald H, Estok R, Fahrbach K, Banel D, Jensen MD, Pories WJ, Bantle JP, Sledge I. Weight and type 2 diabetes after bariatric surgery: systematic review and meta-analysis. Am J Med. 2009 Mar;122(3):24856.

52. Rabl C, Campos GM. The impact of bariatric surgery on nonalcoholic steatohepatitis. Semin Liver Dis. 2012 Feb;32(1):80-91.

53. Pories WJ, Swanson MS, MacDonald KG, Long SB, Morris PG, Brown BM, Barakat HA, deRamon RA, Israel G, Dolezal JM, et al. Who would have thought it? An operation proves to be the most effective therapy for adult-onset diabetes mellitus. Ann Surg. 1995 Sep;222(3):339-50; discussion 50-2.

54. Schauer PR, Kashyap SR, Wolski K, Brethauer SA, Kirwan JP, Pothier CE, Thomas S, Abood B, Nissen SE, Bhatt DL. Bariatric surgery versus intensive medical therapy in obese patients with diabetes. $\mathrm{N}$ Engl J Med. 2012 Apr 26;366(17):1567-76.

55. Mingrone G, Panunzi S, De Gaetano A, Guidone C, laconelli A, Leccesi L, Nanni G, Pomp A, Castagneto M, Ghirlanda $G$, et al. Bariatric surgery versus conventional medical therapy for type 2 diabetes. N Engl J Med. 2012 Apr 26;366(17):1577-85.

56. Buchwald H, Avidor Y, Braunwald E, Jensen MD, Pories W, Fahrbach K, Schoelles K. Bariatric surgery: a systematic review and meta-analysis. JAMA. 2004 Oct 13;292(14):1724-37.

57. Colquitt JL, Picot J, Loveman E, Clegg AJ. Surgery for obesity. Cochrane Database Syst Rev. 2009 2):CD003641.

58. Maggard MA, Shugarman LR, Suttorp M, Maglione M, Sugerman HJ, Livingston EH, Nguyen NT, Li Z, Mojica WA, Hilton L, et al. Meta-analysis: surgical treatment of obesity. Annals of internal medicine. 2005 Apr 5;142(7):547-59.

59. Thaler JP, Cummings DE. Minireview: Hormonal and metabolic mechanisms of diabetes remission after gastrointestinal surgery. Endocrinology. 2009 Jun;150(6):2518-25.

60. Rubino F, Forgione A, Cummings DE, Vix M, Gnuli D, Mingrone G, Castagneto M, Marescaux J. The mechanism of diabetes control after gastrointestinal bypass surgery reveals a role of the proximal small intestine in the pathophysiology of type 2 diabetes. Ann Surg. 2006 Nov;244(5):741-9.

61. Knop FK. Resolution of type 2 diabetes following gastric bypass surgery: involvement of gut-derived glucagon and glucagonotropic signalling? Diabetologia. 2009 Nov;52(11):2270-6. 
62. Fetner R, McGinty J, Russell C, Pi-Sunyer FX, Laferrere B. Incretins, diabetes, and bariatric surgery: a review. Surg Obes Relat Dis. 2005 Nov-Dec;1(6):589-97; discussion 97-8.

63. Geloneze B, Geloneze SR, Chaim E, Hirsch FF, Felici AC, Lambert G, Tambascia MA, Pareja JC. Metabolic surgery for non-obese type 2 diabetes: incretins, adipocytokines, and insulin secretion/resistance changes in a 1-year interventional clinical controlled study. Ann Surg. 2012 Jul;256(1):72-8.

64. Cohen R, Caravatto PP, Correa JL, Noujaim P, Petry TZ, Salles JE, Schiavon CA. Glycemic control after stomach-sparing duodenal-jejunal bypass surgery in diabetic patients with low body mass index. Surg Obes Relat Dis. 2012 Jul-Aug;8(4):375-80.

65. Ramos AC, Galvao Neto MP, de Souza YM, Galvao M, Murakami AH, Silva AC, Canseco EG, Santamaria R, Zambrano TA. Laparoscopic duodenal-jejunal exclusion in the treatment of type 2 diabetes mellitus in patients with BMl<30 kg/m2 (LBMI). Obes Surg. 2009 Mar;19(3):307-12.

66. Bradley D, Conte C, Mittendorfer B, Eagon JC, Varela JE, Fabbrini E, Gastaldelli A, Chambers KT, Su X, Okunade A, et al. Gastric bypass and banding equally improve insulin sensitivity and beta cell function. J Clin Invest. 2012 Dec;122(12):4667-74.

67. Sjostrom L, Lindroos AK, Peltonen M, Torgerson J, Bouchard C, Carlsson B, Dahlgren S, Larsson B, Narbro $\mathrm{K}$, Sjostrom $\mathrm{CD}$, et al. Lifestyle, diabetes, and cardiovascular risk factors 10 years after bariatric surgery. $\mathrm{N}$ Engl J Med. 2004 Dec;351(26):2683-93.

68. Nguyen NT, Silver M, Robinson M, Needleman B, Hartley G, Cooney R, Catalano R, Dostal J, Sama D, Blankenship J, et al. Result of a national audit of bariatric surgery performed at academic centers: a 2004 University HealthSystem Consortium Benchmarking Project. Arch Surg. 2006 May;141(5):445-9; discussion 9-50.

69. Afonso BB, Rosenthal R, Li KM, Zapatier J, Szomstein S. Perceived barriers to bariatric surgery among morbidly obese patients. Surg Obes Relat Dis. 2010 Jan-Feb;6(1):16-21.

70. Dixon JB, Zimmet P, Alberti KG, Mbanya JC, Rubino F, International Diabetes Federation Taskforce on E, Prevention. Bariatric surgery for diabetes: the International Diabetes Federation takes a position. J Diabetes. 2011 Dec;3(4):261-4.

71. Fried M, Hainer V, Basdevant A, Buchwald H, Deitel M, Finer N, Greve JW, Horber F, Mathus-Vliegen E, Scopinaro N, et al. Interdisciplinary European guidelines for surgery for severe (morbid) obesity. Obes Surg. 2007 Feb;17(2):260-70.

72. Mechanick JI, Youdim A, Jones DB, Garvey WT, Hurley DL, McMahon MM, Heinberg L, Kushner R, Adams TD, Shikora S, et al. Clinical practice guidelines for the perioperative nutritional, metabolic, and nonsurgical support of the bariatric surgery patient--2013 update: cosponsored by American Association of Clinical Endocrinologists, The Obesity Society, and American Society for Metabolic \& Bariatric Surgery. Obesity. 2013 Mar;21 Suppl 1:S1-27.

73. Verdam FJ, Schouten R, Greve JW, Koek GH, Bouvy ND. An update on less invasive and endoscopic techniques mimicking the effect of bariatric surgery. Journal of obesity. 2012;2012:597871.

74. Stylopoulos N, Aguirre V. Mechanisms of bariatric surgery and implications for the development of endoluminal therapies for obesity. Gastrointest Endosc. 2009 Dec;70(6):1167-75.

75. Mathus-Vliegen EM, Tytgat GN, Veldhuyzen-Offermans EA. Intragastric balloon in the treatment of super-morbid obesity. Double-blind, sham-controlled, crossover evaluation of 500-milliliter balloon. Gastroenterology. 1990 Aug;99(2):362-9.

76. Benjamin SB, Maher KA, Cattau EL, Jr., Collen MJ, Fleischer DE, Lewis JH, Ciarleglio CA, Earll JM, Schaffer $\mathrm{S}$, Mirkin K, et al. Double-blind controlled trial of the Garren-Edwards gastric bubble: an adjunctive treatment for exogenous obesity. Gastroenterology. 1988 Sep;95(3):581-8.

77. Committee AT, Kethu SR, Banerjee S, Barth BA, Desilets DJ, Kaul V, Pedrosa MC, Pfau PR, Pleskow DK, Tokar JL, et al. Endoluminal bariatric techniques. Gastrointest Endosc. 2012 Jul;76(1):1-7.

78. Moreno C, Closset J, Dugardeyn S, Barea M, Mehdi A, Collignon L, Zalcman M, Baurain M, Le Moine O, Deviere J. Transoral gastroplasty is safe, feasible, and induces significant weight loss in morbidly obese patients: results of the second human pilot study. Endoscopy. 2008 May;40(5):406-13. 
79. de Jong K, Mathus-Vliegen EM, Veldhuyzen EA, Eshuis JH, Fockens P. Short-term safety and efficacy of the Trans-oral Endoscopic Restrictive Implant System for the treatment of obesity. Gastrointest Endosc. 2010 Sep;72(3):497-504.

80. Familiari P, Costamagna G, Blero D, Le Moine O, Perri V, Boskoski I, Coppens E, Barea M, laconelli A, Mingrone G, et al. Transoral gastroplasty for morbid obesity: a multicenter trial with a 1-year outcome. Gastrointest Endosc. 2011 Dec;74(6):1248-58.

81. Sandler BJ, Rumbaut R, Swain CP, Torres G, Morales L, Gonzales L, Schultz S, Talamini M, Horgan S. Human experience with an endoluminal, endoscopic, gastrojejunal bypass sleeve. Surg Endosc. 2011 Sep;25(9):3028-33.

82. Schouten R, Rijs CS, Bouvy ND, Hameeteman W, Koek GH, Janssen IM, Greve JW. A multicenter, randomized efficacy study of the EndoBarrier Gastrointestinal Liner for presurgical weight loss prior to bariatric surgery. Ann Surg. 2010 Feb;251(2):236-43.

83. Patel SR, Hakim D, Mason J, Hakim N. The duodenal-jejunal bypass sleeve (EndoBarrier Gastrointestinal Liner) for weight loss and treatment of type 2 diabetes. Surg Obes Relat Dis. 2013 May-June;9(3):482-4.

84. Gersin KS, Keller JE, Stefanidis D, Simms CS, Abraham DD, Deal SE, Kuwada TS, Heniford BT. Duodenaljejunal bypass sleeve: a totally endoscopic device for the treatment of morbid obesity. Surgical innovation. 2007 Dec;14(4):275-8.

85. Rodriguez-Grunert L, Galvao Neto MP, Alamo M, Ramos AC, Baez PB, Tarnoff M. First human experience with endoscopically delivered and retrieved duodenal-jejunal bypass sleeve. Surg Obes Relat Dis. 2008 Jan-Feb;4(1):55-9.

86. de Moura EG, Martins BC, Lopes GS, Orso IR, de Oliveira SL, Galvao Neto MP, Santo MA, Sakai P, Ramos $A C$, Garrido Junior $A B$, et al. Metabolic improvements in obese type 2 diabetes subjects implanted for 1 year with an endoscopically deployed duodenal-jejunal bypass liner. Diabetes Technol Ther. 2012 Feb;14(2):183-9.

87. Escalona A, Pimentel F, Sharp A, Becerra P, Slako M, Turiel D, Munoz R, Bambs C, Guzman S, Ibanez L, et al. Weight loss and metabolic improvement in morbidly obese subjects implanted for 1 year with an endoscopic duodenal-jejunal bypass liner. Ann Surg. 2012 Jun;255(6):1080-5.

88. Rodriguez L, Reyes E, Fagalde P, Oltra MS, Saba J, Aylwin CG, Prieto C, Ramos A, Galvao M, Gersin KS, et al. Pilot clinical study of an endoscopic, removable duodenal-jejunal bypass liner for the treatment of type 2 diabetes. Diabetes Technol Ther. 2009 Nov;11(11):725-32.

89. Tarnoff M, Rodriguez L, Escalona A, Ramos A, Neto M, Alamo M, Reyes E, Pimentel F, Ibanez L. Open label, prospective, randomized controlled trial of an endoscopic duodenal-jejunal bypass sleeve versus low calorie diet for pre-operative weight loss in bariatric surgery. Surg Endosc. 2009 Mar;23(3):650-6.

90. Gersin KS, Rothstein RI, Rosenthal RJ, Stefanidis D, Deal SE, Kuwada TS, Laycock W, Adrales G, Vassiliou M, Szomstein S, et al. Open-label, sham-controlled trial of an endoscopic duodenojejunal bypass liner for preoperative weight loss in bariatric surgery candidates. Gastrointest Endosc. 2010 May;71(6):976-82.

91. Montana R, Slako M, Escalona A. Implantation of the duodenal-jejunal bypass sleeve under conscious sedation: a case series. Surg Obes Relat Dis. 2012 Sep-Oct;8(5):e63-5.

92. Cohen RV, Neto MG, Correa JL, Sakai P, Martins B, Schiavon CA, Petry T, Salles JE, Mamedio C, Sorli C. A pilot study of the duodenal-jejunal bypass liner in low body mass index type 2 diabetes. J Clin Endocrinol Metab. 2013 Feb;98(2):E279-82. 


\section{Chapter 2}

The effect of the endoscopic

Duodenal-Jejunal Bypass Liner on obesity

and type 2 diabetes mellitus, a multi-center

randomized controlled trial

Charlotte de Jonge*, Parviez Koehestanie*, Frits J Berends, Ignace M Janssen, Nicole D Bouvy, and Jan Willem M Greve Accepted in Annals of Surgery, *shared first 


\section{ABSTRACT}

\section{Background}

The Duodenal-Jejunal Bypass Liner (DJBL) is a bariatric procedure involving an impermeable sleeve which is delivered endoscopically in the proximal intestine. This procedure is less invasive than conventional surgical techniques, but also has beneficial effects on obesity and type 2 diabetes mellitus (T2DM). We investigated the safety and efficacy of six months DJBL treatment in comparison to dietary intervention for obesity and T2DM.

\section{Methods}

A multicenter randomized controlled trial was performed. Seventy-seven patients with obesity and T2DM were included. Thirty-eight patients were randomized to six months DJBL treatment in combination with dietary intervention, (34 successfully implanted, 31 completed the study), 39 patients received only dietary intervention (controls, 35 completed the study). Total study duration for both groups was twelve months, including six months of post-DJBL-removal follow-up.

\section{Results}

After six months, just prior to DJBL removal, the DJBL group had lost 32.0 [22.0 - 46.7] \% of their excess weight vs. 16.4 [4.1 - 34.6] \% in the control group $(p<0.05) . \mathrm{HbA}_{1 c}$ improved to 7.0 [6.4 - 7.5] \% in the DJBL group and to 7.9 [6.6 - 8.3] \% in the control group $(p<0.05)$. Additionally, $85.3 \%$ of DJBL patients showed decreased postprandial glucose excursions vs. $48.7 \%$ of control patients $(p<0.05)$. At twelve months, excess weight loss of the DJBL group was 19.8 [10.6 - 45.0] \% vs. 11.7 [1.4 - 25.4] \% in the control group $(p<0.05)$. $\mathrm{HbA}_{1 \mathrm{c}}$ was $7.3[6.6-8.0] \%$ vs. 8.0 [6.8 - 8.8] \%, DJBL vs. control respectively ( $p=n s)$.

\section{Conclusion}

The DJBL is a safe and effective alternative to invasive bariatric procedures. Six months of DJBL treatment combined with a diet leads to superior weight loss and improvement of T2DM when compared to diet alone. 


\section{INTRODUCTION}

Obesity is a rapidly growing problem worldwide. Once considered only a problem in western society, obesity rates are now also rising dramatically in formerly developing countries. ${ }^{1}$ Importantly, obesity is a major risk factor for several chronic diseases, including type 2 diabetes mellitus (T2DM) and cardiovascular diseases. ${ }^{2}$ Furthermore, it is associated with impaired health-related quality of life. ${ }^{3}$ Today, more than 500 million adults are overweight and millions of these people face the dual challenge of managing T2DM and obesity. ${ }^{1,4}$ Lifestyle changes resulting in weight loss improve T2DM and are, next to medication, the most important treatment modality for T2DM. Although conservative therapy is usually successful in weight control in the short term, long term results are often disappointing. ${ }^{5}$ Bariatric surgery, on the other hand, has proven its effectiveness in achieving and maintaining weight loss and improving T2DM, quality of life, and survival. ${ }^{6-8}$ While surgery is increasingly performed and effective, it is associated with potentially important complications, and although rare, mortality. ${ }^{9}$ Therefore, less invasive and safer techniques that will offer treatment for a broader spectrum of patients are searched for. ${ }^{10}$

Recently, a novel non-surgical bariatric technique has been developed, the DuodenalJejunal Bypass Liner (DJBL, GI Dynamics, Lexington, MA). The DJBL consists of a $60 \mathrm{~cm}$ long fluoropolymer liner which is delivered into and retrieved from the duodenum endoscopically. Its principle is based on the effectiveness of surgical duodenal-jejunal exclusion in treating obesity and T2DM; once placed in the duodenum it mimics the intestinal bypass component of the well-known Roux-en- $Y$ gastric bypass and surgical duodenal-jejunal exclusion. Clinical experience to date has demonstrated the safety of the DJBL and its ability to rapidly improve blood glucose control and induce weight loss. ${ }^{11-16}$ In addition, the DJBL has been shown to improve other metabolic parameters, including lipid profile and blood pressure. ${ }^{17-19}$

In the current randomized controlled study we aimed to investigate the safety of six months DJBL treatment and the effect on obesity, T2DM, and cardiovascular risk profile in obese patients with T2DM. After DJBL treatment patients were followed up for six months to evaluate post-removal effects. 


\section{METHODS}

\section{Patients}

Patients were considered eligible if they were between 18 and 65 years old; had a body mass index (BMI) between 30 and $50 \mathrm{~kg} / \mathrm{m}^{2}$; and had T2DM for less than 10 years with an $\mathrm{HbA}_{1 \mathrm{c}}$ level between 7.5 and $10.0 \%$. Patients were allowed to take metformin, sulfonylurea derivates (SU), and/or insulin with a maximum dose of 150 IU per day. Exclusion criteria were: weight loss of $>4.5 \mathrm{~kg}$ within 12 weeks prior to screening; pregnancy or intention to become pregnant; use of NSAIDS, anticoagulation therapy, corticosteroids, weight loss medication, or drugs known to affect gastrointestinal motility; substance abuse; active $H$. pylori infection; probable insulin production failure as indicated by a c-peptide level of $<1.0 \mathrm{ng} / \mathrm{mL}$; iron deficiency or iron deficiency anemia; GI tract abnormalities or previous surgery in the gastrointestinal tract that could affect the ability to place the device; symptomatic gallstones or kidney stones; known infection; bleeding disorders; gastroesophageal reflux disorder; connective tissue disorders; and severe liver or kidney failure as indicated by a creatinine level of $>180 \mathrm{mmol} / \mathrm{L}$.

\section{Study Protocol}

In a prospective, randomized, controlled, multicenter study, 77 patients were included in Rijnstate Hospital, Arnhem; Maastricht University Medical Center, Maastricht, and Atrium Medical Centrum Parkstad, Heerlen. As shown in Figure 1, 38 patients were randomized to the DJBL treatment group and 39 patients were randomized to the control group. Patients in the DJBL group were to be treated for six months with the DJBL and were followed up for an additional six months after removal of the device. Of the DJBL group, 34 patients were implanted (three failures, one withdrawal). Groups were comparable with respect to age, gender, BMI, and comorbidities, see Table 1.

At the initiation of the study, data on patient demographics, physical examination (including weight, BMI, and blood pressure), and medical history were collected. An ECG, chest X-ray, and abdominal ultrasound were performed to rule out the presence of apparent pulmonary, cardiovascular, or gastrointestinal disease. Laboratory parameters were obtained prior to the start of the treatment $\left(\mathrm{HbA}_{1 \mathrm{c}}\right.$, fasting glucose and insulin, total cholesterol, high-density lipoprotein ( $H D L)$, low-density lipoprotein (LDL), triglycerides (TG), amylase, lipase, hemoglobin, hematocrit, iron, serum creatinine, vitamin D, calcium, and c-peptide) and a 4 hour standard meal tolerance test (MTT) was performed, using a standard liquid meal (Ensure Plus vanilla flavor, Abbott Laboratories, IL; $333 \mathrm{~mL}, 500$ kcal, $20.8 \mathrm{~g}$ protein, $67.3 \mathrm{~g}$ carbohydrates, and $16.4 \mathrm{~g}$ fat). During the study, all patients were prescribed a diet with a maximum of 1,200 kcal for women and 1,500 kcal for men which 
was liquid for the first week. In addition, patients were advised to increase their physical activity. Medical treatment for T2DM was managed by a diabetes nurse under supervision of an endocrinologist. To avoid hypoglycemic events, the dose of glucose-lowering medication, except for metformin, was reduced by $50 \%$ at the time of implant or initiation of the diet. If hypoglycemic or hyperglycemic episodes were experienced, additional adaptations to the medical treatment were performed as regular. Additionally, DJBL patients were prophylactically prescribed a proton pump inhibitor for the duration of DJBL treatment to prevent peptic ulcer formation in the stomach and duodenum.

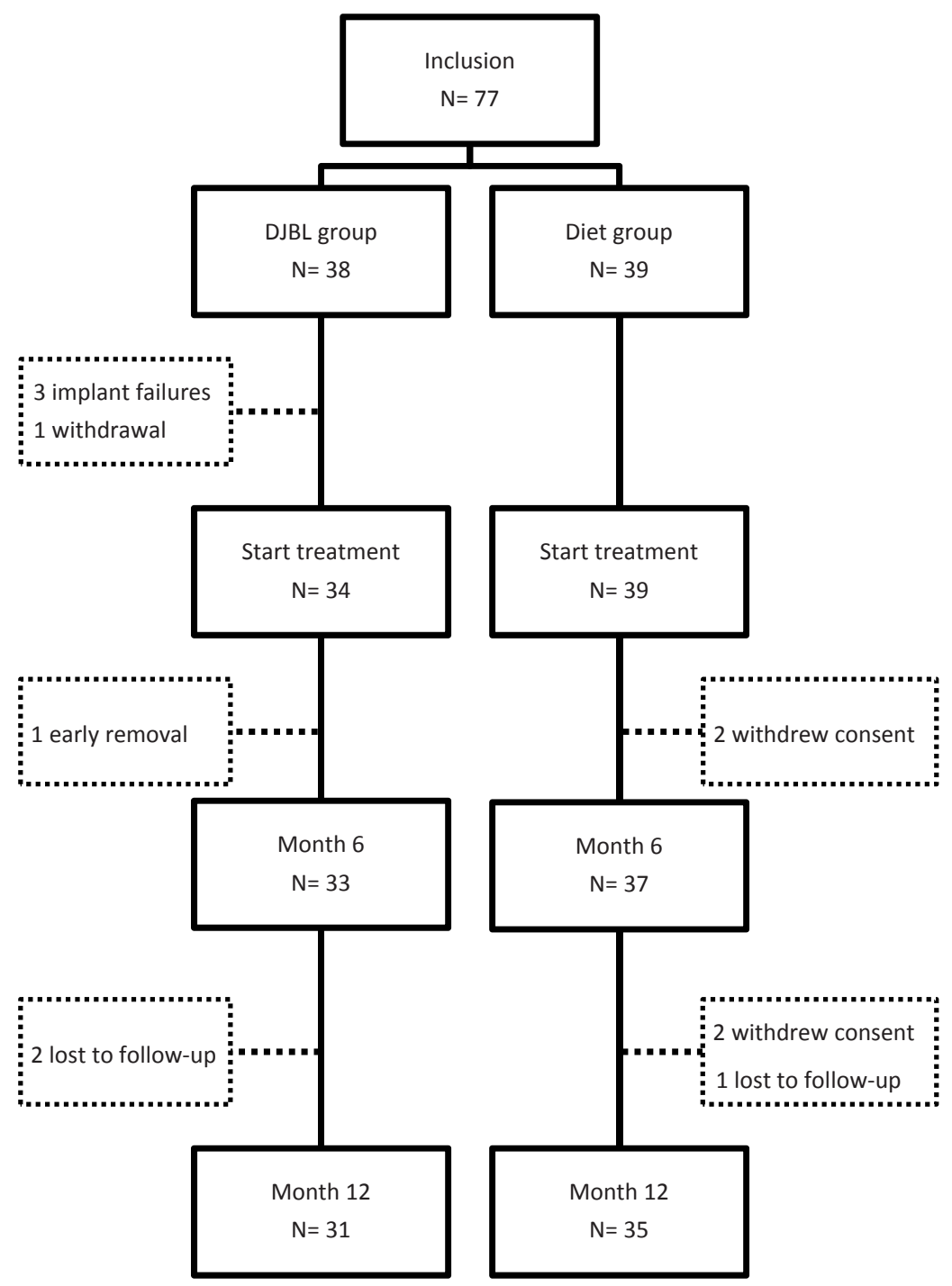

Figure 1. Randomization chart. 
Regular follow-up visits were performed at 1 week, 1 month, 2 months, 3 months, 4 months, 5 months, 6 months, 7 months, 8 months, 9 months, and at 12 months. DJBL patients had an additional hospital visit 1 week after removal of the device. During these visits weight and blood pressure were measured, adverse events were assessed, nutritional and diabetes counselling was performed, and blood was withdrawn to determine the same laboratory parameters as determined at the start of the study. The percentage of excess weight loss was calculated as: ((initial weight)-(current weight))/(weight corresponding with BMI of $25 \mathrm{~kg} / \mathrm{m}^{2}$ ). In addition, a standard 4 hour MTT was performed at 1 week and at 1, 3, and 6 months in both groups.

The study was conducted in accordance with the Standard ISO 14155: 2003 on clinical investigations with medical devices and the recommendations guiding physicians in biomedical research involving human patients adopted by the $18^{\text {th }}$ World Medical Assembly, Helsinki, Finland, 1964 and later revisions. The study was approved by the medical ethical committee of all three participating hospitals. Prior to the start of the study, written informed consent was obtained from all patients.

Table 1. Patient characteristics

\begin{tabular}{llll}
\hline & $\begin{array}{l}\text { Device Group } \\
\mathbf{n}=\mathbf{3 4}\end{array}$ & $\begin{array}{l}\text { Diet Group } \\
\mathrm{n}=39\end{array}$ & P-value \\
\hline Sex (male, No. of patients) & $21(61.8)$ & $25(64.1)$ & 1.00 \\
Age (yr) & $49.5[42-58]$ & $49.0[44-55]$ & 0.83 \\
Weight (kg) & $105.4[98.2-116.1]$ & $110.8[99.7-129]$ & 0.29 \\
BMI (kg/m²) & $34.6[32.4-38.1]$ & $36.8[32.6-42.0]$ & 0.16 \\
Duration of T2DM (yr) & $5.0[3-8]$ & $5.0[3-7]$ & 0.69 \\
HbA $_{1 \mathrm{c}}(\%)$ & $8.3[7.7-9.0]$ & $8.3[7.7-8.9]$ & 0.82 \\
Fasting glucose (mmol/L) & $11.0[9.4-13.0]$ & $11.0[9.3-13.1]$ & 0.87 \\
Fasting insulin (mU/L) & $15.0[9.0-21.0]$ & $17.0[13.0-36.0]$ & 0.11 \\
Systolic blood pressure (mmHg) & $147[139-156]$ & $152[138-160]$ & 0.39 \\
Diastolic blood pressure (mmHg) & $92[82-96]$ & $90[82-96]$ & 0.74 \\
Total cholesterol (mmol/L) & $4.4[3.9-5.0]$ & $4.4[3.6-5.3]$ & 0.88 \\
HDL (mmol/L) & $1.1[0.9-1.4]$ & $1.2[0.9-1.3]$ & 0.88 \\
LDL (mmol/L) & $2.3[1.9-3.1]$ & $2.4[1.8-3.0]$ & 0.95 \\
TG (mmol/L) & $1.7[1.3-3.3]$ & $2.0[1.4-3.0]$ & 0.58 \\
\hline Valus & &
\end{tabular}

Values are presented as No of patients (\%) or mean [interquartile ranges].

\section{DJBL procedure}

The DJBL is a single use endoscopic device mimicking the intestinal bypass component of the Roux-en- $Y$ gastric bypass (Fig. $2 A$ and B). The device consist of a $60 \mathrm{~cm}$ long impermeable fluoropolymer liner and a nitinol anchor, which is used to reversibly affix the device to the duodenum (Fig. $2 \mathrm{C}$ and $\mathrm{D}$ ). The anchor is located in the duodenal bulb and 
the liner stretches out through the duodenum and the proximal part of the jejunum. To allow food passage, the DJBL is open at both the proximal and the distal end. As a result, chyme passes through the interior of the DJBL while pancreatic enzymes and bile pass on the outside of the liner. Digestion and absorption of nutrients therefore start at the end of the liner, creating a bypass of the proximal intestinal tract.

A

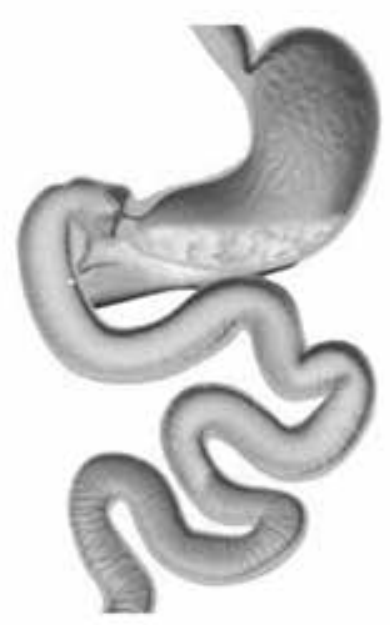

C

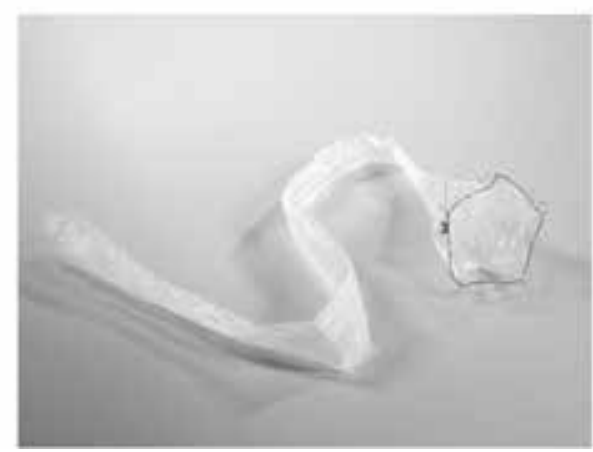

B

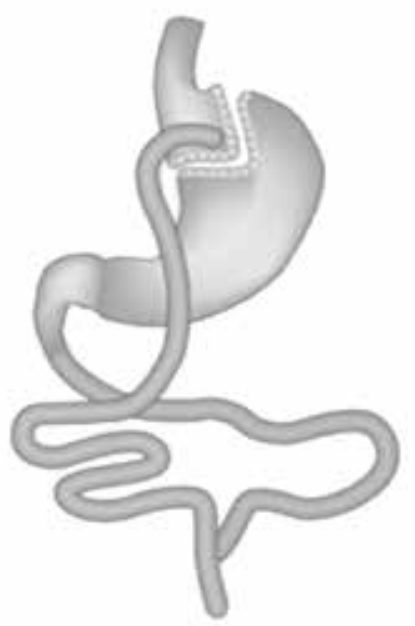

D

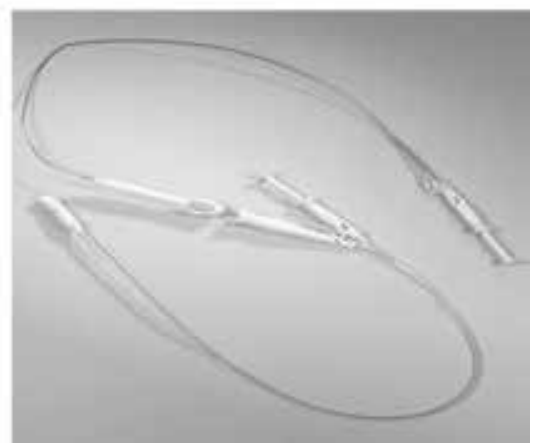

Figure 2. Illustration of the DJBL and the delivery system. A) The DJBL device is endoscopically placed in the duodenum to form a barrier between chyme and the intestinal wall, mimicking the intestinal bypass component of the Roux-en-Y gastric bypass (Panel B). C) The device comprises a $60 \mathrm{~cm}$ long impermeable fluoropolymer sleeve and a nitinol anchor with barbs. The polypropylene drawstring is necessary for removal of the device. D) The implant device with a guide wire, deployment device, and the encapsulated sleeve. 
Implantation of the DJBL was performed under general anesthesia with endotracheal intubation. Initial access to the stomach and duodenum was achieved by a standard gastroduodenoscopy. Next, a guide wire was advanced into the duodenum and the encapsulated device was tracked over the guide wire into the duodenum. The capsule at the distal end holds the liner and anchor. The catheter has an atraumatic ball at the end which is advanced through the intestine deploying the liner behind it. After full extension of the liner, the anchor was deployed in the duodenal bulb, approximately $0.5 \mathrm{~cm}$ distal to the pylorus. Endoscopic and fluoroscopic guidance was used to verify the correct position of the DJBL. Mean procedure time was $32 \pm 4$ minutes. After six months, the DJBL was removed as previously described. ${ }^{15}$ Seventeen removals were performed under general anesthesia and 17 under conscious sedation. The mean procedure time of the removals was $11 \pm 2$ minutes.

\section{Statistical analysis}

With an population of 35 subjects per group, a Fisher's exact test employing an two-tailed alpha of 0.05 will have $80 \%$ power to achieve statistical significance between subject proportions of $25 \%$ (control) and $60 \%$ (device) achieving a $\geq 0.5 \%$ reduction in $\mathrm{HbA}_{1 \mathrm{c}}$ at month 6 or time of explant. In addition, with a sample size of 35 subjects per group, the probability of observing at least one occurrence of an adverse event will be $80 \%$ when the true probability of this event is $5.0 \%$.

Analyses were performed on all patients randomized into the study and successfully treated with DJBL or diet with at least one follow-up visit. A univariate analysis using the Shapiro-Wilk test for normality suggested that several variables in the efficacy and other metabolic data were not normally distributed. Therefore, the median and interquartile ranges are presented of all efficacy, laboratory, and physiological variables. Wilcoxon Rank Sum test were used to compare the difference between two groups for numeric variables. Proportions between the two groups were compared using Fisher's Exact test. Missing data were not imputed. A p-value $<0.05$ was considered statistically significant.

\section{RESULTS}

\section{DJBL vs. control: effect on weight}

Baseline characteristics of both groups are shown in Table 1. At baseline the mean body weight of the DJBL group was 105.4 [98.2 - 116.1] vs. 110.8 [99.7 - 129.0] kg in the control group ( $p=0.29$ ). Mean BMI was $34.6[32.4-38.1] \mathrm{kg} / \mathrm{m}^{2}$ in the DJBL group at baseline vs. $36.8[32.6-42.0] \mathrm{kg} / \mathrm{m}^{2}$ in the control group $(p=0.16)$. 
After six months, body weight had decreased by 10.6 [7.4 - 12.6] kg in the DJBL group (Fig. $3 A)$. In comparison, the weight of the control group had decreased by 5.3 [1.9 - 10.6] kg ( $p<0.05$, DJBL vs. control). Correspondingly, BMI decreased by $3.3[2.2-4.2] \mathrm{kg} / \mathrm{m}^{2}$ in the DJBL group vs. $1.8[0.7-3.4] \mathrm{kg} / \mathrm{m}^{2}$ in the control group (Fig. $3 B, p<0.05$ ). In addition, excess weight loss was superior in the DJBL group: 32.0 [22.0 - 46.7] \% in the DJBL vs. 16.4 [4.1 - 34.6] \% in the control group respectively ( $p<0.05$; Fig. $3 C$ ). In line, the percentage of total weight loss was greater in the DJBL group (DJBL: 10.0 [6.8 - 12.3] vs. control: 4.7 [1.5 - 9.6] \%; p<0.05; Fig. 3D).
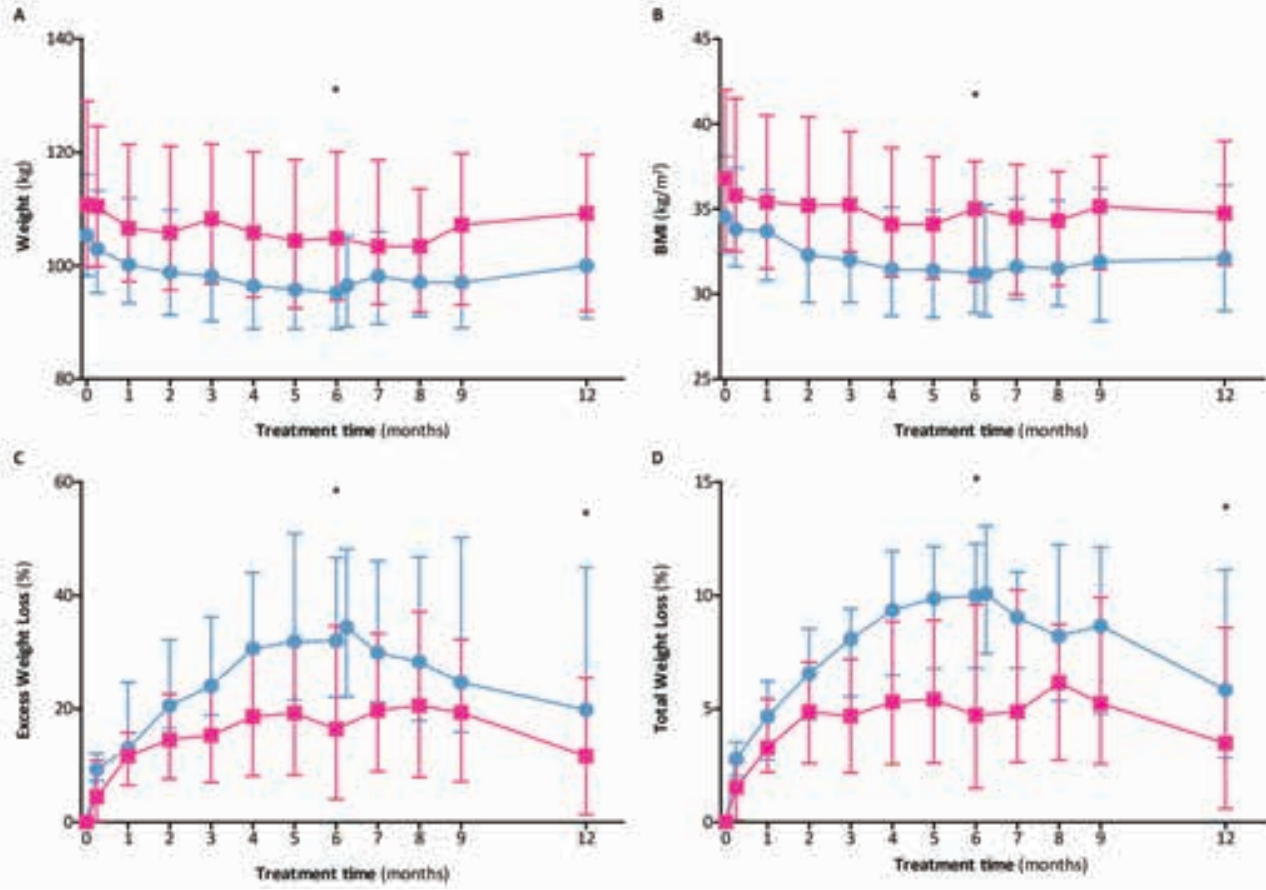

Figure 3. Effects of DJBL treatment vs. control treatment on weight parameters. A) Weight changes over time for both the DJBL and the control group. B) Changes in BMI. C) Percentage of excess weight loss over time. D) Percentage of total body weight loss at all time points for both the DJBL and control group. An asterisk (*) indicates $p<0.05$.

At month twelve, mean body weight of the DJBL patients was still 6.8 [3.3 - 12.0] kg lower than at baseline. In the control group, the weight difference was $4.0[0.8-8.6] \mathrm{kg}$ compared to baseline ( $p=0.07, \mathrm{DJBL}$ vs. control). Accordingly, at this time point, BMI was $2.2[1.2-3.4] \mathrm{kg} / \mathrm{m}^{2}$ lower compared to baseline in the DJBL group and 1.3 [0.3 - 2.8] $\mathrm{kg} / \mathrm{m}^{2}$ lower in the control group $(\mathrm{p}=0.06)$. Importantly, DJBL patients still had an excess weight loss of 19.8 [10.6 - 45.0] \% vs. 11.7 [1.4 - 25.4] \% in the control group $(p<0.05)$. The 
percentage of total weight loss was 5.8 [2.8 - 11.1] \% in the DJBL group vs. 3.5 [0.6 - 8.6] \% in the control group $(p<0.05)$.

\section{Effect of DJBL vs. control treatment on T2DM}

At baseline, the DJBL group was characterized by an $\mathrm{HbA}_{1 c}$ of 8.3 [7.7 - 9.0] vs. 8.3 [7.7 8.9] \% in the control group ( $p=0.82$ ). The fasting glucose level was 11.0 [9.4 - 13.0] mmol/L in the DJBL group and $11.0[9.3-13.1] \mathrm{mmol} / \mathrm{L}$ in the control group $(p=0.87)$. Fasting insulin levels were 15.0 [9.0 - 21.0] and 17.0 [13.0 - 36.0] $\mathrm{mU} / \mathrm{L}$ in the DJBL and control group respectively $(p=0.11$, Table 1$)$.

At six months, $\mathrm{HbA}_{1 \mathrm{c}}$ decreased to 7.0 [6.4 - 7.5] \% in the DJBL group compared to 7.9 [6.6 - 8.3] \% in the control group (Fig. $4 A, p<0.05$ ). Moreover, fasting glucose levels decreased to 8.5 [7.4 - 10.5] mmol/L in the DJBL group (Fig. 4B). In the control group, fasting glucose levels were 10.0 [7.6 - 11.5] mmol/L (Fig. 5D, $p=0.10$ DJBL vs. control). As shown in Figure $4 \mathrm{~F}$ and $\mathrm{H}$, fasting insulin levels decreased to 11.1 [7.0 - 17.8] and 14.0 [10.0 - 19.8] mU/L for the DJBL and control group respectively, $p=0.40$. In the DJBL group $85.3 \%$ of the patients achieved a decrease in postprandial glucose excursion vs. $48.7 \%$ in the control group ( $p<0.05$, Fig $4 C$ and E). Additionally, changes in insulin levels as obtained during the MTT are visualized in Figure 4F-I.

At month twelve, mean $\mathrm{HbA}_{1 \mathrm{c}}$ increased to 7.3 [6.6 - 8.0] \% in the DJBL group vs. an increase to $8.0[6.8-8.8]$ in the control group ( $p=0.95$, DJBL vs. control). Fasting glucose levels were 9.0 [7.4 - 11.1] and 9.7 [8.4 - 12.3] mmol/L for the DJBL and control group respectively $(p=0.41)$ and fasting insulin levels were 15.0 [8.0 - 19.5] and 15.7 [8.6 - 23.6] $\mathrm{mU} / \mathrm{L}$ respectively $(\mathrm{p}=0.73)$.

\section{Changes in glucose-lowering medication}

All participants used glucose-lowering medication at baseline. In the DJBL group $(n=38), 36$ patients were on metformin, 28 patients were on sulfonylurea derivates (SU), and 17 patients were on insulin. In the control group ( $n=39$ ), 33 patients were on metformin, 30 patients were on $\mathrm{SU}$, and 19 patients were on insulin.

Changes in glucose-lowering medication evaluated at month six and month twelve are displayed in Table 2. Importantly, the daily insulin dosage was more often decreased or discontinued in the DJBL group compared to the control group ( $p<0.05$ at month twelve). The same trend was observed for the usage of SUs ( $p<0.05$ at month twelve). 

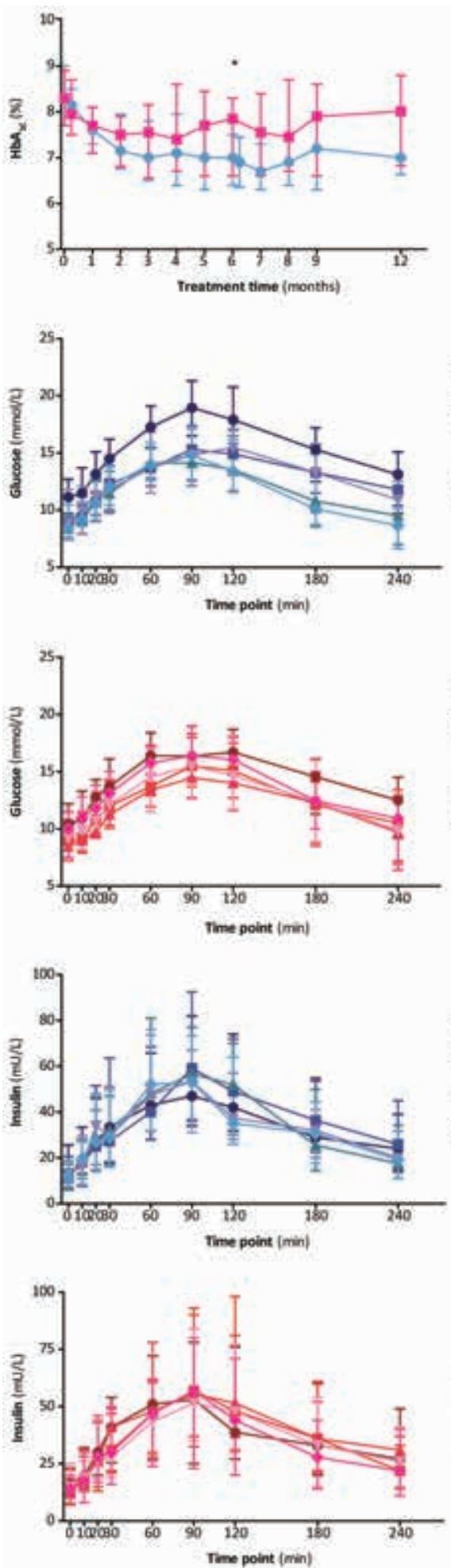

Figure 4. Effects of DJBL treatment on T2DM.

A) $\mathrm{HbA}_{1 c}$ levels. B) Glucose concentrations of the $D J B L$ group during the meal tolerance tests (MTT). C) AUC of glucose. D) Glucose concentrations of the control group during the MTT. E) AUC of glucose. F) Insulin levels during the MTT of the DJBL patients. G) AUC of insulin. $H$ ) Insulin concentrations of the control patients during the MTT. I) AUC of insulin. An asterisk (*) indicates $p<0.05$.
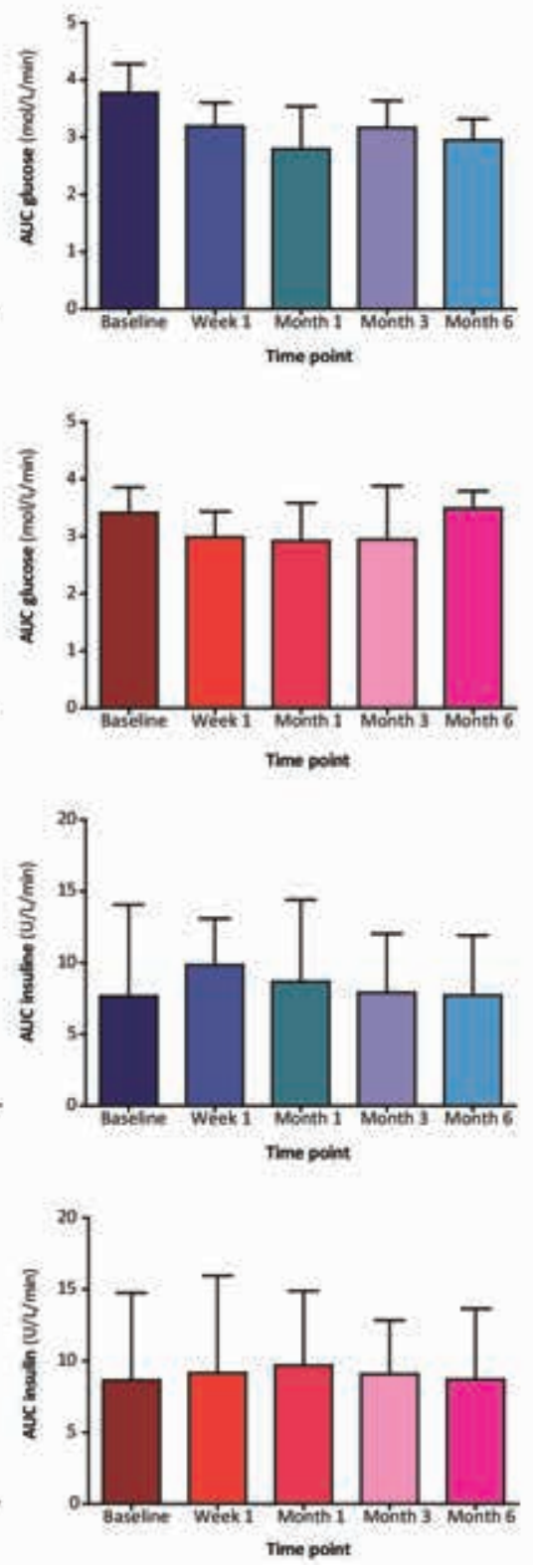
Table 2. Changes in glucose-lowering medication.

\begin{tabular}{|c|c|c|c|c|c|}
\hline & & \multicolumn{2}{|c|}{ Month 6} & \multicolumn{2}{|c|}{ Month 12} \\
\hline & & DJBL & Control & DJBL & Control \\
\hline \multirow[t]{3}{*}{ Metformin } & decreased & 8.8 & 7.7 & 16.7 & 7.9 \\
\hline & discontinued & 2.9 & - & 3.3 & 2.6 \\
\hline & increased & - & - & 3.3 & 10.5 \\
\hline \multirow[t]{3}{*}{ SU } & decreased & 47.1 & 38.5 & 40.0 & 13.9 \\
\hline & discontinued & 14.7 & 23.1 & 13.3 & 13.9 \\
\hline & increased & 2.9 & 2.6 & 6.7 & 13.9 \\
\hline \multirow[t]{3}{*}{ Insulin } & decreased & 41.2 & 30.8 & 36.7 & 20.5 \\
\hline & discontinued & - & - & 13.3 & - \\
\hline & increased & - & 10.3 & - & 23.1 \\
\hline
\end{tabular}

Values are presented as \%.

Table 3. Changes in blood pressure and cholesterol profile.

\begin{tabular}{|c|c|c|c|c|}
\hline & & Baseline & Month 6 & Month 12 \\
\hline \multicolumn{5}{|c|}{ Device Group } \\
\hline & Systolic RR (mmHg) & 147 [139 - 156] & 132 [122 - 140] & 130 [124 - 144] \\
\hline & Diastolic RR (mmHg) & $92[82-96]$ & 81 [72 - 90] & 82 [77 - 90] \\
\hline & Cholesterol (mmol/L) & $4.4[3.9-5.0]$ & $3.7[3.4-4.1] *$ & $4.4[4.0-5.3]$ \\
\hline & $\mathrm{HDL}(\mathrm{mmol} / \mathrm{L})$ & $1.1[0.9-1.4]$ & $1.0[0.8-1.2]$ & $1.1[0.9-1.3]$ \\
\hline & LDL (mmol/L) & $2.3[1.9-3.1]$ & $2.0[1.5-2.3] *$ & $2.4[1.9-3.2]$ \\
\hline & $\mathrm{TG}(\mathrm{mmol} / \mathrm{L})$ & $1.8[1.3-3.3]$ & $1.5[1.2-2.0]$ & $2.0[1.0-2.8]$ \\
\hline \multirow[t]{6}{*}{ Diet Group } & Systolic RR (mmHg) & $152[138-160]$ & 137 [124 - 148] & 140 [122 - 148] \\
\hline & Diastolic RR (mmHg) & $90[82-96]$ & $82[77-90]$ & $85[78-90]$ \\
\hline & Cholesterol (mmol/L) & $4.4[3.6-5.3]$ & $4.5[4.6-5.1]^{*}$ & $4.4[3.9-5.1]$ \\
\hline & $\mathrm{HDL}(\mathrm{mmol} / \mathrm{L})$ & $1.2[0.9-1.3]$ & $1.2[0.9-1.4]$ & $1.1[1.0-1.4]$ \\
\hline & LDL (mmol/L) & $2.4[1.8-3.0]$ & $2.3[1.8-2.8]^{*}$ & $2.3[1.9-3.0]$ \\
\hline & TG (mmol/L) & $2.0[1.5-3.0]$ & $1.8[1.2-2.4]$ & $1.7[1.2-2.5]$ \\
\hline
\end{tabular}

Data are presented as mean [interquartile ranges] in $\mathrm{mmol} / \mathrm{L}$, an asterisk $\left({ }^{*}\right)$ indicates $\mathrm{p}<0.05$. 


\section{Effect of DJBL vs. control treatment on cardiovascular parameters}

At baseline, $34 \%$ of the DJBL patients vs. $41 \%$ of the diet patients were on antihypertensive medication. During the course of the study, only minor medication changes were made. After six months of treatment, blood pressure (RR) decreased from 147 [139 - 156]/92 [82 - 96] to 132 [122 - 140]/81 [72 - 90] mmHg in the DJBL group and from 152 [138 - 160]/90 [82 - 96] to 137 [124 - 148]/82 [79 - 90] mmHg in the control group (Table 2, $p=0.25$ for systolic blood pressure and $p=0.29$ for diastolic blood pressure). Total cholesterol levels decreased from 4.4 [3.9 - 5.0] to 3.7 [3.4 - 4.2] $\mathrm{mmol} / \mathrm{L}$ in the DJBL group. In the control group, no change was observed (4.4 [3.6 - 5.3] vs. 4.5 [3.9 - 5.1] $\mathrm{mmol} / \mathrm{L}, \mathrm{p}<0.05 \mathrm{DJBL}$ vs. control at month six).

At the end of the study, after twelve months, blood pressure had stabilized; for DJBL patients the mean value was 130 [124 - 144]/82 [77 - 90] vs. 140 [122 - 148]/85 [78 - 90] $\mathrm{mmHg}$ in the control group $(\mathrm{p}=0.31$ for systolic blood pressure and $\mathrm{p}=0.38$ for diastolic blood pressure). The total cholesterol level of all patients was comparable to baseline (4.4 [4.0 - 5.3] vs. 4.4 [3.9 - 5.1] DJBL vs. control group respectively, $p=0.79)$. Additional information on changes in HDL, LDL, and TG levels is shown in Table 3.

\section{Safety data}

In the DJBL group, $76.3 \%$ of the patients had at least one adverse event vs. $59 \%$ of the patients in the control group. In the DJBL group, adverse events consisted mainly of minor gastrointestinal complaints, abdominal pain or discomfort $(63.2 \%$ in the DJBL group vs. $28.2 \%$ in the control group respectively). In the DJBL group these complaints occurred primarily during the early post-implantation phase, within two weeks after the implantation. Complaints of nausea or vomiting occurred in $23.7 \%$ of the DJBL patients and in $17.9 \%$ of the control patients. The prevalence of hypoglycemic events was comparable between the two groups, $23.7 \%$ in the DJBL vs. $25.6 \%$ in the control group.

In the DJBL group, there were eight adverse events requiring hospitalization. Five out of the eight events were device-related. One patient presented with melena and pain in the epigastric region, however no bleeding was found during endoscopic evaluation and complaints disappeared with conservative treatment. An additional patient presented with abdominal discomfort and subsequent dehydration due to insufficient fluid intake, which was also managed conservatively. In one patient the DJBL got obstructed with food, making early removal necessary. One patient suffered from symptomatic gallstones during the course of the study and was treated with a laparoscopic cholecystectomy. All devicerelated serious adverse events resolved without sequelae. Only one procedure-related serious adverse event occurred, an esophageal perforation during a scheduled DJBL 
removal at month six. After an apparent uncomplicated removal, final endoscopic evaluation revealed a $6 \mathrm{~cm}$ longitudinal, partially transmural tear of the esophagus. This was probably caused by one of the barbs on the anchor that was not fully covered by the removal hood. Treatment of the perforation was performed by endoscopic stenting and placement of a feeding tube. After three weeks the tear had resolved without sequelae and the patient completed the study. During the study, only one DJBL patient withdrew consent due to an adverse event of abdominal pain at day 10. Two additional patients were lost to follow-up (at days 191 and 272 respectively, for more information see Figure 1).

In the control group, there were also eight adverse events requiring hospitalization. By the end of the study five events had resolved without sequelae. The events that did not resolve without sequelae consisted of a myocardial infarction, a humerus fracture, a lower back hernia, diagnosis of cancer, and a non-specified psychiatric disorder. In this group, four patients withdrew informed consent. One at week one, month three, day 315, and one patient withdrew consent at day 273 when diagnosed with cancer. One patient was lost to follow-up at day 267.

\section{DISCUSSION}

There is overwhelming evidence that bariatric surgery promotes weight loss and improves glucose homeostasis. ${ }^{20}$ The Roux-en-Y gastric bypass and the biliopancreatic diversion seem to be the most effective procedures; both techniques cause significant weight loss and durable remission of T2DM. ${ }^{8,21-23}$ Interestingly, the improvement of T2DM occurs rapidly within days following both types of surgery. ${ }^{23-25}$ This rapid glycemic improvement is thought to be specifically attributable to the intestinal bypass component ${ }^{26-28}$ which, according to the foregut hypothesis, results in glycemic improvement by reduced secretion of diabetogenic factors in the proximal small intestine. ${ }^{29,30}$ The hindgut hypothesis, on the other hand, attributes improved glycemic control to enhanced secretion of incretins in response to undigested nutrients in the distal small intestine. ${ }^{27,31}$ Interestingly, exclusion of the proximal small intestine by means of the surgical duodenaljejunal bypass, rapidly improves T2DM, even in non-obese patients. ${ }^{32}$

The DJBL is a non-surgical endoscopic device developed to create an intestinal bypass in a minimally invasive way. ${ }^{15,33}$ Previous studies have revealed positive effects of the DJBL on obesity, T2DM, and the metabolic syndrome. ${ }^{11-19}$ The aim of the current study was to investigate the effect of the DJBL on obesity and T2DM in a randomized manner, comparing six months of DJBL treatment in combination with dietary intervention to 
dietary treatment alone. This study is the first to report on six months DJBL treatment compared to dietary intervention. Furthermore, our study included six months of postDJBL-removal follow-up.

Six months after treatment initiation, the DJBL group lost significantly more weight than the diet group. In addition, $\mathrm{HbA}_{1 \mathrm{c}}$ decreased significantly compared to the control group. DJBL treatment was associated with a greater percentage of patients achieving a decrease in postprandial glucose levels. Furthermore, glucose-lowering medication was reduced or discontinued in more DJBL patients than control patients. These results are in line with previous studies performed with the DJBL. Since the first report of a successful DJBL implantation in a patient for a period of three months, resulting in a total weight loss of 9 $\mathrm{kg}^{34}$ several studies have demonstrated positive effects of DJBL treatment on obesity. ${ }^{11,18}$ In addition a marked improvement of T2DM was observed. ${ }^{11,18}$ Previously performed randomized controlled trials, comparing DJBL treatment vs. sham or diet control treatment, have displayed superiority of the DJBL in weight control and improvement of T2DM. ${ }^{12-15}$ Taken together, DJBL treatment in combination with a diet is more effective in treating obesity and T2DM when compared to dietary intervention alone.

Interestingly, the mechanisms responsible for the effectiveness of duodenal-jejunal exclusion are still unknown. Since postprandial insulin secretion seemed stable over the course of the study, it is tempting to speculate that the rapid changes in the glucose response to a meal may result from increased insulin sensitivity and/or decreased hepatic glucose production. ${ }^{35}$ As previously shown, changes in glucagon-like peptide-1, glucosedependent insulinotropic polypeptide, and glucagon parallel this phenomenon. ${ }^{16}$

Intraluminal implants in the digestive tract can theoretically be the cause of serious complications. Migration, bleeding, perforation, or obstruction are potential drawbacks and are reported often in numerous studies on stent placement for colonic malignancy. ${ }^{36}$ Although design, indication, and placement behind the pylorus of the DJBL is unprecedented, safety has been a point of meticulous observation. However, DJBL treatment for six months has shown to have a favorable risk/benefit ratio. In the current study, one procedure related event occurred requiring only conventional treatment. Moreover, the early removal rate was low (1 out of 34 ) in this study. Adverse events were mild and most commonly consisted of abdominal discomfort and nausea. They typically occurred during the first few weeks following DJBL implantation and usually resolved without treatment and without sequelae. So far no mortality has been reported after DJBL treatment with a published experience of around 300 patients worldwide. Therefore, the DJBL can be considered as a safe treatment option for obesity and T2DM.

After removal of the device, weight and $\mathrm{HbA}_{1 \mathrm{c}}$ increased slightly in the DJBL group. $A$ similar trend for weight and $\mathrm{HbA}_{1 \mathrm{c}}$ was observed in the control group. At month twelve, 
the percentage of excess weight loss and the percentage of total weight loss was still significantly greater in the DJBL group. Changes in weight and $\mathrm{HbA}_{1 \mathrm{c}}$ were no longer statistically different between the groups. Importantly, weight and T2DM control remained improved compared to baseline in both groups. At the time of study initiation, the maximally approved DJBL treatment duration was six months in the Netherlands. de Moura et al. were the first to investigate one year DJBL treatment and demonstrated the safety and efficacy of the DJBL in reducing obesity and T2DM on the longer term. ${ }^{17}$ These positive effects have now been confirmed by two additional one-year prospective clinical studies. ${ }^{19,37}$ Based on these results, it might be expected that the improvement of T2DM observed in the current study with a treatment duration of six months would be even more pronounced with a longer treatment duration. As DJBL is an innovative technique the maximum potential of this device is as yet uncertain. One of the drawbacks could theoretically be migration of the device's anchor further into the duodenum. As the chance of migration potentially increases when the device is left in place for a longer period of time, implantation time is extended only gradually in order not to compromise the patient's safety. Next to longer implantation time, intermittent implantation could be a valid alternative to prolong the therapeutic effect of the DJBL and studies are now being performed to evaluate the feasibility and efficacy of reimplantation.

With regard to cardiovascular risk profile, as already described by Cohen et al., subtle changes in cardio vascular risk profile can be of major clinical importance. ${ }^{37}$ In the current population, the 10-year risk for coronary heart disease according to the UK Prospective Diabetes Study Risk Engine would be, without intervention, approximately $14.0 \%$ in the DJBL group vs. $12.5 \%$ in the control group at twelve months. With the DJBL intervention, the estimated 10 -year coronary heart disease risk decreased by approximately $2 \%$ vs. $1 \%$ decrease in the control group, ${ }^{38}$ possibly indicating superiority of the DJBL over dietary treatment with respect to reducing risk for development of cardiovascular disease.

In the treatment algorithm for obese patients with type 2 diabetes, the DJBL can be positioned in between medical therapy and invasive bariatric techniques. In addition, it might be beneficial to combine DJBL treatment with the very promising glucose-lowering therapies that have recently become available, such as glucagon-like peptide-1 agonists, dipeptidyl peptidase-4 inhibitors, or sodium/glucose cotransporter- 2 inhibitors. ${ }^{39}$ In the current study, no patients using these types of medication were included. However, studies including these drugs seem of great interest.

In conclusion, the current data suggest that the DJBL is a valid alternative to invasive bariatric procedures in the treatment of obesity and T2DM. Six months of DJBL treatment plus dietary intervention leads to significant weight loss and improvement of T2DM compared to dietary treatment alone. 


\section{REFERENCES}

1. Kelly T, Yang W, Chen CS, Reynolds K, He J. Global burden of obesity in 2005 and projections to 2030. Int J Obes. 2008 Sep;32(9):1431-7.

2. Ogden CL, Yanovski SZ, Carroll MD, Flegal KM. The epidemiology of obesity. Gastroenterology. 2007 May;132(6):2087-102.

3. Rosemann T, Grol R, Herman K, Wensing M, Szecsenyi J. Association between obesity, quality of life, physical activity and health service utilization in primary care patients with osteoarthritis. The international journal of behavioral nutrition and physical activity. 2008 Jan;5:4.

4. Wild S, Roglic G, Green A, Sicree R, King H. Global prevalence of diabetes: estimates for the year 2000 and projections for 2030. Diabetes Care. 2004 May;27(5):1047-53.

5. Sjostrom L. Review of the key results from the Swedish Obese Subjects (SOS) trial - a prospective controlled intervention study of bariatric surgery. Journal of internal medicine. 2013 Mar;273(3):219-34.

6. Sjostrom L, Narbro K, Sjostrom CD, Karason K, Larsson B, Wedel H, Lystig T, Sullivan M, Bouchard C, Carlsson B, et al. Effects of bariatric surgery on mortality in Swedish obese subjects. N Engl J Med. 2007 Aug 23;357(8):741-52.

7. Kral JG, Sjostrom LV, Sullivan MB. Assessment of quality of life before and after surgery for severe obesity. The American journal of clinical nutrition. 1992 Feb;55(2 Suppl):611S-4S.

8. Buchwald H, Estok R, Fahrbach K, Banel D, Jensen MD, Pories WJ, Bantle JP, Sledge I. Weight and type 2 diabetes after bariatric surgery: systematic review and meta-analysis. Am J Med. 2009 Mar;122(3):24856.

9. Morino M, Toppino M, Forestieri P, Angrisani L, Allaix ME, Scopinaro N. Mortality after bariatric surgery: analysis of 13,871 morbidly obese patients from a national registry. Ann Surg. 2007 Dec;246(6):1002-7; discussion 7-9.

10. Committee AT, Kethu SR, Banerjee S, Barth BA, Desilets DJ, Kaul V, Pedrosa MC, Pfau PR, Pleskow DK, Tokar JL, et al. Endoluminal bariatric techniques. Gastrointest Endosc. 2012 Jul;76(1):1-7.

11. Rodriguez-Grunert L, Galvao Neto MP, Alamo M, Ramos AC, Baez PB, Tarnoff M. First human experience with endoscopically delivered and retrieved duodenal-jejunal bypass sleeve. Surg Obes Relat Dis. 2008 Jan-Feb;4(1):55-9.

12. Rodriguez L, Reyes E, Fagalde P, Oltra MS, Saba J, Aylwin CG, Prieto C, Ramos A, Galvao M, Gersin KS, et al. Pilot clinical study of an endoscopic, removable duodenal-jejunal bypass liner for the treatment of type 2 diabetes. Diabetes Technol Ther. 2009 Nov;11(11):725-32.

13. Tarnoff M, Rodriguez L, Escalona A, Ramos A, Neto M, Alamo M, Reyes E, Pimentel F, Ibanez L. Open label, prospective, randomized controlled trial of an endoscopic duodenal-jejunal bypass sleeve versus low calorie diet for pre-operative weight loss in bariatric surgery. Surg Endosc. 2009 Mar;23(3):650-6.

14. Gersin KS, Rothstein RI, Rosenthal RJ, Stefanidis D, Deal SE, Kuwada TS, Laycock W, Adrales G, Vassiliou $\mathrm{M}$, Szomstein S, et al. Open-label, sham-controlled trial of an endoscopic duodenojejunal bypass liner for preoperative weight loss in bariatric surgery candidates. Gastrointest Endosc. 2010 May;71(6):976-82.

15. Schouten R, Rijs CS, Bouvy ND, Hameeteman W, Koek GH, Janssen IM, Greve JW. A multicenter, randomized efficacy study of the EndoBarrier Gastrointestinal Liner for presurgical weight loss prior to bariatric surgery. Ann Surg. 2010 Feb;251(2):236-43.

16. de Jonge C, Rensen SS, Verdam FJ, Vincent RP, Bloom SR, Buurman WA, le Roux CW, Schaper NC, Bouvy ND, Greve JW. Endoscopic duodenal-jejunal bypass liner rapidly improves type 2 diabetes. Obes Surg. 2013 Sep;23(9):1354-60.

17. de Moura EG, Martins BC, Lopes GS, Orso IR, de Oliveira SL, Galvao Neto MP, Santo MA, Sakai P, Ramos $A C$, Garrido Junior $A B$, et al. Metabolic improvements in obese type 2 diabetes subjects implanted for 1 year with an endoscopically deployed duodenal-jejunal bypass liner. Diabetes Technol Ther. 2012 Feb;14(2):183-9. 
18. de Moura EG, Orso IR, Martins Bda C, Lopes GS, de Oliveira SL, Galvao-Neto Mdos P, Mancini MC, Santo MA, Sakai $P$, Ramos AC, et al. Improvement of insulin resistance and reduction of cardiovascular risk among obese patients with type 2 diabetes with the duodenojejunal bypass liner. Obes Surg. 2011 Jul;21(7):941-7.

19. Escalona A, Pimentel F, Sharp A, Becerra P, Slako M, Turiel D, Munoz R, Bambs C, Guzman S, Ibanez L, et al. Weight loss and metabolic improvement in morbidly obese subjects implanted for 1 year with an endoscopic duodenal-jejunal bypass liner. Ann Surg. 2012 Jun;255(6):1080-5.

20. Sjostrom L, Lindroos AK, Peltonen M, Torgerson J, Bouchard C, Carlsson B, Dahlgren S, Larsson B, Narbro $\mathrm{K}$, Sjostrom $\mathrm{CD}$, et al. Lifestyle, diabetes, and cardiovascular risk factors 10 years after bariatric surgery. $\mathrm{N}$ Engl J Med. 2004 Dec;351(26):2683-93.

21. Schauer PR, Burguera B, Ikramuddin S, Cottam D, Gourash W, Hamad G, Eid GM, Mattar S, Ramanathan $\mathrm{R}$, Barinas-Mitchel $\mathrm{E}$, et al. Effect of laparoscopic Roux-en $\mathrm{Y}$ gastric bypass on type 2 diabetes mellitus. Ann Surg. 2003 Oct;238(4):467-84; discussion 84-5.

22. Greenway SE, Greenway FL, 3rd, Klein S. Effects of obesity surgery on non-insulin-dependent diabetes mellitus. Arch Surg. 2002 Oct;137(10):1109-17.

23. Rubino F, Gagner M. Potential of surgery for curing type 2 diabetes mellitus. Ann Surg. 2002 Nov;236(5):554-9.

24. Hickey MS, Pories WJ, MacDonald KG, Jr., Cory KA, Dohm GL, Swanson MS, Israel RG, Barakat HA, Considine RV, Caro JF, et al. A new paradigm for type 2 diabetes mellitus: could it be a disease of the foregut? Ann Surg. 1998 May;227(5):637-43; discussion 43-4.

25. Pories WJ, Swanson MS, MacDonald KG, Long SB, Morris PG, Brown BM, Barakat HA, deRamon RA, Israel G, Dolezal JM, et al. Who would have thought it? An operation proves to be the most effective therapy for adult-onset diabetes mellitus. Ann Surg. 1995 Sep;222(3):339-50; discussion 50-2.

26. Rubino F, Forgione A, Cummings DE, Vix M, Gnuli D, Mingrone G, Castagneto M, Marescaux J. The mechanism of diabetes control after gastrointestinal bypass surgery reveals a role of the proximal small intestine in the pathophysiology of type 2 diabetes. Annals of Surgery. 2006 Nov;244(5):741-9.

27. Thaler JP, Cummings DE. Minireview: Hormonal and metabolic mechanisms of diabetes remission after gastrointestinal surgery. Endocrinology. 2009 Jun;150(6):2518-25.

28. Breen DM, Rasmussen BA, Kokorovic A, Wang R, Cheung GW, Lam TK. Jejunal nutrient sensing is required for duodenal-jejunal bypass surgery to rapidly lower glucose concentrations in uncontrolled diabetes. Nat Med. 2012 Jun;18(6):950-5.

29. Rubino F, Forgione A, Cummings DE, Vix M, Gnuli D, Mingrone G, Castagneto M, Marescaux J. The mechanism of diabetes control after gastrointestinal bypass surgery reveals a role of the proximal small intestine in the pathophysiology of type 2 diabetes. Ann Surg. 2006 Nov;244(5):741-9.

30. Knop FK. Resolution of type 2 diabetes following gastric bypass surgery: involvement of gut-derived glucagon and glucagonotropic signalling? Diabetologia. 2009 Nov;52(11):2270-6.

31. Fetner R, McGinty J, Russell C, Pi-Sunyer FX, Laferrere B. Incretins, diabetes, and bariatric surgery: a review. Surg Obes Relat Dis. 2005 Nov-Dec;1(6):589-97; discussion 97-8.

32. Geloneze B, Geloneze SR, Chaim E, Hirsch FF, Felici AC, Lambert G, Tambascia MA, Pareja JC. Metabolic surgery for non-obese type 2 diabetes: incretins, adipocytokines, and insulin secretion/resistance changes in a 1-year interventional clinical controlled study. Ann Surg. 2012 Jul;256(1):72-8.

33. Goldfine AB, Shoelson SE, Aguirre V. Expansion and contraction: treating diabetes with bariatric surgery. Nat Med. 2009 Jun;15(6):616-7.

34. Gersin KS, Keller JE, Stefanidis D, Simms CS, Abraham DD, Deal SE, Kuwada TS, Heniford BT. Duodenaljejunal bypass sleeve: a totally endoscopic device for the treatment of morbid obesity. Surgical innovation. 2007 Dec;14(4):275-8.

35. Cohen R, le Roux CW, Papamargaritis D, Salles JE, Petry T, Correa JL, Pournaras DJ, Galvao Neto M, Martins B, Sakai $P$, et al. Role of proximal gut exclusion from food on glucose homeostasis in patients with Type 2 diabetes. Diabet Med. 2013 Dec;30(12):1482-6. 
36. Athreya S, Moss J, Urquhart G, Edwards R, Downie A, Poon FW. Colorectal stenting for colonic obstruction: the indications, complications, effectiveness and outcome--5 year review. European journal of radiology. 2006 Oct;60(1):91-4.

37. Cohen RV, Neto MG, Correa JL, Sakai P, Martins B, Schiavon CA, Petry T, Salles JE, Mamedio C, Sorli C. A pilot study of the duodenal-jejunal bypass liner in low body mass index type 2 diabetes. J Clin Endocrinol Metab. 2013 Feb;98(2):E279-82.

38. Stevens RJ, Kothari V, Adler Al, Stratton IM, United Kingdom Prospective Diabetes Study G. The UKPDS risk engine: a model for the risk of coronary heart disease in Type II diabetes (UKPDS 56). Clin Sci. 2001 Dec;101(6):671-9.

39. Piya MK, Tahrani AA, Barnett AH. Emerging Treatment Options for Type 2 Diabetes. British journal of clinical pharmacology. 2010 Aug 4. 



\section{Chapter 3}

\section{Endoscopic Duodenal-Jejunal Bypass Liner rapidly improves type 2 diabetes}

Charlotte de Jonge, Sander S Rensen, Froukje J Verdam, Royce P Vincent, Steve R Bloom, Wim A Buurman, Carel W le Roux, Nicolaas C Schaper, Nicole D Bouvy, and Jan Willem M Greve Obesity Surgery, 2013 


\section{ABSTRACT}

\section{Background}

Bariatric procedures excluding the proximal small intestine improve glycemic control in type 2 diabetes within days. To gain insight into the mediators involved, we investigated factors regulating glucose homeostasis in patients with type 2 diabetes treated with the novel endoscopic Duodenal-Jejunal Bypass Liner (DJBL).

\section{Methods}

Seventeen obese patients (body mass index between 30 and $50 \mathrm{~kg} / \mathrm{m}^{2}$ ) with type 2 diabetes received the DJBL for 24 weeks. Body weight and type 2 diabetes parameters, including $\mathrm{HbA}_{1 \mathrm{c}}$ and plasma levels of glucose, insulin, glucagon-like peptide-1 (GLP-1), glucose-dependent insulinotropic polypeptide (GIP), and glucagon were analyzed after a standard meal, before, during, and 1 week after DJBL treatment.

\section{Results}

At 24 weeks after implantation, patients had lost $12.7 \pm 1.3 \mathrm{~kg}(\mathrm{p}<0.01)$ while $\mathrm{HbA}_{1 \mathrm{c}}$ had improved from $8.4 \pm 0.2$ to $7.0 \pm 0.2 \%(p<0.01)$. Both fasting glucose levels and the postprandial glucose response were decreased at 1 week after implantation and remained decreased at 24 weeks (baseline vs. week 1 vs. week 24 : $11.6 \pm 0.5$ vs. $9.0 \pm 0.5$ vs. $8.6 \pm$ $0.5 \mathrm{mmol} / \mathrm{L}$ and $1,999 \pm 85$ vs. $1,536 \pm 51$ vs. $1,538 \pm 72 \mathrm{mmol} / \mathrm{L} / \mathrm{min}$, both $\mathrm{p}<0.01)$. In parallel, the glucagon response decreased $(23,762 \pm 4,732$ vs. $15,989 \pm 3,193$ vs. $13,1207 \pm$ $1,946 \mathrm{pg} / \mathrm{mL} / \mathrm{min}, \mathrm{p}<0.05)$ and the GLP-1 response increased $(4,440 \pm 249$ vs. $6,407 \pm 480$ vs. $6,008 \pm 429 \mathrm{pmol} / \mathrm{L} / \mathrm{min}, \mathrm{p}<0.01)$. The GIP response was decreased at week 24 (baseline: $115,272 \pm 10,971$ vs. week $24: 88,499 \pm 10,971 \mathrm{pg} / \mathrm{mL} / \mathrm{min}, \mathrm{p}<0.05$ ). Insulin levels did not change significantly. Glycemic control was still improved 1 week after explantation.

\section{Conclusion}

The data indicate DJBL to be a promising treatment for obesity and type 2 diabetes causing rapid improvement of glycemic control, paralleled by changes in gut hormones. 


\section{INTRODUCTION}

The rising prevalence of obesity is accompanied by an increasing number of people suffering from obesity-related comorbidities. Type 2 diabetes (T2DM) is an important comorbidity of obesity and a major cause of morbidity and mortality. ${ }^{1,2}$ For decades, bariatric surgery has been performed to treat obesity, with additional remarkable effects on T2DM. ${ }^{3,4}$ Rapid remission of T2DM occurs particularly after bariatric procedures involving a bypass of the proximal small intestine, such as the Roux-en-Y gastric bypass (RYGB). ${ }^{5-7}$

Two major mechanisms have been hypothesized to explain the rapid improvement of T2DM. Firstly, the foregut hypothesis suggests that improved glycemia after proximal intestinal exclusion results from reduced secretion of diabetogenic hormones/anti-incretin factors in response to the absence of nutrition in the proximal small intestine. ${ }^{8,9}$ For example, intestinal glucagon synthesis has been suggested to decrease after exclusion of the proximal intestine. ${ }^{9}$ Secondly, the hindgut hypothesis attributes improved glycemic control to enhanced secretion of incretins, like glucagon-like peptide-1 (GLP-1), in response to undigested nutrients in the distal small intestine. ${ }^{6,10}$ These theories are not mutually exclusive and additional factors likely play a role in the rapid glycemic improvement after bariatric surgery. Particularly, glucose-dependent insulinotropic polypeptide (GIP), a gut hormone which stimulates glucagon secretion in response to a meal, may also be involved. ${ }^{11}$ Furthermore, caloric intake is of importance in improvement of T2DM. ${ }^{12}$

Recently, a non-surgical Duodenal-Jejunal Bypass Liner (DJBL; GI Dynamics, Lexington, MA) has been developed to mimic RYGB-related proximal small intestinal exclusion. The DJBL is a $60 \mathrm{~cm}$ long impermeable liner which is delivered and retrieved endoscopically. Previous studies have shown its safety and efficacy: like RYGB, the DJBL causes significant weight loss and improvement of glycemic control. ${ }^{13-18}$ Unlike RYGB, the anatomy of the stomach and small intestine is not affected by DJBL treatment, ${ }^{19}$ enabling mechanistic studies focusing exclusively on the role of the proximal intestine in T2DM.

In this pilot study, we investigated mechanisms by which proximal small intestinal exclusion by DJBL improves glycemic control in patients with T2DM. Glucose, insulin, GLP$1, \mathrm{GIP}$, and glucagon responses after a standard meal were studied before, during, and after DJBL treatment. 


\section{METHODS}

\section{Subjects}

Seventeen patients with T2DM and obesity were included at Maastricht University Medical Center and Atrium Medical Center Parkstad. Inclusion criteria were: age between 18 and 65 years; duration of $\mathrm{T} 2 \mathrm{DM}<10$ years; $\mathrm{HbA}_{1 \mathrm{c}}$ between 7.5 and $10.0 \%$; and body mass index (BMI) between 30 to $50 \mathrm{~kg} / \mathrm{m}^{2}$. Main exclusion criteria were: blood glucoselowering medication other than sulfonylurea derivates, metformin, or insulin; requiring $>150$ IU of insulin daily; type 1 diabetes; fasting c-peptide $<1 \mathrm{ng} / \mathrm{mL}$; $>4.5 \mathrm{~kg}$ weight loss within 12 weeks prior to screening; use of weight loss medication or anti-inflammatory drugs; known infection, and exclusion criteria regarding safety of and compatibility with DJBL treatment. The study was approved by the Medical Ethics Committee and conducted according to the revised version of the Declaration of Helsinki. Written informed consent was obtained from every patient.

\section{DJBL procedure}

The DJBL was delivered and retrieved as previously described). ${ }^{16}$ In brief, a gastroduodenal endoscopy was performed. A guide wire was placed into the duodenum over which the encapsulated DJBL was passed into the duodenal bulb. The DJBL was advanced into the small intestine, followed by deployment of the anchor. Correct positioning and patency were verified under fluoroscopy.

Patients were provided a standard of care nutritional counseling program, which suggested a regular diet with a maximum of 1,200 kcal for women and 1,500 kcal for men and was liquid for the first week after DJBL placement. Nutritional and T2DM counseling was performed regularly. After 24 weeks, the DJBL was explanted by a custom retrieval system. $^{16}$

\section{Study design}

Subjects were studied on four occasions: (1) within 1 month prior to implantation, (2) 1 week after implantation, (3) 1 week prior to explantation, and (4) 1 week after explantation in a subset of eight subjects (Fig. 1A). At each time point, weight was determined and a standardized meal tolerance test was performed (Fig. 1B): blood samples were drawn after an overnight fast; thereafter a standard liquid meal (Ensure Plus, Abbott Laboratories, IL; $333 \mathrm{~mL}, 500 \mathrm{kcal}, 20.8 \mathrm{~g}$ protein, $67.3 \mathrm{~g}$ carbohydrates, and $16.4 \mathrm{~g}$ fat) was consumed, followed by collection of blood samples (BD Vacutainer EDTA tube/EDTA aprotinin tube, BD diagnostics, Erembodegem-Aalst, Belgium)at 10, 30, 60, 90, 
and $120 \mathrm{~min}$. Samples were immediately cooled, centrifuged, and stored in aliquots at -80 ${ }^{\circ} \mathrm{C}$ until further analysis.

A

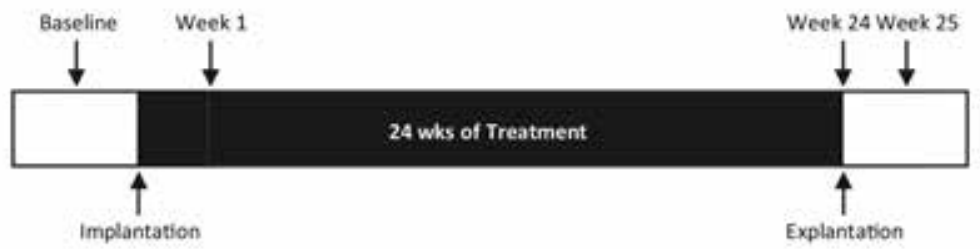

B

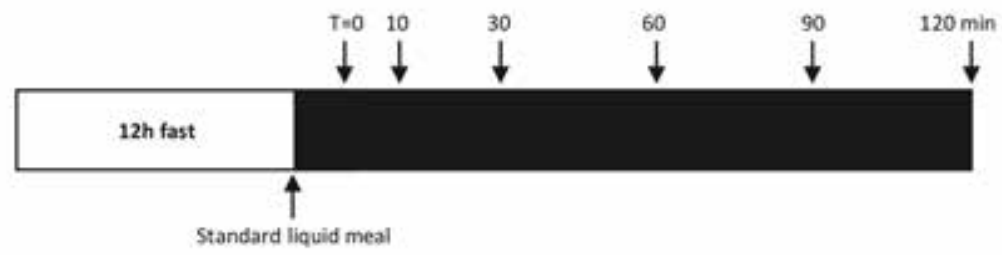

Figure 1. Design of the study and the meal tolerance test. A) Schematic overview of the study design. B) Design of the meal tolerance test.

\section{Plasma parameters}

Total GLP-1 was measured by a radioimmunoassay as previously described. ${ }^{20}$ Glucagon and total GIP was assessed with the human diabetes bio-plex pro assay (Bio-Rad Laboratories BV, Veenendaal, the Netherlands) using Luminex XMAP technology as per the manufacturer's instructions. Glucose, insulin, and $\mathrm{HbA}_{1 \mathrm{c}}$ were determined routinely at the Department of Clinical Chemistry.

\section{Statistical analyses}

GraphPad Prism 5.0 and Statistical Package for Social Sciences 17.0 were used. Total area under the curve (AUC) of the different hormones was calculated using trapezoidal method. Longitudinal changes were tested with linear mixed models. A p-value of $<0.05$ was considered as statistically significant. Data are presented as statistical model estimated means and standard error of the mean (SEM). 


\section{RESULTS}

\section{Proximal small intestinal exclusion results in significant weight loss and rapid glycemic control}

Baseline characteristics of study subjects are shown in Table 1. Patients had a mean BMI of $37.0 \pm 1.3 \mathrm{~kg} / \mathrm{m}^{2}$ with an average weight of $116.0 \pm 5.8 \mathrm{~kg}$ and a mean $\mathrm{HbA}_{1 \mathrm{c}}$ of $8.4 \pm 0.2$ $\%$. After 24 weeks, at the time of device explantation, mean weight loss was $12.7 \pm 1.3 \mathrm{~kg}$, corresponding with an excess weight loss of $29.8 \pm 3.5 \%$ and a BMI reduction of $4.1 \pm 0.4$ $\mathrm{kg} / \mathrm{m}^{2}$ (all $\mathrm{p}<0.01$ ). $\mathrm{HbA}_{1 \mathrm{c}}$ had decreased to $7.0 \pm 0.2 \%(\mathrm{p}<0.01)$. Importantly, this $\mathrm{HbA}_{1 \mathrm{c}}$ reduction occurred despite decreased glucose-lowering medication in 16/17 subjects.

Table 1. Baseline characteristics of the study population.

\begin{tabular}{ll}
\hline & Number of patients, N=17 \\
\hline Age (years) & $51 \pm 2$ \\
Sex (male) & $14(82.4)$ \\
Weight $(\mathrm{kg})$ & $116.0 \pm 5.8$ \\
${\text { BMI }\left(\mathrm{kg} / \mathrm{m}^{2}\right)}{ }_{\text {HbA }}$ (\%) & $37.0 \pm 1.3$ \\
Fasting glucose (mmol/L) & $8.4 \pm 0.2$ \\
Fasting insulin (mU/L) & $11.6 \pm 0.5$ \\
\hline Data are shown as mean \pm SEM or Number (\%)
\end{tabular}

Data are shown as mean \pm SEM or Number (\%).

At baseline, patients had pathognomonic high glucose levels. At 1 week after DJBL placement, fasting glucose had markedly decreased from $11.6 \pm 0.5$ to $9.0 \pm 0.5 \mathrm{mmol} / \mathrm{L}$ ( $p<0.01$; Fig. 2A). The postprandial glucose curve was shifted downwards, resulting in a decreased AUC of the glucose response (baseline: 1,999 \pm 85 vs. week 1: 1,536 \pm 51 $\mathrm{mmol} / \mathrm{L} / \mathrm{min}, \mathrm{p}<0.01 ;$ Fig. $2 \mathrm{~B}$ ). This initial glycemic improvement persisted throughout the study (fasting glucose at baseline: $11.6 \pm 0.5$ vs. week $24: 8.6 \pm 0.5 \mathrm{mmol} / \mathrm{L}$; AUC glucose at baseline: $1,999 \pm 85$ vs. week $24: 1,538 \pm 72 \mathrm{mmol} / \mathrm{L} / \mathrm{min}$, both $\mathrm{p}<0.01$ ).

In line with the high glucose levels, insulin levels were high at baseline. However, despite the decreased glucose levels, fasting insulin levels did not change significantly during DJBL treatment (baseline: $25.5 \pm 7.8$ vs. week 1: $22.5 \pm 7.8 \mathrm{mU} / \mathrm{L}$ and baseline: $25.5 \pm 7.8$ vs. week 24: $15.1 \pm 3.1 \mathrm{mU} / \mathrm{L}, \mathrm{p}=0.23$ and $\mathrm{p}=0.06$, respectively; Fig. $2 \mathrm{C}$ ). Moreover, also the insulin response to a meal, as reflected by the AUC of insulin, was unaffected by DJBL treatment (baseline: 6,603 $\pm 1,100$ vs. week 1: 6,688 $\pm 1,164 \mathrm{mU} / \mathrm{L} / \mathrm{min}$ and baseline: 
$6,603 \pm 1,100$ vs. week $24: 6,446 \pm 770 \mathrm{mU} / \mathrm{L} / \mathrm{min}, \mathrm{p}=0.86$ and $\mathrm{p}=0.84$, respectively; Fig. 2D).

Consistent with the high glucose and insulin concentrations, HOMA-IR as an indicator of insulin sensitivity was high at baseline (14.6 \pm 5.8$)$. At 1 week after DJBL implantation, HOMA-IR had improved in 11/17 patients. This improvement progressed, resulting in an improved HOMA-IR in 14/17 patients at week 24 (baseline: $14.6 \pm 5.8$ vs. week 1: $9.2 \pm 3.5$ and baseline: $14.6 \pm 5.8$ vs. week $24: 6.3 \pm 1.8$, both $p=0.06$; Fig. $2 E$ ).
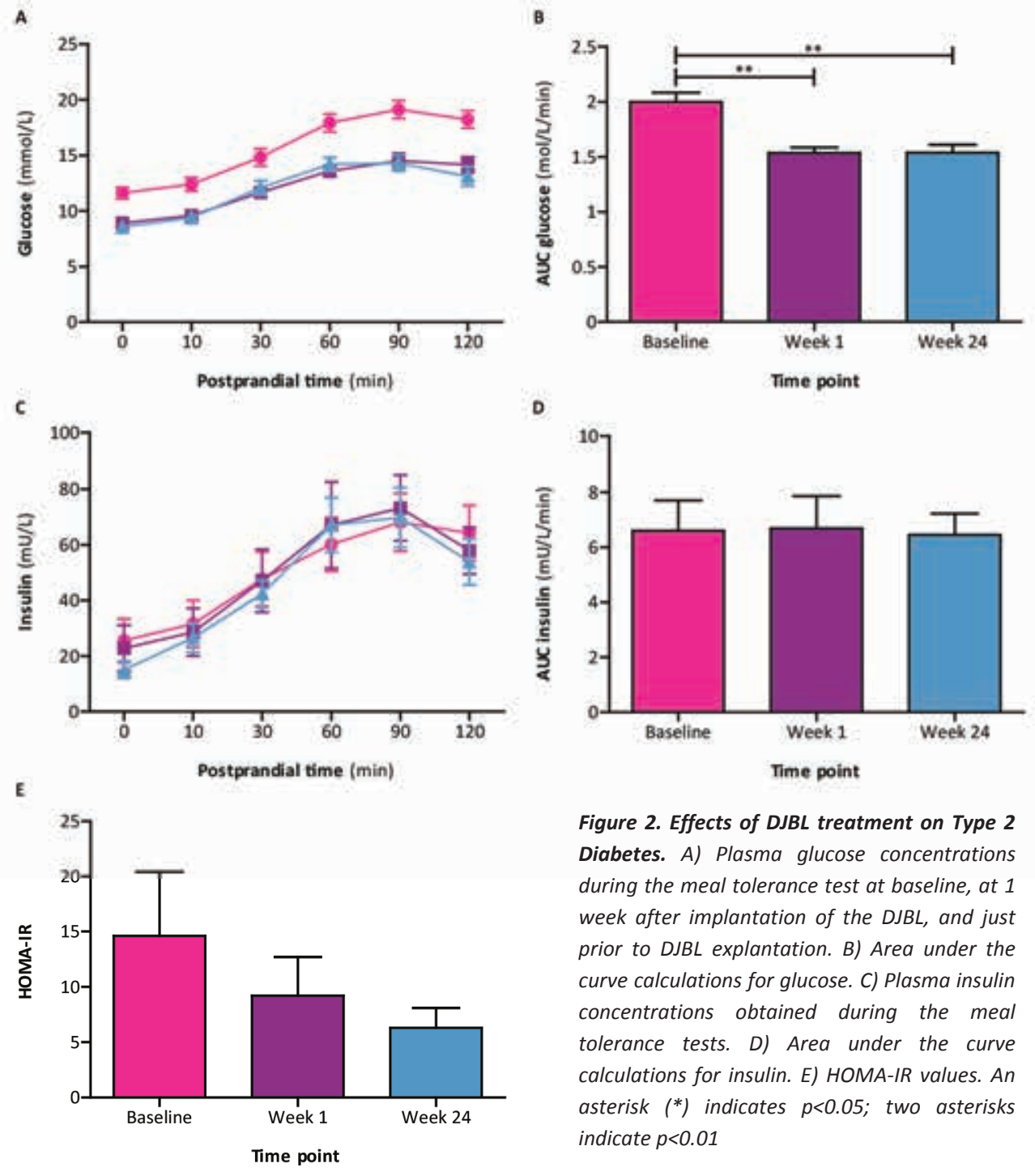

Figure 2. Effects of DJBL treatment on Type 2 Diabetes. A) Plasma glucose concentrations during the meal tolerance test at baseline, at 1 week after implantation of the DJBL, and just prior to DJBL explantation. B) Area under the curve calculations for glucose. C) Plasma insulin concentrations obtained during the meal tolerance tests. D) Area under the curve calculations for insulin. E) HOMA-IR values. An asterisk $\left({ }^{*}\right)$ indicates $p<0.05$; two asterisks indicate $p<0.01$ 


\section{Increased GLP-1 and decreased GIP response after DJBL treatment}

Next, we investigated the effect of DJBL treatment on gut hormones GLP-1 and GIP during a meal tolerance test.

At baseline subjects showed a marginal increase of GLP-1 in response to a meal, indicating an aberrant postprandial GLP-1 response (Fig. 3A). Within 1 week after DJBL implantation, however, postprandial GLP-1 concentrations increased and a clear meal-related response appeared. This pattern remained throughout the treatment period. Whereas fasting GLP-1 levels were not affected by the DJBL (baseline: $29.0 \pm 2.6$ vs. week $1: 32.5 \pm 2.7 \mathrm{pmol} / \mathrm{L}$ and baseline: $29.0 \pm 2.6$ vs. week $24: 30.3 \pm 2.6 \mathrm{pmol} / \mathrm{L}, \mathrm{p}=0.21$ and $\mathrm{p}=0.70$, respectively), the postprandial GLP-1 response increased significantly (baseline: $4,440 \pm 249$ vs. week 1 : $6,407 \pm 480 \mathrm{pmol} / \mathrm{L} / \mathrm{min}$ and baseline: $4,440 \pm 249$ vs. week $24: 6,008 \pm 429 \mathrm{pmol} / \mathrm{L} / \mathrm{min}$, both $\mathrm{p}<0.01$; Fig. 3B).

In contrast, a postprandial rise in GIP levels was present before DJBL implantation (Fig. 3C). At 1 week after DJBL placement, postprandial GIP levels had not significantly changed, although they tended to be lower (baseline: $115,272 \pm 10,971$ vs. week 1: 99,388 $\pm 11,073$ $\mathrm{pg} / \mathrm{mL} / \mathrm{min}, \mathrm{p}=0.06$; Fig. 3D). During the study period, postprandial GIP levels further decreased, reaching statistical significance at week 24 (baseline: 115,272 \pm 10,971 vs. week 24: $88,499 \pm 10,971 \mathrm{pg} / \mathrm{mL} / \mathrm{min}, \mathrm{p}=0<05)$. DJBL treatment did not affect fasting GIP concentrations (baseline: $145.9 \pm 23.3$ vs. week $1: 233.1 \pm 128.3 \mathrm{pg} / \mathrm{mL}$ and baseline: $145.9 \pm 23.3$ vs. week $24: 155.1 \pm 29.8 \mathrm{pg} / \mathrm{mL}, \mathrm{p}=0.50$ and $\mathrm{p}=0.79$, respectively).

\section{Decreased postprandial glucagon after DJBL treatment}

Since both GLP-1 and GIP affect glucagon secretion, we next assessed the potential effect of DJBL treatment on glucagon levels in response to a meal.

At baseline, glucagon levels peaked following meal ingestion (Fig. 3E), which is typical for patients with T2DM. ${ }^{21}$ This abnormal pattern was largely corrected 1 week after DJBL implantation. Furthermore, the AUC of the glucagon response was significantly decreased at this time point (baseline: $23,762 \pm 4,732$ vs. week 1: 15,989 $\pm 3,193 \mathrm{pg} / \mathrm{mL} / \mathrm{min}, \mathrm{p}<0.05$; Fig. 3F). The improved glucagon response remained throughout the study resulting in only a minor meal-related glucagon induction after 24 weeks (baseline: 23,762 $\pm 4,732$ vs. week 24: 13,207 $\pm 1,946 \mathrm{pg} / \mathrm{mL} / \mathrm{min}, \mathrm{p}<0.05)$. Fasting glucagon levels did not change over time (baseline: $105.9 \pm 14.9$ vs. week 1 : $79.7 \pm 15.2 \mathrm{pg} / \mathrm{mL}$ and baseline: $105.9 \pm 14.9$ vs. week $24: 78.7 \pm 14.9 \mathrm{pg} / \mathrm{mL}, \mathrm{p}=0.12$ and $\mathrm{p}=0.16$, respectively). 
A

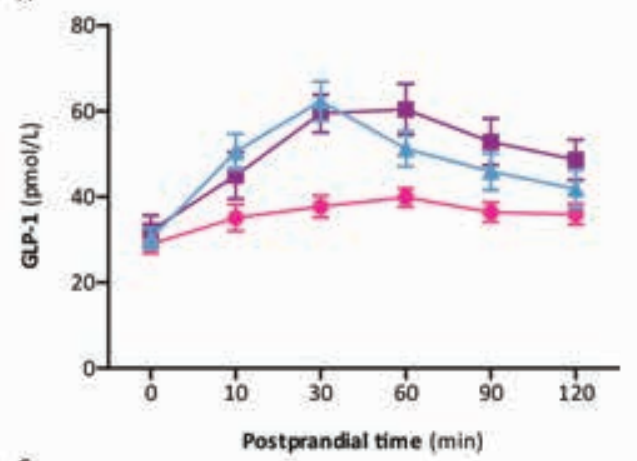

C

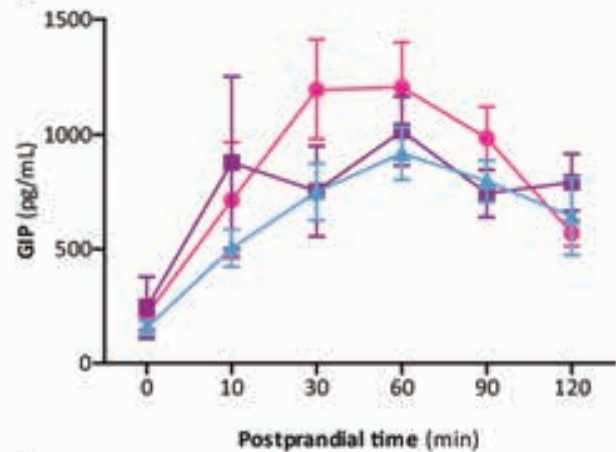

E

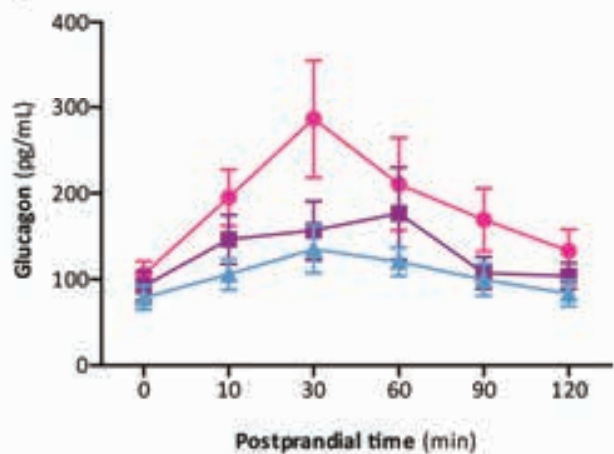

B

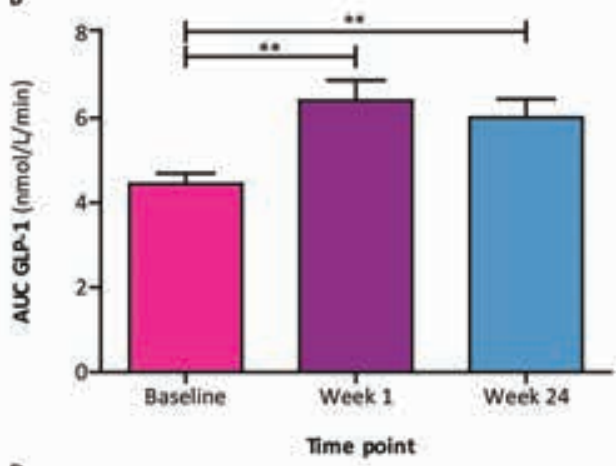

D
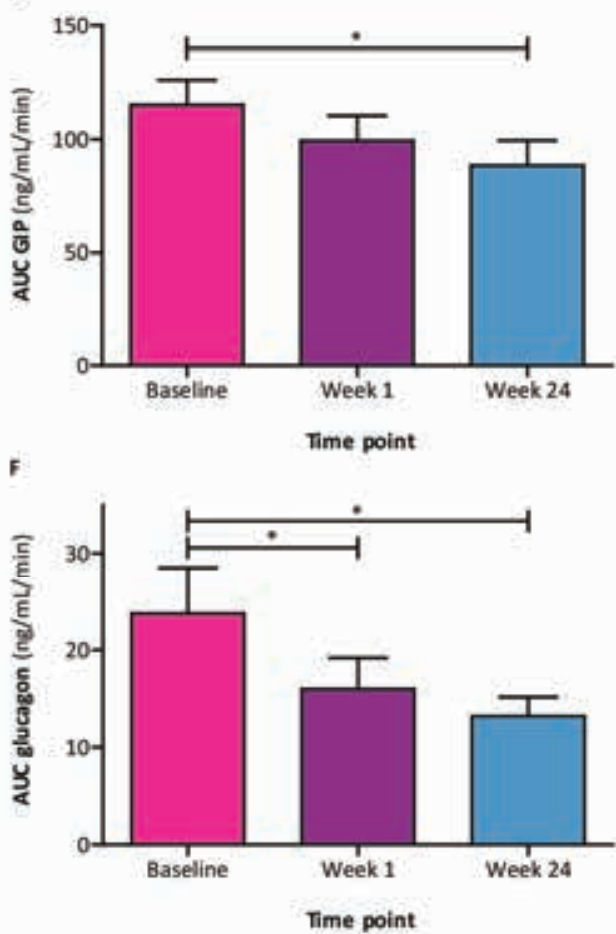

Figure 3. Effects of DJBL treatment on fasting and postprandial GLP-1, GIP, and glucagon levels. A) Plasma concentrations of GLP-1 during the meal tolerance test at baseline, at 1 week after implantation of the DJBL, and just prior to DJBL explantation. B) Area under the curve calculations for GLP-1. C) Plasma GIP concentrations during the meal tolerance test. D) Area under the curve calculations for GIP. E) Plasma glucagon levels during the meal tolerance tests. F) Area under the curve calculations for glucagon. An asterisk (*) indicates $p<0.05$; two asterisks indicate $p<0.01$ 


\section{Persistent amelioration of glycemic control 1 week after DJBL explantation}

To determine if the improved glucose homeostasis was maintained after removal of the DJBL, we studied a subset of patients 1 week after explantation. Importantly, the glucose response to a meal remained decreased (Table 2). No significant changes in the insulin response or HOMA-IR were observed. GLP-1 levels decreased from 6,342 \pm 557 just prior to explantation to $5,226 \pm 557 \mathrm{pmol} / \mathrm{L} / \mathrm{min}$ at 1 week post-explantation $(\mathrm{p}<0.05)$. In contrast, the improved glucagon and GIP response remained at 1 week after device removal.

Table 2. Changes in total glucose, insulin, GLP-1, GIP, and glucagon response after DJBL explantation.

\begin{tabular}{llll}
\hline & Week 24, N=8 & Week 25, N=8 & p-value \\
\hline AUC of glucose (mmol/L/min) & $1,560 \pm 126$ & $1,506 \pm 126$ & 0.55 \\
AUC of insulin $(\mathrm{mU} / \mathrm{L} / \mathrm{min})$ & $7,520 \pm 937$ & $6,183 \pm 1,068$ & 0.06 \\
AUC of GLP-1 (pmol/L/min) & $6,342 \pm 557$ & $5,226 \pm 557$ & $<0.05$ \\
AUC of GIP $(\mathrm{pg} / \mathrm{mL} / \mathrm{min})$ & $73,645 \pm 10,389$ & $144,947 \pm 54,331$ & 0.16 \\
AUC of glucagon $(\mathrm{pg} / \mathrm{mL} / \mathrm{min})$ & $8,686 \pm 713$ & $10,655 \pm 2,446$ & 0.36 \\
HOMA-IR & $8.3 \pm 4.2$ & $7.3 \pm 4.2$ & 0.28 \\
\hline
\end{tabular}

Data are shown as mean \pm SEM.

\section{DISCUSSION}

The mechanisms responsible for the improvement of T2DM after proximal intestinal exclusion are subject to debate. In the current pilot study, we investigated the effect of duodenal-jejunal exclusion by a novel device, the DJBL, on glycemic control and hormones involved in glucose homeostasis. Our results show that exclusion of the proximal small intestine by DJBL results in significant weight loss and rapid decrease of both fasting and postprandial glucose levels, whereas insulin levels do not change significantly. Hence, it is tempting to speculate that the rapid improvement of glucose homeostasis might result from increased insulin sensitivity and/or decreased hepatic glucose production. DJBLinduced changes in glucagon, GLP-1, and GIP suggest that these hormones are involved in the improvement of glycemic control.

Surgically bypassing the duodenum and jejunum has been shown effective in treating T2DM in both overweight and mildly obese subjects. ${ }^{22,23}$ Moreover, T2DM can resolve within 24 hours after RYGB. ${ }^{5}$ Previous studies indicated that the DJBL improves T2DM rapidly. ${ }^{13,16}$ The initial improvement of T2DM therefore seems to be weight lossindependent, and may result from increased insulin sensitivity, mediated by increased 
GLP-1 levels. ${ }^{24,25}$ In line with this, we observed increased GLP-1 levels as early as 1 week after DJBL implantation. The improved HOMA-IR levels further indicate that DJBL treatment might increase insulin sensitivity.

Improved insulin sensitivity has also been reported following caloric restriction. In particular, very low calorie diets $(<<1,000 \mathrm{kcal} /$ day) have been shown to rapidly improve insulin sensitivity. ${ }^{12,26}$ In the present study, patients were advised a moderate diet with a maximum of 1,500 kcal/day for men and 1,200 kcal/day for women. Interestingly, Pournaras et al. compared RYGB, gastric banding, and a diet of $\sim 1,000 \mathrm{kcal} /$ day and found reduced insulin resistance only after RYGB. ${ }^{27}$ In view of these data, we consider calorie restriction to be responsible only to a limited extent for the observed improved glycemic control. Unpublished data of a group of patients subjected to similar nutritional and type 2 diabetic counseling further support this; inferior improvement of type 2 diabetes was observed.

In addition, reduced hepatic glucose production may be responsible for the DJBL-induced improvement of T2DM. Hepatic glucose production was likely reduced due to the decreased glucagon response observed already early after DJBL treatment. This assumption finds support in the rapid decrease of fasting glucose levels since fasting glucose levels are primarily determined by hepatic glucose synthesis. ${ }^{28}$ Decreased hepatic glucose production might also be related to the increase in GLP-1 and the decrease in GIP that occurred after DJBL implantation. GLP-1 inhibits glucagon secretion, ${ }^{29}$ whereas GIP tends to augment the glucagon response to a meal. ${ }^{30,31}$

Taken together, we propose that proximal intestinal exclusion by DJBL treatment affects insulin sensitivity and hepatic glucose production. However, to thoroughly assess the involvement of these mechanisms in the amelioration of glucose homeostasis, further investigations including hyperinsulinemic euglycemic clamping studies enhanced by glucose tracers are required.

Our data fit both proposed major hypotheses to explain the rapid improvement of T2DM after proximal small intestinal exclusion. In accordance with the foregut hypothesis, prevention of digestion and uptake of nutrients in the proximal intestine after DJBL treatment was associated with decreased secretion of glucagon, a diabetogenic factor, contributing to reduced glucose levels. ${ }^{8,9}$ The DJBL-induced decrease of GIP is also in line with this theory because GIP is secreted in the proximal intestine and affects glucagon secretion. ${ }^{9}$ Additionally, our data are in agreement with the hindgut hypothesis because the observed GLP-1 increase is likely to be the result of undigested nutrients in the distal small intestine. ${ }^{6,10}$ 
Whereas the initial rapid improvement of T2DM after bariatric surgery is considered weight loss-independent, weight loss plays a role in longer term improvement of T2DM. ${ }^{32,33}$ Given the observed weight loss after 24 weeks of DJBL treatment, these mechanisms may contribute to improvement of glucose homeostasis by DJBL treatment and its sustained amelioration at 1 week after explantation.

According to the recent position statement of the International Diabetes Federation, bariatric surgery should be incorporated in T2DM treatment algorithms. ${ }^{34}$ In comparison to conventional bariatric procedures, the DJBL procedure is less invasive, reversible, and safe. ${ }^{13-18}$ The majority of the device-related adverse events was minor, mainly consisting of abdominal discomfort. Three patients presented with an adverse event requiring hospitalization: one with obstipation, one with melena, and one patient with abdominal discomfort causing dehydration. All adverse events were managed conservatively; neither early explantation nor surgical intervention was required.

DJBL treatment appears to have similar effects on glycemic control as invasive bariatric techniques. We therefore propose it as a promising alternative for bariatric surgery in the treatment of T2DM. Further studies should be directed at investigating maximal treatment duration, longer term impact on glucose homeostasis, and its effects on other obesityrelated comorbidities. Additionally, the DJBL provides a unique human model enabling insight into mechanisms responsible for the beneficial effects of proximal small intestinal exclusion on body weight and T2DM.

In conclusion, our pilot study shows that DJBL treatment leads to rapid improvement of glycemic control which is paralleled by changes in the GLP-1, GIP, and glucagon response to food intake. Additional studies may provide further insight into the role of the proximal small intestine in T2DM. 


\section{REFERENCES}

1. Zimmet P, Alberti KG, Shaw J. Global and societal implications of the diabetes epidemic. Nature. 2001 Dec 13;414(6865):782-7.

2. Wild S, Roglic G, Green A, Sicree R, King H. Global prevalence of diabetes: estimates for the year 2000 and projections for 2030. Diabetes Care. 2004 May;27(5):1047-53.

3. Schauer PR, Burguera B, Ikramuddin S, Cottam D, Gourash W, Hamad G, Eid GM, Mattar S, Ramanathan R, Barinas-Mitchel E, Rao RH, Kuller L, Kelley D. Effect of laparoscopic Roux-en Y gastric bypass on type 2 diabetes mellitus. Ann Surg. 2003 Oct;238(4):467-84.

4. Sjostrom L, Lindroos AK, Peltonen M, Torgerson J, Bouchard C, Carlsson B, Dahlgren S, Larsson B, Narbro $\mathrm{K}$, Sjostrom CD, Sullivan M, Wedel H. Lifestyle, diabetes, and cardiovascular risk factors 10 years after bariatric surgery. N Engl J Med. 2004 Dec 23;351(26):2683-93.

5. Pories WJ, Swanson MS, MacDonald KG, Long SB, Morris PG, Brown BM, Barakat HA, deRamon RA, Israel G, Dolezal JM, et al. Who would have thought it? An operation proves to be the most effective therapy for adult-onset diabetes mellitus. Ann Surg. 1995 Sep;222(3):339-50.

6. Thaler JP Cummings DE. Minireview: Hormonal and metabolic mechanisms of diabetes remission after gastrointestinal surgery. Endocrinology. 2009 Jun;150(6):2518-25.

7. Laferrere B, Reilly D, Arias S, Swerdlow N, Gorroochurn P, Bawa B, Bose M, Teixeira J, Stevens RD, Wenner BR, Bain JR, Muehlbauer MJ, Haqq A, Lien L, Shah SH, Svetkey LP, Newgard CB. Differential metabolic impact of gastric bypass surgery versus dietary intervention in obese diabetic subjects despite identical weight loss. Sci Transl Med. 2011 Apr 27;3(80):80re2.

8. Rubino F, Forgione A, Cummings DE, Vix M, Gnuli D, Mingrone G, Castagneto M, Marescaux J. The mechanism of diabetes control after gastrointestinal bypass surgery reveals a role of the proximal small intestine in the pathophysiology of type 2 diabetes. Ann Surg. 2006 Nov;244(5):741-9.

9. Knop FK. Resolution of type 2 diabetes following gastric bypass surgery: involvement of gut-derived glucagon and glucagonotropic signalling? Diabetologia. 2009 Nov;52(11):2270-6.

10. Fetner R, McGinty J, Russell C, Pi-Sunyer FX, Laferrere B. Incretins, diabetes, and bariatric surgery: a review. Surg Obes Relat Dis. 2005 Nov-Dec;1(6):589-97.

11. Rao RS Kini S. GIP and bariatric surgery. Obes Surg. 2011 Feb;21(2):244-52.

12. Bradley D, Magkos F, Klein S. Effects of Bariatric Surgery on Glucose Homeostasis and Type 2 Diabetes. Gastroenterology. 2012 Aug;143(4):879-912.

13. Rodriguez-Grunert L, Galvao Neto MP, Alamo M, Ramos AC, Baez PB, Tarnoff M. First human experience with endoscopically delivered and retrieved duodenal-jejunal bypass sleeve. Surg Obes Relat Dis. 2008 Jan-Feb;4(1):55-9.

14. Tarnoff M, Rodriguez L, Escalona A, Ramos A, Neto M, Alamo M, Reyes E, Pimentel F, Ibanez L. Open label, prospective, randomized controlled trial of an endoscopic duodenal-jejunal bypass sleeve versus low calorie diet for pre-operative weight loss in bariatric surgery. Surg Endosc. 2009 Mar;23(3):650-6.

15. Gersin KS, Rothstein RI, Rosenthal RJ, Stefanidis D, Deal SE, Kuwada TS, Laycock W, Adrales G, Vassiliou M, Szomstein S, Heller S, Joyce AM, Heiss F, Nepomnayshy D. Open-label, sham-controlled trial of an endoscopic duodenojejunal bypass liner for preoperative weight loss in bariatric surgery candidates. Gastrointest Endosc. 2010 May;71(6):976-82.

16. Schouten R, Rijs CS, Bouvy ND, Hameeteman W, Koek GH, Janssen IM, Greve JW. A multicenter, randomized efficacy study of the EndoBarrier Gastrointestinal Liner for presurgical weight loss prior to bariatric surgery. Ann Surg. 2010 Feb;251(2):236-43.

17. de Moura EG, Martins BC, Lopes GS, Orso IR, de Oliveira SL, Galvao Neto MP, Santo MA, Sakai P, Ramos AC, Garrido Junior AB, Mancini MC, Halpern A, Cecconello I. Metabolic improvements in obese type 2 diabetes subjects implanted for 1 year with an endoscopically deployed duodenal-jejunal bypass liner. Diabetes Technol Ther. 2012 Feb;14(2):183-9. 
18. Escalona A, Pimentel F, Sharp A, Becerra P, Slako M, Turiel D, Munoz R, Bambs C, Guzman S, Ibanez L, Gersin K. Weight loss and metabolic improvement in morbidly obese subjects implanted for 1 year with an endoscopic duodenal-jejunal bypass liner. Ann Surg. 2012 Jun;255(6):1080-5.

19. Goldfine $A B$, Shoelson $S E$, Aguirre V. Expansion and contraction: treating diabetes with bariatric surgery. Nat Med. 2009 Jun;15(6):616-7.

20. Kreymann B, Williams G, Ghatei MA, Bloom SR. Glucagon-like peptide-1 7-36: a physiological incretin in man. Lancet. 1987 Dec 5;2(8571):1300-4.

21. Menge BA, Gruber L, Jorgensen SM, Deacon CF, Schmidt WE, Veldhuis JD, Holst JJ, Meier JJ. Loss of inverse relationship between pulsatile insulin and glucagon secretion in patients with type 2 diabetes. Diabetes. 2011 Aug;60(8):2160-8.

22. Klein S, Fabbrini E, Patterson BW, Polonsky KS, Schiavon CA, Correa JL, Salles JE, Wajchenberg BL, Cohen R. Moderate effect of duodenal-jejunal bypass surgery on glucose homeostasis in patients with type 2 diabetes. Obesity. 2012 Jun;20(6):1266-72.

23. Geloneze B, Geloneze SR, Fiori C, Stabe C, Tambascia MA, Chaim EA, Astiarraga BD, Pareja JC. Surgery for nonobese type 2 diabetic patients: an interventional study with duodenal-jejunal exclusion. Obes Surg. 2009 Aug;19(8):1077-83.

24. Zander M, Madsbad S, Madsen JL, Holst JJ. Effect of 6-week course of glucagon-like peptide 1 on glycaemic control, insulin sensitivity, and beta-cell function in type 2 diabetes: a parallel-group study. Lancet. 2002 Mar 9;359(9309):824-30.

25. Umeda LM, Silva EA, Carneiro G, Arasaki CH, Geloneze B, Zanella MT. Early Improvement in Glycemic Control After Bariatric Surgery and Its Relationships with Insulin, GLP-1, and Glucagon Secretion in Type 2 Diabetic Patients. Obes Surg. 2011 Jul;21(7):896-901.

26. Kelley DE, Wing R, Buonocore C, Sturis J, Polonsky K, Fitzsimmons M. Relative effects of calorie restriction and weight loss in noninsulin-dependent diabetes mellitus. J Clin Endocrinol Metab. 1993 Nov;77(5):1287-93.

27. Pournaras DJ, Osborne A, Hawkins SC, Vincent RP, Mahon D, Ewings P, Ghatei MA, Bloom SR, Welbourn $\mathrm{R}$, le Roux CW. Remission of type 2 diabetes after gastric bypass and banding: mechanisms and 2 year outcomes. Ann Surg. 2010 Dec;252(6):966-71.

28. DeFronzo RA, Ferrannini E, Simonson DC. Fasting hyperglycemia in non-insulin-dependent diabetes mellitus: contributions of excessive hepatic glucose production and impaired tissue glucose uptake. Metabolism. 1989 Apr;38(4):387-95.

29. Hare KJ, Knop FK, Asmar M, Madsbad S, Deacon CF, Holst JJ, Vilsboll T. Preserved inhibitory potency of GLP-1 on glucagon secretion in type 2 diabetes mellitus. J Clin Endocrinol Metab. 2009 Dec;94(12):467987.

30. Yabe D Seino Y. Two incretin hormones GLP-1 and GIP: Comparison of their actions in insulin secretion and beta cell preservation. Prog Biophys Mol Biol. $2011 \mathrm{Jul}$ 28;107(2):248-56.

31. Holst JJ, Christensen M, Lund A, de Heer J, Svendsen B, Kielgast U, Knop FK. Regulation of glucagon secretion by incretins. Diabetes Obes Metab. 2011 Oct;13 Suppl 1:89-94.

32. Dixon JB, O'Brien PE, Playfair J, Chapman L, Schachter LM, Skinner S, Proietto J, Bailey M, Anderson M. Adjustable gastric banding and conventional therapy for type 2 diabetes: a randomized controlled trial. JAMA. 2008 Jan 23;299(3):316-23.

33. Buchwald H, Estok R, Fahrbach K, Banel D, Jensen MD, Pories WJ, Bantle JP, Sledge I. Weight and type 2 diabetes after bariatric surgery: systematic review and meta-analysis. Am J Med. 2009 Mar;122(3):248256.

34. Dixon JB, Zimmet P, Alberti KG, Mbanya JC, Rubino F. Bariatric surgery for diabetes: the International Diabetes Federation takes a position. J Diabetes. 2011 Dec;3(4):261-4. 


\section{Chapter 4 \\ Impact of duodenal-jejunal exclusion on satiety hormones}

Charlotte de Jonge, Sander S Rensen, Froukje J Verdam, Royce P Vincent, Steve R Bloom, Wim A Buurman, Carel W le Roux, Nicole D Bouvy, and Jan Willem M Greve 


\section{ABSTRACT}

\section{Background}

Bariatric procedures that exclude the proximal small intestine lead to significant weight loss which is probably mediated by changes in hormones that alter appetite, such as peptide YY (PYY), ghrelin, cholecystokinin (CCK), and leptin. We investigated the effect of the non-surgical Duodenal-Jejunal Bypass Liner (DJBL) on concentrations of hormones implicated in appetite control.

\section{Methods}

A two-center prospective study was conducted between January and December 2010. Seventeen obese subjects with type 2 diabetes were treated with the DJBL for 24 weeks. Fasting concentrations of leptin and meal responses of plasma PYY, CCK, and ghrelin were determined prior to and after implantation of the DJBL.

\section{Results}

At baseline, subjects had an average body weight of $116.0 \pm 5.8 \mathrm{~kg}$. One week after implantation, subjects had lost $4.3 \pm 0.6 \mathrm{~kg}(\mathrm{p}<0.01)$, which progressed to $12.7 \pm 1.3 \mathrm{~kg}$ at week 24 ( $p<0.01)$. Post-prandial concentrations of PYY and ghrelin increased (baseline vs. week 1 vs. week 24 PYY: $2.6 \pm 0.2$ vs. $4.1 \pm 0.4$ vs. $4.1 \pm 0.7 \mathrm{nmol} / \mathrm{L} / \mathrm{min}$ and ghrelin: $7.8 \pm$ 1.8 vs. $11.0 \pm 1.8$ vs. $10.6 \pm 1.8 \mathrm{ng} / \mathrm{mL} / \mathrm{min}$, all $\mathrm{p}<0.05)$. In parallel, the CCK response decreased (baseline vs. week 1 vs. week 24: $434 \pm 51$ vs. $229 \pm 52$ vs. $256 \pm 51$ pmol/L/min, $\mathrm{p}<0.01$ ). Fasting leptin concentrations also decreased (baseline vs. week 24: $98 \pm 17$ vs. 53 $\pm 10 \mathrm{ng} / \mathrm{mL}, \mathrm{p}<0.01$ ).

\section{Conclusion}

DJBL treatment induces weight loss paralleled by changes in concentrations of hormones involved in appetite control. 


\section{INTRODUCTION}

Treating obesity with lifestyle interventions or drugs is notoriously difficult. In particular, weight loss is hard to maintain. ${ }^{1,2}$ Bariatric surgery is considered an effective strategy to achieve long term reduction of body weight. ${ }^{3}$ This type of surgery has been reported to increase satiety and decrease caloric intake, ${ }^{4,5}$ probably associated with changes in appetite regulating hormones, such as peptide YY (PYY), glucagon-like peptide-1 (GLP-1), cholecystokinin (CCK), ghrelin, and leptin. ${ }^{6-8}$

CCK and PYY are satiety promoting hormones. CCK is secreted in the proximal small intestine in response to intraluminal nutrients, especially lipids, and signals satiety via vagal afferents. ${ }^{9}$ PYY secreting cells, on the other hand, are predominantly found in the distal gastrointestinal tract. Secreted PYY reduces food intake by increasing satiety and reducing gut motility. ${ }^{10,11}$ In contrast, secretion of the orexigenic hormone ghrelin is stimulated in the fasted state and plasma levels fall shortly after food ingestion. The primary secreting region is the stomach fundus. ${ }^{12,13}$ Whereas CCK, PYY, and ghrelin are predominantly involved in short term signaling in relation to food intake, leptin, secreted by adipocytes in proportion to whole body adipose tissue mass, is a long term regulator of energy balance. $^{14}$

In obese individuals, plasma CCK levels have been reported to be low, ${ }^{15}$ the postprandial PYY response is attenuated, ${ }^{16}$ and ghrelin levels are also low. ${ }^{17,18}$ Furthermore, obesity is characterized by high levels of leptin which do not temper appetite because of leptin resistance. ${ }^{14,19}$

Bariatric procedures have been suggested to alter hormonal responses thereby affecting satiety. In particular, the Roux-en- $Y$ gastric bypass leads to increased satiety and postprandial PYY levels. ${ }^{20-22}$ Little is known about changes in the CCK response after bariatric surgery, ${ }^{23,24}$ while the effects on ghrelin levels are controversial. ${ }^{23,25}$ Leptin levels decrease after bariatric procedures, mirroring weight loss. ${ }^{26}$

Recently, a non-surgical bariatric technique, the Duodenal-Jejunal Bypass Liner (DJBL, GI Dynamics, Lexington, MA), was developed to treat obesity. The DJBL is a $60 \mathrm{~cm}$ long impermeable liner which is delivered and retrieved endoscopically. Once in place, it mimics the intestinal bypass component of the Roux-en-Y gastric bypass. Previously, DJBL treatment has been shown to result in weight loss and improvement of type 2 diabetes. $^{27-29}$

We aimed to investigate the effect of duodenal-jejunal exclusion by DJBL on fasting and postprandial plasma concentrations of hormones involved in appetite control. CCK, 
ghrelin, and PYY responses to a standard meal and fasting leptin levels were studied in subjects with obesity and type 2 diabetes prior to and after DJBL implantation.

\section{SUBJECTS AND METHODS}

\section{Subjects}

Seventeen subjects with obesity and type 2 diabetes were consecutively included in the Maastricht University Medical Center, Maastricht, and the Atrium Medical Center Parkstad, Heerlen, the Netherlands between February and July 2010. Inclusion criteria were: age between 18 and 65 years; body mass index (BMI) between 30 and $50 \mathrm{~kg} / \mathrm{m}^{2}$; duration of type 2 diabetes less than 10 years; and a $\mathrm{HbA}_{1 \mathrm{c}}$ between 7.5 and $10.0 \%$. Main exclusion criteria were: weight loss of more than $4.5 \mathrm{~kg}$ within 12 weeks prior to screening; use of weight loss medication; use of anticoagulation medication, NSAIDs, or corticosteroids; iron deficiency or anemia; gastrointestinal abnormalities; gastroesophageal reflux disease; symptomatic gallstones or kidney stones; known infection including Helicobacter pylori; history of coagulopathy or upper gastro-intestinal bleeding conditions, connective tissue disorder, and severe kidney or liver failure.

\section{The DJBL procedure}

The DJBL was delivered and retrieved endoscopically as previously described. ${ }^{28}$ In brief, a gastroduodenal endoscopy was performed under general anesthesia. A guide wire was placed into the duodenum over which the encapsulated DJBL was directed through the pylorus into the duodenal bulb. The DJBL was advanced into the small intestine, followed by deployment of the anchor in the duodenal bulb. Correct positioning and patency of the DJBL were verified under fluoroscopy.

After 24 weeks, removal of the DJBL was performed endoscopically under general anesthesia by use of a custom retrieval system containing a grasper and a retrieval hood. By grasping the retrieval suture on the proximal face of the anchor, the anchor collapsed and was pulled into the retrieval hood at the distal end of the endoscope. After verification of the collapsed anchor by fluoroscopy, the device was removed.

\section{Study design}

Subjects were studied on three occasions: 1) within one month prior to implantation, 2) one week after implantation, and 3) 24 weeks after implantation, just prior to removal. All 
patients completed the study. After implantation of the DJBL, subjects were provided a standard of care bariatric nutritional counseling program, which suggested a regular diet with a maximum of $1,200 \mathrm{kcal}$ for women and 1,500 kcal for men. For safety reasons, liquid nutrition was advised for the first week after DJBL placement. At every visit, body weight was determined and subjects were asked if their satiety and caloric intake had increased, decreased, or was unchanged when compared to baseline. Daily caloric intake was evaluated by a dietitian and if necessary, dietary adaptations were made. Additionally, a standardized meal tolerance test was performed: venous blood samples were drawn after an overnight fast; subsequently a standard liquid meal was consumed (Ensure Plus, Abbott Laboratories, IL; $333 \mathrm{~mL}, 500 \mathrm{kcal}, 20.8 \mathrm{~g}$ protein, $67.3 \mathrm{~g}$ carbohydrates, and $16.4 \mathrm{~g}$ fat), followed by collection of blood samples after 10, 30, 60, 90, and 120 minutes (BD Vacutainer EDTA tube/EDTA aprotinin tube, BD diagnostics, Erembodegem-Aalst, Belgium). Samples were immediately cooled, centrifuged, and stored at $-80^{\circ} \mathrm{C}$ until analysis.

\section{Plasma hormone assays}

Plasma levels of total PYY and leptin were measured respectively by radioimmunoassay and sandwich enzyme-linked immunosorbent assay, making use of the ELISA plates from Greiner Bio-One (Alphen aan de Rijn, the Netherlands) as previously described. ${ }^{30,31}$ Plasma CCK was determined using a commercially available CCK-radioimmunoassay according to the manufacturer's protocol (Euro-diagnostica, Malmö, Sweden). Plasma active ghrelin concentrations were assessed with the human diabetes bio-plex pro assay (Bio-Rad Laboratories BV, Veenendaal, the Netherlands) using Luminex xMAP technology. The assay was performed with a Luminex 100 IS 2.3 system using Bio-Plex Manager 4.1.1. software as described by the manufacturer's instructions.

\section{Ethics}

The study was approved by the Medical Ethics Committee of both centers and conducted according to the revised version of the Declaration of Helsinki. Written informed consent was obtained from every subject prior to study participation.

\section{Statistical analyses}

GraphPad Prism 5.0 and Statistical Package for Social Sciences (SPSS) 17.0 were used. The area under the curve (AUC) was calculated using GraphPad Prism. Longitudinal changes were tested with linear mixed models in SPSS. The correct covariance structure for the repeated measures was chosen according to Akaike Information Criterion and Bayesian 
Information Criterion values. Nonparametric bivariate correlations were tested with Spearman's correlation coefficient. A p-value of $<0.05$ was considered statistically significant. Data are presented as statistical model estimated mean and standard error of the mean (SEM).

\section{RESULTS}

\section{Exclusion of the proximal small intestine by DJBL affects body weight}

At baseline, subjects (14 males, 3 females) were $51 \pm 2$ years old and weighed $116.0 \pm 5.8$ $\mathrm{kg}$ with a BMI of $37.0 \pm 1.3 \mathrm{~kg} / \mathrm{m}^{2}$. One week after placement of the DJBL, body weight had decreased by $4.3 \pm 0.6 \mathrm{~kg}$, corresponding to an excess weight loss of $10.2 \pm 1.7 \%$ and a $\mathrm{BMI}$ reduction of $1.4 \pm 0.2 \mathrm{~kg} / \mathrm{m}^{2}$ ( $\left.p<0.01\right)$. After 24 weeks, at the time of device removal, mean body weight had further decreased resulting in a total weight loss of $12.7 \pm 1.3 \mathrm{~kg}$, with an excess weight loss of $29.8 \pm 3.5 \%$ and a BMI reduction of $4.1 \pm 0.4 \mathrm{~kg} / \mathrm{m}^{2}(p<0.01)$. Meanwhile, all subjects reported lowered caloric intake during the study and $88 \%$ of the subjects (15/17) reported increased satiety.

\section{Rapid increase of PYY after DJBL implantation}

As shown in Figure 1A, prior to DJBL placement, PYY only increased marginally in response to a meal. Within one week after placement, the AUC of the PYY response increased significantly (baseline: $2.6 \pm 0.2$ vs. week $1: 4.1 \pm 0.4 \mathrm{nmol} / \mathrm{L} / \mathrm{min}, \mathrm{p}<0.01$, Fig. $1 \mathrm{~B}$ ). This increase sustained during the remainder of the study period (baseline: $2.6 \pm 0.2$ vs. week 24: $4.1 \pm 0.7 \mathrm{nmol} / \mathrm{L} / \mathrm{min}, \mathrm{p}<0.05)$. Furthermore, fasting PYY levels increased, reaching significance at week 24 (baseline: $17.0 \pm 1.5$ vs. week 24: $23.1 \pm 2.7 \mathrm{pmol} / \mathrm{L}, \mathrm{p}<0.05$ ).

\section{Decreased postprandial CCK response after DJBL implantation}

Before DJBL placement, CCK levels increased rapidly following meal ingestion (Fig. 1B). After DJBL placement, this postprandial peak was still observed, but the maximal CCK concentration decreased strongly from $7.8 \pm 1.2 \mathrm{pmol} / \mathrm{L}$ at baseline to $3.3 \pm 1.1$ and $3.8 \pm$ $1.0 \mathrm{pmol} / \mathrm{L}$ at week 1 and week 24, respectively. This resulted in a decreased AUC for CCK (baseline: $434 \pm 51$ vs. week 1: $229 \pm 52$ and baseline: $434 \pm 51$ vs. week 24: $256 \pm 51$ $\mathrm{pmol} / \mathrm{L} / \mathrm{min}$, both $\mathrm{p}<0.01$ ). 
A.

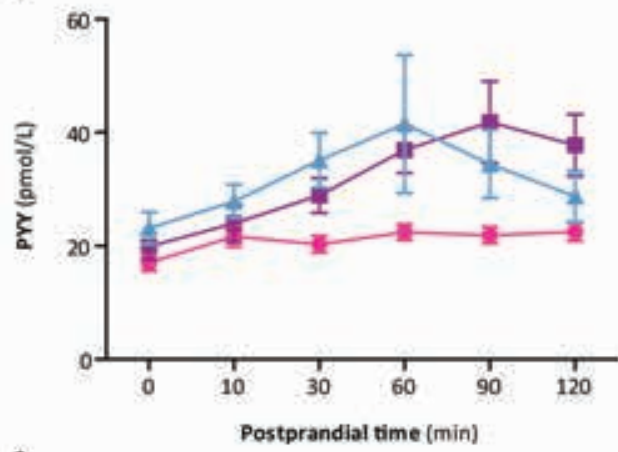

c

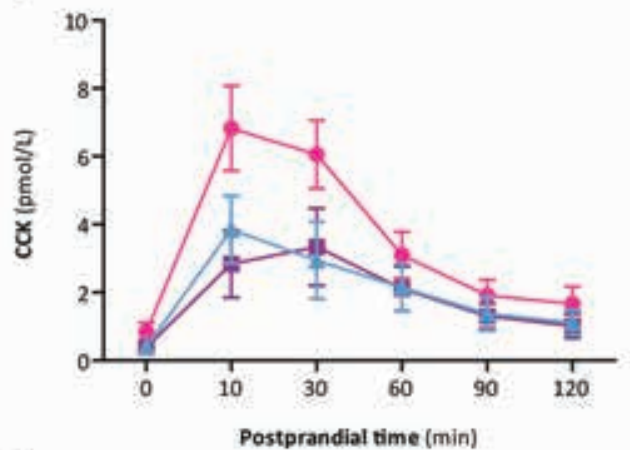

E

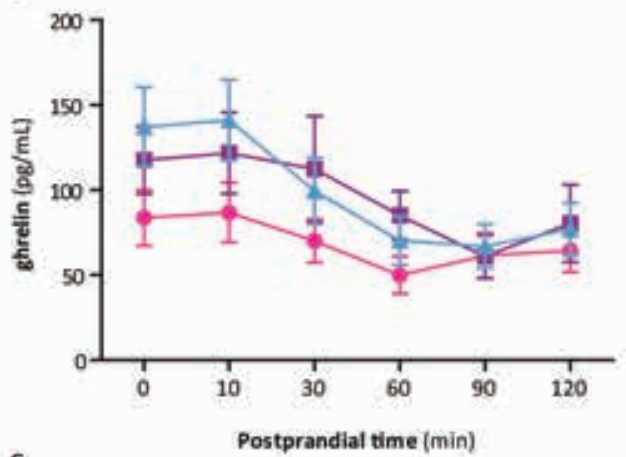

G

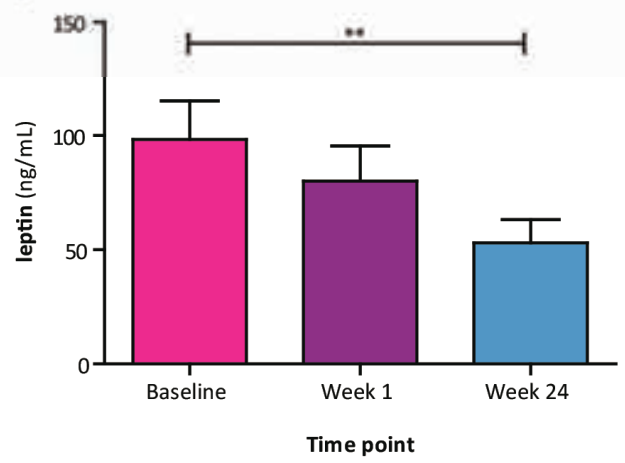

B
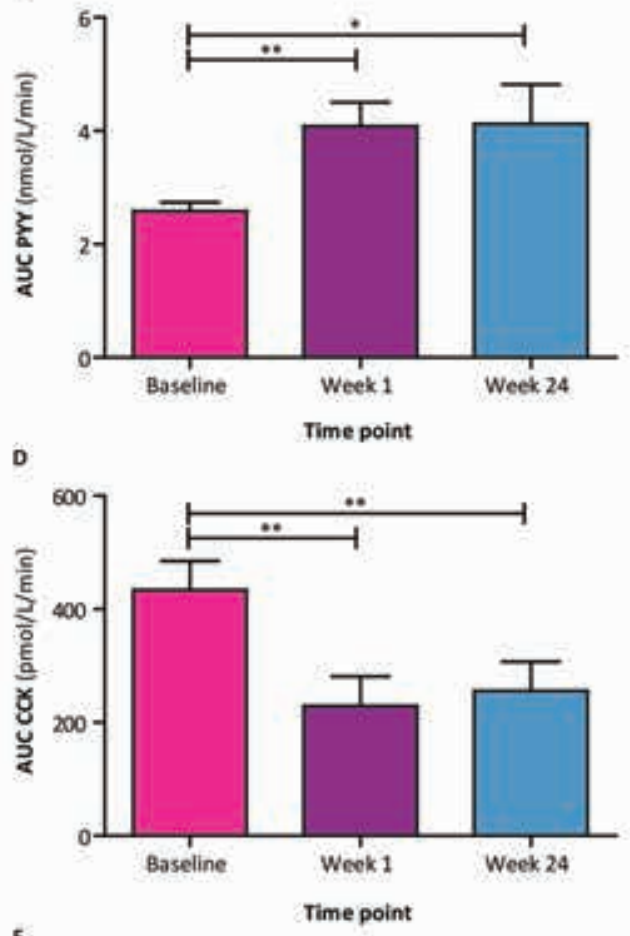

F

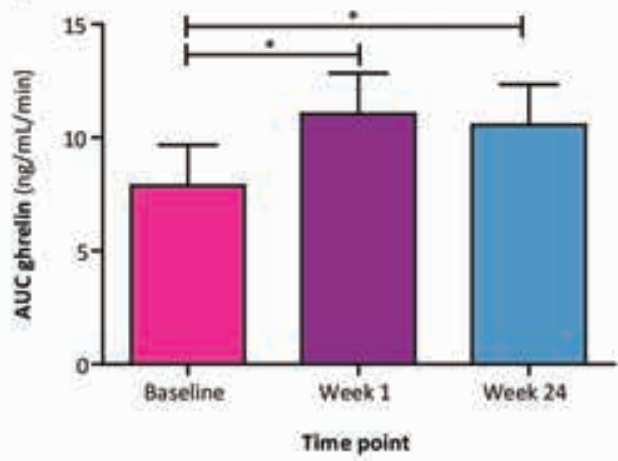

Figure 1. Effects of DJBL treatment on PYY, $C C K$, ghrelin, and leptin levels. A) Plasma PYY concentrations during the meal tolerance test at baseline, week 1 and week 24. B) Area under the curve calculations for PYY. C) Plasma CCK concentrations obtained during the meal tolerance tests. D) Area under the curve calculations for CCK. E) Plasma ghrelin levels during the meal tolerance tests. F) Area under the curve calculations for ghrelin. G) Fasting plasma leptin levels. An asterisk $\left({ }^{*}\right)$ indicates $p<0.05$, two asterisks indicate $p<0.01$. 


\section{DJBL treatment results in changes in fasting and postprandial ghrelin levels}

A postprandial decline in plasma levels of ghrelin, suggesting inhibition of hunger after meal consumption, was present at baseline (Fig. 1E). After DJBL placement, fasting ghrelin levels increased (baseline: $38.8 \pm 19.9$ vs. week $1: 120.7 \pm 20.2 \mathrm{pg} / \mathrm{mL}$ and baseline: $38.8 \pm$ 19.9 vs. week $24: 137.1 \pm 19.9 \mathrm{pg} / \mathrm{mL}, \mathrm{p}<0.05$ and $\mathrm{p}<0.01$ respectively). Interestingly, the difference between fasting and nadir ghrelin levels also increased after placement of the DJBL, resulting in comparable nadir of plasma ghrelin levels at 90 minutes postprandially. Though, the AUC for ghrelin increased after DJBL placement (baseline: $7.9 \pm 1.8$ vs. week 1: $11.0 \pm 1.8 \mathrm{ng} / \mathrm{mL} / \mathrm{min}$ and baseline: $7.9 \pm 1.8 \mathrm{vs}$. week $24: 10.6 \pm 1.8 \mathrm{ng} / \mathrm{mL} / \mathrm{min}, \mathrm{p}<0.05$ and $\mathrm{p}<0.01$ respectively, Fig. $1 \mathrm{~F})$.

\section{Leptin levels decrease in relation to weight loss after DJBL implantation}

At baseline, fasting plasma leptin levels correlated with $\mathrm{BMI}\left(r_{s}=0.65, p<0.01\right)$. After DJBL placement, leptin levels decreased, reaching statistical significance at week 24 (baseline: $98 \pm 17$ vs. week 1: $80 \pm 15 \mathrm{ng} / \mathrm{mL}$ and baseline: $98 \pm 17$ vs. week $24: 53 \pm 10 \mathrm{ng} / \mathrm{mL}$, $\mathrm{p}=0.11$ and $\mathrm{p}<0.01$ respectively, Fig. 1G). In addition, plasma leptin levels and $\mathrm{BMI}$ remained correlated at both week 1 and week 24 (week 1: $r_{s}=0.87, p<0.01$ and week 24: $r_{\mathrm{s}}=0.58, \mathrm{p}<0.05$ respectively).

\section{DISCUSSION}

Bariatric surgery leads to extensive weight loss. Additionally, several changes in human physiology occur; alterations in satiety, taste, and food preference have been described. ${ }^{32,33}$ These changes are considered essential for the process of losing weight. Bypassing the duodenum and jejunum by DJBL treatment has previously been shown to induce weight loss. ${ }^{27,28}$ In the current study, the effect of the DJBL on concentrations of satiety hormones was investigated. We are the first to report on changes in plasma PYY, CCK, ghrelin, and leptin after DJBL implantation.

Appetite control results from a complex interplay between several hormones and neuronal networks. ${ }^{11}$ In obese subjects, various aberrations within this system have been described, with leptin resistance as the most reported feature. ${ }^{34}$ In addition, obesity is associated with altered hormonal responses to food, such as an attenuated PYY response. ${ }^{16}$ Roux-en-Y gastric bypass augments postprandial PYY levels and increases satiety. ${ }^{23}$ In line, the current study shows that the postprandial PYY response to a meal was increased after implantation of the DJBL. Interestingly, subjects treated with the DJBL 
also reported increased satiety and reduced caloric intake. The underlying mechanism for the increased PYY levels might be related to the presence of undigested nutrients in the distal gut, the region where PYY secreting cells are predominantly located. Both the Rouxen-Y gastric bypass and the DJBL prevent uptake and digestion of nutrients in the proximal small intestine. As a result, undigested nutrients will be present at more distal sites in the small intestine, where they can stimulate PYY release resulting in increased satiety, reduced food intake, and reduced gut motility. ${ }^{10,11}$ This is consistent with the so-called ileal brake theory, which proposes that intestinal feedback mechanisms, such as PYY and GLP-1, are activated by undigested nutrients in the distal gut, resulting in reduced food intake and increased satiety by delaying gastric emptying and intestinal transit. ${ }^{35,36}$ In line, we observed increased postprandial GLP-1 levels shortly after initiation of DJBL treatment. $^{29}$

To obtain insight into changes in additional hormones involved in appetite control and putatively affected by the DJBL, postprandial levels of CCK, a hormone with important digestive and satiety functions, were determined. After implantation of the DJBL, the CCK response to a meal decreased. We propose that the absence of direct contact of food with the proximal small gut, where the CCK producing I-cells are predominantly located, might underlie this decreased CCK response after DJBL treatment. The decrease in CCK levels could lead to a decrease in satiety. However, in obese subject CCK resistance has been suggested, ${ }^{37}$ putatively reducing the aforementioned effect.

Furthermore, DJBL implantation resulted in an enhanced postprandial ghrelin response compared to the minimal pre-implant kinetics. After DJBL placement, fasting ghrelin levels were increased, whereas postprandial levels showed a more distinct drop. Taking into account the wide spectrum of physiological functions of ghrelin ${ }^{13,38}$ and the controversial results obtained following other bariatric procedures, ${ }^{25}$ these changes are not easily explained. However, the more pronounced decrease in postprandial ghrelin levels after DJBL placement might be associated with increased satiety following meal ingestion. Furthermore, although the stomach is the principal site of ghrelin production, up to one third of the circulating ghrelin is thought to originate from the proximal small intestine. ${ }^{39}$ The increased (fasting) ghrelin levels might therefore be induced by the exclusion of this part of the intestine from nutrients, thereby locally mimicking starvation. Additionally, circulating ghrelin levels have been reported to be inversely correlated with adipose tissue mass. ${ }^{17,18}$ The subjects in the current study lost a significant amount of weight, therefore loss of adipose tissue mass might be expected. In line, leptin levels, considered to reflect adipose tissue mass, ${ }^{23,26}$ decreased along with BMI following DJBL placement.

Subjects included in the current study suffered from both obesity and type 2 diabetes. In these subjects, with insulin resistance, satiety control is probably even more disturbed 
than in subjects with obesity alone, since insulin is involved in satiety control via signaling of long term energy stores. ${ }^{40}$ Interestingly, increased insulin sensitivity has been reported following both bariatric surgery ${ }^{41}$ and DJBL placement. ${ }^{27,29,42}$

In conclusion, our data show that DJBL treatment induces weight loss paralleled by changes in plasma concentrations of hormones involved in appetite control. We observed an elevated post-prandial PYY response, an increased ghrelin response, and a decreased CCK response to a meal. In addition, the fasting plasma concentration of leptin decreased after initiation of DJBL treatment. 


\section{REFERENCES}

1. Sjostrom L, Lindroos AK, Peltonen M, Torgerson J, Bouchard C, Carlsson B, Dahlgren S, Larsson B, Narbro $\mathrm{K}$, Sjostrom $\mathrm{CD}$, et al. Lifestyle, diabetes, and cardiovascular risk factors 10 years after bariatric surgery. $\mathrm{N}$ Engl J Med. 2004 Dec;351(26):2683-93.

2. Kaplan LM. Pharmacological therapies for obesity. Gastroenterol Clin North Am. 2005 Mar;34(1):91-104.

3. Brolin RE. Bariatric surgery and long-term control of morbid obesity. JAMA. 2002 Dec;288(22):2793-6.

4. Borg CM, le Roux CW, Ghatei MA, Bloom SR, Patel AG, Aylwin SJ. Progressive rise in gut hormone levels after Roux-en-Y gastric bypass suggests gut adaptation and explains altered satiety. Br J Surg. 2006 Feb;93(2):210-5.

5. le Roux CW, Welbourn R, Werling M, Osborne A, Kokkinos A, Laurenius A, Lonroth H, Fandriks L, Ghatei MA, Bloom SR, et al. Gut hormones as mediators of appetite and weight loss after Roux-en-Y gastric bypass. Ann Surg. 2007 Nov;246(5):780-5.

6. Strader AD, Woods SC. Gastrointestinal hormones and food intake. Gastroenterology. 2005 Jan;128(1):175-91.

7. Wren AM, Bloom SR. Gut hormones and appetite control. Gastroenterology. 2007 May;132(6):2116-30.

8. Michalakis K, le Roux C. Gut hormones and leptin: impact on energy control and changes after bariatric surgery--what the future holds. Obes Surg. 2012 Oct;22(10):1648-57.

9. Cummings DE, Overduin J. Gastrointestinal regulation of food intake. J Clin Invest. 2007 Jan;117(1):13-23.

10. Batterham RL, Cohen MA, Ellis SM, Le Roux CW, Withers DJ, Frost GS, Ghatei MA, Bloom SR. Inhibition of food intake in obese subjects by peptide YY3-36. N Engl J Med. 2003 Sep;349(10):941-8.

11. Huda MS, Wilding JP, Pinkney JH. Gut peptides and the regulation of appetite. Obes Rev. 2006 May;7(2):163-82.

12. Cummings $\mathrm{DE}$, Shannon $\mathrm{MH}$. Roles for ghrelin in the regulation of appetite and body weight. Arch Surg. 2003 Apr;138(4):389-96.

13. Sato T, Nakamura Y, Shiimura Y, Ohgusu H, Kangawa K, Kojima M. Structure, regulation and function of ghrelin. Journal of biochemistry. 2012 Feb;151(2):119-28.

14. Considine RV, Sinha MK, Heiman ML, Kriauciunas A, Stephens TW, Nyce MR, Ohannesian JP, Marco CC, McKee LJ, Bauer TL, et al. Serum immunoreactive-leptin concentrations in normal-weight and obese humans. N Engl J Med. 1996 Feb;334(5):292-5.

15. Zwirska-Korczala K, Konturek SJ, Sodowski M, Wylezol M, Kuka D, Sowa P, Adamczyk-Sowa M, Kukla M, Berdowska A, Rehfeld JF, et al. Basal and postprandial plasma levels of PYY, ghrelin, cholecystokinin, gastrin and insulin in women with moderate and morbid obesity and metabolic syndrome. J Physiol Pharmacol. 2007 Mar;58 Suppl 1:13-35.

16. le Roux CW, Batterham RL, Aylwin SJ, Patterson M, Borg CM, Wynne KJ, Kent A, Vincent RP, Gardiner J, Ghatei MA, et al. Attenuated peptide YY release in obese subjects is associated with reduced satiety. Endocrinology. 2006 Jan;147(1):3-8.

17. Tschop M, Weyer C, Tataranni PA, Devanarayan V, Ravussin E, Heiman ML. Circulating ghrelin levels are decreased in human obesity. Diabetes. 2001 Apr;50(4):707-9.

18. Cummings DE, Foster KE. Ghrelin-leptin tango in body-weight regulation. Gastroenterology. 2003 May;124(5):1532-5.

19. Meier U, Gressner AM. Endocrine regulation of energy metabolism: review of pathobiochemical and clinical chemical aspects of leptin, ghrelin, adiponectin, and resistin. Clin Chem. 2004 Sep;50(9):1511-25.

20. le Roux CW, Aylwin SJ, Batterham RL, Borg CM, Coyle F, Prasad V, Shurey S, Ghatei MA, Patel AG, Bloom SR. Gut hormone profiles following bariatric surgery favor an anorectic state, facilitate weight loss, and improve metabolic parameters. Ann Surg. 2006 Jan;243(1):108-14.

21. Beckman LM, Beckman TR, Earthman CP. Changes in gastrointestinal hormones and leptin after Roux-enY gastric bypass procedure: a review. J Am Diet Assoc. 2010 Apr;110(4):571-84. 
22. Peterli R, Wolnerhanssen B, Peters T, Devaux N, Kern B, Christoffel-Courtin C, Drewe J, von Flue M, Beglinger C. Improvement in glucose metabolism after bariatric surgery: comparison of laparoscopic Roux-en-Y gastric bypass and laparoscopic sleeve gastrectomy: a prospective randomized trial. Ann Surg. 2009 Aug;250(2):234-41.

23. Ochner CN, Gibson C, Shanik M, Goel V, Geliebter A. Changes in neurohormonal gut peptides following bariatric surgery. Int J Obes. 2011 Feb;35(2):153-66.

24. Peterli R, Steinert RE, Woelnerhanssen B, Peters T, Christoffel-Courtin C, Gass M, Kern B, von Fluee M, Beglinger C. Metabolic and hormonal changes after laparoscopic Roux-en-Y gastric bypass and sleeve gastrectomy: a randomized, prospective trial. Obes Surg. 2012 May;22(5):740-8.

25. Tymitz K, Engel A, McDonough S, Hendy MP, Kerlakian G. Changes in ghrelin levels following bariatric surgery: review of the literature. Obes Surg. 2011 Jan;21(1):125-30.

26. Korner J, Inabnet W, Febres G, Conwell IM, McMahon DJ, Salas R, Taveras C, Schrope B, Bessler M. Prospective study of gut hormone and metabolic changes after adjustable gastric banding and Roux-en-Y gastric bypass. Int J Obes. 2009 Jul;33(7):786-95.

27. Escalona A, Pimentel F, Sharp A, Becerra P, Slako M, Turiel D, Munoz R, Bambs C, Guzman S, Ibanez L, et al. Weight loss and metabolic improvement in morbidly obese subjects implanted for 1 year with an endoscopic duodenal-jejunal bypass liner. Ann Surg. 2012 Jun;255(6):1080-5.

28. Schouten R, Rijs CS, Bouvy ND, Hameeteman W, Koek GH, Janssen IM, Greve JW. A multicenter, randomized efficacy study of the EndoBarrier Gastrointestinal Liner for presurgical weight loss prior to bariatric surgery. Ann Surg. 2010 Feb;251(2):236-43.

29. de Jonge C, Rensen SS, Verdam FJ, Vincent RP, Bloom SR, Buurman WA, le Roux CW, Schaper NC, Bouvy ND, Greve JW. Endoscopic duodenal-jejunal bypass liner rapidly improves type 2 diabetes. Obes Surg. 2013 Sep;23(9):1354-60.

30. Kreymann B, Williams G, Ghatei MA, Bloom SR. Glucagon-like peptide-1 7-36: a physiological incretin in man. Lancet. 1987 Dec;2(8571):1300-4.

31. van Dielen FM, Buurman WA, Hadfoune M, Nijhuis J, Greve JW. Macrophage inhibitory factor, plasminogen activator inhibitor-1, other acute phase proteins, and inflammatory mediators normalize as a result of weight loss in morbidly obese subjects treated with gastric restrictive surgery. J Clin Endocrinol Metab. 2004 Aug;89(8):4062-8.

32. Miras AD, le Roux CW. Bariatric surgery and taste: novel mechanisms of weight loss. Current opinion in gastroenterology. 2010 Mar;26(2):140-5.

33. Bueter M, le Roux CW. Gastrointestinal hormones, energy balance and bariatric surgery. Int J Obes. 2011 Sep;35 Suppl 3:S35-9.

34. Oswal A, Yeo G. Leptin and the control of body weight: a review of its diverse central targets, signaling mechanisms, and role in the pathogenesis of obesity. Obesity. 2010 Feb;18(2):221-9.

35. Maljaars PW, Symersky T, Kee BC, Haddeman E, Peters HP, Masclee AA. Effect of ileal fat perfusion on satiety and hormone release in healthy volunteers. Int J Obes. 2008 Nov;32(11):1633-9.

36. Maljaars PW, Peters HP, Mela DJ, Masclee AA. lleal brake: a sensible food target for appetite control. A review. Physiol Behav. 2008 Oct;95(3):271-81.

37. Dockray GJ. Cholecystokinin. Curr Opin Endocrinol Diabetes Obes. 2012 Feb;19(1):8-12.

38. Verhulst PJ, Depoortere I. Ghrelin's second life: from appetite stimulator to glucose regulator. World J Gastroenterol. 2012 Jul;18(25):3183-95.

39. Ariyasu H, Takaya K, Tagami T, Ogawa Y, Hosoda K, Akamizu T, Suda M, Koh T, Natsui K, Toyooka S, et al. Stomach is a major source of circulating ghrelin, and feeding state determines plasma ghrelin-like immunoreactivity levels in humans. J Clin Endocrinol Metab. 2001 Oct;86(10):4753-8.

40. Woods SC, D'Alessio DA. Central control of body weight and appetite. J Clin Endocrinol Metab. 2008 Nov;93(11 Suppl 1):S37-50.

41. Bradley D, Conte C, Mittendorfer B, Eagon JC, Varela JE, Fabbrini E, Gastaldelli A, Chambers KT, Su X, Okunade A, et al. Gastric bypass and banding equally improve insulin sensitivity and beta cell function. J Clin Invest. 2012 Dec;122(12):4667-74. 
42. de Moura EG, Orso IR, Martins Bda C, Lopes GS, de Oliveira SL, Galvao-Neto Mdos P, Mancini MC, Santo MA, Sakai $P$, Ramos AC, et al. Improvement of insulin resistance and reduction of cardiovascular risk among obese patients with type 2 diabetes with the duodenojejunal bypass liner. Obes Surg. 2011 Jul;21(7):941-7. 



\section{Chapter 5}

\section{Endoscopic Duodenal-Jejunal Bypass Liner}

rapidly improves plasma parameters of Nonalcoholic Fatty Liver Disease in obese subjects 


\section{ABSTRACT}

\section{Background}

Bariatric surgery reduces obesity, type 2 diabetes, and nonalcoholic fatty liver disease (NAFLD). The Duodenal-Jejunal Bypass Liner (DJBL) was recently developed to mimic the bypass component of the gastric bypass with minimal invasion. Previous studies with this device have revealed showed that it reduced features of obesity and type 2 diabetes in patients. We performed a clinical trial to investigate the effects of DJBL treatment on plasma parameters of NAFLD.

\section{Methods}

In a prospective study, 17 subjects with obesity (body mass index (BMI) of $37.0 \pm 1.3$ $\mathrm{kg} / \mathrm{m}^{2}$ ) and type 2 diabetes received the DJBL for 24 weeks. Before, during, and after DJBL treatment, we measured plasma levels of aspartate aminotransferase (AST), alanine aminotransferase (ALT), gamma-glutamyltransferase $(\gamma-G T)$, albumin, caspase-cleaved cytokeratin-18 (CK-18), and liver fatty acid-binding protein (L-FABP).

\section{Results}

At baseline, subjects had increased levels of AST (35 $\pm 4 \mathrm{U} / \mathrm{L}), \operatorname{ALT}(54 \pm 5 \mathrm{U} / \mathrm{L})$, and $\gamma$-GT (66 $\pm 14 \mathrm{U} / \mathrm{L})$, compared with healthy individuals; subjects' mean concentrations of caspase-cleaved CK-18 and L-FABP were $214.4 \pm 35.6 \mathrm{U} / \mathrm{L}$ and $29.3 \pm 2.6 \mathrm{ng} / \mathrm{mL}$, respectively. Three months after initiation of DJBL treatment, the subjects' mean BMI had decreased to $33.6 \pm 1.2 \mathrm{~kg} / \mathrm{m}^{2}$ ( $p<0.05$, compared with baseline). Their plasma levels of all NAFLD-related parameters had also decreased (AST: $28 \pm 3 \mathrm{U} / \mathrm{L} ; \mathrm{ALT}: 32 \pm 2 \mathrm{U} / \mathrm{L} ; \mathrm{Y}$-GT: $44 \pm$ $7 \mathrm{U} / \mathrm{L}$; caspase-cleaved CK-18: $140.6 \pm 16.3 \mathrm{U} / \mathrm{L}$; and L-FABP: $18.2 \pm 1.5 \mathrm{ng} / \mathrm{mL}$; all $\mathrm{p}<0.05)$. By 6 months, levels of ALT and $\mathrm{Y}$-GT had further decreased (ALT: $28 \pm 2 \mathrm{U} / \mathrm{L}$ and $\mathrm{\gamma}$-GT: $35 \pm$ $5 \mathrm{U} / \mathrm{L}$ ) and BMI decreased to $32.9 \pm 1.2 \mathrm{~kg} / \mathrm{m}^{2}$ (all $\mathrm{p}<0.05$ ), but levels of AST, caspasecleaved CK-18, and L-FABP levels had stabilized (all $p=n s$ ). After 12 months, levels of ALT (37 $\pm 3 \mathrm{U} / \mathrm{L}), \gamma$-GT $(42 \pm 5 \mathrm{U} / \mathrm{L})$, and caspase-cleaved CK-18 (124.5 $\pm 12.5 \mathrm{U} / \mathrm{L})$ were still reduced, compared with baseline $(p<0.05)$. AST and L-FABP had returned to near baseline levels $(p=n s)$.

\section{Conclusion}

In a prospective trial of 17 obese patients with type 2 diabetes, proximal small intestinal exclusion through DJBL reduced BMI and plasma parameters of NAFLD for at least a year. 


\section{INTRODUCTION}

Nonalcoholic fatty liver disease (NAFLD) encompasses a disease spectrum ranging from simple steatosis to nonalcoholic steatohepatitis (NASH). NASH is defined by the presence of steatosis, hepatocyte ballooning, and lobular inflammation. ${ }^{1,2}$ Whereas steatosis is considered to be benign, NASH is associated with important morbidity and mortality since it can progress to liver fibrosis, cirrhosis, end-stage liver failure, and even hepatocellular carcinoma. ${ }^{3}$ Obesity and the metabolic syndrome are important risk factors for developing NAFLD. ${ }^{4,5}$ With the increasing prevalence of both diseases, NAFLD has become the most common chronic liver disease worldwide, affecting approximately $20 \%$ of the general population. Even higher disease rates are reported among obese patients. ${ }^{5,6}$

For years, bariatric surgery has been successfully employed to treat obesity. ${ }^{7,8}$ This type of surgery has also been shown to positively affect obesity-related comorbidities. ${ }^{9,10}$ In particular, a large body of evidence exists on the beneficial effects of bariatric techniques on type 2 diabetes. ${ }^{9-13}$ Interestingly, positive effects of bariatric surgery on NAFLD have also been reported. ${ }^{14-20}$

Most bariatric techniques are invasive and associated with complications. This had led to a search for minimally invasive techniques. Recently, the Duodenal-Jejunal Bypass Liner (DJBL, GI Dynamics, Lexington, MA), a non-surgical bariatric technique, was developed to mimic the intestinal bypass component of the Roux-en-Y gastric bypass. The initial purpose of the DJBL was to treat obesity. ${ }^{21}$ Remarkably, this device turned out to not only lead to significant weight loss, but also to rapid improvement of type 2 diabetes and the metabolic syndrome. ${ }^{21-26}$ Since these conditions are important risk factors for NAFLD ${ }^{4,5}$ and previous research with surgical bariatric techniques has revealed beneficial effects on NAFLD, ${ }^{14-20}$ we hypothesized that DJBL treatment would also have a favorable impact on NAFLD.

We investigated the effect of DJBL treatment on plasma parameters linked to NAFLD. Changes in AST, ALT, $\gamma$-GT, L-FABP, caspase-cleaved CK-18, and albumin in obese patients with type 2 diabetes prior to, during, and after DJBL treatment are reported.

\section{METHODS}

\section{Subjects}

Seventeen patients with obesity and type 2 diabetes were included in two centers: an academic hospital; the Maastricht University Medical Center, Maastricht, the Netherlands 
and a large teaching hospital; the Atrium Medical Center Parkstad, Heerlen, the Netherlands. Inclusion criteria were: age between 18 and 65 years; body mass index (BMI) between 30 and $50 \mathrm{~kg} / \mathrm{m}^{2}$; duration of type 2 diabetes less than 10 years; and $\mathrm{HbA}_{1 \mathrm{c}}$ between 7.5 and $10.0 \%$. Main exclusion criteria were: alcohol consumption of more than 1 unit/day for women or more than 2 units/day for men; weight loss of more than $4.5 \mathrm{~kg}$ within 12 weeks prior to screening; use of weight loss medication or anti-inflammatory drugs; history of inflammatory diseases or other known liver diseases than NAFLD; and exclusion criteria regarding safety of DJBL placement or DJBL compatibility. The study was approved by the Medical Ethics Committee of each center and conducted according to the revised version of the Declaration of Helsinki (October 2008, Seoul). Written informed consent was obtained from every patient before study participation.

\section{The DJBL procedure}

The DJBL was delivered and retrieved endoscopically as previously described. ${ }^{21}$ In brief, a gastroduodenal endoscopy was performed under general anesthesia. A guide wire was placed into the duodenum over which the encapsulated DJBL was directed through the pylorus into the duodenal bulb. The DJBL was advanced into the small intestine, followed by deployment of the anchor in the duodenal bulb. Correct positioning and patency of the DJBL were verified under fluoroscopy.

During the study period, patients were provided a standard of care nutritional counseling program, which suggested a regular diet with a maximum of 1,200 kcal for women and $1,500 \mathrm{kcal}$ for men which was liquid for the first week after DJBL placement. At every visit, daily caloric intake was evaluated by a dietitian. If necessary, dietary adaptations were made. Compliance to the diet was considered as moderate to good by a dedicated nutritional counselor.

After 24 weeks, the device was explanted as previously described. ${ }^{21}$ In brief, explantation was performed endoscopically under general anesthesia using a custom retrieval system containing a grasper and a retrieval hood. By grasping the wires on the anchor, the anchor collapsed and was pulled into the retrieval hood on top of the endoscope. After verification of the collapsed anchor by fluoroscopy, the device was removed.

\section{Study design}

Subjects were studied on four occasions: within one month prior to the start of the study (D0), three and six months after implantation of the DJBL ( $M 3$ and M6, respectively), and again six months after explantation of the DJBL (M12). The baseline visit included physical examination and history taking. At all study visits, body weight was determined and 
fasting venous blood samples were collected (BD Vacutainer EDTA tube, BD diagnostics, Erembodegem-Aalst, Belgium). Samples were immediately cooled, centrifuged and stored at $-80{ }^{\circ} \mathrm{C}$ until further analysis.

\section{Plasma parameters}

Plasma levels of AST, ALT, $\mathrm{\gamma}-\mathrm{GT}$, albumin, and $\mathrm{HbA}_{1 \mathrm{c}}$ were determined routinely at the Department of Clinical Chemistry at the Maastricht University Medical Center. Reference ranges can be found in Table 1.

Recent reports indicate that plasma levels of caspase-cleaved CK-18 reflect hepatocyte apoptosis and are closely related to NAFLD severity. ${ }^{27-31}$ We therefore determined plasma caspase-cleaved CK-18 concentrations using a commercially available enzyme-linked immunosorbent assay (ELISA) according to the manufacturer's protocol (caspase-cleaved CK-18: M30 Apoptosense ELISA, Peviva AB, Bromma, Sweden). Additionally, we used a commercially available ELISA to determine plasma L-FABP concentrations, analysis were performed according to the manufacturer's protocol (L-FABP ELISA, kindly provided by Hycult Biotechnology, Uden, the Netherlands).

\section{Statistical analyses}

Statistical analyses were performed using GraphPad Prism 5.0. Longitudinal changes were tested using Wilcoxon signed rank test. A p-value of $<0.05$ was considered statistically significant. Data are presented as mean and standard error of the mean (SEM).

\section{RESULTS}

\section{DJBL treatment results in significant weight loss}

At baseline, patients were aged $51 \pm 2$ years. The majority of patients were male (14/17). Patients had an average body weight of $116.0 \pm 5.8 \mathrm{~kg}$ with a mean BMl of $37.0 \pm 1.3$ $\mathrm{kg} / \mathrm{m}^{2}$. Patients mean $\mathrm{HbA}_{1 \mathrm{c}}$ was $8.4 \pm 0.2 \%$. Additional baseline characteristics of the study subjects and subsequent changes are shown in Table 1.

Three months after implantation of the DJBL, body weight had decreased to $105.3 \pm 5.5$ $\mathrm{kg}$, corresponding with an excess weight loss of $25.2 \pm 3.1 \%$ and a BMI reduction of $3.4 \pm$ $0.4 \mathrm{~kg} / \mathrm{m}^{2}$ ( $\mathrm{p}<0.01$ ). After 24 weeks, at the time of device explantation, mean body weight had further decreased to $103.3 \pm 5.5 \mathrm{~kg}$ resulting in a total weight loss of $12.7 \pm 1.3 \mathrm{~kg}$, which corresponds to an excess weight loss of $29.8 \pm 3.5 \%$ and a BMI reduction of $4.1 \pm$ 
$0.4 \mathrm{~kg} / \mathrm{m}^{2}(\mathrm{p}<0.01)$. At month twelve, six months after explantation of the device, body weight had increased slightly to $106.7 \pm 6.1 \mathrm{~kg}$, but was still significantly decreased when compared to baseline $(p<0.01)$. Accordingly, the mean BMI was $34.3 \pm 1.5 \mathrm{~kg} / \mathrm{m}^{2}(p<0.01$ vs. baseline). Excess weight loss was $19.9 \pm 3.9 \%$ at that time.

Table 1. Baseline characteristics of the study population.

\begin{tabular}{|c|c|c|c|c|c|}
\hline & Baseline & Month 3 & Month 6 & Month 12 & Reference range \\
\hline Weight (kg) & $116.0 \pm 5.8$ & $105.3 \pm 5.5$ & $103.3 \pm 5.5$ & $106.7 \pm 6.1$ & \\
\hline BMI $\left(\mathrm{kg} / \mathrm{m}^{2}\right)$ & $37.0 \pm 1.3$ & $33.6 \pm 1.2$ & $32.9 \pm 1.2$ & $34.3 \pm 1.5$ & $20-25$ \\
\hline AST (U/L) & $35 \pm 4$ & $28 \pm 3$ & $23 \pm 2$ & $34 \pm 3$ & $j<35 ; q<30$ \\
\hline ALT (U/L) & $54 \pm 5$ & $32 \pm 2$ & $28 \pm 2$ & $37 \pm 3$ & $\hat{\delta}<45 ; q<35$ \\
\hline V-GT (U/L) & $66 \pm 14$ & $44 \pm 7$ & $35 \pm 5$ & $42 \pm 5$ & $\hat{\delta}<55 ; q<40$ \\
\hline CK-18 (U/L) & $214.4 \pm 35.6$ & $140.6 \pm 16.3$ & $149.2 \pm 23.1$ & $124.5 \pm 12.5$ & \\
\hline L-FABP (ng/mL) & $29.3 \pm 2.6$ & $18.2 \pm 1.5$ & $20.2 \pm 1.6$ & $29.5 \pm 3.1$ & \\
\hline
\end{tabular}

Data are shown as mean \pm SEM or No (\%).

\section{Established clinical plasma liver parameters decrease following DJBL implantation}

To gain insight into the potential effects of DJBL treatment on NAFLD, several established clinical plasma parameters that have been linked to NAFLD ${ }^{32,33}$ were evaluated. At baseline, AST levels were elevated in 9 out of 17 patients with a mean AST level of $35 \pm 4$ $\mathrm{U} / \mathrm{L}$ (Fig. 1A). In line, ALT levels were elevated in 11 out of 17 patients resulting in a mean ALT above the upper reference limit ( $54 \pm 5 \mathrm{U} / \mathrm{L}$, Fig. 1B). In addition, 6 patients had elevated $\gamma$-GT levels resulting in an elevated mean $\gamma$-GT of $66 \pm 14 \mathrm{U} / \mathrm{L}$ (Fig. 1C).

After explantation of the device, at month twelve, AST levels were elevated in 6 patients. The mean AST level had increased and returned to baseline levels ( $34 \pm 3 U / L, p=0.63$ compared to baseline). Interestingly, ALT levels were still diminished at six months postexplantation ( $37 \pm 3$ vs. $54 \pm 5 \mathrm{U} / \mathrm{L}$ at baseline, $\mathrm{p}<0.01$ ) and only 3 patients had an elevated ALT at this time point. Similarly, only 2 patients displayed elevated $\gamma$-GT levels at month 12 and the mean $\gamma$-GT concentration was still decreased $(42 \pm 5 \mathrm{U} / \mathrm{L}, \mathrm{p}<0.01$ compared to baseline). Albumin levels of all patients stayed within the reference range at all times. 
A

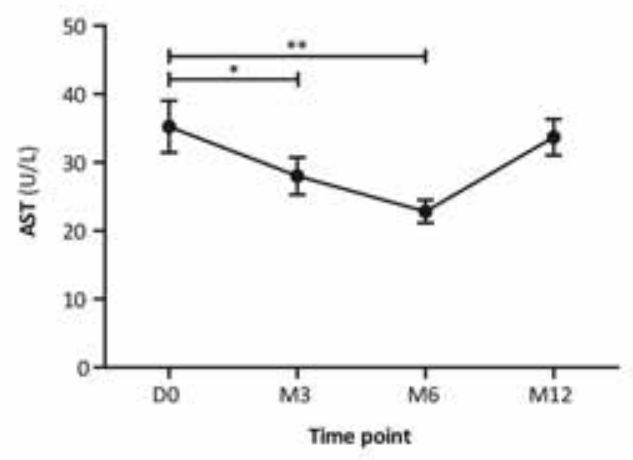

c

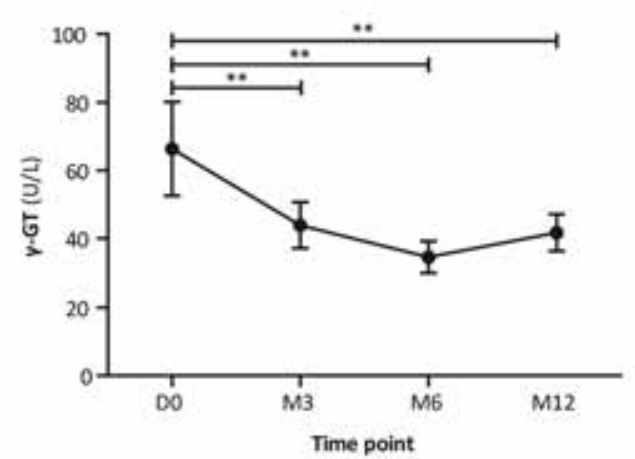

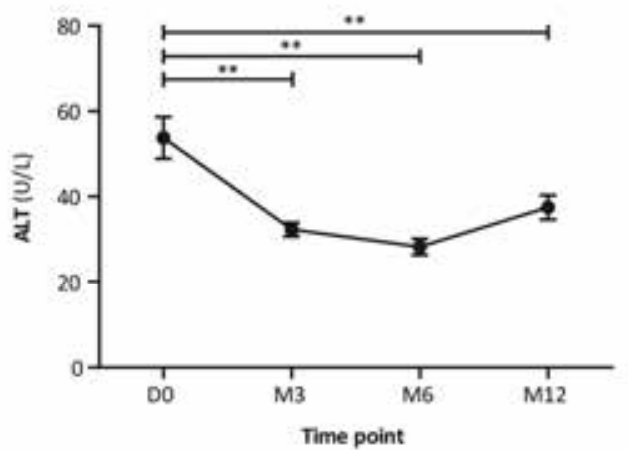

Figure 1. Effects of DJBL treatment on AST, ALT, and $\boldsymbol{\gamma}$-GT. A) Plasma AST levels at baseline (DO), three (M3) and six (M6) months after implantation of the DJBL, and six months after removal of the DJBL (M12). B) Plasma levels of $A L T$ at these time points. C) Plasma concentrations of $\gamma$-GT. An asterisk $\left({ }^{*}\right)$ indicates $p<0.05$, two asterisks indicate $p<0.01$.

\section{DJBL treatment rapidly reduces plasma markers of liver damage and liver apoptosis}

The effect of DJBL treatment on NAFLD-related liver damage, investigated by use of a marker of hepatocyte injury, L-FABP ${ }^{34}$ is shown in Figure 2A. Mean plasma L-FABP levels decreased following DJBL implantation, from $29.3 \pm 2.6 \mathrm{ng} / \mathrm{mL}$ at baseline to $18.2 \pm 1.5$ $\mathrm{ng} / \mathrm{mL}$ after three months of treatment $(\mathrm{p}<0.01)$. Until month six, plasma L-FABP levels stayed at this lower level $(20.2 \pm 1.6 \mathrm{ng} / \mathrm{mL}, \mathrm{p}<0.05$ compared to baseline). At month twelve, six months after device removal, L-FABP levels had returned to baseline levels (29.5 $\pm 3.1 \mathrm{ng} / \mathrm{mL}, \mathrm{p}=0.85$ compared to baseline).

We next determined the effect of DJBL treatment on hepatocyte apoptosis, as investigated by plasma concentrations of caspase-cleaved CK-18. Changes in plasma caspase-cleaved CK-18 showed a similar pattern as the changes in L-FABP concentration (Fig. 2B). At baseline, mean caspase-cleaved CK-18 levels were $214.4 \pm 35.6 \mathrm{U} / \mathrm{L}$. After 
three months, the levels had decreased to $140.6 \pm 16.3 \mathrm{U} / \mathrm{L}(\mathrm{p}<0.05)$. During the remainder of the study, the decrease in caspase-cleaved CK-18 concentrations stabilized; $149.2 \pm 23.1$ at month six and $124.5 \pm 12.5 \mathrm{U} / \mathrm{L}$ at month twelve, $\mathrm{p}=0.12$ and $\mathrm{p}<0.01$ compared to baseline, respectively).

A

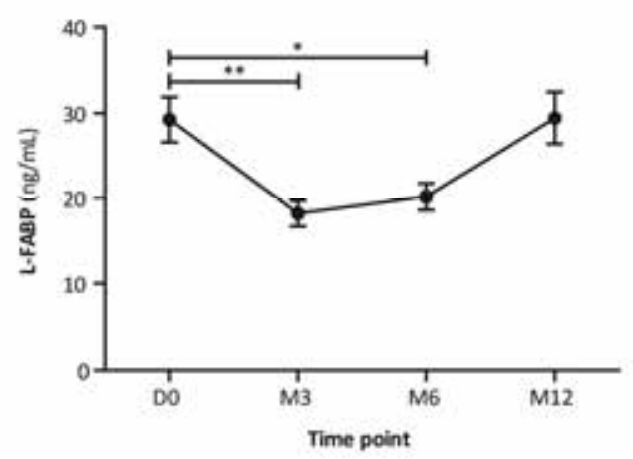

B

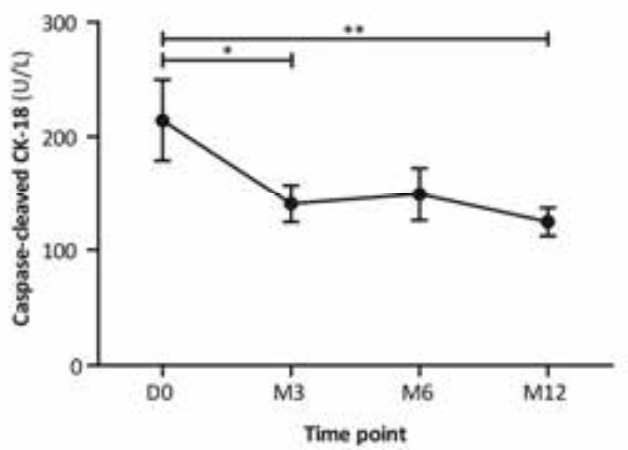

Figure 2. Effects of DJBL treatment on L-FABP and caspase-cleaved CK-18. A) Plasma L-FABP levels at baseline (DO), three (M3) and six (M6) months after DJBL implantation, and six months after DJBL explantation (M12). B) Plasma levels of caspase-cleaved CK-18 at the different time points. An asterisk $\left({ }^{*}\right)$ indicates $p<0.05$, two asterisks indicate $p<0.01$.

\section{DISCUSSION}

As the obesity epidemic keeps on growing, the incidence of NAFLD steeply increases. Fortunately, treatment options for both diseases are available. In particular, bariatric surgery has been shown effective in treating obesity, accompanied by improvement of NAFLD. ${ }^{14-20}$ However, bariatric surgery is invasive and associated with complications, causing a hesitative attitude in patients towards this type of surgery. ${ }^{35}$ Therefore new, less invasive, anatomy-sparing devices, like the DJBL, have been developed. This new, nonsurgical device has been shown to be safe and effective in treating obesity and different aspects of the metabolic syndrome, such as type 2 diabetes. ${ }^{21-26}$ In the current study, we investigated the effect of DJBL treatment on plasma parameters that have been associated with NAFLD. We here confirm that DJBL is effective in treating obesity and are the first to report improvement of plasma liver parameters after duodenal-jejunal exclusion by DJBL.

The gold standard for diagnosing NAFLD is histopathologic evaluation of a liver biopsy. ${ }^{33}$ However, a biopsy represents only a small portion of the liver, making the technique 
susceptible to sampling errors. ${ }^{36}$ Furthermore, the accuracy of histopathologic evaluation of liver biopsies suffers from inter- and intra-observer variability. ${ }^{37}$ Moreover, obtaining a liver biopsy is associated with complications, such as pain and bleeding. ${ }^{38}$ Plasma parameters are, therefore, often used for screening, despite their limited sensitivity and specificity. ${ }^{30,32,33}$ In the current study with a minimally invasive bariatric technique, we chose to not expose our subjects to the burden of repeated invasive biopsies, but instead determined plasma parameters reflecting NAFLD.

Our data show that clinical plasma liver parameters decrease following DJBL implantation. Normalization of AST, ALT and $y$-GT levels occurred in almost all patients. Dixon et al. have shown that a decrease in $\gamma$-GT and AST levels is associated with improvement of liver histology in NAFLD patients following weight loss by bariatric surgery. ${ }^{39}$ This advocates for improvement of NAFLD by DJBL treatment in our subjects. Additionally, DJBL treatment resulted in diminished levels plasma of L-FABP, a small intracellular protein that rapidly leaks out of damaged hepatocytes into the plasma. ${ }^{34} \mathrm{~A}$ similar response pattern was observed for caspase-cleaved CK-18 plasma levels. Caspase-cleaved CK-18 is a protein generated during hepatocyte apoptosis, a prominent pathologic feature of $\mathrm{NASH}^{40}$ the more severe form of NAFLD. Plasma levels of caspase-cleaved CK-18 positively correlate with NAFLD severity, independently predicting the presence of NASH. ${ }^{27-31}$ In our subjects, a decrease in caspase-cleaved CK-18 was observed after start of the DJBL treatment, potentially indicating NAFLD regression. Taken together, all plasma parameters associated with NAFLD diminished after DJBL implantation. Interestingly, six month after DJBL removal, plasma levels of ALT, $Y-G T$, and caspase-cleaved CK-18 were still diminished when compared to baseline, suggesting a prolonged effect of the DJBL treatment.

Notably, NAFLD severity was probably limited in our study population, since it was characterized by modest elevation of plasma liver parameters. ${ }^{27,30,31}$ These subjects are therefore probably in an early, still reversible stage of NAFLD, when cure through intervention is still possible. ${ }^{3}$

In conclusion, we observed a rapid improvement of all NAFLD parameters after initiation of DJBL treatment. It appears that the DJBL reverses liver parameters associated with NAFLD at least temporarily. Further research evaluating longer-term follow-up and/or histologic changes of the liver is needed to fully elaborate the potential positive effect of DJBL treatment on NAFLD. 


\section{REFERENCES}

1. Brunt EM, Janney CG, Di Bisceglie AM, Neuschwander-Tetri BA, Bacon BR. Nonalcoholic steatohepatitis: a proposal for grading and staging the histological lesions. Am J Gastroenterol. 1999 Sep;94(9):2467-74.

2. Kleiner DE, Brunt EM, Van Natta M, Behling C, Contos MJ, Cummings OW, Ferrell LD, Liu YC, Torbenson MS, Unalp-Arida A, et al. Design and validation of a histological scoring system for nonalcoholic fatty liver disease. Hepatology. 2005 Jun;41(6):1313-21.

3. Smith BW, Adams LA. Non-alcoholic fatty liver disease. Crit Rev Clin Lab Sci. 2011 May-Jun;48(3):97-113.

4. Angulo P. Obesity and nonalcoholic fatty liver disease. Nutrition reviews. 2007 65(6 Pt 2):S57-63.

5. Lazo M, Clark JM. The epidemiology of nonalcoholic fatty liver disease: a global perspective. Semin Liver Dis. 2008 Nov;28(4):339-50.

6. Chalasani N, Younossi Z, Lavine JE, Diehl AM, Brunt EM, Cusi K, Charlton M, Sanyal AJ. The diagnosis and management of non-alcoholic fatty liver disease: practice Guideline by the American Association for the Study of Liver Diseases, American College of Gastroenterology, and the American Gastroenterological Association. Hepatology. 2012 Jun;55(6):2005-23.

7. Sjostrom L, Narbro K, Sjostrom CD, Karason K, Larsson B, Wedel H, Lystig T, Sullivan M, Bouchard C, Carlsson B, et al. Effects of bariatric surgery on mortality in Swedish obese subjects. N Engl J Med. 2007 Aug 23;357(8):741-52.

8. Buchwald H, Avidor Y, Braunwald E, Jensen MD, Pories W, Fahrbach K, Schoelles K. Bariatric surgery: a systematic review and meta-analysis. JAMA. 2004 Oct 13;292(14):1724-37.

9. Sjostrom L, Lindroos AK, Peltonen M, Torgerson J, Bouchard C, Carlsson B, Dahlgren S, Larsson B, Narbro $\mathrm{K}$, Sjostrom $\mathrm{CD}$, et al. Lifestyle, diabetes, and cardiovascular risk factors 10 years after bariatric surgery. $\mathrm{N}$ Engl J Med. 2004 Dec;351(26):2683-93.

10. Buchwald H, Estok R, Fahrbach K, Banel D, Jensen MD, Pories WJ, Bantle JP, Sledge I. Weight and type 2 diabetes after bariatric surgery: systematic review and meta-analysis. Am J Med. 2009 Mar;122(3):24856.

11. Schauer PR, Kashyap SR, Wolski K, Brethauer SA, Kirwan JP, Pothier CE, Thomas S, Abood B, Nissen SE, Bhatt DL. Bariatric surgery versus intensive medical therapy in obese patients with diabetes. N Engl J Med. 2012 Apr 26;366(17):1567-76.

12. Cummings DE. Metabolic surgery for type 2 diabetes. Nat Med. 2012 May;18(5):656-8.

13. Mingrone G, Panunzi S, De Gaetano A, Guidone C, laconelli A, Leccesi L, Nanni G, Pomp A, Castagneto M, Ghirlanda $G$, et al. Bariatric surgery versus conventional medical therapy for type 2 diabetes. N Engl J Med. 2012 Apr 26;366(17):1577-85.

14. Blackburn GL, Mun EC. Effects of weight loss surgeries on liver disease. Semin Liver Dis. 2004 Nov;24(4):371-9.

15. Mattar SG, Velcu LM, Rabinovitz M, Demetris AJ, Krasinskas AM, Barinas-Mitchell E, Eid GM, Ramanathan R, Taylor DS, Schauer PR. Surgically-induced weight loss significantly improves nonalcoholic fatty liver disease and the metabolic syndrome. Ann Surg. 2005 Oct;242(4):610-20.

16. Klein S, Mittendorfer B, Eagon JC, Patterson B, Grant L, Feirt N, Seki E, Brenner D, Korenblat K, McCrea J. Gastric bypass surgery improves metabolic and hepatic abnormalities associated with nonalcoholic fatty liver disease. Gastroenterology. 2006 May;130(6):1564-72.

17. Barker KB, Palekar NA, Bowers SP, Goldberg JE, Pulcini JP, Harrison SA. Non-alcoholic steatohepatitis: effect of Roux-en-Y gastric bypass surgery. Am J Gastroenterol. 2006 Feb;101(2):368-73.

18. Mathurin P, Hollebecque A, Arnalsteen L, Buob D, Leteurtre E, Caiazzo R, Pigeyre M, Verkindt $H$, Dharancy $S$, Louvet $A$, et al. Prospective study of the long-term effects of bariatric surgery on liver injury in patients without advanced disease. Gastroenterology. 2009 Aug;137(2):532-40.

19. Chavez-Tapia NC, Tellez-Avila FI, Barrientos-Gutierrez T, Mendez-Sanchez N, Lizardi-Cervera J, Uribe M. Bariatric surgery for non-alcoholic steatohepatitis in obese patients. Cochrane Database Syst Rev. 2010 1):CD007340. 
20. Rabl C, Campos GM. The impact of bariatric surgery on nonalcoholic steatohepatitis. Semin Liver Dis. 2012 Feb;32(1):80-91.

21. Schouten R, Rijs CS, Bouvy ND, Hameeteman W, Koek GH, Janssen IM, Greve JW. A multicenter, randomized efficacy study of the EndoBarrier Gastrointestinal Liner for presurgical weight loss prior to bariatric surgery. Ann Surg. 2010 Feb;251(2):236-43.

22. Tarnoff M, Rodriguez L, Escalona A, Ramos A, Neto M, Alamo M, Reyes E, Pimentel F, Ibanez L. Open label, prospective, randomized controlled trial of an endoscopic duodenal-jejunal bypass sleeve versus low calorie diet for pre-operative weight loss in bariatric surgery. Surg Endosc. 2009 Mar;23(3):650-6.

23. Rodriguez L, Reyes E, Fagalde P, Oltra MS, Saba J, Aylwin CG, Prieto C, Ramos A, Galvao M, Gersin KS, et al. Pilot clinical study of an endoscopic, removable duodenal-jejunal bypass liner for the treatment of type 2 diabetes. Diabetes Technol Ther. 2009 Nov;11(11):725-32.

24. de Moura EG, Martins BC, Lopes GS, Orso IR, de Oliveira SL, Galvao Neto MP, Santo MA, Sakai P, Ramos AC, Garrido Junior AB, et al. Metabolic improvements in obese type 2 diabetes subjects implanted for 1 year with an endoscopically deployed duodenal-jejunal bypass liner. Diabetes Technol Ther. 2012 Feb;14(2):183-9.

25. Escalona A, Pimentel F, Sharp A, Becerra P, Slako M, Turiel D, Munoz R, Bambs C, Guzman S, Ibanez L, et al. Weight loss and metabolic improvement in morbidly obese subjects implanted for 1 year with an endoscopic duodenal-jejunal bypass liner. Ann Surg. 2012 Jun;255(6):1080-5.

26. de Jonge C, Rensen SS, Verdam FJ, Vincent RP, Bloom SR, Buurman WA, le Roux CW, Schaper NC, Bouvy ND, Greve JW. Endoscopic duodenal-jejunal bypass liner rapidly improves type 2 diabetes. Obes Surg. 2013 Sep;23(9):1354-60.

27. Wieckowska A, Zein NN, Yerian LM, Lopez AR, McCullough AJ, Feldstein AE. In vivo assessment of liver cell apoptosis as a novel biomarker of disease severity in nonalcoholic fatty liver disease. Hepatology. 2006 Jul;44(1):27-33.

28. Yilmaz Y, Dolar E, Ulukaya E, Akgoz S, Keskin M, Kiyici M, Aker S, Yilmaztepe A, Gurel S, Gulten M, et al. Soluble forms of extracellular cytokeratin 18 may differentiate simple steatosis from nonalcoholic steatohepatitis. World J Gastroenterol. 2007 Feb 14;13(6):837-44.

29. Diab DL, Yerian L, Schauer P, Kashyap SR, Lopez R, Hazen SL, Feldstein AE. Cytokeratin 18 fragment levels as a noninvasive biomarker for nonalcoholic steatohepatitis in bariatric surgery patients. Clin Gastroenterol Hepatol. 2008 Nov;6(11):1249-54.

30. Shen J, Chan HL, Wong GL, Choi PC, Chan AW, Chan HY, Chim AM, Yeung DK, Chan FK, Woo J, et al. Noninvasive diagnosis of non-alcoholic steatohepatitis by combined serum biomarkers. J Hepatol. 2012 Jun;56(6):1363-70.

31. Feldstein AE, Wieckowska A, Lopez AR, Liu YC, Zein NN, McCullough AJ. Cytokeratin-18 fragment levels as noninvasive biomarkers for nonalcoholic steatohepatitis: a multicenter validation study. Hepatology. 2009 Oct;50(4):1072-8.

32. Wieckowska A, McCullough AJ, Feldstein AE. Noninvasive diagnosis and monitoring of nonalcoholic steatohepatitis: present and future. Hepatology. 2007 Aug;46(2):582-9.

33. Neuschwander-Tetri BA, Clark JM, Bass NM, Van Natta ML, Unalp-Arida A, Tonascia J, Zein CO, Brunt EM, Kleiner DE, McCullough AJ, et al. Clinical, laboratory and histological associations in adults with nonalcoholic fatty liver disease. Hepatology. 2010 Sep;52(3):913-24.

34. Pelsers MM, Morovat A, Alexander GJ, Hermens WT, Trull AK, Glatz JF. Liver fatty acid-binding protein as a sensitive serum marker of acute hepatocellular damage in liver transplant recipients. Clin Chem. 2002 Nov;48(11):2055-7.

35. Afonso BB, Rosenthal R, Li KM, Zapatier J, Szomstein S. Perceived barriers to bariatric surgery among morbidly obese patients. Surg Obes Relat Dis. 2010 Jan-Feb;6(1):16-21.

36. Ratziu V, Charlotte F, Heurtier A, Gombert S, Giral P, Bruckert E, Grimaldi A, Capron F, Poynard T, Group LS. Sampling variability of liver biopsy in nonalcoholic fatty liver disease. Gastroenterology. 2005 Jun;128(7):1898-906. 


\section{Chapter 5}

37. Cholongitas E, Senzolo M, Standish R, Marelli L, Quaglia A, Patch D, Dhillon AP, Burroughs AK. A systematic review of the quality of liver biopsy specimens. Am J Clin Pathol. 2006 May;125(5):710-21.

38. Bravo AA, Sheth SG, Chopra S. Liver biopsy. N Engl J Med. 2001 Feb 15;344(7):495-500.

39. Dixon JB, Bhathal PS, O'Brien PE. Weight loss and non-alcoholic fatty liver disease: falls in gammaglutamyl transferase concentrations are associated with histologic improvement. Obes Surg. 2006 Oct;16(10):1278-86.

40. Feldstein AE, Canbay A, Angulo P, Taniai M, Burgart LJ, Lindor KD, Gores GJ. Hepatocyte apoptosis and fas expression are prominent features of human nonalcoholic steatohepatitis. Gastroenterology. 2003 Aug;125(2):437-43. 


\section{Chapter 6}

\section{Human intestinal microbiota}

composition is associated with local and systemic inflammation in obesity

Froukje J Verdam, Susana Fuentes, Charlotte de Jonge, Erwin G Zoetendal, Runi Erbil, Jan Willem M Greve, Wim A Buurman, Willem M de Vos, and Sander S Rensen 


\section{ABSTRACT}

\section{Background}

Intestinal microbiota have been suggested to contribute to the development of obesity, but the mechanism remains elusive. We investigated the relationship between microbiota composition, intestinal permeability, and inflammation in non-obese and obese subjects.

\section{Methods}

Fecal microbiota composition of 28 subjects (body mass index 18.6 to $60.3 \mathrm{~kg} / \mathrm{m}^{2}$ ) was analyzed by a phylogenetic profiling microarray. Fecal calprotectin and plasma C-reactive protein (CRP) levels were determined to evaluate intestinal and systemic inflammation. Furthermore, $\mathrm{HbA}_{1 c}$, and plasma levels of transaminases and lipids were analyzed. Gastroduodenal, small intestinal, and colonic permeability were assessed by a multisaccharide test.

\section{Results}

Based on microbiota composition, the study population segregated into two clusters with predominantly obese (15/19) or exclusively non-obese (9/9) subjects. Whereas intestinal permeability did not differ between clusters, the obese cluster showed reduced bacterial diversity, a decreased Bacteroidetes/Firmicutes ratio, and an increased abundance of potential pro-inflammatory Proteobacteria. Interestingly, fecal calprotectin was only detectable in subjects within the obese microbiota cluster $(n=8 / 19, p=0.02)$. Plasma CRP was also increased in these subjects $(p=0.0005)$, and correlated with the Bacteroidetes/Firmicutes ratio $\left(r_{s}=-0.41, p=0.03\right)$.

\section{Conclusions}

Intestinal microbiota alterations in obese subjects are associated with local and systemic inflammation, suggesting that the obesity-related microbiota composition has a proinflammatory effect. 


\section{INTRODUCTION}

The intestinal microbiota are increasingly acknowledged to be involved in the development of obesity and the metabolic syndrome. ${ }^{1}$ For instance, germ-free mice are protected from diet-induced obesity, ${ }^{2}$ while intestinal microbiota transplantation from obese mice into lean germ-free mice results in a larger fat deposition than transplantation from lean donor mice. ${ }^{3}$ Furthermore, both genetically-modified ${ }^{4}$ and diet-induced ${ }^{5}$ obese animals display a different intestinal microbiota composition compared to lean controls. This 'obese microbiota composition' is characterized by a reduction in the abundance of Bacteroidetes paralleled by an increase in Firmicutes. ${ }^{4,5}$

Human data on gut microbiota composition in relation to obesity are however more scarce and less consistent. Increased Firmicutes and decreased Bacteroidetes have been reported ${ }^{3,6,7}$ but a lower ratio of Firmicutes to Bacteroidetes in obesity ${ }^{8}$ and similar microbiota composition in lean and obese subjects ${ }^{9}$ have also been described. The mechanisms by which the intestinal microbiota affect obesity and metabolic disorders are the focus of intense research. The intestinal microbiota have been shown to influence intestinal permeability in obese mice, thereby promoting translocation of bacterial products and stimulating the low-grade inflammation characteristic of obesity and insulin resistance. ${ }^{10,11}$ Furthermore, microbiota composition alterations in obesity-prone rats have been found to coincide with intestinal inflammation. ${ }^{12}$ Finally, several studies suggest that the intestinal microbiota influence energy extraction from nutrition and subsequent fat storage in adipose tissue. ${ }^{2,3,13}$

In view of these data, we investigated the intestinal microbiota composition in obese and non-obese subjects by means of a phylogenetic profiling DNA microarray, and correlated these data to parameters of intestinal permeability and local and systemic inflammation. We here present the first evidence that the gut microbiota in human obesity are related to both intestinal and systemic inflammation in man.

\section{METHODS}

\section{Subjects}

From May to September 2010, 28 adults (age 19 - 54 years, body mass index (BMI) 18.6 $60.3 \mathrm{~kg} / \mathrm{m}^{2}$ ) were recruited through advertising at the Atrium Medical Center Parkstad in Heerlen, the Netherlands. Thirteen subjects were non-obese, of whom 9 subjects were lean (BMI $18.6-24.6 \mathrm{~kg} / \mathrm{m}^{2}$ ) and four subjects were overweight (BMI $25.2-29.6 \mathrm{~kg} / \mathrm{m}^{2}$ ). Fifteen subjects were obese (BMI $\left.30.5-60.3 \mathrm{~kg} / \mathrm{m}^{2}\right)$, of whom nine subjects had a BMI of 
over $40 \mathrm{~kg} / \mathrm{m}^{2}$ (range $40.4-60.3 \mathrm{~kg} / \mathrm{m}^{2}$ ); population characteristics are presented in Table 1. Subjects were excluded if they received antibiotic treatment in the last six months, used anti-inflammatory drugs, or reported alcohol consumption $>8$ units $(80 \mathrm{~mL}$ of ethanol)/week. Other exclusion criteria were acute and chronic inflammatory diseases (e.g. Crohn's disease, colitis, viral hepatitis, type 1 diabetes, auto-immune diseases, asthma, and chronic obstructive pulmonary disease). The study was approved on the $21^{\text {st }}$ of December 2009 by the Medical Ethics Committee of the Atrium Medical Center and conducted according to the revised version of the Declaration of Helsinki (October 2008, Seoul). Informed consent in writing was obtained from each subject individually.

Table 1. Characteristics of the study population.

\begin{tabular}{|c|c|c|c|c|c|c|}
\hline & $\begin{array}{l}\text { non-obese } \\
\text { subjects }\end{array}$ & $\begin{array}{l}\text { obese } \\
\text { subjects }\end{array}$ & p-value & $\begin{array}{l}\text { non-obese } \\
\text { microbiota } \\
\text { cluster * }\end{array}$ & $\begin{array}{l}\text { obese } \\
\text { microbiota } \\
\text { cluster * }\end{array}$ & p-value \\
\hline No. of patients & 13 & 15 & & 9 & 19 & \\
\hline Age (years) & $28.2 \pm 3.3$ & $35.3 \pm 2.8$ & $<0.04$ & $23.3 \pm 3.3$ & $36.2 \pm 2.4$ & $<0.0008$ \\
\hline $\operatorname{Sex}(F: M)$ & $8: 5$ & $12: 3$ & & $6: 3$ & $14: 5$ & \\
\hline BMI $\left(\mathrm{kg} / \mathrm{m}^{2}\right)$ & $23.4 \pm 0.8$ & $44.2 \pm 2.3$ & $<0.01$ & $22.2 \pm 0.7$ & $40.4 \pm 2.5$ & $<0.0001$ \\
\hline $\mathrm{HbA}_{1 \mathrm{c}}(\%)$ & $5.4 \pm 0.1$ & $6.1 \pm 0.3$ & $<0.02$ & $5.4 \pm 0.1$ & $6.0 \pm 0.3$ & 0.07 \\
\hline Cholesterol (mmol/L) & $4.8 \pm 0.4$ & $4.6 \pm 0.2$ & ns & $5.1 \pm 0.5$ & $4.5 \pm 0.2$ & ns \\
\hline $\mathrm{HDL}(\mathrm{mmol} / \mathrm{L})$ & $1.5 \pm 0.1$ & $1.1 \pm 0.1$ & $<0.02$ & $1.5 \pm 0.2$ & $1.1 \pm 0.1$ & 0.05 \\
\hline LDL (mmol/L) & $2.8 \pm 0.3$ & $2.7 \pm 0.3$ & ns & $3.0 \pm 0.4$ & $2.6 \pm 0.2$ & ns \\
\hline TG (mmol/L) & $1.4 \pm 0.3$ & $1.8 \pm 0.3$ & ns & $1.1 \pm 0.3$ & $1.8 \pm 0.3$ & 0.07 \\
\hline AST (U/L) & $17 \pm 2$ & $19 \pm 2$ & ns & $18 \pm 3$ & $18 \pm 2$ & ns \\
\hline $\operatorname{ALT}(U / L)$ & $21 \pm 2$ & $29 \pm 3$ & ns & $21 \pm 3$ & $28 \pm 3$ & ns \\
\hline CRP (mg/L) & $1.5 \pm 0.2$ & $12.4 \pm 2.5$ & $<0.01$ & $1.5 \pm 0.3$ & $10.4 \pm 2.2$ & $<0.0005$ \\
\hline
\end{tabular}

* Microbiota clusters were determined by means of phylogenetic profiling (HITChip analysis).

\section{Blood sampling and analysis}

Venous blood samples were obtained in the outpatient clinic, collected into pre-chilled EDTA tubes (BD Vacutainer, BD diagnostics, Erembodegem-Aalst, Belgium), and kept on ice. Parameters reflecting inflammation (high sensitivity $\mathrm{C}$-reactive protein (CRP) and obesity co-morbidity $\left(\mathrm{HbA}_{1 c}\right.$, plasma glucose, insulin, cholesterol, high-density lipoprotein (HDL), low-density lipoprotein (LDL), free fatty acids (FFA), triglycerides (TG), liver transaminases (AST and ALT)) were assessed at the Department of Clinical Chemistry according to the protocol of the Atrium Medical Center Parkstad (Table 1). 


\section{Fecal microbiota and fecal calprotectin analysis}

Subjects collected feces 24 hours prior to the intestinal permeability test, and kept this refrigerated until the morning of the test, when samples were stored in polystyrene tubes (Greiner Bio-One, Alphen aan de Rijn, the Netherlands) at $-20^{\circ} \mathrm{C}$. DNA was isolated as previously described ${ }^{14}$ and intestinal microbiota composition was assessed using the Human Intestinal Tract Chip (HITChip), a phylogenetic profiling DNA microarray containing over 4,800 probes based on 16S rRNA gene sequences of over 1,100 intestinal bacterial phylotypes. This microarray identifies both variation and relative quantity of the human intestinal tract communities. ${ }^{15}$ Hybridizations were performed in duplicate with samples labeled with Cy3 and Cy5 dyes, respectively. Slides were scanned and the data were extracted from the microarray images using the Agilent Feature Extraction software, version 10.7.3.1 (http://www.agilent.com). Array normalization was performed as previously described ${ }^{15}$ using a set of R-based scripts (http://r-project.org) in combination with a custom designed relational database which runs under the MySQL database management system (http://www.mysql.com). This was implemented on both dyes for each sample, and duplicate hybridizations with a Pearson correlation over 0.98 were considered for further analysis. Ward's minimum variance method was used for the construction of hierarchical clusters of the total microbiota probe profiles, while the distance matrix between the samples was based on Euclidian distance. The bacterial diversity of the fecal samples was assessed by Simpson's reciprocal index of diversity using the HITChip probe levels. Furthermore, fecal calprotectin levels reflecting intestinal inflammation were measured by enzyme-linked immunosorbent assay (Hycult Biotech, Uden, the Netherlands) according to Van der Sluis Veer et al. to improve sensitivity, ${ }^{16}$ resulting in a detection limit of $20 \mu \mathrm{g} / \mathrm{g}$ feces.

\section{Assessment of intestinal permeability}

Intestinal permeability was assessed as previously described. ${ }^{17}$ In short, after at least eight hours of fasting, a multi saccharide mix was orally administered after a double challenge with a non-steroid anti-inflammatory drug $(400 \mathrm{mg}$ ibuprofen the evening prior to the test and $400 \mathrm{mg}$ the following morning) to magnify potential differences in intestinal permeability. The saccharide mix consisted of $1 \mathrm{~g}$ sucrose (Van Gilse, Dinteloord, the Netherlands), $1 \mathrm{~g}$ lactulose (Centrafarm, Etten-Leur, the Netherlands), $0.5 \mathrm{~g}$ L-rhamnose (Danisco, Copenhagen, Denmark), 1 g sucralose (Brenntag, Sittard, the Netherlands), and 1 g erythritol (Danisco), dissolved in $150 \mathrm{~mL}$ tap water. Urinary excretion of sucrose after one hour reflects gastroduodenal permeability, the ratio of lactulose/L-rhamnose (L/R) after five hours reflects small intestinal permeability, and large intestinal permeability is reflected by the ratio of sucralose/erythritol (S/E) after five hours. One and five hours after oral administration of the saccharide mix, total urine collection was recorded and 
sampled. Urine samples were centrifuged at $4{ }^{\circ} \mathrm{C}$ for 15 minutes at $2300 \mathrm{~g}$, and immediately stored in aliquots at $-80{ }^{\circ} \mathrm{C}$ until analysis. Urinary excretion of mono- and disaccharides was quantified by high pressure liquid chromatography and mass spectrometry (Model LTQ-XL, Thermo Electron, Breda, the Netherlands).

\section{Statistical analysis}

Multivariate statistical software Canoco 4.5 for Windows ${ }^{18}$ (Biometrix, Plant Research International, Wageningen) was used to perform redundancy analysis (RDA) on log transformed data, and statistical significance was evaluated using a Monte Carlo Permutation Procedure. The log transformed sum of the hybridization signals for the 131 genus-like phylogenetic groups targeted by the HITChip was used as species variables. Comparisons between groups at the genus level (subsets of phylotypes with $90 \%$ or more $16 \mathrm{~S}$ rRNA sequence similarity) were performed using the Wilcoxon signed-rank test corrected for multiple comparisons (q-value); $q<0.05$ was considered statistically significant. Additional statistical analyses were performed using Prism 5.0 for Windows (GraphPad Software Inc., San Diego, CA). Correlations were calculated using Spearman's rank correlation coefficient, while differences between groups were analyzed by the nonparametric Mann-Whitney test or the Chi-square test. A p-value $<0.05$ was considered statistically significant and denoted with an asterisk in the figures. Data are presented as mean \pm standard error of the mean.

\section{RESULTS}

\section{Obese and non-obese subjects segregate in distinct microbiota clusters with different bacterial diversity}

The microbial profiles obtained from the fecal samples of all 28 subjects ( 13 non-obese subjects with a BMI $<30 \mathrm{~kg} / \mathrm{m}^{2}$ and 15 obese subjects, $\mathrm{BMI}>30 \mathrm{~kg} / \mathrm{m}^{2}$ ) were hierarchically clustered based on the signal intensity of the HITChip oligonucleotide probes. Remarkably, all obese subjects clustered separately from the non-obese subjects. Four out of the 13 non-obese subjects (two normal weight and two overweight subjects) clustered with the 'obese microbiota composition' (Fig. 1A). The microbiota cluster was characterized by a significantly lower bacterial diversity than the non-obese cluster (128.7 \pm 33.2 vs. $174.6 \pm$ 37.3, $p=0.002$, Fig. 1B), a difference which was not observed when subjects were divided based upon BMI.

Further detailed analyses of both clusters revealed significant differences in microbiota groups between the obese and non-obese clusters. The main differences were observed 
within the Firmicutes and the Bacteroidetes phyla (Table 2), leading to a decreased Bacteroidetes/Firmicutes ratio in the obese microbiota cluster (Fig. 1C). More specifically, Clostridium cluster IV and XIVa of the Firmicutes phylum were more abundantly present in the obese microbiota cluster, with specific groups showing 1.8 to 2.6-fold increases. In addition, the uncultured Clostridiales I group belonging to the Firmicutes phylum was more than sixfold decreased in the obese cluster. On the other hand, Bacteroidetes were less abundantly present in the obese microbiota cluster. In particular, Allistipes et rel. and Bacteroides intestinalis et rel. showed over 3.5 fold reductions (Table 2). The relatively lower abundance of Bacteroidetes as opposed to Firmicutes in the obese cluster was confirmed by redundancy analysis (Fig. 1D). Overall, bacteria associated to butyrate production accounted for $21.4 \pm 7.4 \%$ of the total hybridization signal of the samples. The relative abundance of the butyrate producers was similar in the non-obese and the obese microbiota cluster ( $19.8 \pm 7.8 \%$ vs. $22.1 \pm 7.3 \%$, respectively, $p=0.45)$.

\section{The Bacteroidetes/Firmicutes ratio is strongly and negatively associated with BMI}

Division of subjects into non-obese and obese categories according to BMI revealed similar and consistent microbiota composition differences (Table 2). The Bacteroidetes phylum was threefold less abundant in obese subjects $(5.9 \pm 5.8 \%$ of the total hybridization signal) compared to non-obese subjects (19.2 $\pm 9.2 \%$; $<<0.002$, Fig. $2 \mathrm{~A}$ ). In contrast, Firmicutes were more numerous in obese subjects, contributing $85.8 \pm 8.5 \%$ of the total hybridization signal, whereas they accounted for $74.6 \pm 9.2 \%$ of the signal in non-obese subjects ( $q=0.002$, Fig. $2 A$ ). As a result of these shifts in Bacteroidetes and Firmicutes abundance, the ratio of Bacteroidetes to Firmicutes was also strongly decreased in obese subjects (BMI $>30 \mathrm{~kg} / \mathrm{m}^{2}, \mathrm{p}=0.0002$, Fig. $2 \mathrm{~B}$ ). In corroboration of these findings, a strong negative correlation was observed between Bacteroidetes/Firmicutes ratio and $\mathrm{BMI}\left(\mathrm{r}_{\mathrm{s}}=-0.59, \mathrm{p}=0.0009\right.$, Fig. $\left.2 \mathrm{C}\right)$.

Moreover, a positive relationship between BMI and Roseburia intestinalis bacteria -that are associated with butyrate producers- was found within the Firmicutes phylum (Table 3). In line with the microbiota cluster differentiation, the total signal corresponding to butyrate producers was similar in non-obese and obese subjects. Strikingly, several members of the Proteobacteria including those related to E.aerogenes, K.pneumoniea, Vibrio and Yersina spp. were positively associated with BMI and more abundantly present in obese subjects (Table 3). Some of these have recently described to be increased in mice on a high fat diet. ${ }^{19}$ In contrast, a strong negative correlation was observed between BMI and many level 2 groups belonging to the Bacteroidetes. Allistipes et rel. was most significantly decreased in obese subjects, by more than six-fold (Table 3 ). 
A

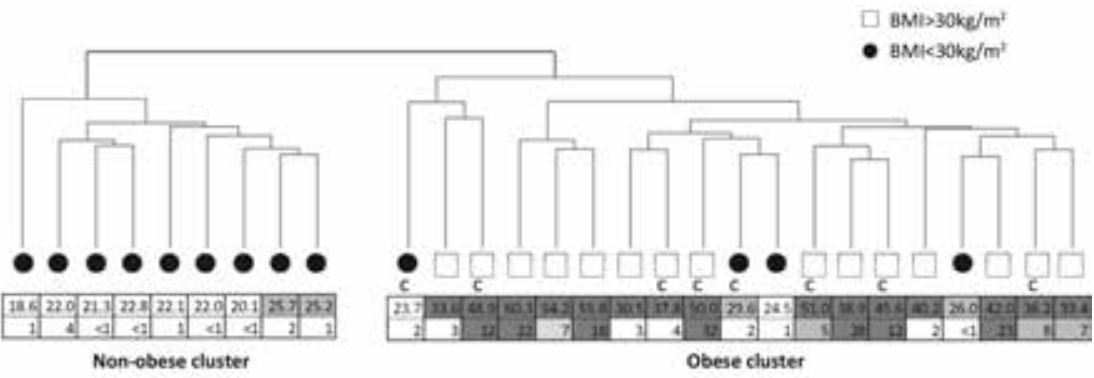

B

c
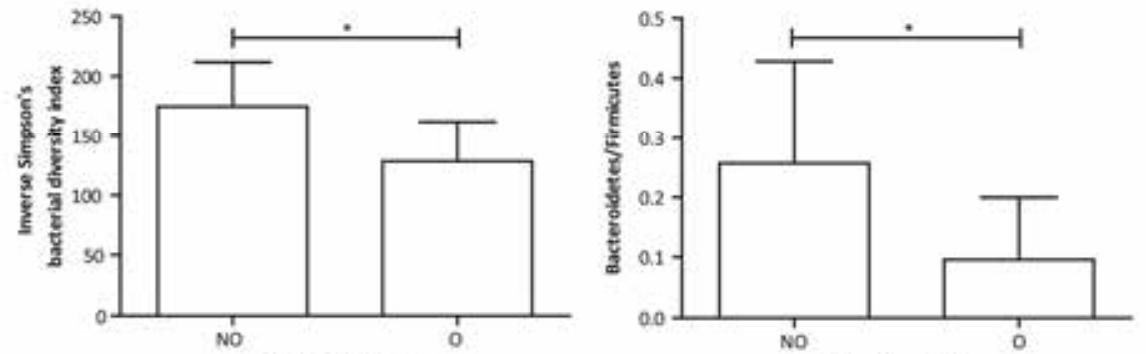

D Microbiota cluster

Microbiota duster

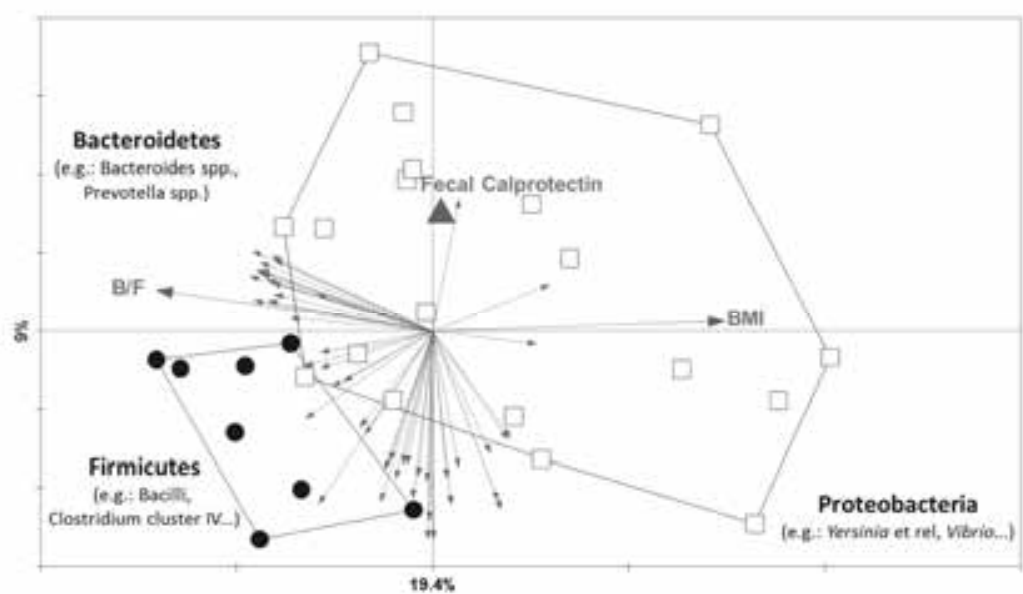

Figure 1. Obese and non-obese subjects segregate in distinct microbiota clusters. A) Hierarchical clustering of the fecal samples of obese $(\square)$ and non-obese (•) subjects. Subjects with detectable fecal calprotectin (Calp) are denoted by a ' $c$ '. Corresponding BMI and CRP values are shown below in white for normal $B M I<25 \mathrm{~kg} / \mathrm{m}^{2} ; C R P<5 \mathrm{mg} /$ ), light grey for $B M I 25-30 \mathrm{~kg} / \mathrm{m}^{2} ; 5>C R P<10 \mathrm{mg} / \mathrm{L}$, and dark grey for $B M I>30 \mathrm{~kg} / \mathrm{m}^{2} ; C R P>10 \mathrm{mg} / \mathrm{L}$. B) Simposon's inverse bacterial diversity index was significantly reduced in the obese microbiota cluster $(p=0.003)$. C) Significantly decreased Bacteroidetes/Firmicutes ratio in the obese microbiota cluster ( $p=0.007)$. D) RDA plot of subjects in the obese ( $\square$ ) and non-obese (-) microbiota cluster based on their microbiota composition. First and second ordination axes are plotted, explaining $19.4 \%$ and $9 \%$ of the variability in the dataset, respectively. The variation in the abundance of 48 level 2 groups (light arrows) belonging to the phyla Bacteroidetes, Firmicutes, Proteobacteria, and Actinobacteria is explained to at least $20 \%$ by subject characteristics. Environmental variables shown in the plot (dark arrows) are statistically significant (BMI $p=0.002$, fecal calprotectin $p=0.02$, and Bacteroidetes/Firmicutes ratio $p=0.01$ ). 
Table 2. Relative abundance of bacterial groups that significantly differ between the non-obese vs. the obese microbiota cluster and between non-obese vs. obese subjects.

Non-obese vs. obese cluster

Relative contribution (\%)

\begin{tabular}{llll}
\hline Bacteroidetes & & Non-obese & Obese \\
& Allistipes et rel & & \\
& Bacteroides fragilis et rel & $3.02 \pm 1.73$ & $0.81 \pm 0.80$ \\
& Bacteroides intestinalis et rel & $0.94 \pm 0.53$ & $0.33 \pm 0.32$ \\
& Bacteroides splachnicus et rel & $0.87 \pm 0.48$ & $0.25 \pm 0.25$ \\
Firmicutes & & $1.62 \pm 1.30$ & $0.51 \pm 0.54$ \\
Clostridium cluster IV & Oscillospira guillermondii et rel & $5.56 \pm 3.44$ & $2.18 \pm 2.61$ \\
Clostridium cluster XIVa & Clostridium colinum et rel & $0.37 \pm 0.23$ & $0.79 \pm 0.34$ \\
& Clostridium symbiosum et rel & $2.03 \pm 0.84$ & $3.75 \pm 1.72$ \\
Uncultured Clostridiales & Eubacterium hallii et rel & $0.44 \pm 0.18$ & $0.93 \pm 0.44$ \\
\hline Non-obese vs. obese subjects & & $2.00 \pm 3.69$ & $0.32 \pm 0.85$ \\
\hline & & Relative contribution (\%)
\end{tabular}

\section{Bacteroidetes}

$\begin{array}{lll}\text { Allistipes et rel } & 2.72 & 0.48 \\ \text { Bacteroides fragilis et rel } & 0.84 & 0.25 \\ \text { Bacteroides intestinalis et rel } & 0.72 & 0.21 \\ \text { Bacteroides ovatus et rel } & 1.20 & 0.52 \\ \text { Bacteroides plebeius et rel } & 1.66 & 0.42 \\ \text { Bacteroides splachnicus et rel } & 1.52 & 0.30 \\ \text { Bacteroides stercoris et rel } & 1.08 & 0.39 \\ \text { Bacteroides uniformis et rel } & 0.91 & 0.26 \\ \text { Parabacteroides distasonis et rel } & 2.11 & 0.60 \\ \text { Prevotella oralis et rel } & 0.57 & 0.13 \\ \text { Prevotella ruminicola et rel } & 0.50 & 0.16 \\ \text { Prevotella tannerae et rel } & 1.24 & 0.53 \\ \text { Tannerella et rel } & 0.83 & 0.33 \\ \text { Uncultured Bacteroidetes } & 0.19 & 0.01\end{array}$

Firmicutes

Clostridium cluster IV

Clostridium cluster XIVa

$\begin{array}{lll}\text { Papillibacter cinnamivorans et rel } & 0.30 & 0.77 \\ \text { Clostridium symbiosum et rel } & 2.54 & 3.76 \\ \text { Dorea formicigenerans et rel } & 4.11 & 6.27\end{array}$

Level 2 phylogenetic groups with higher relative abundance in the obese subjects are indicated in grey. For all groups, $\mathrm{q}<0.05$. 
A

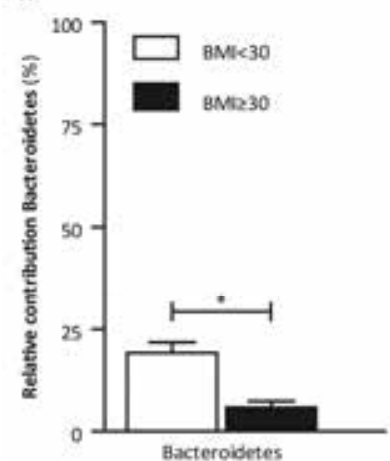

8

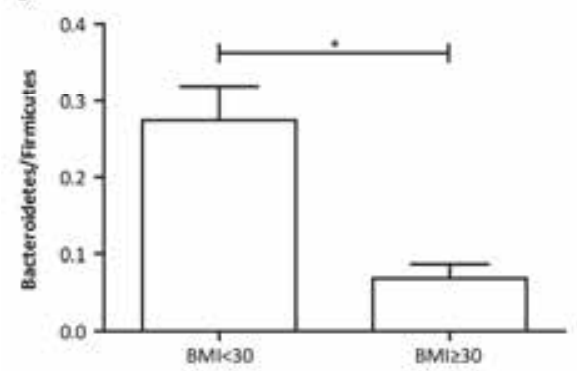

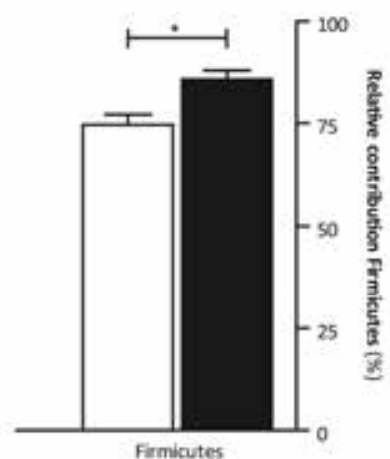

c

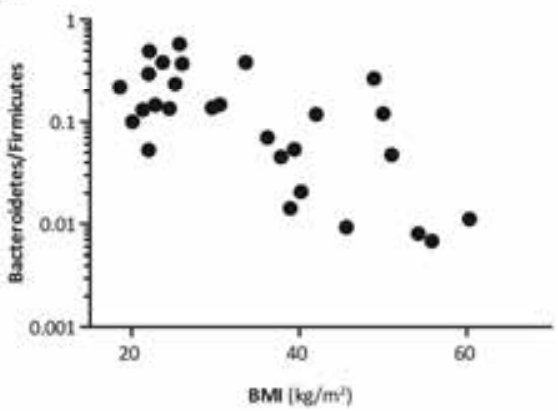

Figure 2. Strong relation between Bacteroidetes/Firmicutes and BMI. A) Relative contribution of Bacteroidetes and Firmicutes in the samples of obese and non-obese subjects. Both phyla differed significantly between obese and non-obese populations. B) The Bacteroidetes/Firmicutes ratio in obese subjects was strongly decreased (p=0.0002). C) A strong correlation between the Bacteroidetes/Firmicutes ratio and BMI was observed $\left(r_{s}=-0.59, p=0.0009\right)$.

A

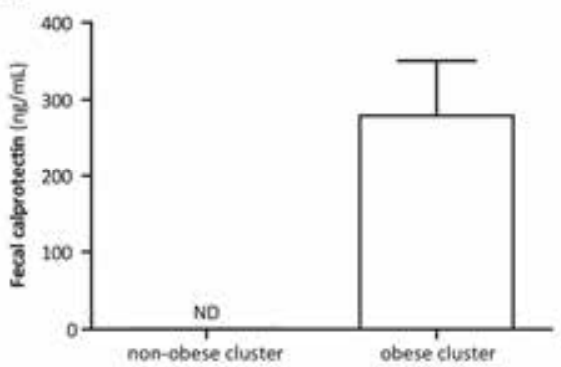

B

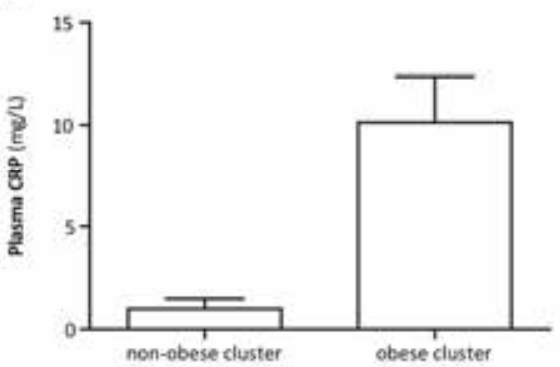

Figure 3. The obese microbiota cluster is associated with inflammation. A) None of the subjects within the non-obese microbiota cluster had detectable fecal calprotectin levels, whereas 8 out of 19 subjects (42\%) within the obese microbiota cluster showed calprotectin in their feces $(p=0.02)$. Of these subjects, two were overweight and six were obese. ND: not detectable. B) Plasma CRP levels were significantly higher in subjects within the obese microbiota cluster as opposed to subjects within the non-obese microbiota cluster $(p<0.01)$. 
Table 3. Relative abundance of bacterial groups that correlate significantly with BMI, CRP, and/or fecal calprotectin (Calp) levels in non-obese (NO) and obese (O) subjects.

\begin{tabular}{|c|c|c|c|c|c|c|}
\hline \multirow{2}{*}{ Level 1} & \multirow{2}{*}{ Level 2} & \multicolumn{3}{|c|}{ Correlation Coefficient } & \multicolumn{2}{|c|}{ Relative abundance } \\
\hline & & BMI & CRP & Calp & NO (\%) & $\mathrm{O}(\%)$ \\
\hline \multicolumn{7}{|l|}{ Bacteroidetes } \\
\hline & Allistipes et rel & $-0.642 * *$ & $-0.470 *$ & & 2.733 & 0.446 \\
\hline & Bacteroides fragilis et rel & $-0.552 * *$ & & & 0.832 & 0.239 \\
\hline & Bacteroides intestinalis et rel & $-0.539 * *$ & $-0.433^{*}$ & & 0.730 & 0.210 \\
\hline & Bacteroides plebeius et rel & $-0.508^{* *}$ & $-0.413^{*}$ & & 1.680 & 0.413 \\
\hline & Bacteroides splanchnicus et rel & $-0.539 * *$ & $-0.429 *$ & & 1.525 & 0.275 \\
\hline & Bacteroides uniformis et rel & $-0.483 * *$ & & & 0.921 & 0.264 \\
\hline & Bacteroides vulgatus et rel & $-0.499 * *$ & $-0.449 *$ & & 1.663 & 0.599 \\
\hline & ParaBacteroides distasonis et rel & $-0.505^{* *}$ & $-0.443^{*}$ & & 2.130 & 0.583 \\
\hline & Prevotella oralis et rel & $-0.389 *$ & & & 0.576 & 0.121 \\
\hline & Prevotella ruminicola et rel & $-0.404^{*}$ & & & 0.506 & 0.158 \\
\hline & Tannerella et rel & $-0.511 * *$ & $-0.440^{*}$ & & 0.815 & 0.308 \\
\hline \multicolumn{7}{|l|}{ Firmicutes } \\
\hline \multirow[t]{2}{*}{ Bacilli } & Aneurinibacillus & $0.375^{*}$ & $0.458^{*}$ & & 0.004 & 0.010 \\
\hline & Lactococcus & & & $0.395^{*}$ & 0.002 & 0.002 \\
\hline \multirow[t]{3}{*}{ C. cluster IV } & Faecalibacterium prausnitzii et rel & $-0.374^{*}$ & & & 9.324 & 6.245 \\
\hline & Papillibacter cinnamivorans et rel & $0.522^{* *}$ & $0.579 * *$ & & 0.295 & 0.775 \\
\hline & Subdoligranulum variable et rel & & $0.402 *$ & & 3.669 & 5.377 \\
\hline \multirow[t]{7}{*}{ C. cluster XIVa } & Clostridium colinum et rel & $0.409 *$ & & & 0.506 & 0.780 \\
\hline & Clostridium nexile et rel & & & $0.437^{*}$ & 2.094 & 3.114 \\
\hline & Clostridium sphenoides et rel & & $0.374 *$ & & 2.898 & 3.819 \\
\hline & Dorea formicigenerans et rel & $0.487^{* *}$ & & & 4.154 & 6.357 \\
\hline & Eubacterium rectale et rel \# & & & $0.378^{*}$ & 3.556 & 5.175 \\
\hline & Roseburia intestinalis et rel \# & $0.448 *$ & $0.479 * *$ & & 2.366 & 4.652 \\
\hline & Ruminococcus gnavus et rel & $0.396^{*}$ & & & 1.772 & 2.792 \\
\hline C. cluster XV & Eubacterium limosum et rel & $0.395^{*}$ & & & 0.001 & 0.003 \\
\hline C. cluster XVIII & Coprobacillus catenaformis et rel & $-0.424^{*}$ & & & 0.059 & 0.026 \\
\hline \multicolumn{7}{|l|}{ Proteobacteria } \\
\hline & Alcaligenes faecalis et rel & $-0.416^{*}$ & & & 0.002 & 0.000 \\
\hline & Enterobacter aerogenes et rel & $0.585^{* *}$ & & & 0.006 & 0.018 \\
\hline & Klebsiella pneumoniae et rel & $0.530 * *$ & & & 0.004 & 0.008 \\
\hline & Vibrio & $0.498 * *$ & & & 0.001 & 0.003 \\
\hline & Yersinia et rel & $0.562 * *$ & & & 0.001 & 0.002 \\
\hline \multicolumn{7}{|l|}{ Actinobacteria } \\
\hline & Bifidobacterium & $0.386 *$ & & & 4.627 & 6.621 \\
\hline
\end{tabular}


* Correlation is significant at the 0.05 level (2-tailed). ** Correlation is significant at the 0.01 level (2-tailed). Grey shading indicates groups negatively correlated to the different variables. \# a Known butyrate producing bacteria.

A

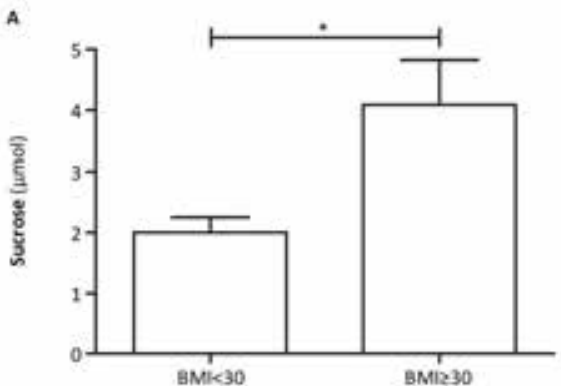

c

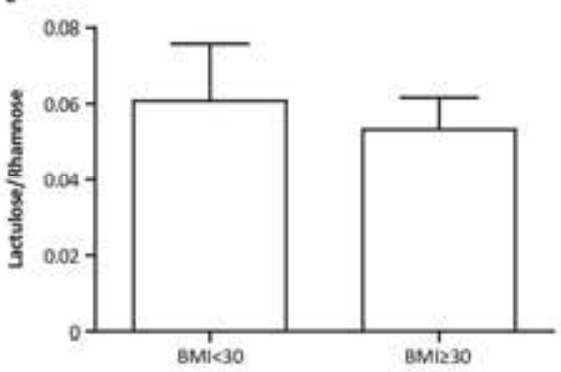

E

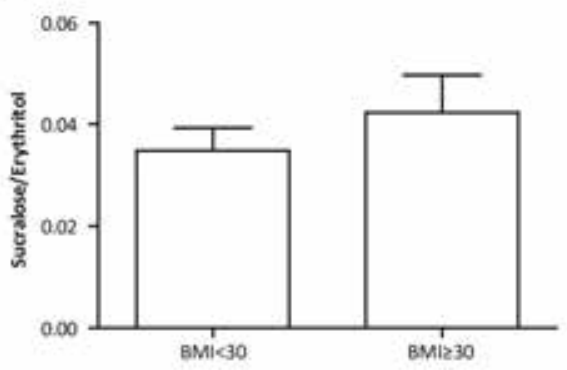

B

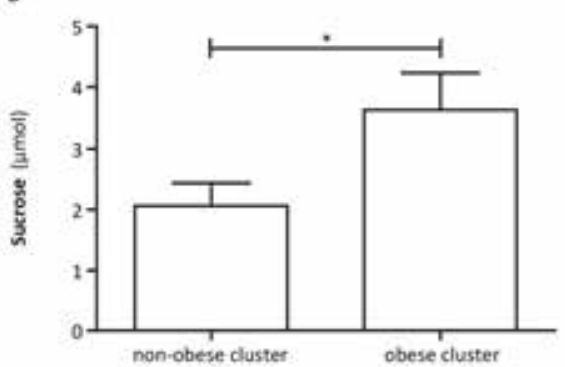

D

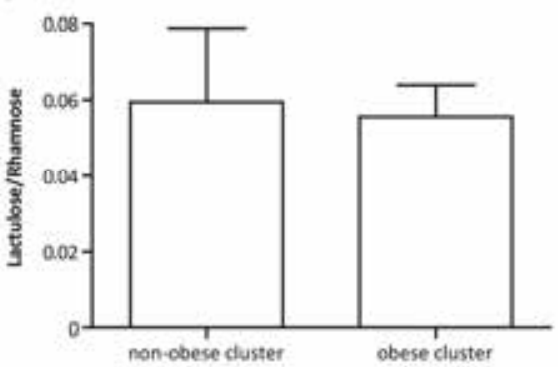

,

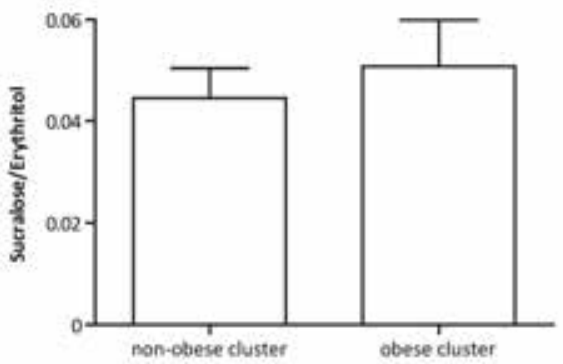

Figure 4. Permeability of the gastro-intestinal tract in non-obese vs. obese subjects and in obese vs. non-obese microbiota clusters. A) Significantly higher gastroduodenal permeability in obese subjects and in subjects within the obese microbiota cluster, as reflected by elevated urinary sucrose levels after one hour ( $p=0.003$ in obese compared to non-obese subjects and $p=0.03$ for the obese microbiota cluster respectively). B) A similar lactulose/rhamnose ratio was observed in both obese and non-obese subjects ( $p=0.9)$ and obese and non-obese microbiota clusters $(p=0.7)$, indicating comparable small intestinal permeability. $C$ ) The sucralose/erythritol ratio reflecting large intestinal permeability was not significantly different between either non-obese and obese subjects $(p=0.65)$, or between the nonobese and obese microbiota cluster ( $p=0.74)$. 


\section{The obese microbiota cluster is associated with intestinal and systemic inflammation}

Since obesity-prone rats show intestinal inflammation in conjunction with microbiota shifts, $^{12}$ we next investigated whether the obesity-associated intestinal microbiota composition changes were related to intestinal inflammation. Strikingly, the intestinal inflammation marker fecal calprotectin was only detectable in subjects within the obese microbiota cluster $(n=8 / 19,42 \%$ of subjects, vs. $n=0 / 9$ in the non-obese microbiota cluster, p=0.02; Fig. 1A, Fig. 3A). Of these subjects, 2 were overweight and 6 were obese. The mean fecal calprotectin level was $279 \pm 70 \mathrm{ng} / \mathrm{mL}$, ranging from 80 to $570 \mathrm{ng} / \mathrm{mL}$. Remarkably, high sensitivity CRP plasma levels reflecting systemic inflammation correlated with the Bacteroidetes/Firmicutes ratio $\left(r_{s}=-0.41, p=0.03\right)$, implying a relationship between systemic inflammation and microbiota composition. In line with this, plasma CRP levels were also significantly higher in subjects within the obese microbiota cluster $(10 \pm 2.2$ vs. $1.5 \pm 0.31 ; p<0.0005$, Fig. 3B). Moreover, both fecal calprotectin and systemic CRP levels were also related to specific groups of bacteria that were more abundant in obese subjects (Table 3 ). The strongest correlations were observed between fecal calprotectin and the abundance of Clostridium nexile et rel, and between CRP and the abundance of Aneurinibacillus, Papillibacter cinnamivorans et rel, and Roseburia intestinalis et rel. Conversely, plasma CRP levels showed negative correlations with 7 groups belonging to the Bacteroidetes, which were all more abundant in the non-obese subjects (Table 3 ).

\section{Microbiota composition and BMI are not related to intestinal permeability}

Gut microbiota have been suggested to induce low-grade inflammation in obese rodents by increasing intestinal permeability. ${ }^{11,20}$ Therefore, we next studied permeability of different segments of the gastro-intestinal tract in relation to BMI and microbiota composition. Gastroduodenal permeability was twice as high in the obese compared to the non-obese microbiota cluster $(3.6 \pm 0.6 \mu \mathrm{mol}$ vs. $2.1 \pm 0.4 \mu \mathrm{mol}, \mathrm{p}=0.03$, Fig. $4 \mathrm{~A})$. Obese and non-obese subjects displayed a similar difference $(4.1 \pm 0.7 \mu \mathrm{mol}$ vs. $1.9 \pm 0.3$ $\mu \mathrm{mol}, \mathrm{p}=0.003$, Fig. $4 \mathrm{~A}$ ). However, gastroduodenal permeability was not related to the Bacteroidetes/Firmicutes ratio, BMI, CRP, or fecal calprotectin $\left(r_{s}=-0.28, p=0.16 ; r_{s}=0.25\right.$, $p=0.21, r_{s}=0.08, p=0.70, r_{s}=-0.02, p=0.96$, respectively). Small intestinal permeability was also not related to the Bacteroidetes/Firmicutes ratio $\left(r_{s}=-0.01, p=0.94\right)$ or to $B M I\left(r_{s}=0.06\right.$, $p=0.76)$, and similar in both microbiota clusters ( $0.06 \pm 0.02$ vs. $0.06 \pm 0.01 ; p=0.7)$ and in non-obese and obese subjects ( $0.06 \pm 0.02$ vs. $0.05 \pm 0.01 ; p=0.9$, Fig. $4 B$ ). We also did not observe significant associations between small intestinal permeability and either CRP or calprotectin $\left(r_{s}=-0.03, p=0.89, \quad r_{s}=-0.44, p=0.23\right.$, respectively). Similarly, colonic permeability was not related to the Bacteroidetes/Firmicutes ratio or to BMI $\left(r_{s}=-0.19\right.$, $p=0.34 ; r_{s}=-0.14, p=0.50$, respectively), and comparable in both the obese and non-obese groups based upon either microbiota cluster or BMI ( $0.04 \pm 0.01$ vs. $0.05 \pm 0.01 ; p=0.74$; 
$0.03 \pm 0.01$ vs. $0.04 \pm 0.01 ; p=0.65$, Fig. 4 C). Colonic permeability was not associated with plasma CRP or fecal calprotectin levels $\left(r_{s}=0.04, p=0.83, r_{s}=-0.30, p=0.43\right.$, respectively).In short, intestinal permeability was neither related to the observed differences in microbiota composition nor to BMI or inflammatory markers.

In order to investigate the determining and potential confounding factors in the relation between microbiota composition and inflammation, multivariate analyses were performed, taking into account $\mathrm{BMI}$, age, $\mathrm{CRP}, \mathrm{HbA}_{1 \mathrm{c}}$, fecal calprotectin, intestinal permeability, and the Bacteroidetes/Firmicutes ratio. A total of $34.5 \%$ of the variation in the microbiota composition was related to these characteristics (Fig. 1D). Supporting our data on the specific inflammation-associated microbiota composition in the obese population, fecal calprotectin levels were found to contribute significantly $(p=0.004)$ to the observed microbiota variations, followed by BMI $(p=0.002)$ and the Bacteroidetes/Firmicutes ratio $(p=0.01)$. Although ageing has been implied to affect gut microbiota composition later in life (>60 years), ${ }^{21}$ age was not found to contribute to the observed variation in microbiota composition ( $p=0.74)$. Collectively, our data indicate that a specific 'obese' bacterial composition is related to both intestinal and systemic inflammation.

\section{DISCUSSION}

Gut microbiota are considered to play an important role in the development of obesity and obesity-associated chronic low grade inflammation. However, the majority of microbiota studies have been performed in rodent models. Human data are scarcer and less consistent. In the present human study, we observed profound differences in fecal microbiota composition that were related to the extent of obesity. Two microbiota clusters were identified by a phylogenetic fingerprinting tool: an obese microbiota cluster on the one hand, which was characterized by diminished bacterial diversity, a decreased ratio of Bacteroidetes to Firmicutes, and associated with intestinal and systemic inflammation, and a non-obese microbiota cluster on the other hand, characterized by a higher bacterial diversity, higher Bacteroidetes/Firmicutes ratio, and a lack of inflammation. We further identified significant differences in relative abundance of specific microbiota in the obese vs. non-obese clusters and subjects. In contrast to findings in animal studies, intestinal permeability was neither altered in obesity nor related to inflammation or to microbiota composition. Our data therefore suggest that in man, the obesity-associated intestinal microbiota modulate intestinal and systemic inflammation independent of gut permeability. 
Microbiota have been described to affect the intestinal barrier and promote inflammation by several mechanisms. First of all, pro-inflammatory bacterial compounds such as endotoxin have been shown to translocate via an increased intestinal permeability in obese rodents. ${ }^{10,11,20}$ This was also suggested to occur in obese subjects with non-alcoholic steatohepatitis. ${ }^{22}$ Furthermore, a high fat diet may enhance endotoxin absorption through chylomicron-facilitated transport. ${ }^{23}$ In addition, it was recently shown that high-fat dietinduced translocation of bacteria over the intestinal wall occurs after phagocytosis by dendritic cells, leading to systemic and adipose tissue inflammation. ${ }^{24}$ Our data are in best agreement with the last mechanism, since the observed microbiota alterations were not related to transcellular or paracellular gut permeability as probed by oligosaccharides, but nonetheless associated with local intestinal and systemic inflammation. However, we cannot rule out that the limitations of the permeability test in terms of sensitivity and/or specificity precluded the detection of potential effects of the altered microbiota on permeability. Furthermore, we did find increased gastroduodenal permeability in obesity that could be related to potential microbiota alterations in this part of the gut, which we could not investigate.

Intestinal inflammation was only observed in subjects within the obese microbiota cluster, implying that microbiota in this cluster may have a local pro-inflammatory activity. Along this line, it is well known that interactions of the microbiota with the intestinal epithelium can either provoke an inflammatory response, ${ }^{25}$ or can prevent inflammation. ${ }^{26}$ Given our data, it is conceivable that the bacterial species promoting obesity-associated inflammation belong to the Firmicutes. On the other hand, bacterial species abundantly present in the non-obese microbiota composition may have a protective effect. For instance, F. prausnitzii, a butyrate producer from Clostridium cluster IV, was increased in the non-obese subjects. Butyrate and other short chain fatty acids are known to inhibit inflammation by limiting immune cell migration, adhesion, and cytokine production. ${ }^{27}$ In line with this, F. prausnitzii has been found to stimulate anti-inflammatory responses in mice, ${ }^{28}$ and its abundance was negatively correlated with inflammatory markers in obese subjects, ${ }^{29}$ suggesting that this microbe belonging to the Firmicutes may protect nonobese subjects from inflammation. Intestinal inflammation with concomitant microbiota alterations has previously been found in obese rats, ${ }^{12,30}$ which is in line with our results in man. Elevated fecal calprotectin levels have previously been reported in obese subjects, ${ }^{31}$ although microbiota composition was not analyzed. Another study did not observe enhanced fecal calprotectin levels in obese subjects, while, in support of our findings, no relation between gut permeability and obese microbiota composition was found. ${ }^{32}$ However, the subjects included in that study were less obese and a less sensitive calprotectin assay was used. This may have prevented the detection of the calprotectin levels that we observed, which are considered to be relatively low. ${ }^{31}$ These low levels might indicate that there is only a low-grade inflammation. The inflammation may be 
present in all parts of the intestinal tract since fecal calprotectin levels are elevated in subjects with both small intestinal and colonic inflammation. ${ }^{33,34}$

The decreased Bacteroidetes/Firmicutes ratio that we observed in obese individuals is supported by results from several other groups, $3,4,6,7$ although up to now, a direct correlation between this ratio and BMI has never been shown. Contradictory results have even been reported, e.g. a similar microbiota composition in lean and obese subjects, ${ }^{9}$ or even an opposite change in Bacteroidetes/Firmicutes ratio in obesity. ${ }^{8}$ These conflicting data may be attributable to factors such as diet, ${ }^{5}$ recent use of antibiotics, ${ }^{35}$ host physiology, $^{30}$ and the presence of obesity associated co-morbidity such as insulin resistance. ${ }^{36}$ Perhaps more importantly, the subjects included in these studies were less obese than in the current study. Our data indicate that a decreased Bacteroidetes/Firmicutes ratio is particularly characteristic of severely obese individuals with a $\mathrm{BMI}>35 \mathrm{~kg} / \mathrm{m}^{2}$.

Subjects with type 2 diabetes were recently shown to have a different microbiota profile. ${ }^{37}$ In our study, obese subjects showed a minor increase in $\mathrm{HbA}_{1 c}$, which was no longer significant when the population was divided into clusters according to intestinal microbiota composition. In line with this, multivariate analysis also indicated that $\mathrm{HbA}_{1 \mathrm{c}}$ was not related to differences in microbiota composition. Likewise, multivariate analysis did not show that age contributed to the observed microbiota composition differences. This is further supported by studies showing that gut microbiota composition of adults between the age of 20 and 50 is relatively stable. ${ }^{15,21,38}$ Nonetheless, the relationship between microbiota composition and inflammation here described needs to be confirmed in larger studies taking into account factors such as the presence of type 2 diabetes, diet, geography, and age.

The observed increase in Firmicutes and concomitant decreased Bacteroidetes/Firmicutes ratio in obese subjects could be mainly attributed to an increased abundance of Clostridium cluster XIVa, which contains many butyrate producing species. Interestingly, an increased synthesis of short chain fatty acids such as butyrate by obesity-associated microbiota has been suggested to contribute to increased energy harvesting in obesity. ${ }^{3,8}$ Even though it remains speculative to imply a cause and effect relationship, Clostridium cluster XIVa species may actively contribute to the development of obesity. More evidence for this hypothesis comes from a recent study showing that modulation of specific bacteria within Clostridium cluster XIVa, i.e., Roseburia spp, which we also identified to be related to $\mathrm{BMI}$ and $\mathrm{CRP}$, improves body weight, insulin sensitivity, and hepatic steatosis in mice. ${ }^{39}$

The causes of the microbiota composition changes and the associated intestinal inflammation in obesity remain speculative, though we previously found evidence for a 
potential involvement of Paneth cells. ${ }^{40}$ Obese subjects displayed diminished levels of Paneth cell derived antimicrobial proteins. Strikingly, Paneth cells are pivotal in limiting bacterial translocation, thereby inhibiting systemic inflammation.

In conclusion, we present here the first evidence that a human obesity-associated microbiota profile is associated with both intestinal and systemic inflammation. Since no relation between the obese microbiota composition and intestinal permeability was found, our data suggest that microbiota-derived factors may directly promote inflammation in obesity. 


\section{REFERENCES}

1 Tilg H, Kaser A. Gut microbiome, obesity, and metabolic dysfunction. J Clin Invest. 2011 Jun;121(6):212632.

2 Backhed F, Manchester JK, Semenkovich CF, Gordon JI. Mechanisms underlying the resistance to dietinduced obesity in germ-free mice. Proc Natl Acad Sci USA. 2007 Jan;104(3):979-84.

3 Ley RE, Turnbaugh PJ, Klein S, Gordon JI. Microbial ecology: human gut microbes associated with obesity. Nature. 2006 Dec;444(7122):1022-3.

4 Ley RE, Backhed F, Turnbaugh P, Lozupone CA, Knight RD, Gordon Jl. Obesity alters gut microbial ecology. Proc Natl Acad Sci USA. 2005 Aug;102(31):11070-5.

5 Turnbaugh PJ, Backhed F, Fulton L, Gordon JI. Diet-induced obesity is linked to marked but reversible alterations in the mouse distal gut microbiome. Cell Host Microbe. 2008 Apr;3(4):213-23.

6 Armougom F, Henry M, Vialettes B, Raccah D, Raoult D. Monitoring bacterial community of human gut microbiota reveals an increase in Lactobacillus in obese patients and Methanogens in anorexic patients. PLoS One. 2009 Sep;4(9):e7125.

7 Santacruz A, Collado MC, Garcia-Valdes L, Sequra MT, Martin-Lagos JA, Anjos T, Marti-Romero M, Lopez RM, Florido J, Campoy C, et al. Gut microbiota composition is associated with body weight, weight gain and biochemical parameters in pregnant women. Br J Nutr. 2010 Jul;104(1):83-92.

Schwiertz A, Taras D, Schafer K, Beijer S, Bos NA, Donus C, Hardt PD. Microbiota and SCFA in lean and overweight healthy subjects. Obesity. $2010 \mathrm{Jan} ; 18(1): 190-5$.

Duncan SH, Lobley GE, Holtrop G, Ince J, Johnstone AM, Louis P, Flint HJ. Human colonic microbiota associated with diet, obesity and weight loss. Int J Obes. 2008 Nov;32(11):1720-4.

Amar J, Burcelin R, Ruidavets JB, Cani PD, Fauvel J, Alessi MC, Chamontin B, Ferrieres J. Energy intake is associated with endotoxemia in apparently healthy men. Am J Clin Nutr. 2008 May;87(5):1219-23.

Cani PD, Possemiers S, Van de Wiele T, Guiot Y, Everard A, Rottier O, Geurts L, Naslain D, Neyrinck A, Lambert DM, et al. Changes in gut microbiota control inflammation in obese mice through a mechanism involving GLP-2-driven improvement of gut permeability. Gut. 2009 Aug;58(8):1091-103.

de La Serre CB, Ellis CL, Lee J, Hartman AL, Rutledge JC, Raybould HE. Propensity to high-fat diet-induced obesity in rats is associated with changes in the gut microbiota and gut inflammation. Am J Physiol Gastrointest Liver Physiol. 2010 Aug;299(2):G440-8.

Backhed F, Ding H, Wang T, Hooper LV, Koh GY, Nagy A, Semenkovich CF, Gordon JI. The gut microbiota as an environmental factor that regulates fat storage. Proc Natl Acad Sci USA. 2004 Nov;101(44):1571823.

Salonen A, Nikkila J, Jalanka-Tuovinen J, Immonen O, Rajilic-Stojanovic M, Kekkonen RA, PlavA A, de Vos WM. Comparative analysis of fecal DNA extraction methods with phylogenetic microarray: effective recovery of bacterial and archaeal DNA using mechanical cell lysis. J Microbiol Methods. 2010 May;81(2):127-34.

Rajilic-Stojanovic M, Heilig HG, Molenaar D, Kajander K, Surakka A, Smidt H, de Vos WM. Development and application of the human intestinal tract chip, a phylogenetic microarray: analysis of universally conserved phylotypes in the abundant microbiota of young and elderly adults. Environ Microbiol. 2009 Jul;11(7):1736-51.

van der Sluijs Veer G, van den Hoven B, Russel MG, van den Bergh FA. Time-resolved fluorimetric immunoassay of calprotectin: technical and clinical aspects in diagnosis of inflammatory bowel diseases. Clin Chem Lab Med. 2006;44(3):292-8. van Wijck K, Verlinden TJ, van Eijk HM, Dekker J, Buurman WA, Dejong CH, Lenaerts K. Novel multi-sugar assay for site-specific gastrointestinal permeability analysis: A randomized controlled crossover trial. Clin Nutr. 2013 Apr;32(2):245-51.

Leps J, Smilauer P. Multivariate Analysis of Ecological Data using CANOCO. Cambridge University Press: Cambridge, UK, 2003. 
Hildebrandt MA, Hoffmann C, Sherrill-Mix SA, Keilbaugh SA, Hamady M, Chen YY, Knright R, Ahima RS, Bushman F, Wu GD. High-fat diet determines the composition of the murine gut microbiome independently of obesity. Gastroenterology. 2009 Nov;137(5):1716-24.

Brun P, Castagliuolo I, Di Leo V, Buda A, Pinzani M, Palu G, Mertines D. Increased intestinal permeability in obese mice: new evidence in the pathogenesis of nonalcoholic steatohepatitis. Am J Physiol Gastrointest Liver Physiol. 2007 Feb;292(2):G518-25.

Biagi E, Nylund L, Candela M, Ostan R, Bucci L, Pini E, Nikkila J, Monti D, Satokari R, Franceschi C, et al. Through ageing, and beyond: gut microbiota and inflammatory status in seniors and centenarians. PLoS One. 2010 Nat;5(5)e10667.

Verdam FJ, Rensen SS, Driessen A, Greve JW, Buurman WA. Novel evidence for chronic exposure to endotoxin in human nonalcoholic steatohepatitis. J Clin Gastroenterol. 2011 Feb;45(2):149-52.

Ghoshal S, Witta J, Zhong J, de Villiers W, Eckhardt E. Chylomicrons promote intestinal absorption of lipopolysaccharides. J Lipid Res. 2009 Jan;50(1):90-7.

Amar J, Chabo C, Waget A, Klopp P, Vachoux C, Bermudez-Humaran LG, Smirnova N, Berge M, Sulpice T, Lahtinen $\mathrm{S}$, et al. Intestinal mucosal adherence and translocation of commensal bacteria at the early onset of type 2 diabetes: molecular mechanisms and probiotic treatment. EMBO Mol Med. 2011 Sep;3(9):559-72.

Maslowski KM, Vieira AT, Ng A, Kranich J, Sierro F, Yu D, Schilter HC, Rolph MS, Mackay F, Artis D, et al. Regulation of inflammatory responses by gut microbiota and chemoattractant receptor GPR43. Nature. 2009 Oct;461(7268):1282-6.

Mazmanian SK, Round JL, Kasper DL. A microbial symbiosis factor prevents intestinal inflammatory disease. Nature. 2008 May;453(7195):620-5.

Meijer K, de Vos P, Priebe MG. Butyrate and other short-chain fatty acids as modulators of immunity: what relevance for health? Curr Opin Clin Nutr Metab Care. 2010 Nov;13(6):715-21. Sokol H, Pigneur B, Watterlot L, Lakhdari O, Bermudez-Humaran LG, Gratadoux JJ, Blugeon S, Bridonneua C, Furet JP, Corthier G, et al. Faecalibacterium prausnitzii is an anti-inflammatory commensal bacterium identified by gut microbiota analysis of Crohn disease patients. Proc Natl Acad Sci USA. 2008 Oct;105(43):16731-6.

Furet JP, Kong LC, Tap J, Poitou C, Basdevant A, Bouilot JL, Mariat D, Corthier G, Dore J, Henegar C, et al. Differential adaptation of human gut microbiota to bariatric surgery-induced weight loss: links with metabolic and low-grade inflammation markers. Diabetes. 2010 Dec;59(12):3049-57.

Benson AK, Kelly SA, Legge $\mathrm{R}$, et al. Individuality in gut microbiota composition is a complex polygenic trait shaped by multiple environmental and host genetic factors. Proc Natl Acad Sci USA. 2010;107:18933-8.

31 Poullis A, Foster R, Shetty A, Fagerhol MK, Mendall MA. Bowel inflammation as measured by fecal calprotectin: a link between lifestyle factors and colorectal cancer risk. Cancer Epidemiol Biomarkers Prev. 2004 Feb;13(2):279-84.

Brignardello J, Morales P, Diaz E, Romero J, Brunser O, Gotteland M. Pilot study: alterations of intestinal microbiota in obese humans are not associated with colonic inflammation or disturbances of barrier function. Aliment Pharmacol Ther. 2010 Dec;32(11-12):1307-14. Jensen MD, Kjeldsen J, Nathan T. Fecal calprotectin is equally sensitive in Crohn's disease affecting the small bowel and colon. Scand J Gastroenterol. 2011 Jun;46(6):694-700. Konikoff MR, Denson LA. Role of fecal calprotectin as a biomarker of intestinal inflammation in inflammatory bowel disease. Inflamm Bowel Dis. 2006 Jun;12(6):524-34.

Dethlefsen L, Huse S, Sogin ML, Relman DA. The pervasive effects of an antibiotic on the human gut microbiota, as revealed by deep 16S rRNA sequencing. PLoS Biol. 2008 Nov;6(11):e280. Larsen N, Vogensen FK, van den Berg FW, Nielsen DS, Andreasen AS, Pedersen BK, Al-Soud WA, Sorensen SJ, Hansen LH, Jakobsen M. Gut microbiota in human adults with type 2 diabetes differs from nondiabetic adults. PLoS One. 2010 Feb5;5(2):e9085. 


\section{Chapter 6}

37 Qin J, Li Y, Cai Z, Li S, Zhu J, Zhang F, Liang S, Zhang W, Guan Y, Shen D, et al. A metagenome-wide association study of gut microbiota in type 2 diabetes. Nature. 2012 Oct;490(7418):55-60.

38 Yatsunenko T, Rey FE, Manary MJ, Trhan I, Dominiquez-Bello MG, Contreras M, Magris M, Hidalgo G, Baldassano RN, Anokhin AP, et al. Human gut microbiome viewed across age and geography. Nature. 2012 May;486(7402):222-7.

39 Neyrinck AM, Possemiers S, Verstraete W, De Backer F, Cani PD, Delzenne NM. Dietary modulation of clostridial cluster XIVa gut bacteria (Roseburia spp.) by chitin-glucan fiber improves host metabolic alterations induced by high-fat diet in mice. J Nutr Biochem. 2012 Jan;23(1):51-9.

40 Hodin CM, Verdam FJ, Grootjans J, Rensen SS, Verheyen FK, Dejong CH, Buurman WA, Greve JW, Lenaerts K, et al. Reduced Paneth cell antimicrobial protein levels correlate with activation of the unfolded protein response in the gut of obese individuals. J Pathol. 2011 Oct;225(2):276-84. 


\section{Chapter 7}

\section{Metabolic improvement after}

duodenal-jejunal exclusion correlates to

changes in intestinal microbiota

\section{composition}

Charlotte de Jonge, Susana Fuentes, Erwin G Zoetendal, Nicole D Bouvy, Rochelle Nelissen, Wim A Buurman, Jan Willem M Greve, Sander S Rensen, Willem M de Vos 


\section{ABSTRACT}

\section{Background}

Intestinal microbiota have been suggested to play an important role in the pathogenesis of obesity and type 2 diabetes. Bariatric surgery improves both diseases and has also been associated with changes in intestinal microbiota composition. We here investigated the effect of a novel nonsurgical bariatric technique on intestinal microbiota composition in relation to metabolic improvement.

\section{Methods}

Fourteen patients with obesity and type 2 diabetes were treated with the nonsurgical Duodenal-Jejunal Bypass Liner (DJBL), which excludes the proximal small intestine from food. Fecal samples as well as metabolic parameters reflecting obesity and type 2 diabetes were obtained from the patients at baseline, at six months after implantation of the device, and at six months after explantation.

\section{Results}

After six months of treatment, both obesity and type 2 diabetes had improved with a decrease in weight from 106.1 [99.4 - 123.5] to 97.4 [89.4 - 114.0] $\mathrm{kg}$ and a decrease in $\mathrm{HbA}_{1 \mathrm{c}}$ from 8.5 [7.6 - 9.2] to 7.2 [6.3 - 8.1] \% (both $\mathrm{p}<0.05$ ). This was paralleled by an increased abundance of typical small intestinal bacteria such as Proteobacteria, Veillonella and Lactobacillus in feces. After removal of the DJBL, fecal microbial composition was comparable to baseline.

\section{Conclusion}

Improvement of obesity and type 2 diabetes after exclusion of the proximal small intestine by DJBL treatment is associated with changes in fecal microbiota composition. 


\section{INTRODUCTION}

The human gastrointestinal tract is inhabited by an enormous number and diversity of microorganisms referred to as the intestinal microbiota. ${ }^{1}$ The collective genome of our intestinal microbiota, the intestinal microbiome, exceeds the human genome by a magnitude of more than $100 .^{2}$ Recent evidence suggests that the intestinal microbiota plays an important role in the pathogenesis of obesity and type 2 diabetes. ${ }^{3,4}$ Gordon and colleagues were the first to report that conventionalization of lean germ-free mice with intestinal microbiota from obese mice led to body fat increase and insulin resistance, while this was not observed after colonization with microbiota from lean donor mice. ${ }^{5,6}$ In addition, germ-free mice were found to be protected from high-fat diet-induced obesity. ${ }^{7}$ Furthermore, both genetically and diet-induced obese mice displayed a different intestinal microbiota composition compared to lean controls; obesity was associated with an increased ratio of the two most dominant divisions within the gut microbiome, the Firmicutes and the Bacteroidetes. ${ }^{8,9}$ An increased capacity of the 'obese microbiota' to harvest energy from ingested food and to facilitate storage of these calories in host adipose tissue has been suggested to form the basis of the association between gut microbiota composition and the development of obesity and type 2 diabetes. ${ }^{5,6}$

In humans, similar observations have been made; particular gut microbiota compositions have been associated with obesity. ${ }^{8,10-12}$ In addition, changes in the composition have been found related to weight loss. ${ }^{11,13-15}$ In line with these findings, bariatric surgery, the most durable obesity and type 2 diabetes treatment, has also been associated with changes in microbiota composition. ${ }^{16-18}$ Moreover, transplantation of intestinal microbiota from lean donors into obese human subjects has been shown to increase their insulin sensitivity. ${ }^{19}$ These data indicate that intestinal microbiota might also mediate the development of obesity and type 2 diabetes in humans. Since both obesity and the metabolic syndrome have been shown to improve after implantation of the DuodenalJejunal Bypass Liner (DJBL, GI Dynamics, Lexington, MA), a non-surgical bariatric device, ${ }^{20-}$ ${ }^{23}$ we here investigated the intestinal microbiota composition in relation to metabolic improvement induced by the DJBL.

\section{METHODS}

\section{Subjects}

Fecal samples were obtained from 14 patients with obesity and type 2 diabetes treated with the DJBL in the Maastricht University Medical Center, Maastricht or the Atrium Medical Center Parkstad, Heerlen, the Netherlands. The patients were studied at baseline 
and at six months after implantation of the device. A subset of six patients was also studied at six months after explantation of the device. Inclusion criteria were: age between 18 and 65 years; body mass index (BMI) between 30 and $50 \mathrm{~kg} / \mathrm{m}^{2}$; duration of type 2 diabetes less than 10 years. Main exclusion criteria were: use of weight loss medication or anti-inflammatory drugs; history of inflammatory diseases; exclusion criteria regarding safety of DJBL placement or DJBL compatibility. The study was approved by the Medical Ethics Committee of both centers and conducted according to the revised version of the Declaration of Helsinki (October 2008, Seoul). Written informed consent was obtained from every patient before study participation.

\section{The DJBL}

The DJBL is a $60 \mathrm{~cm}$ long impermeable liner which has been developed to mimic the intestinal bypass component of the Roux-en- $Y$ gastric bypass in a non-surgical way. The DJBL was delivered and retrieved endoscopically as previously described. ${ }^{20}$ In brief, a gastroduodenal endoscopy was performed under general anesthesia. A guide wire was placed into the duodenum over which the encapsulated DJBL was directed through the pylorus into the duodenal bulb. The DJBL was advanced into the small intestine, followed by deployment of the anchor in the duodenal bulb. Correct positioning and patency of the DJBL were verified under fluoroscopy.

In 8 patients, the devices were explanted after 6 months; in 6 patients, explantation was done after 12 months, as previously described. ${ }^{20}$ In brief, explantation was performed endoscopically under general anesthesia using a custom retrieval system containing a grasper and a retrieval hood. By grasping the wires on the anchor, the anchor collapsed and was pulled into the retrieval hood on top of the endoscope. After verification of the collapsed anchor by fluoroscopy, the device was removed. Throughout the study, patients were prescribed a diet with a maximum of 1,200 kcal for women and 1,500 kcal for men.

\section{Study design}

Subjects were studied before, during, and after DJBL treatment. At each time point (prior to DJBL (B), six months after initiation of DJBL treatment $(6 \mathrm{M})$, and six months after explantation (6MPE)), body weight was determined and venous blood samples were obtained in the outpatient clinic. Plasma levels of $\mathrm{HbA}_{1 c}$, glucose, and insulin were determined routinely at the Department of Clinical Chemistry. In addition, a standardized meal tolerance test was performed: blood samples were drawn after an overnight fast; thereafter a standard liquid meal (Ensure Plus, Abbott Laboratories, IL; $333 \mathrm{~mL}, 500 \mathrm{kcal}$, $20.8 \mathrm{~g}$ protein, $67.3 \mathrm{~g}$ carbohydrates, and $16.4 \mathrm{~g}$ fat) was consumed, followed by collection 
of blood samples in EDTA with aprotinin at up to 240 minutes postprandial. Samples were immediately cooled, centrifuged, and stored in aliquots at $-80^{\circ} \mathrm{C}$ until further analysis. Fecal samples were collected within 24 hours prior to the visits and were kept refrigerated until arrival at the outpatient clinic where the samples were immediately stored in polystyrene tubes (Greiner Bio-One, Alphen aan de Rijn, the Netherlands) at $-20^{\circ} \mathrm{C}$ until further analysis.

\section{Fecal microbiota analysis}

DNA was isolated as previously described ${ }^{24}$ and the intestinal microbiota composition was determined using the Human Intestinal Tract chip (HITChip), a phylogenetic profiling DNA microarray containing over 5,000 probes based on $16 \mathrm{~S}$ rRNA gene sequences of over 1,100 intestinal bacterial phylotypes. This microarray has been extensively used for the study of the microbiota in different conditions, including obesity and related diseases ${ }^{10,19}$ and it identifies both variation and relative quantity of the human intestinal tract communities. ${ }^{25}$ Hybridizations were performed in duplicate with samples labeled with Cy3 and Cy5 dyes. Slides were scanned and the data were extracted from the microarray images using the Agilent Feature Extraction software, version 10.7.3.1 (http://www.agilent.com). Array normalization was performed as previously described ${ }^{25,26}$ using a set of R-based scripts (http://r-project.org) in combination with a custom designed database which runs under the MySQL database management system (http://www.mysql.com). This was implemented on both dyes for each sample, and duplicate hybridizations with a Pearson correlation over 0.98 were considered for further analysis. Complete linkage was used for the construction of hierarchical clusters of the total microbiota probe profiles, while the distance matrix between the samples was based on Pearson correlation. The bacterial diversity of the fecal samples was assessed by Shannon's index of diversity using the HITChip probe level. ${ }^{27}$

\section{Statistical analysis}

Total area under the curve (AUC) of glucose and insulin was calculated using the trapezoidal method. HOMA-IR was calculated with the following formula: ((fasting glucose)x(fasting insulin))/22.5. For comprehensive multivariate statistical analyses, Canoco software for Windows 5.0 was used. ${ }^{28}$ Redundancy analysis (RDA) was used to assess correlations between the microbial groups detected by the HITChip analysis in function of sample characteristics. The log transformed hybridization signals of 130 genuslevel phylogenetic groups were used as biological variables. As environmental variables, we included $B M I$, weight, excess weight loss (EWL), $\mathrm{HbA}_{1 c}$, fasting glucose, fasting insulin, AUC glucose, AUC insulin, HOMA-IR, and sample source (i.e. a factor combination of 
treatment and time). Monte Carlo permutation testing (MCPT) as implemented in the Canoco software package was used to assess statistical significance of these variables in the dataset. The bacterial composition of the samples was compared at the phylum level (Class level for the Firmicutes) and at the approximate genus level (130 phylogenetic groups with more than $90 \%$ 16s rRNA gene sequence similarity ${ }^{25}$ ) using the Wilcoxon signed-rank test corrected for false discovery rate for which corrected $\mathrm{P}<0.05$ was considered significant. Differences in microbiota diversity were assessed by Student's T test. Differences in weight and plasma parameters over time were assessed with the Wilcoxon Matched-pairs Signed Rank test. Values were considered significant at corrected $p$ values $<0.05$. Data are presented as median and interquartile range or percentage and standard deviation (SD).

\section{RESULTS}

\section{Metabolic changes initiated by DJBL treatment}

At baseline, patients had a median body weight of 106.1 [99.4 - 123.5] kg, a BMI of 35.2 [32.2 - 40.9] kg/m², and an $\mathrm{HbA}_{1 \mathrm{c}}$ of 8.5 [7.6 - 9.2] \%. Fasting glucose and insulin levels were 9.8 [8.9 - 12.8] mmol/L and 16.4 [10.1 - 21.3] mU/L, respectively. HOMA-IR was 7.3 [5.0 - 10.4].

Changes after 6 months of DJBL treatment are depicted in Figure 1. Median body weight had decreased to 97.4 [89.4 - 114.0] kg ( $p<0.05$, Fig. 1A). This corresponds with a BMI of 31.5 [29.5 - 38.1] kg/m² and an excess weight loss of 18.3 [10.2 - 26.4] \% (both $p<0.05$, Fig. $1 \mathrm{~B}+\mathrm{C}) . \mathrm{HbA}_{1 \mathrm{c}}$ had decreased to $7.2[6.3-8.1] \%(\mathrm{p}<0.05$, Fig 1D). In addition, fasting glucose levels, fasting insulin levels, and HOMA-IR were decreased to 7.8 [7.1 - 8.7] $\mathrm{mmol} / \mathrm{L}, 10.8$ [8.4-16.1] mU/L, and 3.5 [2.5 - 6.4], respectively (all $\mathrm{p}<0.05$, Fig. 1E+F+G). Moreover, the glucose response to a meal as reflected by the AUC for glucose had decreased (Fig. $1 \mathrm{H}, \mathrm{p}<0.05$ ). The AUC for insulin was not significantly changed (Fig. 1I, $\mathrm{p}=0.07$ ). In conclusion, DJBL treatment significantly improves body weight and type 2 diabetes parameters. 
A

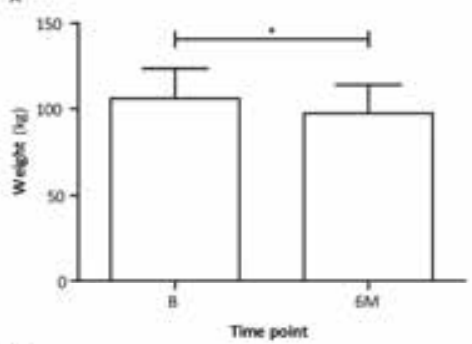

c
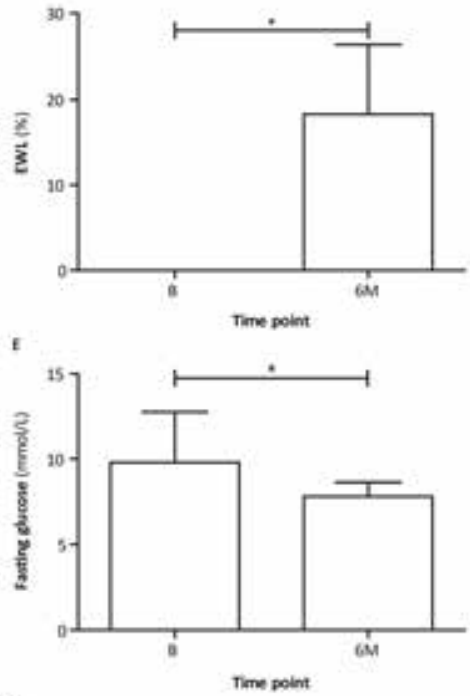

G
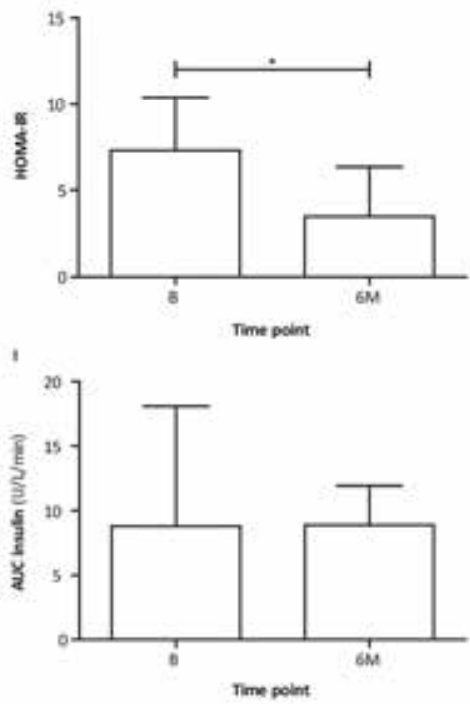

B

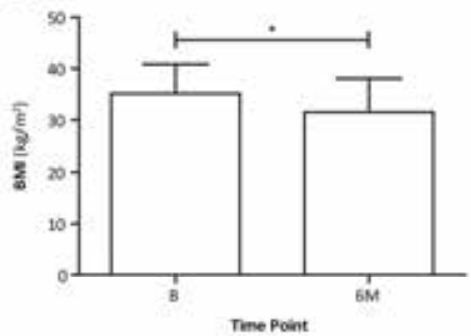

D
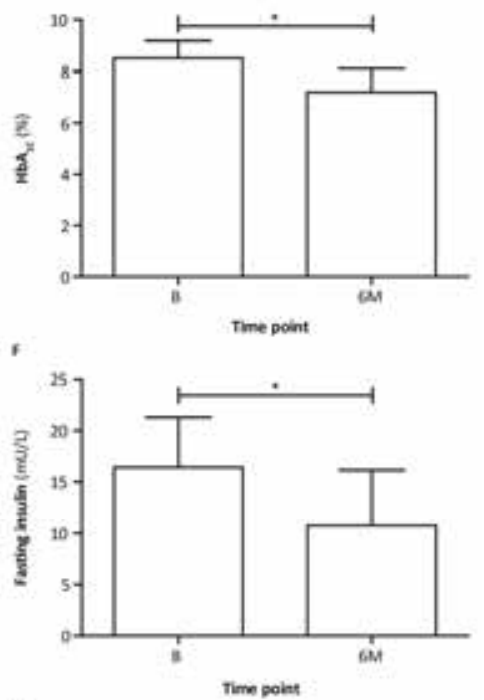

H

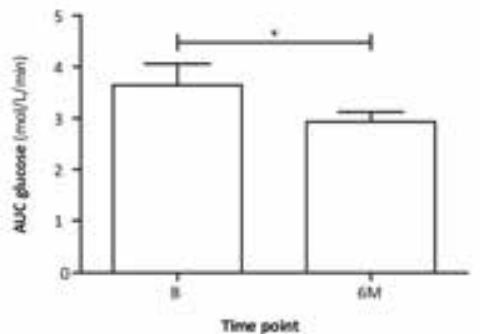

Figure 1. Effects of DJBL treatment on metabolic parameters. A) Body weight of patients before and six months after initiation of DJBL treatment. B) BMI changes over time. C) Excess weight loss after six months of DJBL treatment. D) Changes in HbA1c concentrations. $E$ and F) Fasting glucose and insulin levels obtained at baseline and at six months after initiation of DJBL treatment. G) Changes in HOMA-IR initiated by $D J B L$ treatment. $H$ and I) Area under the curve calculations for glucose and insulin respectively. An asterisk (*) indicates $p<0.05$.

$p<0.05$. 


\section{DJBL treatment induces gut microbiota composition alterations}

Fecal microbiota composition was profoundly affected by DJBL treatment as shown in Table 1. A positive association of DJBL intervention with Bacilli, Bacteroidetes, and Proteobacteria abundance was observed. Furthermore, several changes within the Firmicutes phylum were observed. The genera Oscillospira guillermondii et rel., Sporobacter termitidis et rel., and Veillonella increased after six months of DJBL treatment, whereas the relative abundance of Megamonas hypermegale et rel. and Ruminococcus obeum et rel. decreased. In addition, the diversity of the fecal microbiota composition, as reflected by the Shannon diversity index, tended to increase from 5.4 [5.2 - 5.7] to 5.8 [5.4 - 5.9] by DJBL treatment (Fig. 2, p=0.053).

Table 1: Significant differences of genus-like bacterial groups after DJBL intervention.

\begin{tabular}{|c|c|c|c|c|c|}
\hline \multirow{2}{*}{ Level 1} & \multirow{2}{*}{ Level 2} & \multicolumn{2}{|c|}{ Relative abundance ( $\% \pm$ SD) } & \multicolumn{2}{|c|}{ Significance } \\
\hline & & Baseline & 6 months & p-value & Corrected $p$ \\
\hline \multicolumn{6}{|l|}{ Bacteroidetes } \\
\hline & Bacteroides uniformis et rel. & $0.26 \pm 0.47$ & $0.56 \pm 0.88$ & $0.029 *$ & 0.347 \\
\hline \multicolumn{6}{|l|}{ Firmicutes } \\
\hline \multirow[t]{2}{*}{ Bacili } & Lactobacillus gasseri et rel. & $0.16 \pm 0.08$ & $3.95 \pm 4.14$ & $0.000 * *$ & 0.000 \\
\hline & Lactobacillus plantarum et rel. & $0.31 \pm 0.42$ & $3.55 \pm 3.84$ & $0.000 * *$ & 0.001 \\
\hline \multirow[t]{3}{*}{ C. cluster IV } & Clostridium cellulosi et rel. & $1.74 \pm 3.38$ & $2.00 \pm 2.46$ & 0.134 & 0.738 \\
\hline & Oscillospira guillermondii et rel. & $2.69 \pm 6.52$ & $3.87 \pm 3.79$ & $0.022^{*}$ & 0.291 \\
\hline & Sporobacter termitidis et rel. & $1.37 \pm 2.19$ & $2.59 \pm 1.83$ & $0.011^{*}$ & 0.164 \\
\hline \multirow[t]{3}{*}{ C. cluster IX } & Dialister & $0.39 \pm 0.61$ & $0.29 \pm 0.30$ & 0.483 & 0.747 \\
\hline & Megamonas hypermegale et rel. & $0.11 \pm 0.24$ & $0.03 \pm 0.02$ & $0.045^{*}$ & 0.449 \\
\hline & Veillonella & $0.07 \pm 0.07$ & $0.47 \pm 0.43$ & $0.000 * *$ & 0.000 \\
\hline \multirow[t]{5}{*}{ C. cluster XIVa } & Bryantella formatexigens et rel. & $1.55 \pm 1.03$ & $1.29 \pm 0.89$ & 0.424 & 0.738 \\
\hline & Clostridium nexile et rel. & $1.69 \pm 1.44$ & $1.26 \pm 0.87$ & 0.613 & 0.813 \\
\hline & Coprococcus eutactus et rel. & $5.88 \pm 6.93$ & $2.47 \pm 1.81$ & 0.126 & 0.738 \\
\hline & Eubacterium hallii et rel. & $1.07 \pm 0.98$ & $0.50 \pm 0.40$ & 0.062 & 0.534 \\
\hline & Ruminococcus obeum et rel. & $15.66 \pm 12.76$ & $7.56 \pm 7.90$ & $0.038^{*}$ & 0.412 \\
\hline \multicolumn{6}{|l|}{ Proteobacteria } \\
\hline & Enterobacter aerogenes et rel. & $0.28 \pm 0.42$ & $2.37 \pm 3.85$ & $0.000 * *$ & 0.000 \\
\hline & Escherichia coli et rel. & $0.64 \pm 1.40$ & $3.37 \pm 4.14$ & $0.001 * *$ & 0.016 \\
\hline & Klebsiella pneumoniae et rel. & $0.24 \pm 0.38$ & $2.84 \pm 4.57$ & $0.000 * *$ & 0.002 \\
\hline & Serratia & $0.05 \pm 0.08$ & $0.31 \pm 0.44$ & $0.002 * *$ & 0.039 \\
\hline & Yersinia et rel. & $0.06 \pm 0.03$ & $0.23 \pm 0.31$ & $0.003 *$ & 0.055 \\
\hline
\end{tabular}

$* \mathrm{p}<0.05 . * * \mathrm{p}<0.05$ after FDR correction. Increased (light gray) and decreased (dark gray) groups. 


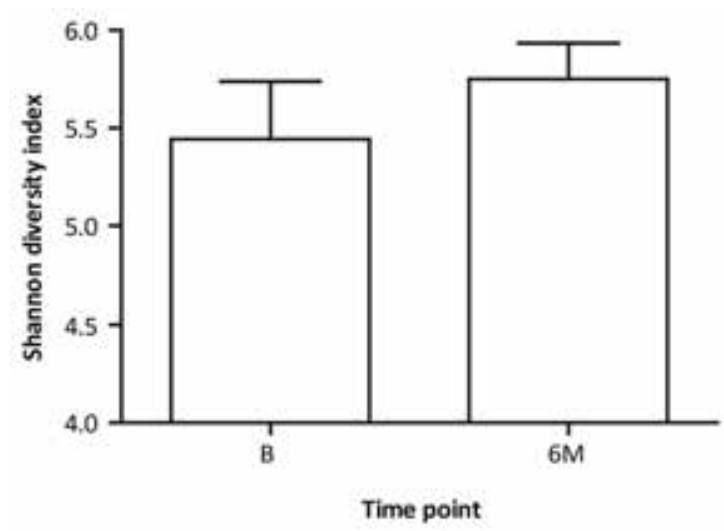

Figure 2. Changes in Shannon diversity index of the microbiota at baseline and six months after initiation of DJBL treatment.

\section{Relation between DJBL induced metabolic improvement and microbiota composition}

Next, we studied the relation between body weight and metabolic parameters at the different time points and microbiota composition. The DJBL-induced improvement in body weight and type 2 diabetes parameters negatively correlated with the relative abundance of C. cluster XIVa and other Firmicutes (Fig. 3). In addition, a positive correlation was found between Bacilli, Proteobacteria, Bacteroidetes, and excess weight loss. This suggests that the metabolic improvement as observed after DJBL treatment is associated with rather specific changes in gut microbiota composition.

Additional correlation analyses further revealed that changes in specific bacterial groups correlate with the decreased obesity and type 2 diabetes parameters (Fig. 4). For example, both fasting glucose and $\mathrm{HbA}_{1 c}$ strongly correlated with members of the Firmicutes phylum: Ruminococcus callidus et rel. and Oscillospira guillermondii et rel. respectively. Furthermore, changes in several other bacterial groups correlated negatively with excess weight loss. As displayed in Figure 4, positive correlations were found between both Lactobacillus gasseri and Lactobacillus plantarum and excess weight loss. Additional positive correlations were found between excess weight loss and members from the phylum Proteobacteria: Escherichia coli, Yersinia, Klepsiella pneumoniae, and Enterobacter aerogenes. Thus, changes in specific bacterial groups are associated with the metabolic improvement induced by DJBL treatment. 


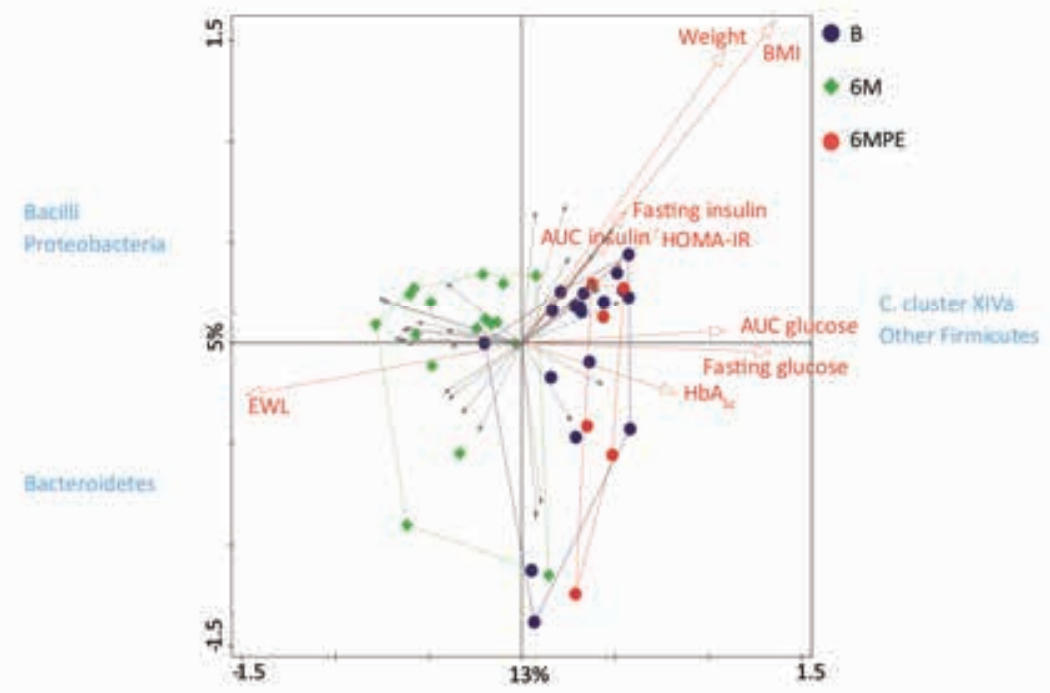

Figure 3. RDA: groups in comparisons with variables and bacterial groups. RDA of the association between metabolic parameters and the baseline microbiota composition of patients (blue dots), the microbiota composition of patients after 6 months of DJBL intervention (green dots), and 6 months post-intervention (red dots). The plotted first and second ordinations axes explain 13 and $5 \%$ of the variability in the dataset. Bacterial associations are shown with Bacilli and Proteobacteria, Bacteroidetes, and Clostridium cluster XIVa and other Firmicutes. In addition, correlations with all included variables are shown though none were significant.

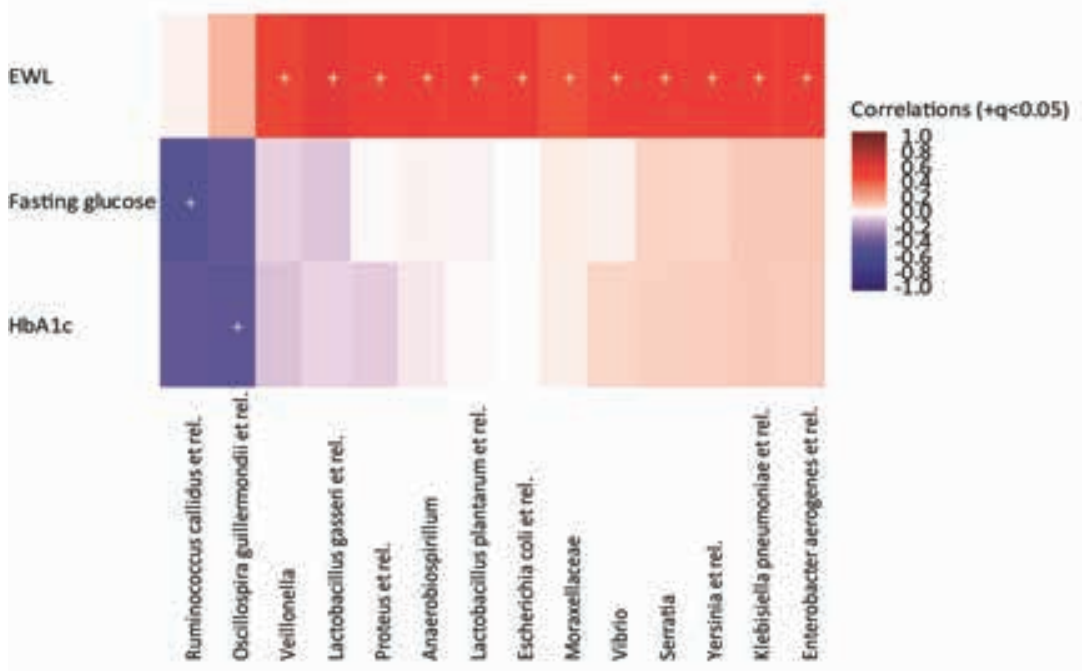

Figure 4. Correlations between bacterial groups and patient characteristics. Positive correlations are depicted in red and negative correlations in blue. + significant after FDR. 


\section{Reversal of microbiota alterations after DJBL explantation}

Six months after explantation of the DJBL, fecal microbiota composition of the patients was again comparable to baseline (Fig. 3). In addition, no significant difference was found between the Shannon diversity index at baseline vs. 6 months post-explantation (5.4 [5.25.7] vs. 5.5 [5.4-5.6], Fig. 5A, $p=0.87$ ). In contrast, six months after explantation, excess weight loss, HOMA-IR, and the AUC for glucose remained significantly improved when compared to baseline (Fig. $5 \mathrm{D}+\mathrm{H}+\mathrm{I}$ ). This indicates a sustained effect of the DJBL after explantion of the device, independent of microbiota changes.

\section{DISCUSSION}

Gut microbiota are considered to play an important role in the development of obesity and its related comorbidities. In the current study, the relation between improvement of obesity and type 2 diabetes following a nonsurgical bariatric technique and the intestinal microbiota composition was investigated. Our results indicate that metabolic improvement after a bariatric intervention excluding the proximal small intestine correlates with changes in microbiota composition.

The DJBL can be considered a nonsurgical bariatric technique mimicking the intestinal bypass component of the Roux-en-Y gastric bypass. Interestingly, our results on changes in microbiota composition in relation to weight loss and metabolic improvement after initiation of DJBL treatment are in line with previous results obtained after Roux-en-Y gastric bypass surgery. Changes in gut microbiota were shown to be associated with weight loss and metabolic improvement. ${ }^{16,18}$

As shown in Table 1, the abundance of several members of the Proteobacteria phylum was increased after DJBL implantation. In both animals and humans undergoing Roux-en-Y gastric bypass surgery, similar increases of Proteobacteria have been reported. ${ }^{16,18,29,30}$ An explanation for this shift might be found in the effects of proximal small intestinal exclusion. After DJBL implantation as well as after Roux-en- $Y$ gastric bypass surgery, digestion and absorption of nutrients is delayed to the mid-jejunum as the proximal small intestine is excluded from alimentary flow. ${ }^{31}$ As a result, undigested nutrients will be available more distal in the small intestine. This might relocate typical small intestinal microbiota, such as Proteobacteria, to the colon. In line, we observed a tremendous increase of Veillonella, a frequently encountered commensal in the human small intestine belonging to the Firmicutes phylum, ${ }^{32}$ in feces of DJBL treated subjects. 


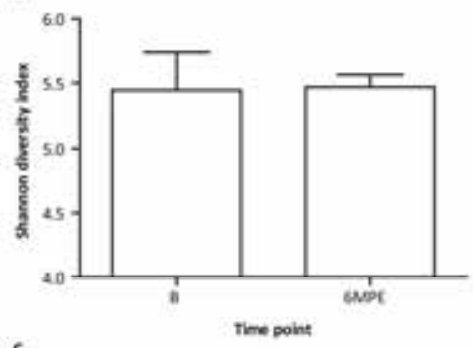

c
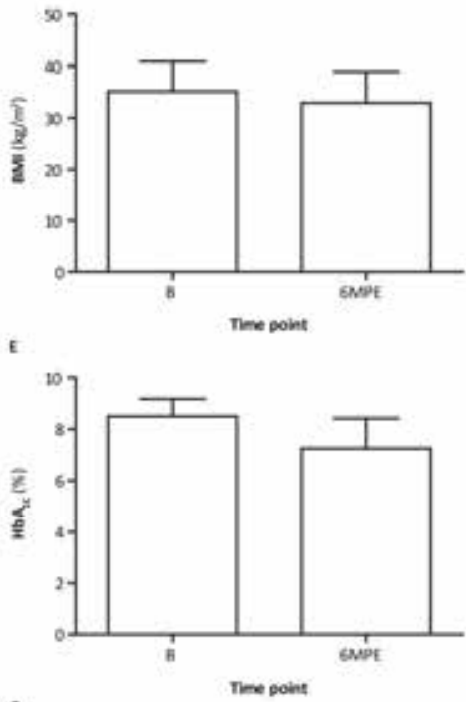

6
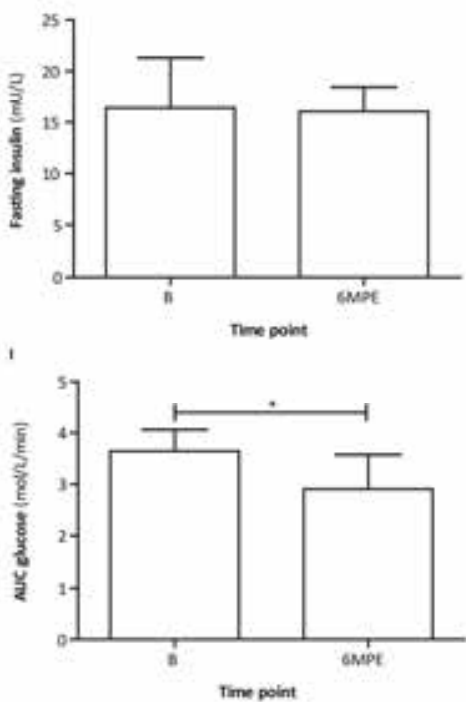

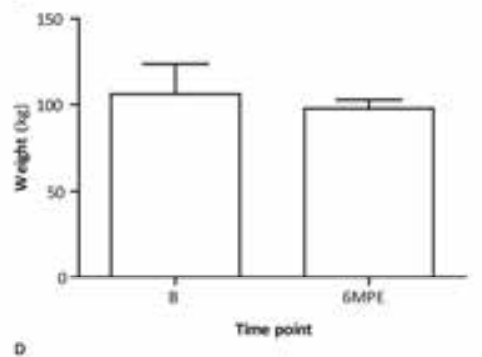

D
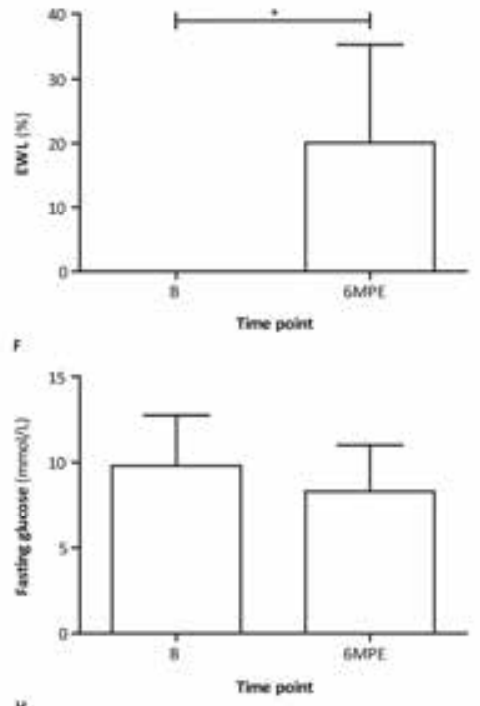

H
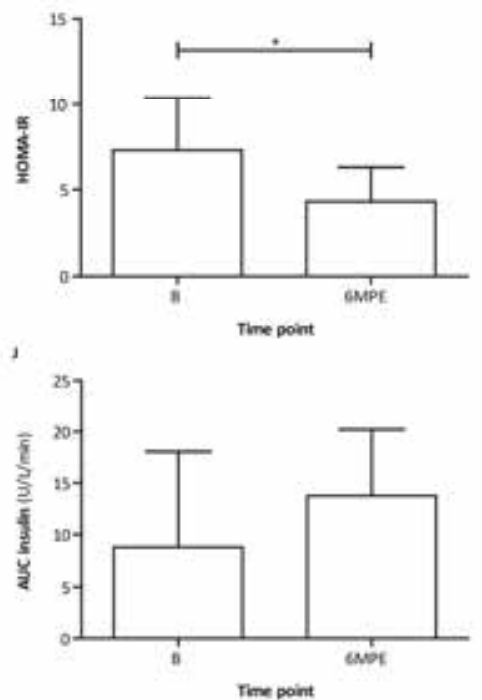

Figure 5. Changes in metabolic parameters after DJBL explantation.

A) Shannon diversity index at baseline and at six months postexplantation. B) Changes in patients' weight. C) Changes in BMI. D) Percentage of excess weight loss at six months post-explantation of the DJBL. E) Changes in $\mathrm{HbA}_{1 c}$ levels. $F$ and $G$ ) Changes in fasting glucose and insulin levels respectively. H) HOMA-IR levels at baseline and six months post-explantation. I and J) Area under the curve calculations for glucose and insulin at baseline and 6 months postexplant respectively. An asterisk $\left({ }^{*}\right) \quad$ indicates $p<0.05$. 
Next to these changes, DJBL treatment induced a microbial shift in favor of Lactobacillus. Both Lactobacillus plantarum and Lactobacillus gasseri increased tremendously after initiation of DJBL treatment. Interestingly, Lactobacilli strains have been associated with weight loss. In small animal models, administration of Lactobacillus plantarum caused body weight loss. ${ }^{33}$ Administration of fermented milk containing Lactobacillus gasseri to humans also led to a decrease in body weight and BMI reduction. ${ }^{34}$ This supports an important role for the observed shift in favor of these Lactobacilli in the improvement of body weight following DJBL treatment. Although speculative, the bloom in Lactobacilli may also be related to an increased availability of unabsorbed nutrients in more distal intestinal segments.

Interestingly, the Shannon diversity index, representing the variation in the fecal microbiota composition, was increased by DJBL treatment. An increased richness of the gut microbiota composition after bariatric surgery has also been observed by Kong et al. ${ }^{35}$ Importantly, an association between a decreased diversity and both obesity and type 2 diabetes have been reported. ${ }^{36,37}$ In addition, the Shannon diversity index as calculated from the fecal samples obtained from non-obese controls from our previous study was similar to the index obtained from the samples collected six months after initiation of DJBL treatment (5.9 [5.6 - 6.1] vs. 5.8 [5.4 - 5.9], non-obese control vs. 6 months after initiation of DJBL treatment, $p=0.15) .{ }^{10}$ This suggests a normalization of intestinal microbial diversity by DJBL treatment.

Whereas the abundance of Clostridium cluster IV tended to be increased by DJBL treatment, the abundance of Clostridium cluster XIVa was decreased. These clusters both contain many butyrate-producing species. Interestingly, butyrate has been put forward as an important anti-inflammatory mediator in metabolic diseases ${ }^{38}$ and has been shown to protect against diet-induced obesity. ${ }^{39}$ On the other hand, short chain fatty acids such as butyrate have been linked to increased energy harvest from the diet possibly mediating obesity development. ${ }^{12}$ Propionate, another short chain fatty acid, is mainly produced by Clostridium cluster IX members, but also by Bacteroidetes members. ${ }^{40}$ Within this cluster decreases as well as increases were observed after DJBL treatment. Therefore, conclusions on whether or not the observed changes within the Clostridium clusters are beneficial are difficult to draw.

After explantation of the device, the excess weight loss, HOMA-IR, and the AUC for glucose remained significantly improved when compared to baseline, indicating a prolonged effect of the DJBL treatment. However, the microbiota composition returned to the baseline situation. This may suggest that the metabolic improvement after DJBL treatment is independent of microbiota composition changes. Alternatively, DJBL treatment effect on gut microbiota composition may drive the initial improvement in 
glucose homeostasis with other mechanisms, such as hormonal changes, responsible for the prolonged improvement. Importantly, the number of patients studied at six months post explantation was small $(n=6)$, warranting further investigation.

All in all, we have shown for the first time that improvement of obesity and type 2 diabetes after exclusion of the proximal small intestine by DJBL treatment is associated with changes in microbiota composition. Our data may provide keys to the pathogenesis of obesity and type 2 diabetes and further studies might lead to new treatment modalities based on prebiotics and probiotics. 


\section{REFERENCES}

1. Tilg H, Moschen AR, Kaser A. Obesity and the microbiota. Gastroenterology. 2009 May;136(5):1476-83.

2. Cani PD, Delzenne NM. The gut microbiome as therapeutic target. Pharmacol Ther. 2011 May;130(2):202-12.

3. DiBaise JK, Zhang H, Crowell MD, Krajmalnik-Brown R, Decker GA, Rittmann BE. Gut microbiota and its possible relationship with obesity. Mayo Clinic proceedings Mayo Clinic. 2008 Apr;83(4):460-9.

4. Tilg H, Kaser A. Gut microbiome, obesity, and metabolic dysfunction. J Clin Invest. 2011 Jun;121(6):212632.

5. Backhed F, Ding H, Wang T, Hooper LV, Koh GY, Nagy A, Semenkovich CF, Gordon JI. The gut microbiota as an environmental factor that regulates fat storage. Proceedings of the National Academy of Sciences of the United States of America. 2004 Nov 2;101(44):15718-23.

6. Turnbaugh PJ, Ley RE, Mahowald MA, Magrini V, Mardis ER, Gordon JI. An obesity-associated gut microbiome with increased capacity for energy harvest. Nature. 2006 Dec 21;444(7122):1027-31.

7. Backhed F, Manchester JK, Semenkovich CF, Gordon JI. Mechanisms underlying the resistance to dietinduced obesity in germ-free mice. Proceedings of the National Academy of Sciences of the United States of America. 2007 Jan 16;104(3):979-84.

8. Ley RE, Backhed F, Turnbaugh P, Lozupone CA, Knight RD, Gordon JI. Obesity alters gut microbial ecology. Proceedings of the National Academy of Sciences of the United States of America. 2005 Aug 2;102(31):11070-5.

9. Turnbaugh PJ, Backhed F, Fulton L, Gordon JI. Diet-induced obesity is linked to marked but reversible alterations in the mouse distal gut microbiome. Cell host \& microbe. 2008 Apr 17;3(4):213-23.

10. Verdam FJ, Fuentes S, de Jonge C, Zoetendal EG, Erbil R, Greve JW, Buurman WA, de Vos WM, Rensen SS. Human intestinal microbiota composition is associated with local and systemic inflammation in obesity. Obesity. 2013 Dec;21(12):E607-15.

11. Santacruz A, Collado MC, Garcia-Valdes L, Segura MT, Martin-Lagos JA, Anjos T, Marti-Romero M, Lopez RM, Florido J, Campoy C, et al. Gut microbiota composition is associated with body weight, weight gain and biochemical parameters in pregnant women. Br J Nutr. 2010 Jul;104(1):83-92.

12. Schwiertz A, Taras D, Schafer K, Beijer S, Bos NA, Donus C, Hardt PD. Microbiota and SCFA in lean and overweight healthy subjects. Obesity. 2010 Jan;18(1):190-5.

13. Ley RE, Turnbaugh PJ, Klein S, Gordon JI. Microbial ecology: human gut microbes associated with obesity. Nature. 2006 Dec 21;444(7122):1022-3.

14. Duncan SH, Lobley GE, Holtrop G, Ince J, Johnstone AM, Louis P, Flint HJ. Human colonic microbiota associated with diet, obesity and weight loss. Int J Obes. 2008 Nov;32(11):1720-4.

15. Nadal I, Santacruz A, Marcos A, Warnberg J, Garagorri JM, Moreno LA, Martin-Matillas M, Campoy C, Marti A, Moleres A, et al. Shifts in clostridia, bacteroides and immunoglobulin-coating fecal bacteria associated with weight loss in obese adolescents. Int J Obes (Lond). 2009 Jul;33(7):758-67.

16. Zhang H, DiBaise JK, Zuccolo A, Kudrna D, Braidotti M, Yu Y, Parameswaran P, Crowell MD, Wing R, Rittmann BE, et al. Human gut microbiota in obesity and after gastric bypass. Proceedings of the National Academy of Sciences of the United States of America. 2009 Feb 17;106(7):2365-70.

17. Bjorneklett A, Viddal KO, Midtvedt T, Nygaard K. Intestinal and gastric bypass. Changes in intestinal microecology after surgical treatment of morbid obesity in man. Scandinavian journal of gastroenterology. 1981 16(5):681-7.

18. Furet JP, Kong LC, Tap J, Poitou C, Basdevant A, Bouillot JL, Mariat D, Corthier G, Dore J, Henegar C, et al. Differential adaptation of human gut microbiota to bariatric surgery-induced weight loss: links with metabolic and low-grade inflammation markers. Diabetes. 2010 Dec;59(12):3049-57.

19. Vrieze A, Van Nood E, Holleman F, Salojarvi J, Kootte RS, Bartelsman JF, Dallinga-Thie GM, Ackermans MT, Serlie MJ, Oozeer R, et al. Transfer of intestinal microbiota from lean donors increases insulin sensitivity in individuals with metabolic syndrome. Gastroenterology. 2012 Oct;143(4):913-6. 
20. Schouten R, Rijs CS, Bouvy ND, Hameeteman W, Koek GH, Janssen IM, Greve JW. A multicenter, randomized efficacy study of the EndoBarrier Gastrointestinal Liner for presurgical weight loss prior to bariatric surgery. Ann Surg. 2010 Feb;251(2):236-43.

21. de Moura EG, Martins BC, Lopes GS, Orso IR, de Oliveira SL, Galvao Neto MP, Santo MA, Sakai P, Ramos AC, Garrido Junior AB, et al. Metabolic improvements in obese type 2 diabetes subjects implanted for 1 year with an endoscopically deployed duodenal-jejunal bypass liner. Diabetes Technol Ther. 2012 Feb;14(2):183-9.

22. de Jonge C, Rensen SS, Verdam FJ, Vincent RP, Bloom SR, Buurman WA, le Roux CW, Schaper NC, Bouvy ND, Greve JW. Endoscopic duodenal-jejunal bypass liner rapidly improves type 2 diabetes. Obes Surg. 2013 Sep;23(9):1354-60.

23. Escalona A, Pimentel F, Sharp A, Becerra P, Slako M, Turiel D, Munoz R, Bambs C, Guzman S, Ibanez L, et al. Weight loss and metabolic improvement in morbidly obese subjects implanted for 1 year with an endoscopic duodenal-jejunal bypass liner. Ann Surg. 2012 Jun;255(6):1080-5.

24. Salonen A, Nikkila J, Jalanka-Tuovinen J, Immonen O, Rajilic-Stojanovic M, Kekkonen RA, Palva A, de Vos WM. Comparative analysis of fecal DNA extraction methods with phylogenetic microarray: effective recovery of bacterial and archaeal DNA using mechanical cell lysis. Journal of microbiological methods. 2010 May;81(2):127-34.

25. Rajilic-Stojanovic M, Heilig HG, Molenaar D, Kajander K, Surakka A, Smidt H, de Vos WM. Development and application of the human intestinal tract chip, a phylogenetic microarray: analysis of universally conserved phylotypes in the abundant microbiota of young and elderly adults. Environmental microbiology. 2009 Jul;11(7):1736-51.

26. Jalanka-Tuovinen J, Salonen A, Nikkila J, Immonen O, Kekkonen R, Lahti L, Palva A, de Vos WM. Intestinal microbiota in healthy adults: temporal analysis reveals individual and common core and relation to intestinal symptoms. PLoS ONE. 2011 6(7):e23035.

27. Magurran AE. Measuring biological diversity. Malden, Mass. Oxford: Blackwell; 2004.

28. ter Braak CJF, Similauer P. Canoco reference manual and user's guide: software for ordination, version 5.0. Microcomputer Power: Ithaca, USA. 2012.

29. Li JV, Ashrafian H, Bueter M, Kinross J, Sands C, le Roux CW, Bloom SR, Darzi A, Athanasiou T, Marchesi JR, et al. Metabolic surgery profoundly influences gut microbial-host metabolic cross-talk. Gut. 2011 Sep;60(9):1214-23.

30. Liou AP, Paziuk M, Luevano JM, Jr., Machineni S, Turnbaugh PJ, Kaplan LM. Conserved shifts in the gut microbiota due to gastric bypass reduce host weight and adiposity. Sci Transl Med. 2013 Mar 27;5(178):178ra41.

31. Goldfine $A B$, Shoelson $\mathrm{SE}$, Aguirre V. Expansion and contraction: treating diabetes with bariatric surgery. Nat Med. 2009 Jun;15(6):616-7.

32. van den Bogert B, Erkus O, Boekhorst J, de Goffau M, Smid EJ, Zoetendal EG, Kleerebezem M. Diversity of human small intestinal Streptococcus and Veillonella populations. FEMS microbiology ecology. 2013 Aug;85(2):376-88.

33. Arora T, Singh S, Sharma RK. Probiotics: Interaction with gut microbiome and antiobesity potential. Nutrition. 2013 Apr;29(4):591-6.

34. Kadooka Y, Sato M, Imaizumi K, Ogawa A, Ikuyama K, Akai Y, Okano M, Kagoshima M, Tsuchida T. Regulation of abdominal adiposity by probiotics (Lactobacillus gasseri SBT2055) in adults with obese tendencies in a randomized controlled trial. European journal of clinical nutrition. 2010 Jun;64(6):636-43.

35. Kong LC, Tap J, Aron-Wisnewsky J, Pelloux V, Basdevant A, Bouillot JL, Zucker JD, Dore J, Clement K. Gut microbiota after gastric bypass in human obesity: increased richness and associations of bacterial genera with adipose tissue genes. The American journal of clinical nutrition. 2013 Jul;98(1):16-24.

36. Le Chatelier E, Nielsen T, Qin J, Prifti E, Hildebrand F, Falony G, Almeida M, Arumugam M, Batto JM, Kennedy S, et al. Richness of human gut microbiome correlates with metabolic markers. Nature. 2013 Aug 29;500(7464):541-6. 
37. Zhang X, Shen D, Fang Z, Jie Z, Qiu X, Zhang C, Chen Y, Ji L. Human gut microbiota changes reveal the progression of glucose intolerance. PLoS One. 2013 8(8):e71108.

38. Brahe LK, Astrup A, Larsen LH. Is butyrate the link between diet, intestinal microbiota and obesity-related metabolic diseases? Obes Rev. 2013 Dec;14(12):950-9.

39. Lin HV, Frassetto A, Kowalik EJ, Jr., Nawrocki AR, Lu MM, Kosinski JR, Hubert JA, Szeto D, Yao X, Forrest G, et al. Butyrate and propionate protect against diet-induced obesity and regulate gut hormones via free fatty acid receptor 3-independent mechanisms. PLoS One. 2012 7(4):e35240.

40. Van den Abbeele P, Grootaert C, Marzorati M, Possemiers S, Verstraete W, Gerard P, Rabot S, Bruneau A, El Aidy S, Derrien $M$, et al. Microbial community development in a dynamic gut model is reproducible, colon region specific, and selective for Bacteroidetes and Clostridium cluster IX. Applied and environmental microbiology. 2010 Aug;76(15):5237-46. 



\section{Chapter 8}

Six months of treatment with the endoscopic Duodenal-Jejunal Bypass Liner does not lead to decreased systemic inflammation in obese patients with type 2 diabetes 


\section{ABSTRACT}

\section{Background}

Obesity is associated with chronic low-grade systemic inflammation. Bariatric surgery has been shown to reduce this inflammation. Here, the effect of a nonsurgical bariatric technique, the Duodenal-Jejunal Bypass Liner (DJBL), on systemic inflammation was investigated.

\section{Methods}

Seventeen obese patients with type 2 diabetes were treated with the DJBL for six months. Plasma C-reactive protein (CRP), myeloperoxidase (MPO), interleukin-6 (IL-6), and tumor necrosis factor alpha (TNF- $\alpha$ ) were determined prior to and during DJBL treatment.

\section{Results}

Three months after initiation of DJBL treatment, TNF- $\alpha$ levels had increased from $1.8 \pm 0.1$ to $2.1 \pm 0.1 \mathrm{pg} / \mathrm{mL}$ whereas IL-6 increased from $2.7 \pm 0.3$ to $4.0 \pm 0.5 \mathrm{pg} / \mathrm{mL}$ (both $\mathrm{p}<0.05$ ). CRP and MPO also increased, though the differences were not significant. After six months, the levels of all parameters were similar to baseline levels (CRP: $4.2 \pm 0.6 \mathrm{mg} / \mathrm{L}$, TNF- $\alpha$ : $2.0 \pm 0.1 \mathrm{pg} / \mathrm{mL}$, IL-6: $3.5 \pm 0.5 \mathrm{pg} / \mathrm{mL}$, MPO: $53.6 \pm \mathrm{ng} / \mathrm{mL}$, all $\mathrm{p}=\mathrm{ns}$ compared to baseline).

\section{Conclusion}

In the current study, six months of endoscopic DJBL treatment did not lead to decreased systemic inflammation. 


\section{INTRODUCTION}

Obesity is associated with chronic low-grade systemic inflammation. ${ }^{1,2}$ This inflammatory state has been suggested to originate, at least for an important part, from the adipose tissue., ${ }^{3,4}$ Visceral adipose tissue, in particular, secretes several pro-inflammatory cytokines, called adipokines. In obesity, adipose tissue expansion leads to an imbalance in adipokine production contributing to the local and systemic inflammation typical of obese patients. $^{3}$

The obesity-associated pro-inflammatory state is suggested to be a crucial pathogenic component in the development of obesity-related comorbid conditions such as type 2 diabetes. ${ }^{5-7}$ Bariatric surgery is effective in treating both obesity and type 2 diabetes. ${ }^{8,9}$ In addition, it is often accompanied by a decrease of the low-grade inflammation. ${ }^{10-12}$ Therefore, improvement of the inflammatory state has been suggested to underlie the resolution of type 2 diabetes after bariatric surgery. ${ }^{11,13}$

We here investigated the effect of the endoscopic Duodenal-Jejunal Bypass Liner (DJBL) on systemic inflammation. The DJBL is a non-surgical bariatric technique previously shown to be effective in treating obesity and type 2 diabetes. ${ }^{14-16}$ To obtain more insight into the possible involvement of inflammation in this improvement, plasma C-reactive protein (CRP), myeloperoxidase (MPO), interleukin 6 (IL-6), and tumor necrosis factor alpha (TNFa) were determined before and during DJBL treatment.

\section{METHODS}

\section{Patients}

Seventeen patients with obesity and type 2 diabetes were included in two centers: the Maastricht University Medical Center, Maastricht, the Netherlands and the Atrium Medical Center Parkstad, Heerlen, the Netherlands. Inclusion criteria were: age between 18 and 65 years; body mass index (BMI) between 30 and $50 \mathrm{~kg} / \mathrm{m}^{2}$; duration of type 2 diabetes less than 10 years; and $\mathrm{HbA}_{1 \mathrm{c}}$ between 7.5 and $10.0 \%$. Main exclusion criteria were: use of anti-inflammatory drugs or history of inflammatory diseases; use of weight loss medication; pregnancy or the intention to become pregnant during the course of the study, and exclusion criteria regarding safety of DJBL placement or DJBL compatibility. The study was approved by the Medical Ethics Committee of each center and conducted according to the revised version of the Declaration of Helsinki (October 2008, Seoul). Written informed consent was obtained from every patient before study participation. 


\section{The DJBL}

The DJBL is a $60 \mathrm{~cm}$ long impermeable liner which has been developed to mimic the intestinal bypass component of the Roux-en-Y gastric bypass in a non-surgical way. The DJBL was delivered and retrieved endoscopically as previously described. ${ }^{15}$ In brief, a gastroduodenal endoscopy was performed under general anesthesia. A guide wire was placed into the duodenum over which the encapsulated DJBL was directed through the pylorus into the duodenal bulb. The DJBL was advanced into the small intestine, followed by deployment of the anchor in the duodenal bulb. Correct positioning and patency of the DJBL were verified under fluoroscopy. No abnormalities were observed. For safety reasons, liquid nutrition was advised during the first week post-implantation. In addition, patients were provided standard of care bariatric nutritional counseling.

After 24 weeks, all patients had completed the treatment and the DJBL was explanted as previously described. ${ }^{15}$ In brief, explantation was performed endoscopically under general anesthesia using a custom retrieval system containing a grasper and a retrieval hood. No patient showed any sign of malfunction or malposition of the DJBL. By grasping the wires on the anchor, the anchor collapsed and was pulled into the retrieval hood on top of the endoscope. After verification of the collapsed anchor by fluoroscopy, the device was removed.

\section{Study design and plasma analysis}

Patients were studied on three occasions, i.e. within one month prior to (D0) and at three and six months after initiation of DJBL treatment ( $M 3$ and $M 6$ respectively). At each time point, patients visited the outpatient clinic where body weight was determined and fasting venous blood samples were obtained, immediately centrifuged and stored at $-80^{\circ} \mathrm{C}$ until further analysis.

To determine plasma levels of CRP, a high sensitivity sandwich enzyme-linked immunosorbent assay (ELISA) was used as previously described. ${ }^{17}$ ELISA plates from Greiner Bio-One (Alphen aan de Rijn, the Netherlands) were used. Plasma MPO, TNF- $\alpha$, and IL- 6 concentrations were determined using commercially available ELISA according to the manufacturer's protocol (MPO: kindly provided by Hycult Biotechnology, Uden, the Netherlands, TNF- $\alpha$ and IL-6: both high sensitive assays from R\&D systems, Minneapolis, $\mathrm{MN}$ ). 


\section{Statistical analysis}

Statistical analyses were performed using GraphPad Prism 5.0. Longitudinal changes were tested using the Wilcoxon signed rank test. A p-value of $<0.05$ was considered statistically significant. Data are presented as mean and standard error of the mean (SEM).

\section{RESULTS}

\section{Effects of the DJBL on obesity}

Baseline characteristics of the study population can be found in Table 1. As shown, patients had an average body weight of $116.0 \pm 5.8 \mathrm{~kg}$ with a mean BMl of $37.0 \pm 1.3$ $\mathrm{kg} / \mathrm{m}^{2}$ at baseline. Three months after DJBL-implantation, body weight had decreased to $105.3 \pm 5.5 \mathrm{~kg}$, corresponding with a reduction of excess weight of $25.2 \pm 3.1 \%$ and a BMI reduction of $3.4 \pm 0.4 \mathrm{~kg} / \mathrm{m}^{2}$ ( $\left.p<0.05\right)$. After six months, at the time of device explantation, mean body weight had further decreased to $103.3 \pm 5.5 \mathrm{~kg}$ resulting in a total weight loss of $12.7 \pm 1.3 \mathrm{~kg}$, which corresponds to an excess weight loss of $29.8 \pm 3.5 \%$ and a $\mathrm{BMI}$ reduction of $4.1 \pm 0.4 \mathrm{~kg} / \mathrm{m}^{2}$ ( $p<0.05$ when compared to baseline).

Table 1. Baseline characteristics of the study population.

\begin{tabular}{|c|c|}
\hline & $\mathrm{N}=17$ \\
\hline Age (y) & $51 \pm 2$ \\
\hline Sex (male) & $14(82.4)$ \\
\hline Weight (kg) & $116.0 \pm 5.8$ \\
\hline BMI $\left(\mathrm{kg} / \mathrm{m}^{2}\right)$ & $37.0 \pm 1.3$ \\
\hline $\mathrm{HbA}_{1 \mathrm{c}}(\%)$ & $8.4 \pm 0.2$ \\
\hline CRP (mg/L) & $5.3 \pm 1.1$ \\
\hline TNF- $\alpha(\mathrm{pg} / \mathrm{mL})$ & $1.8 \pm 0.1$ \\
\hline IL-6 (pg/mL) & $2.7 \pm 0.3$ \\
\hline MPO (ng/mL) & $45.5 \pm 4.3$ \\
\hline
\end{tabular}

\section{Effect of DJBL treatment on systemic inflammation as indicated by plasma CRP levels}

To obtain insight into the effects of DJBL treatment on systemic inflammation, plasma concentrations of CRP were determined before and at three and six months after DJBL implantation. As shown in Figure $1 \mathrm{~A}$, at baseline the mean CRP level was marginally 
elevated as typical for the low-grade systemic inflammatory state in obese patients $15.3 \pm$ $1.1 \mathrm{mg} / \mathrm{L}) .{ }^{1}$ Three months after implantation of the DJBL, plasma CRP had slightly but nonsignificantly increased to $7.9 \pm 1.3 \mathrm{mg} / \mathrm{L}(p=0.06)$. After six months, the mean concentration of plasma CRP had decreased to baseline levels $(4.2 \pm 0.6 \mathrm{mg} / \mathrm{L}, \mathrm{p}<0.05$ compared to month three).

A

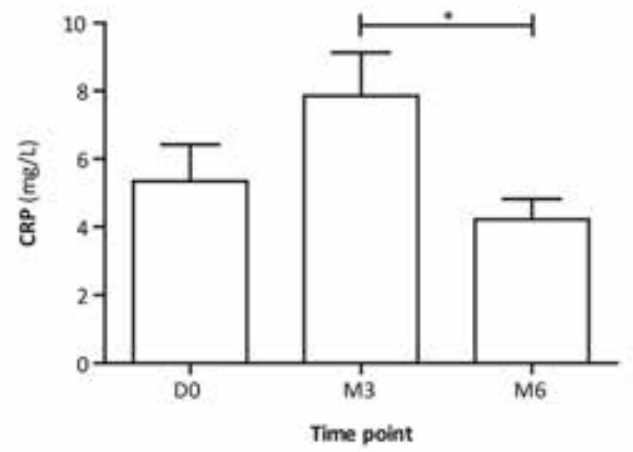

E

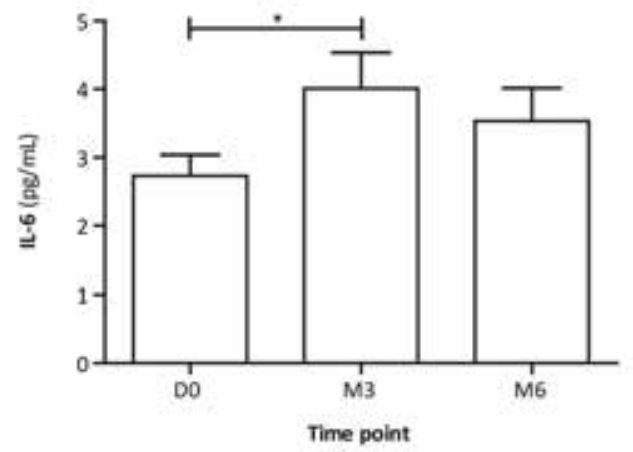

8

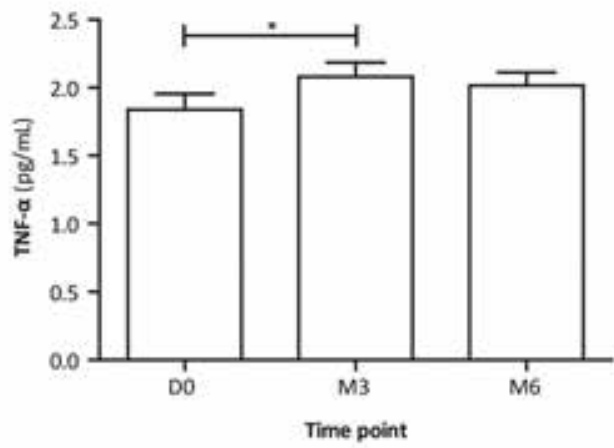

D

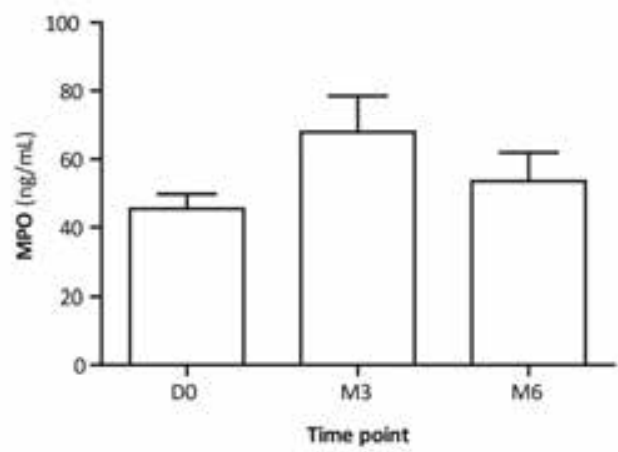

Figure. 1. The effect of DJBL treatment on plasma levels of CRP, TNF- $\alpha, I L-6$, and MPO. A) Plasma CRP levels at baseline and three and six months after implantation of the DJBL. B) Plasma levels of TNF- $\alpha$ at baseline and three and six months post-implantation. C) Plasma concentrations of IL-6 obtained at baseline and three and six months after implantation of the DJBL. D) MPO plasma concentrations prior to and three and six months after initiation of $D J B L$ treatment. An asterisk $\left({ }^{*}\right)$ indicates $p<0.05$.

\section{Changes in TNF- $\alpha$ and IL-6 concentrations after DJBL implantation}

At baseline, patients showed a mean plasma TNF- $\alpha$ concentration of $1.8 \pm 0.1 \mathrm{pg} / \mathrm{mL}$ (Fig. 1b). The mean IL-6 concentration was $2.7 \pm 0.3 \mathrm{pg} / \mathrm{mL}$ (Fig. 1C). Three months after implantation of the DJBL, plasma levels of both TNF- $\alpha$ and IL-6 were slightly but significantly increased to $2.1 \pm 0.1$ and $4.0 \pm 0.5 \mathrm{pg} / \mathrm{mL}$, respectively (both $\mathrm{p}<0.05$ ). After 
six months, the concentrations of TNF- $\alpha$ and IL- 6 were no longer significantly different from the baseline levels (TNF- $\alpha$ : $2.0 \pm 0.1 \mathrm{pg} / \mathrm{mL}, \mathrm{p}=0.13$ and IL-6: $3.5 \pm 0.5 \mathrm{pg} / \mathrm{mL}$, $\mathrm{p}=0.12)$.

\section{Effect of DJBL treatment on neutrophil activation as assessed by MPO plasma concentrations}

As previously shown, neutrophil activation as reflected by plasma MPO levels is increased in obese patients. ${ }^{18}$ We here evaluated the effect of DJBL treatment on concentrations of plasma MPO. At baseline, the mean plasma MPO concentration was $45.5 \pm 4.3 \mathrm{ng} / \mathrm{mL}$ (Fig. 1D). After initiation of DJBL treatment, this concentration increased to $67.9 \pm 10.5 \mathrm{ng} / \mathrm{mL}$ $(p=0.06)$. After six months, mean MPO concentrations were decreased again, and not significantly different from baseline levels $(53.6 \pm \mathrm{ng} / \mathrm{mL}, \mathrm{p}=0.82$ compared to baseline).

\section{DISCUSSION}

In obesity, particularly the abdominal or visceral adipose tissue depots secrete increased amounts of pro-inflammatory cytokines such as IL- 6 and TNF- $\alpha$. These cytokines are, in turn, important stimulators of the hepatic production of the acute-phase protein CRP, thereby establishing the chronic low-grade inflammatory status characterizing obese subjects. ${ }^{3,4}$ In addition, increased neutrophil activation as indicated by elevated MPO levels, a neutrophil secretion product, has been observed in obese patients. ${ }^{18}$ We here investigated the effect of a nonsurgical bariatric technique, the endoscopic DJBL on inflammatory plasma parameters and found a transient increase after three months of treatment, followed by a return to baseline levels after six months.

On the long term, reduction of the obesity-related chronic low-grade inflammatory profile has been observed after bariatric surgery. ${ }^{10-12}$ However, contradicting results have been found within weeks to months after the procedures. ${ }^{10,12,19}$ Miller et al. evaluated early changes in inflammatory biomarkers after Roux-and- $Y$ gastric bypass and observed no changes in IL- 6 and TNF- $\alpha$ levels. CRP levels were only decreased after six months. A study by van Dielen et al. revealed elevated levels of inflammatory mediators for at least three months after gastric restrictive surgery. Rao performed a meta-analysis evaluating CRP, TNF- $\alpha$, and IL- 6 levels at one month, three months, six months, and twelve months after bariatric surgery and showed decreased CRP levels at all time points. However, TNF- $\alpha$ levels seemed to remain stable over time and IL-6 levels dropped after 3 months. A possible explanation for the transiently increased inflammatory state that we observed might be an enhanced metabolic stress response initiated by relative starvation. In 
anorectic patients, elevated inflammatory parameters have been found. Weight loss after bariatric surgery can be considered comparable to chronic starvation, probably contributing to the increased inflammatory profile. ${ }^{19}$ In addition, the DJBL itself might trigger the immune system: the presence of an inflammatory reaction has been described at the anchor site after three months of DJBL treatment. ${ }^{20}$ Notably, the observed enhanced low-grade inflammation was only temporary. Significant differences from baseline concentrations as seen after three months were absent after six months of DJBL treatment. Moreover, with regard to the observed decrease of CRP levels after six months, it is tempting to speculate that a trend is initiated and that patients could potentially benefit from longer treatment duration. This suggestion finds support in the publication of van Dielen et al, which also described increased CRP levels at three months after gastric restrictive surgery, with a subsequent decrease when weight loss continued. ${ }^{19}$

Remarkably, previous studies with the DJBL have demonstrated rapid improvement of type 2 diabetes. ${ }^{14,15}$ This was confirmed in our previous study investigating the effect of DJBL treatment on type 2 diabetes and related hormones which revealed rapid hormonal changes and improvement of type 2 diabetes. ${ }^{16}$ It can be speculated that reduced inflammation might mediate this improvement, since type 2 diabetes and chronic lowgrade systemic inflammation seem strongly linked ${ }^{5-7}$ and previous research performed after bariatric surgery is supportive of this theory. ${ }^{11,13}$ However, the current data do not support this suggestion; no improvement of inflammatory parameters was observed. Importantly, it should be taken into account that the group of patients studied in the current manuscript had relatively low levels of inflammatory parameters at baseline. ${ }^{11-13}$ Therefore a tremendous improvement of the inflammatory status was not to be expected in these patients. In addition, the sample size of the current study is rather small. Nevertheless, it's the first data available on the effect of DJBL treatment on inflammatory parameters and further studies in patients with a larger number of patients and/or with patients with a more pronounced inflammatory profile are warranted to more thoroughly investigate the effect of the DJBL on inflammation and elucidate the relation with type 2 diabetes. Additionally, this study lacks a control group of patients subjected to nutritional counseling alone. Interestingly, unpublished data comparing DJBL treatment in combination with nutritional counseling vs. nutritional counseling alone show inferior weight loss in the control group. Therefore, a mere nutritional effect is not expected.

Taken together, the data in the current manuscript suggest that six months of endoscopic DJBL treatment is not associated with reduced systemic inflammation in moderately obese subjects with type 2 diabetes. Nevertheless, it seems worthwhile to evaluate the effect of longer treatment duration in further studies as well as the effect of the DJBL in a larger group of patients with a more severe inflammatory profile. 


\section{REFERENCES}

1. Visser M, Bouter LM, McQuillan GM, Wener MH, Harris TB. Elevated C-reactive protein levels in overweight and obese adults. JAMA. 1999 Dec 8;282(22):2131-5.

2. Gregor MF, Hotamisligil GS. Inflammatory mechanisms in obesity. Annu Rev Immunol. 2011 29(415-45.

3. Ouchi N, Parker JL, Lugus JJ, Walsh K. Adipokines in inflammation and metabolic disease. Nat Rev Immunol. 2011 Feb;11(2):85-97.

4. Maachi M, Pieroni L, Bruckert E, Jardel C, Fellahi S, Hainque B, Capeau J, Bastard JP. Systemic low-grade inflammation is related to both circulating and adipose tissue TNFalpha, leptin and IL-6 levels in obese women. Int J Obes Relat Metab Disord. 2004 Aug;28(8):993-7.

5. Donath MY, Shoelson SE. Type 2 diabetes as an inflammatory disease. Nat Rev Immunol. 2011 Feb;11(2):98-107.

6. Cottam DR, Mattar SG, Barinas-Mitchell E, Eid G, Kuller L, Kelley DE, Schauer PR. The chronic inflammatory hypothesis for the morbidity associated with morbid obesity: implications and effects of weight loss. Obes Surg. 2004 May;14(5):589-600.

7. Kalupahana NS, Moustaid-Moussa N, Claycombe KJ. Immunity as a link between obesity and insulin resistance. Mol Aspects Med. 2012 Feb;33(1):26-34.

8. Sjostrom L, Lindroos AK, Peltonen M, Torgerson J, Bouchard C, Carlsson B, Dahlgren S, Larsson B, Narbro $\mathrm{K}$, Sjostrom $\mathrm{CD}$, et al. Lifestyle, diabetes, and cardiovascular risk factors 10 years after bariatric surgery. $\mathrm{N}$ Engl J Med. 2004 Dec;351(26):2683-93.

9. Buchwald H, Estok R, Fahrbach K, Banel D, Jensen MD, Pories WJ, Bantle JP, Sledge I. Weight and type 2 diabetes after bariatric surgery: systematic review and meta-analysis. Am J Med. 2009 Mar;122(3):24856.

10. Rao SR. Inflammatory markers and bariatric surgery: a meta-analysis. Inflammation research : official journal of the European Histamine Research Society. 2012 Aug;61(8):789-807.

11. Illan-Gomez F, Gonzalvez-Ortega M, Orea-Soler I, Alcaraz-Tafalla MS, Aragon-Alonso A, Pascual-Diaz M, Perez-Paredes M, Lozano-Almela ML. Obesity and inflammation: change in adiponectin, C-reactive protein, tumour necrosis factor-alpha and interleukin-6 after bariatric surgery. Obes Surg. 2012 Jun;22(6):950-5.

12. Miller GD, Nicklas BJ, Fernandez A. Serial changes in inflammatory biomarkers after Roux-en-Y gastric bypass surgery. Surg Obes Relat Dis. 2011 Sep-Oct;7(5):618-24.

13. Kopp HP, Kopp CW, Festa A, Krzyzanowska K, Kriwanek S, Minar E, Roka R, Schernthaner G. Impact of weight loss on inflammatory proteins and their association with the insulin resistance syndrome in morbidly obese patients. Arteriosclerosis, thrombosis, and vascular biology. 2003 Jun 1;23(6):1042-7.

14. Escalona A, Pimentel F, Sharp A, Becerra P, Slako M, Turiel D, Munoz R, Bambs C, Guzman S, Ibanez L, et al. Weight loss and metabolic improvement in morbidly obese subjects implanted for 1 year with an endoscopic duodenal-jejunal bypass liner. Ann Surg. 2012 Jun;255(6):1080-5.

15. Schouten R, Rijs CS, Bouvy ND, Hameeteman W, Koek GH, Janssen IM, Greve JW. A multicenter, randomized efficacy study of the EndoBarrier Gastrointestinal Liner for presurgical weight loss prior to bariatric surgery. Ann Surg. 2010 Feb;251(2):236-43.

16. de Jonge C, Rensen SS, Verdam FJ, Vincent RP, Bloom SR, Buurman WA, le Roux CW, Schaper NC, Bouvy ND, Greve JW. Endoscopic duodenal-jejunal bypass liner rapidly improves type 2 diabetes. Obes Surg. 2013 Sep;23(9):1354-60.

17. van Dielen FM, van't Veer C, Schols AM, Soeters PB, Buurman WA, Greve JW. Increased leptin concentrations correlate with increased concentrations of inflammatory markers in morbidly obese individuals. Int J Obes Relat Metab Disord. 2001 Dec;25(12):1759-66.

18. Nijhuis J, Rensen SS, Slaats Y, van Dielen FM, Buurman WA, Greve JW. Neutrophil activation in morbid obesity, chronic activation of acute inflammation. Obesity. 2009 Nov;17(11):2014-8. 
19. van Dielen FM, Buurman WA, Hadfoune M, Nijhuis J, Greve JW. Macrophage inhibitory factor, plasminogen activator inhibitor-1, other acute phase proteins, and inflammatory mediators normalize as a result of weight loss in morbidly obese subjects treated with gastric restrictive surgery. J Clin Endocrinol Metab. 2004 Aug;89(8):4062-8.

20. Tarnoff M, Shikora S, Lembo A, Gersin K. Chronic in-vivo experience with an endoscopically delivered and retrieved duodenal-jejunal bypass sleeve in a porcine model. Surg Endosc. 2008 Apr;22(4):1023-8. 


\section{Chapter 9}

General Discussion 
Chapter 9 


\section{GENERAL DISCUSSION}

Obesity and its related diseases are an important health burden and a large economic problem. ${ }^{1}$ For years, bariatric surgery has been used to treat this complex disease spectrum. ${ }^{2}$ Bariatric surgery is the most effective weight losing therapy. ${ }^{3}$ In addition, bariatric surgery leads to improvement of obesity-related comorbid conditions such as type 2 diabetes, cardiovascular disease, and nonalcoholic fatty liver disease (NAFLD). ${ }^{4-6}$ Furthermore, it is associated with beneficial changes in satiety and hormones regulating appetite, inflammatory profile, and gut microbiota composition. ${ }^{7-12}$ However, bariatric surgery is also associated with morbidity and mortality. ${ }^{3,13,14}$ Therefore less invasive techniques have been developed. ${ }^{15}$ One example is the Duodenal-Jejunal Bypass Liner or DJBL. The DJBL consists of a $60 \mathrm{~cm}$ long impermeable fluoropolymer sleeve with a nitinol anchor, which is used to reversibly affix the device to the wall of the duodenal bulb. Once in place, the DJBL excludes the proximal small intestine from food contact, thereby mimicking the bypass component of the Roux-en- $Y$ gastric bypass. ${ }^{16,17}$ In the current thesis, we aimed to investigate the effect of this non-surgical bariatric technique on obesity and its comorbidities.

\section{The weight losing effect of proximal small intestinal exclusion by DJBL treatment}

In Chapter 2, we investigated the efficacy of the DJBL in treating obesity. DJBL treatment in combination with nutritional counseling was compared with nutritional counseling alone in a multicenter randomized controlled trial. Seventy-seven patients were included and randomized; 38 patients were allocated to the DJBL group of which 34 patients were successfully implanted and 39 control patients started a dietary intervention. After six months of treatment, the DJBL group showed significantly more weight loss, with an excess weight loss of 32.0 vs. $16.4 \%$ for the DJBL vs. diet group. This is in line with previous studies comparing DJBL treatment with sham or diet control treatment showing superior weight loss in the DJBL group. ${ }^{16,18,19}$

Weight loss after bariatric techniques excluding the proximal small intestine has been suggested to be related to increased satiety and decreased caloric intake, possibly mediated by altered secretion of appetite regulating hormones. ${ }^{7,8,20-22}$ In Chapter 4, we described the possible role of appetite regulating hormones in weight loss following DJBL treatment. Responses to a meal challenge of gut hormones involved in appetite control were determined before and after initiation of DJBL treatment. Interestingly, during DJBL treatment, all patients reported decreased caloric intake and satiety was reported to be increased by $88 \%$ of the patients. This was paralleled by an increase in the peptide $Y Y$ (PYY) and glucagon-like peptide-1 (GLP-1) response to a meal (Chapter 3). PYY and GLP-1 are both potent satiety inducers secreted by the distal small intestine. ${ }^{23-25}$ They have been 
proposed to be important factors in the so-called ileal brake theory which suggests that intestinal feedback mechanisms are activated by undigested nutrients in the distal gut, leading to increased satiety and reduced food intake by delaying gastric emptying and intestinal transit. ${ }^{26,27}$ Importantly, similar results of increased PYY and GLP-1 responses have been observed after surgical techniques excluding the proximal small intestine such as the Roux-en-Y gastric bypass and the surgical duodenal-jejunal bypass. ${ }^{25,28-32}$

In addition, we investigated changes in plasma levels of cholecystokinine (CCK) induced by DJBL treatment. CCK is secreted in the proximal small intestine in response to intraluminal nutrients and signals satiety via vagal afferents. ${ }^{33}$ After initiation of DJBL treatment, the CCK response to food was diminished. This may be explained by the fact that DJBL placement eliminates chemical food triggers in the proximal small intestine. Importantly, it has been suggested that obese subjects are CCK resistant, ${ }^{34}$ putatively reducing the importance of the observed decreased CCK response in relation to satiety. These data suggest other factors to be more important in appetite regulation after DJBL implantation than CCK.

Furthermore, the effect of DJBL treatment on the ghrelin response to a meal was investigated. Ghrelin is an orexigenic hormone secreted primarily by the gastric fundus in the fasted state. After food ingestion, plasma levels fall rapidly. ${ }^{35,36}$ We observed increased fasting ghrelin levels following DJBL treatment. However, we also observed a more distinct drop of plasma ghrelin levels after meal ingestion, possibly mediating decreased hunger. In addition, plasma leptin levels were measured. Leptin is considered a long term regulator of energy balance and is secreted by adipocytes in proportion to whole body adipose tissue mass. ${ }^{37,38}$ In line, we observed plasma leptin concentrations to be decreased along with body mass index (BMI) during DJBL treatment. Importantly, obesity is characterized by resistance to the effects of leptin, even high levels do not seem to influence energy balance. ${ }^{37,39,40}$

Notably, all subjects included in our study suffered from type 2 diabetes, a disease in which resistance to insulin plays an important role. Insulin can be considered as a long term energy signaler ${ }^{41}$ and resistance to the effects of insulin may therefore disturb energy balance. Interestingly, increased insulin sensitivity has been reported following both bariatric surgery ${ }^{42}$ and DJBL placement ${ }^{43}$, as will be discussed in the next section. Taken together, these data suggest that DJBL treatment induces weight loss possibly mediated by altered plasma concentrations of appetite regulating hormones. 


\section{The amelioration of type 2 diabetes induced by DJBL treatment}

In Chapter 2, we reported the effect of DJBL treatment vs. dietary intervention on type 2 diabetes. After six months of treatment, DJBL patients showed a more prominent decrease in $\mathrm{HbA}_{1 c}$ levels when compared to the diet group. In addition, a larger percentage of patients in the DJBL group achieved a decrease in postprandial glucose excursion than in the control group. This indicates that the DJBL is more effective in treating type 2 diabetes in comparison with dietary restriction alone. This is in line with studies comparing Roux-en-Y gastric bypass surgery with dietary regimen showing better diabetes outcome after surgery. ${ }^{44,45}$ In addition, studies evaluating bariatric surgery in comparison with medical therapy show a superior effect in favor of bariatric surgery. ${ }^{46,47}$

Next, possible mediators involved in the rapid improvement of type 2 diabetes induced by DJBL treatment were studied (Chapter 3). To this end, meal tolerance tests were performed before, during, and shortly after DJBL treatment. Our results showed that DJBL treatment results in a rapid decrease of both fasting and postprandial glucose levels, whereas the insulin response did not change significantly. This might indicate increased insulin sensitivity and/or decreased hepatic glucose production. This is in line with results of Cohen et al. who observed insulin sensitivity, as determined by HOMA-IR and Matsuda index, to increase rapidly after initiation of DJBL treatment, while insulin secretion was unchanged. $^{43}$

To further elucidate the factors involved, we determined the GLP-1, glucose-dependent insulinotropic polypeptide (GIP), and glucagon response to a meal. GLP-1 and GIP are incretins, gut hormones stimulating insulin secretion in response to glucose levels. ${ }^{48} \mathrm{We}$ observed an increased GLP-1 response to a meal. This is in line with the increased GLP-1 response observed after Roux-en- $Y$ gastric bypass surgery. ${ }^{31,48,49}$ In contrast to the increased GLP-1 levels, GIP levels decreased during DJBL treatment. Importantly, in patients with type 2 diabetes, the insulinotropic effect of GIP seems largely ablated, ${ }^{50,51}$ indicating only a minor effect of the decreased GIP levels on the insulin response to a meal. Next to their effect on insulin, both GLP-1 and PYY influence glucagon secretion. Whereas GLP-1 strongly inhibits glucagon secretion, ${ }^{52}$ GIP tends to stimulate glucagon release. ${ }^{53,54}$ The net result of the increased GLP-1 response and decreased GIP response would then be a decreased glucagon response. This is indeed what we observed: at baseline, a pathognomonic glucagon response to a meal was present. ${ }^{55}$ During DJBL treatment, this response tended to normalize. It is tempting to speculate that this probably contributed to the reduced glucose levels in the absence of increased insulin levels.

Two major hypotheses on the mechanisms underlying the rapid improvement of type 2 diabetes after proximal small intestinal exclusion have been proposed, the so-called 
foregut and hindgut hypothesis. Our data seem to fit both hypotheses. The foregut hypothesis suggests that improved glycemic control results from reduced secretion of a diabetogenic factor in the absence of nutritional triggers in the proximal small intestine. ${ }^{56,57}$ Glucagon has been suggested to be a key player in this respect. ${ }^{57}$ In line, we observed decreased postprandial glucagon levels during DJBL treatment. In line with our results, the hindgut hypothesis attributes improved glycemic control to enhanced secretion of incretins such as glucagon-like peptide-1 (GLP-1) in response to undigested nutrients in the distal small intestine. ${ }^{48,49}$

Of note, incretins are not only of interest within the bariatric surgical field. In the pharmaceutical regimen for type 2 diabetes, incretin-based medical therapies such as GLP1 receptor agonists or Dipeptidyl Peptidase-4 (DPP-IV) inhibitors are becoming popular. DPP-IV is a peptidase that rapidly degrades GLP-1. Administration of DPP-IV inhibitor slows down GLP-1 degradation, thereby increasing the endogenous GLP-1 concentration, whereas a GLP-1 agonist directly stimulates the GLP-1 receptor. ${ }^{58,59}$ According to the recently renewed global guideline of the International Diabetes Federation, incretin-based drug therapy is now included in the treatment algorithm of type 2 diabetes. ${ }^{60}$

\section{Effect of DJBL treatment on inflammation, NAFLD, and cardiovascular parameters}

In obesity, fat accumulation is increased in organs and tissues. The primary storage site for triglycerides is the adipose tissue. Excessive triglyceride accumulation is associated with disturbed secretion of adipokines, cytokines secreted by adipose tissue. ${ }^{61}$ These disturbances favor a low-grade inflammatory state, ${ }^{61-64}$ which has been suggested to be crucial in the development of obesity-related comorbidities. ${ }^{65-67}$ Bariatric surgery has been shown to improve both obesity and its related comorbidities. ${ }^{3,5,10-12}$ In addition, bariatric surgery often leads to a decrease of the low-grade inflammation. ${ }^{10-12}$ This underlines the involvement of inflammation in the pathogenesis of obesity and the obesity-related diseases. As described above, DJBL treatment led to weight loss and improvement of the comorbid conditions of obesity. Therefore, in Chapter 8 we described the effect of DJBL treatment on low-grade systemic inflammation. We determined several inflammation related parameters in plasma before and during DJBL treatment: C-reactive protein (CRP), myeloperoxidase (MPO), interleukin 6 (IL-6), and tumor necrosis factor alpha (TNF- $\alpha$ ). Both TNF- $\alpha$ and IL- 6 are pro-inflammatory cytokines. These cytokines are important stimulators of hepatic CRP production. ${ }^{61,64} \mathrm{MPO}$ is a neutrophil secretion product; its presence in plasma indicates activation of the innate immune system and the levels MPO in plasma have been observed to be increased in obese subjects. ${ }^{68}$ In our study, we observed a transient increase of the inflammation parameters three months after initiation of DJBL treatment. After six months of treatment, the levels had returned to baseline levels, indicating a transient reaction after DJBL implantation. 
Importantly, as described in the previous section, DJBL treatment was associated with improvement of type 2 diabetes. Because of the suggested importance of systemic inflammation in the pathophysiology of type 2 diabetes, ${ }^{65-67}$ we expected to observe decreased systemic inflammation. Our data showing a transient increase of inflammatory parameters during DJBL treatment do not support that the DJBL-related improvement of type 2 diabetes is caused by effects on inflammation. However, our study subjects had relatively low levels of the inflammatory parameters at baseline, indicating only minor systemic inflammation and making improvement i.e. even lower levels hard to achieve. ${ }^{69}$

Interestingly, CCK, mentioned previously as satiety hormone, is also known for its important anti-inflammatory properties. In response to food triggers, CCK receptors on the vagal nerve are activated and do not only signal satiety but also trigger a potent antiinflammatory response. ${ }^{70,71}$ The decreased CCK levels after DJBL treatment might therefore play a role in the observed transiently increased inflammation parameters.

In Chapter 5, the effect of DJBL treatment on nonalcoholic fatty liver disease (NAFLD) was described. NAFLD is the result of fat accumulation in the liver which may progress to nonalcoholic steatohepatitis (NASH), a state in which inflammation is present. ${ }^{72,73}$ With the obesity epidemic, NAFLD has become the most common chronic liver disease worldwide. $^{74,75}$ Bariatric surgery has been reported to positively affect NAFLD. ${ }^{6,76-81}$ We were interested in the effect of DJBL treatment on NAFLD. Plasma markers reflecting NAFLD were measured before, during, and after DJBL treatment. Our data show that plasma liver parameters used in clinical practice such as aspartate aminotransferase (AST), alanine aminotransferase (ALT), and gamma-glutamyltransferase $(\gamma-\mathrm{GT}){ }^{82,83}$ decreased following DJBL implantation; normalization of these parameters occurred in almost all patients. In addition, plasma levels of caspase-cleaved cytokeratin-18 (CK-18), a marker of hepatocyte apoptosis, ${ }^{84}$ and liver fatty acid-binding protein (L-FABP), a liver damage marker, ${ }^{85}$ were diminished. This indicates a DJBL-induced improvement of NAFLD and may have important implications for the increasing number of patients needing liver transplantation due to NAFLD-related liver failure.

In our multicenter study (Chapter 2), we have studied the effect of DJBL vs. control treatment on cardiovascular parameters. Six months after implantation of DJBL treatment, a significant improvement of total cholesterol levels was observed, indicating a positive effect of the DJBL. Six months after removal of the DJBL, the total cholesterol level had returned to baseline levels. Neither high-density lipoprotein, low-density lipoprotein (LDL), triglyceride (TG) levels, nor blood pressure changed over time. A study by de Moura et al. also found improved total cholesterol levels after DJBL treatment. Interestingly, in addition they found LDL and TG levels to be improved during DJBL treatment. ${ }^{86}$ 


\section{Role of gut microbiota in obesity and the impact of DJBL treatment}

Both in animals and in human subjects, obesity has been associated with an altered intestinal microbiota composition. ${ }^{87,88}$ Bacteria are suggested to play a critical role in the development of obesity and its associated diseases by affecting energy balance, glucose metabolism, and low grade systemic inflammation. ${ }^{89}$ Germ-free mice have been shown to be protected from diet-induced obesity. ${ }^{90}$ In addition, colonization of germ-free mice with intestinal microbiota from obese mice resulted in obesity and insulin resistance, whereas colonization with microbiota from lean mice did not. ${ }^{91,92}$ These findings might be related to an increased capacity of the obese microbiome to harvest energy from food. ${ }^{91,92}$ Interestingly, fecal transplantation from lean donors to obese human subjects has been shown to increase insulin sensitivity. ${ }^{93}$ In addition, gut microbiota composition has been associated with intestinal permeability in obese mice. A higher intestinal permeability has been suggested to trigger the low-grade systemic inflammatory state of obesity and its related diseases such as NAFLD and type 2 diabetes, mediated by translocation of bacterial translocation causing endotoxemia. ${ }^{94-96}$

In Chapter 6, differences in microbiota composition between lean and obese subjects in relation to both intestinal inflammation and systemic inflammation and gut permeability were reported. We found that microbiota composition is altered in human obesity, with an increased Firmicutes to Bacteroidetes ratio: the ratio between the two most dominant phyla within the gut microbiota. In addition, obesity was associated with decreased bacterial diversity in the gut. Interestingly, the obese microbiota was found to be related to both intestinal and systemic inflammation. In contrast to animal studies, ${ }^{89,95,97}$ intestinal permeability was neither altered in obesity nor related to inflammation or to microbiota composition.

In Chapter 7, we investigated the effect of DJBL treatment on microbiota composition in relation to weight loss and improvement of type 2 diabetes, and found that metabolic improvement correlated with changes in microbiota composition. This is in line with a study from Furet et al. who observed changes in gut microbiota after Roux-en-Y gastric bypass to be associated with metabolic improvement. ${ }^{98}$ Next, microbial diversity was investigated. Importantly, decreased diversity has been found to be associated to type 2 diabetes. ${ }^{99}$ We found the diversity of the microbiota to increase after initiation of DJBL treatment. All in all, these data suggest an effect of the DJBL in gut microbiota composition possibly mediating the beneficial effects of DJBL treatment on obesity and type 2 diabetes. However, preliminary data indicate that after termination of DJBL treatment, the microbiota composition tended to return to the composition found at baseline. This is in line with studies revealing that the human microbiota composition is relatively stable over years ${ }^{100-102}$ and this might have important implications with regard to 
the possibility of treating obesity and its comorbidities with prebiotics and probiotics, suggesting long-term treatment to be necessary.

\section{Conclusions and future perspectives}

According to the International Diabetes Federation position statement, bariatric surgery should be incorporated in the treatment algorithms of type 2 diabetes. ${ }^{103}$ In comparison to conventional surgical bariatric procedures, the DJBL procedure is less invasive and reversible. Despite that, it is shown here to have beneficial effects on obesity and its related diseases. In the current thesis, the first studies investigating the possible mechanisms underlying these beneficial effects of DJBL treatment are described. Possible involvement of satiety hormones, gut hormones related to type 2 diabetes, and intestinal microbiota composition was discovered. Furthermore, DJBL treatment improved plasma parameters related to NAFLD, suggesting an effect on NAFLD as well. Importantly, DJBL treatment has a high safety profile with no mortality reported and in general only minor complications. ${ }^{16,18,19,86,104-106}$ All in all, the DJBL seems a valuable option in the fight against obesity and its related diseases.

The target group for treatment with the DJBL are patients with obesity, with a BMI between 30 and $50 \mathrm{~kg} / \mathrm{m}^{2}$, and type 2 diabetes, as studied in the current thesis. Cohen et al. published two studies with the DJBL including patients with a relatively low BMI revealing improvement of type 2 diabetes also in this group. ${ }^{104,107}$ Hence, DJBL treatment seems also useful in the group of patients not yet eligible for invasive bariatric techniques. Importantly, bariatric procedures are never a stand-alone procedure, i.e. requiring a lifestyle program and dietary support. Therefore, DJBL treatment should be combined with optimal conservative treatment. In particular, the recently developed glucagon-like peptide-1 agonists and dipeptidyl peptidase- 4 inhibitors seem very promising in this respect. $^{108}$

In the current thesis, DJBL treatment duration was limited to six months. In recent studies, treatment duration has been extended to a year resulting in CE mark approval for one year. ${ }^{86,104,109}$ Preliminary data have shown that in a selected group of patients even longer treatment duration of up to three years is feasible. In addition, studies on repetitive DJBL treatment are being performed with one year of treatment followed by re-implantation one year after removal; this seems feasible and even more effective. Importantly, we reported the first post-explantation results. These results are promising, suggesting a sustained effect, and longer term data are to become available. Of note, the first data on DJBL implantation under conscious sedation have been presented, eliminating the increased risk of general anesthesia in obese patients. ${ }^{110,111}$ These developments strength- 
en the position of DJBL treatment as a safe and feasible technique and optimization of the treatment will probably also make it effective on the longer term.

In future studies, the effect of DJBL treatment on other obesity-related diseases such as diabetic nephropathy, obstructive sleep apnea, and atherosclerosis is worth studying, because improvement of these diseases might be expected based on previous results from the surgical bariatric field. ${ }^{112-114}$ In addition, a direct comparison between surgical bariatric techniques, DJBL treatment, and maximal medical and lifestyle treatment are warranted.

In conclusion, the DJBL is a promising non-surgical bariatric treatment option for obese patients with or without type 2 diabetes. With the data available to date, ${ }^{17,115}$ the DJBL could be best positioned in between medical therapy and invasive surgical bariatric procedures. 


\section{REFERENCES}

1. World Health Organization World Wide Web Media Centre. Obesity and overweight Fact sheet $\mathrm{N}^{\circ} 311$. 2013.

2. Pories WJ, Swanson MS, MacDonald KG, Long SB, Morris PG, Brown BM, Barakat HA, deRamon RA, Israel G, Dolezal JM, et al. Who would have thought it? An operation proves to be the most effective therapy for adult-onset diabetes mellitus. Ann Surg. 1995 Sep;222(3):339-50; discussion 50-2.

3. Sjostrom L, Lindroos AK, Peltonen M, Torgerson J, Bouchard C, Carlsson B, Dahlgren S, Larsson B, Narbro $\mathrm{K}$, Sjostrom $\mathrm{CD}$, et al. Lifestyle, diabetes, and cardiovascular risk factors 10 years after bariatric surgery. $\mathrm{N}$ Engl J Med. 2004 Dec;351(26):2683-93.

4. Sjostrom L. Review of the key results from the Swedish Obese Subjects (SOS) trial - a prospective controlled intervention study of bariatric surgery. Journal of internal medicine. 2013 Mar;273(3):219-34.

5. Buchwald H, Estok R, Fahrbach K, Banel D, Jensen MD, Pories WJ, Bantle JP, Sledge I. Weight and type 2 diabetes after bariatric surgery: systematic review and meta-analysis. Am J Med. 2009 Mar;122(3):24856.

6. Rabl C, Campos GM. The impact of bariatric surgery on nonalcoholic steatohepatitis. Semin Liver Dis. 2012 Feb;32(1):80-91.

7. Borg CM, le Roux CW, Ghatei MA, Bloom SR, Patel AG, Aylwin SJ. Progressive rise in gut hormone levels after Roux-en-Y gastric bypass suggests gut adaptation and explains altered satiety. Br J Surg. 2006 Feb;93(2):210-5.

8. le Roux CW, Welbourn R, Werling M, Osborne A, Kokkinos A, Laurenius A, Lonroth H, Fandriks L, Ghatei MA, Bloom SR, et al. Gut hormones as mediators of appetite and weight loss after Roux-en-Y gastric bypass. Ann Surg. 2007 Nov;246(5):780-5.

9. Zhang H, DiBaise JK, Zuccolo A, Kudrna D, Braidotti M, Yu Y, Parameswaran P, Crowell MD, Wing R, Rittmann BE, et al. Human gut microbiota in obesity and after gastric bypass. Proceedings of the National Academy of Sciences of the United States of America. 2009 Feb 17;106(7):2365-70.

10. Rao SR. Inflammatory markers and bariatric surgery: a meta-analysis. Inflammation research : official journal of the European Histamine Research Society. 2012 Aug;61(8):789-807.

11. Illan-Gomez F, Gonzalvez-Ortega M, Orea-Soler I, Alcaraz-Tafalla MS, Aragon-Alonso A, Pascual-Diaz M, Perez-Paredes M, Lozano-Almela ML. Obesity and inflammation: change in adiponectin, C-reactive protein, tumour necrosis factor-alpha and interleukin-6 after bariatric surgery. Obes Surg. 2012 Jun;22(6):950-5.

12. Miller GD, Nicklas BJ, Fernandez A. Serial changes in inflammatory biomarkers after Roux-en-Y gastric bypass surgery. Surg Obes Relat Dis. 2011 Sep-Oct;7(5):618-24.

13. Buchwald H, Avidor Y, Braunwald E, Jensen MD, Pories W, Fahrbach K, Schoelles K. Bariatric surgery: a systematic review and meta-analysis. JAMA. 2004 Oct 13;292(14):1724-37.

14. Nguyen NT, Silver M, Robinson M, Needleman B, Hartley G, Cooney R, Catalano R, Dostal J, Sama D, Blankenship J, et al. Result of a national audit of bariatric surgery performed at academic centers: a 2004 University HealthSystem Consortium Benchmarking Project. Arch Surg. 2006 May;141(5):445-9; discussion 9-50.

15. Verdam FJ, Schouten R, Greve JW, Koek GH, Bouvy ND. An update on less invasive and endoscopic techniques mimicking the effect of bariatric surgery. J Obes. 2012;597871.

16. Schouten R, Rijs CS, Bouvy ND, Hameeteman W, Koek GH, Janssen IM, Greve JW. A multicenter, randomized efficacy study of the EndoBarrier Gastrointestinal Liner for presurgical weight loss prior to bariatric surgery. Ann Surg. 2010 Feb;251(2):236-43.

17. Patel SR, Hakim D, Mason J, Hakim N. The duodenal-jejunal bypass sleeve (EndoBarrier Gastrointestinal Liner) for weight loss and treatment of type 2 diabetes. Surg Obes Relat Dis. 2013 May-June;9(3):482-4. 
18. Tarnoff M, Rodriguez L, Escalona A, Ramos A, Neto M, Alamo M, Reyes E, Pimentel F, Ibanez L. Open label, prospective, randomized controlled trial of an endoscopic duodenal-jejunal bypass sleeve versus low calorie diet for pre-operative weight loss in bariatric surgery. Surg Endosc. 2009 Mar;23(3):650-6.

19. Gersin KS, Rothstein RI, Rosenthal RJ, Stefanidis D, Deal SE, Kuwada TS, Laycock W, Adrales G, Vassiliou $M$, Szomstein S, et al. Open-label, sham-controlled trial of an endoscopic duodenojejunal bypass liner for preoperative weight loss in bariatric surgery candidates. Gastrointest Endosc. 2010 May;71(6):976-82.

20. Strader AD, Woods SC. Gastrointestinal hormones and food intake. Gastroenterology. 2005 Jan;128(1):175-91.

21. Wren AM, Bloom SR. Gut hormones and appetite control. Gastroenterology. 2007 May;132(6):2116-30.

22. Michalakis K, le Roux C. Gut hormones and leptin: impact on energy control and changes after bariatric surgery--what the future holds. Obes Surg. 2012 Oct;22(10):1648-57.

23. Batterham RL, Cohen MA, Ellis SM, Le Roux CW, Withers DJ, Frost GS, Ghatei MA, Bloom SR. Inhibition of food intake in obese subjects by peptide YY3-36. N Engl J Med. 2003 Sep;349(10):941-8.

24. Huda MS, Wilding JP, Pinkney JH. Gut peptides and the regulation of appetite. Obes Rev. 2006 May;7(2):163-82.

25. Beckman LM, Beckman TR, Earthman CP. Changes in gastrointestinal hormones and leptin after Roux-enY gastric bypass procedure: a review. J Am Diet Assoc. 2010 Apr;110(4):571-84.

26. Maljaars PW, Symersky T, Kee BC, Haddeman E, Peters HP, Masclee AA. Effect of ileal fat perfusion on satiety and hormone release in healthy volunteers. Int J Obes. 2008 Nov;32(11):1633-9.

27. Maljaars PW, Peters HP, Mela DJ, Masclee AA. lleal brake: a sensible food target for appetite control. A review. Physiol Behav. 2008 Oct;95(3):271-81.

28. Lee HC, Kim MK, Kwon HS, Kim E, Song KH. Early changes in incretin secretion after laparoscopic duodenal-jejunal bypass surgery in type 2 diabetic patients. Obes Surg. 2010 Nov;20(11):1530-5.

29. Ochner CN, Gibson C, Shanik M, Goel V, Geliebter A. Changes in neurohormonal gut peptides following bariatric surgery. Int J Obes. 2011 Feb;35(2):153-66.

30. Pournaras DJ, Osborne A, Hawkins SC, Mahon D, Ghatei MA, Bloom SR, Welbourn R, le Roux CW. The gut hormone response following Roux-en-Y gastric bypass: cross-sectional and prospective study. Obes Surg. 2010 Jan;20(1):56-60.

31. le Roux CW, Aylwin SJ, Batterham RL, Borg CM, Coyle F, Prasad V, Shurey S, Ghatei MA, Patel AG, Bloom SR. Gut hormone profiles following bariatric surgery favor an anorectic state, facilitate weight loss, and improve metabolic parameters. Ann Surg. 2006 Jan;243(1):108-14.

32. Peterli R, Wolnerhanssen B, Peters T, Devaux N, Kern B, Christoffel-Courtin C, Drewe J, von Flue M, Beglinger $C$. Improvement in glucose metabolism after bariatric surgery: comparison of laparoscopic Roux-en-Y gastric bypass and laparoscopic sleeve gastrectomy: a prospective randomized trial. Ann Surg. 2009 Aug;250(2):234-41.

33. Cummings DE, Overduin J. Gastrointestinal regulation of food intake. J Clin Invest. 2007 Jan;117(1):13-23.

34. Dockray GJ. Cholecystokinin. Curr Opin Endocrinol Diabetes Obes. 2012 Feb;19(1):8-12.

35. Cummings $\mathrm{DE}$, Shannon $\mathrm{MH}$. Roles for ghrelin in the regulation of appetite and body weight. Arch Surg. 2003 Apr;138(4):389-96.

36. Sato T, Nakamura Y, Shiimura Y, Ohgusu H, Kangawa K, Kojima M. Structure, regulation and function of ghrelin. Journal of biochemistry. 2012 Feb;151(2):119-28.

37. Considine RV, Sinha MK, Heiman ML, Kriauciunas A, Stephens TW, Nyce MR, Ohannesian JP, Marco CC, McKee LJ, Bauer TL, et al. Serum immunoreactive-leptin concentrations in normal-weight and obese humans. N Engl J Med. 1996 Feb;334(5):292-5.

38. Korner J, Inabnet W, Febres G, Conwell IM, McMahon DJ, Salas R, Taveras C, Schrope B, Bessler M. Prospective study of gut hormone and metabolic changes after adjustable gastric banding and Roux-en- $Y$ gastric bypass. Int J Obes. 2009 Jul;33(7):786-95.

39. Meier U, Gressner AM. Endocrine regulation of energy metabolism: review of pathobiochemical and clinical chemical aspects of leptin, ghrelin, adiponectin, and resistin. Clin Chem. 2004 Sep;50(9):1511-25. 
40. Oswal A, Yeo G. Leptin and the control of body weight: a review of its diverse central targets, signaling mechanisms, and role in the pathogenesis of obesity. Obesity. 2010 Feb;18(2):221-9.

41. Woods SC, D'Alessio DA. Central control of body weight and appetite. J Clin Endocrinol Metab. 2008 Nov;93(11 Suppl 1):S37-50.

42. Bradley D, Conte C, Mittendorfer B, Eagon JC, Varela JE, Fabbrini E, Gastaldelli A, Chambers KT, Su X, Okunade A, et al. Gastric bypass and banding equally improve insulin sensitivity and beta cell function. J Clin Invest. 2012 Dec;122(12):4667-74.

43. Cohen R, le Roux CW, Papamargaritis D, Salles JE, Petry T, Correa JL, Pournaras DJ, Galvao Neto M, Martins B, Sakai $P$, et al. Role of proximal gut exclusion from food on glucose homeostasis in patients with Type 2 diabetes. Diabet Med. 2013 Dec;30(12):1482-6.

44. Laferrere B, Teixeira J, McGinty J, Tran H, Egger JR, Colarusso A, Kovack B, Bawa B, Koshy N, Lee H, et al. Effect of weight loss by gastric bypass surgery versus hypocaloric diet on glucose and incretin levels in patients with type 2 diabetes. J Clin Endocrinol Metab. 2008 Jul;93(7):2479-85.

45. Pournaras DJ, Osborne A, Hawkins SC, Vincent RP, Mahon D, Ewings P, Ghatei MA, Bloom SR, Welbourn $\mathrm{R}$, le Roux CW. Remission of type 2 diabetes after gastric bypass and banding: mechanisms and 2 year outcomes. Ann Surg. 2010 Dec;252(6):966-71.

46. Schauer PR, Kashyap SR, Wolski K, Brethauer SA, Kirwan JP, Pothier CE, Thomas S, Abood B, Nissen SE, Bhatt DL. Bariatric surgery versus intensive medical therapy in obese patients with diabetes. $\mathrm{N}$ Engl J Med. 2012 Apr 26;366(17):1567-76.

47. Mingrone G, Panunzi S, De Gaetano A, Guidone C, laconelli A, Leccesi L, Nanni G, Pomp A, Castagneto M, Ghirlanda $G$, et al. Bariatric surgery versus conventional medical therapy for type 2 diabetes. N Engl J Med. 2012 Apr 26;366(17):1577-85.

48. Fetner R, McGinty J, Russell C, Pi-Sunyer FX, Laferrere B. Incretins, diabetes, and bariatric surgery: a review. Surg Obes Relat Dis. 2005 Nov-Dec;1(6):589-97; discussion 97-8.

49. Thaler JP, Cummings DE. Minireview: Hormonal and metabolic mechanisms of diabetes remission after gastrointestinal surgery. Endocrinology. 2009 Jun;150(6):2518-25.

50. Nauck MA, Heimesaat MM, Orskov C, Holst JJ, Ebert R, Creutzfeldt W. Preserved incretin activity of glucagon-like peptide 1 [7-36 amide] but not of synthetic human gastric inhibitory polypeptide in patients with type-2 diabetes mellitus. J Clin Invest. 1993 Jan;91(1):301-7.

51. Rao RS, Kini S. GIP and bariatric surgery. Obes Surg. 2011 Feb;21(2):244-52.

52. Hare KJ, Knop FK, Asmar M, Madsbad S, Deacon CF, Holst JJ, Vilsboll T. Preserved inhibitory potency of GLP-1 on glucagon secretion in type 2 diabetes mellitus. J Clin Endocrinol Metab. 2009 Dec;94(12):467987.

53. Holst JJ, Christensen M, Lund A, de Heer J, Svendsen B, Kielgast U, Knop FK. Regulation of glucagon secretion by incretins. Diabetes Obes Metab. 2011 Oct;13 Suppl 1:89-94.

54. Yabe D, Seino Y. Two incretin hormones GLP-1 and GIP: comparison of their actions in insulin secretion and beta cell preservation. Prog Biophys Mol Biol. 2011 Nov;107(2):248-56.

55. Menge BA, Gruber L, Jorgensen SM, Deacon CF, Schmidt WE, Veldhuis JD, Holst JJ, Meier JJ. Loss of inverse relationship between pulsatile insulin and glucagon secretion in patients with type 2 diabetes. Diabetes. 2011 Aug;60(8):2160-8.

56. Rubino F, Forgione A, Cummings DE, Vix M, Gnuli D, Mingrone G, Castagneto M, Marescaux J. The mechanism of diabetes control after gastrointestinal bypass surgery reveals a role of the proximal small intestine in the pathophysiology of type 2 diabetes. Ann Surg. 2006 Nov;244(5):741-9.

57. Knop FK. Resolution of type 2 diabetes following gastric bypass surgery: involvement of gut-derived glucagon and glucagonotropic signalling? Diabetologia. 2009 Nov;52(11):2270-6.

58. Aroda VR, Henry RR, Han J, Huang W, DeYoung MB, Darsow T, Hoogwerf BJ. Efficacy of GLP-1 receptor agonists and DPP-4 inhibitors: meta-analysis and systematic review. Clinical therapeutics. 2012 Jun;34(6):1247-58.

59. Nauck MA. Incretin-based therapies for type 2 diabetes mellitus: properties, functions, and clinical implications. Am J Med. 2011 Jan;124(1 Suppl):S3-18. 
60. Global Guideline for Type 2 Diabetes. 2012.

61. Ouchi N, Parker JL, Lugus JJ, Walsh K. Adipokines in inflammation and metabolic disease. Nat Rev Immunol. 2011 Feb;11(2):85-97.

62. Visser M, Bouter LM, McQuillan GM, Wener MH, Harris TB. Elevated C-reactive protein levels in overweight and obese adults. JAMA. 1999 Dec 8;282(22):2131-5.

63. Gregor MF, Hotamisligil GS. Inflammatory mechanisms in obesity. Annu Rev Immunol. 201;29:415-45.

64. Maachi M, Pieroni L, Bruckert E, Jardel C, Fellahi S, Hainque B, Capeau J, Bastard JP. Systemic low-grade inflammation is related to both circulating and adipose tissue TNFalpha, leptin and IL-6 levels in obese women. Int J Obes Relat Metab Disord. 2004 Aug;28(8):993-7.

65. Donath MY, Shoelson SE. Type 2 diabetes as an inflammatory disease. Nat Rev Immunol. 2011 Feb;11(2):98-107.

66. Cottam DR, Mattar SG, Barinas-Mitchell E, Eid G, Kuller L, Kelley DE, Schauer PR. The chronic inflammatory hypothesis for the morbidity associated with morbid obesity: implications and effects of weight loss. Obes Surg. 2004 May;14(5):589-600.

67. Kalupahana NS, Moustaid-Moussa N, Claycombe KJ. Immunity as a link between obesity and insulin resistance. Mol Aspects Med. 2012 Feb;33(1):26-34.

68. Nijhuis J, Rensen SS, Slaats Y, van Dielen FM, Buurman WA, Greve JW. Neutrophil activation in morbid obesity, chronic activation of acute inflammation. Obesity. 2009 Nov;17(11):2014-8.

69. Shoelson SE, Lee J, Goldfine AB. Inflammation and insulin resistance. J Clin Invest. 2006 Jul;116(7):1793801.

70. Lubbers T, de Haan JJ, Luyer MD, Verbaeys I, Hadfoune M, Dejong CH, Buurman WA, Greve JW. Cholecystokinin/Cholecystokinin-1 receptor-mediated peripheral activation of the afferent vagus by enteral nutrients attenuates inflammation in rats. Ann Surg. 2010 Aug;252(2):376-82.

71. Luyer MD, Greve JW, Hadfoune M, Jacobs JA, Dejong CH, Buurman WA. Nutritional stimulation of cholecystokinin receptors inhibits inflammation via the vagus nerve. The Journal of experimental medicine. 2005 Oct 17;202(8):1023-9.

72. Verna EC, Berk PD. Role of fatty acids in the pathogenesis of obesity and fatty liver: impact of bariatric surgery. Semin Liver Dis. 2008 Nov;28(4):407-26.

73. Walenbergh SM, Koek GH, Bieghs V, Shiri-Sverdlov R. Non-alcoholic steatohepatitis: The role of oxidized low-density lipoproteins. J Hepatol. 2013 Apr;58(4):801-10.

74. Lazo M, Clark JM. The epidemiology of nonalcoholic fatty liver disease: a global perspective. Semin Liver Dis. 2008 Nov;28(4):339-50.

75. Chalasani N, Younossi Z, Lavine JE, Diehl AM, Brunt EM, Cusi K, Charlton M, Sanyal AJ. The diagnosis and management of non-alcoholic fatty liver disease: practice Guideline by the American Association for the Study of Liver Diseases, American College of Gastroenterology, and the American Gastroenterological Association. Hepatology. 2012 Jun;55(6):2005-23.

76. Blackburn GL, Mun EC. Effects of weight loss surgeries on liver disease. Semin Liver Dis. 2004 Nov;24(4):371-9.

77. Mattar SG, Velcu LM, Rabinovitz M, Demetris AJ, Krasinskas AM, Barinas-Mitchell E, Eid GM, Ramanathan R, Taylor DS, Schauer PR. Surgically-induced weight loss significantly improves nonalcoholic fatty liver disease and the metabolic syndrome. Ann Surg. 2005 Oct;242(4):610-20.

78. Klein S, Mittendorfer B, Eagon JC, Patterson B, Grant L, Feirt N, Seki E, Brenner D, Korenblat K, McCrea J. Gastric bypass surgery improves metabolic and hepatic abnormalities associated with nonalcoholic fatty liver disease. Gastroenterology. 2006 May;130(6):1564-72.

79. Barker KB, Palekar NA, Bowers SP, Goldberg JE, Pulcini JP, Harrison SA. Non-alcoholic steatohepatitis: effect of Roux-en-Y gastric bypass surgery. Am J Gastroenterol. 2006 Feb;101(2):368-73.

80. Mathurin P, Hollebecque A, Arnalsteen L, Buob D, Leteurtre E, Caiazzo R, Pigeyre M, Verkindt $H$, Dharancy $S$, Louvet $A$, et al. Prospective study of the long-term effects of bariatric surgery on liver injury in patients without advanced disease. Gastroenterology. 2009 Aug;137(2):532-40. 
81. Chavez-Tapia NC, Tellez-Avila FI, Barrientos-Gutierrez T, Mendez-Sanchez N, Lizardi-Cervera J, Uribe M. Bariatric surgery for non-alcoholic steatohepatitis in obese patients. Cochrane Database Syst Rev. 2010 1):CD007340.

82. Wieckowska A, McCullough AJ, Feldstein AE. Noninvasive diagnosis and monitoring of nonalcoholic steatohepatitis: present and future. Hepatology. 2007 Aug;46(2):582-9.

83. Neuschwander-Tetri BA, Clark JM, Bass NM, Van Natta ML, Unalp-Arida A, Tonascia J, Zein CO, Brunt EM, Kleiner DE, McCullough AJ, et al. Clinical, laboratory and histological associations in adults with nonalcoholic fatty liver disease. Hepatology. 2010 Sep;52(3):913-24.

84. Feldstein AE, Canbay A, Angulo P, Taniai M, Burgart LJ, Lindor KD, Gores GJ. Hepatocyte apoptosis and fas expression are prominent features of human nonalcoholic steatohepatitis. Gastroenterology. 2003 Aug;125(2):437-43.

85. Pelsers MM, Morovat A, Alexander GJ, Hermens WT, Trull AK, Glatz JF. Liver fatty acid-binding protein as a sensitive serum marker of acute hepatocellular damage in liver transplant recipients. Clin Chem. 2002 Nov;48(11):2055-7.

86. de Moura EG, Martins BC, Lopes GS, Orso IR, de Oliveira SL, Galvao Neto MP, Santo MA, Sakai P, Ramos $A C$, Garrido Junior AB, et al. Metabolic improvements in obese type 2 diabetes subjects implanted for 1 year with an endoscopically deployed duodenal-jejunal bypass liner. Diabetes Technol Ther. 2012 Feb;14(2):183-9.

87. Ley RE. Obesity and the human microbiome. Current opinion in gastroenterology. 2010 Jan;26(1):5-11.

88. Diamant M, Blaak EE, de Vos WM. Do nutrient-gut-microbiota interactions play a role in human obesity, insulin resistance and type 2 diabetes? Obes Rev. 2011 Apr;12(4):272-81.

89. Cani PD, Osto M, Geurts L, Everard A. Involvement of gut microbiota in the development of low-grade inflammation and type 2 diabetes associated with obesity. Gut microbes. 2012 Jul-Aug;3(4):279-88.

90. Backhed F, Manchester JK, Semenkovich CF, Gordon JI. Mechanisms underlying the resistance to dietinduced obesity in germ-free mice. Proceedings of the National Academy of Sciences of the United States of America. 2007 Jan 16;104(3):979-84.

91. Backhed F, Ding H, Wang T, Hooper LV, Koh GY, Nagy A, Semenkovich CF, Gordon Jl. The gut microbiota as an environmental factor that regulates fat storage. Proceedings of the National Academy of Sciences of the United States of America. 2004 Nov 2;101(44):15718-23.

92. Turnbaugh PJ, Ley RE, Mahowald MA, Magrini V, Mardis ER, Gordon JI. An obesity-associated gut microbiome with increased capacity for energy harvest. Nature. 2006 Dec 21;444(7122):1027-31.

93. Vrieze A, Van Nood E, Holleman F, Salojarvi J, Kootte RS, Bartelsman JF, Dallinga-Thie GM, Ackermans MT, Serlie MJ, Oozeer R, et al. Transfer of intestinal microbiota from lean donors increases insulin sensitivity in individuals with metabolic syndrome. Gastroenterology. 2012 Oct;143(4):913-6.

94. Amar J, Burcelin R, Ruidavets JB, Cani PD, Fauvel J, Alessi MC, Chamontin B, Ferrieres J. Energy intake is associated with endotoxemia in apparently healthy men. The American journal of clinical nutrition. 2008 May;87(5):1219-23.

95. Cani PD, Possemiers S, Van de Wiele T, Guiot Y, Everard A, Rottier O, Geurts L, Naslain D, Neyrinck A, Lambert DM, et al. Changes in gut microbiota control inflammation in obese mice through a mechanism involving GLP-2-driven improvement of gut permeability. Gut. 2009 Aug;58(8):1091-103.

96. Farhadi A, Gundlapalli S, Shaikh M, Frantzides C, Harrell L, Kwasny MM, Keshavarzian A. Susceptibility to gut leakiness: a possible mechanism for endotoxaemia in non-alcoholic steatohepatitis. Liver Int. 2008 Aug;28(7):1026-33.

97. Cani PD, Bibiloni R, Knauf C, Waget A, Neyrinck AM, Delzenne NM, Burcelin R. Changes in gut microbiota control metabolic endotoxemia-induced inflammation in high-fat diet-induced obesity and diabetes in mice. Diabetes. 2008 Jun;57(6):1470-81.

98. Furet JP, Kong LC, Tap J, Poitou C, Basdevant A, Bouillot JL, Mariat D, Corthier G, Dore J, Henegar C, et al. Differential adaptation of human gut microbiota to bariatric surgery-induced weight loss: links with metabolic and low-grade inflammation markers. Diabetes. 2010 Dec;59(12):3049-57. 
99. Zhang X, Shen D, Fang Z, Jie Z, Qiu X, Zhang C, Chen Y, Ji L. Human gut microbiota changes reveal the progression of glucose intolerance. PLoS One. 2013 8(8):e71108.

100. Biagi E, Nylund L, Candela M, Ostan R, Bucci L, Pini E, Nikkila J, Monti D, Satokari R, Franceschi C, et al. Through ageing, and beyond: gut microbiota and inflammatory status in seniors and centenarians. PLoS One. 2010 5(5):e10667.

101. Rajilic-Stojanovic M, Heilig HG, Molenaar D, Kajander K, Surakka A, Smidt H, de Vos WM. Development and application of the human intestinal tract chip, a phylogenetic microarray: analysis of universally conserved phylotypes in the abundant microbiota of young and elderly adults. Environmental microbiology. 2009 Jul;11(7):1736-51.

102. Yatsunenko T, Rey FE, Manary MJ, Trehan I, Dominguez-Bello MG, Contreras M, Magris M, Hidalgo G, Baldassano RN, Anokhin AP, et al. Human gut microbiome viewed across age and geography. Nature. 2012 Jun 14;486(7402):222-7.

103. Dixon JB, Zimmet P, Alberti KG, Mbanya JC, Rubino F, International Diabetes Federation Taskforce on E, Prevention. Bariatric surgery for diabetes: the International Diabetes Federation takes a position. J Diabetes. 2011 Dec;3(4):261-4.

104. Cohen RV, Neto MG, Correa JL, Sakai P, Martins B, Schiavon CA, Petry T, Salles JE, Mamedio C, Sorli C. A pilot study of the duodenal-jejunal bypass liner in low body mass index type 2 diabetes. J Clin Endocrinol Metab. 2013 Feb;98(2):E279-82.

105. Rodriguez L, Reyes E, Fagalde P, Oltra MS, Saba J, Aylwin CG, Prieto C, Ramos A, Galvao M, Gersin KS, et al. Pilot clinical study of an endoscopic, removable duodenal-jejunal bypass liner for the treatment of type 2 diabetes. Diabetes Technol Ther. 2009 Nov;11(11):725-32.

106. Rodriguez-Grunert L, Galvao Neto MP, Alamo M, Ramos AC, Baez PB, Tarnoff M. First human experience with endoscopically delivered and retrieved duodenal-jejunal bypass sleeve. Surg Obes Relat Dis. 2008 Jan-Feb;4(1):55-9.

107. Cohen R, le Roux CW, Papamargaritis D, Salles JE, Petry T, Correa JL, Pournaras DJ, Galvao Neto M, Martins $B$, Sakai $P$, et al. Role of proximal gut exclusion from food on glucose homeostasis in patients with Type 2 diabetes. Diabet Med. 2013 Dec;30(12):1482-6.

108. Piya MK, Tahrani AA, Barnett AH. Emerging Treatment Options for Type 2 Diabetes. British journal of clinical pharmacology. 2010 Aug 4.

109. Escalona A, Pimentel F, Sharp A, Becerra P, Slako M, Turiel D, Munoz R, Bambs C, Guzman S, Ibanez L, et al. Weight loss and metabolic improvement in morbidly obese subjects implanted for 1 year with an endoscopic duodenal-jejunal bypass liner. Ann Surg. 2012 Jun;255(6):1080-5.

110. Montana R, Slako M, Escalona A. Implantation of the duodenal-jejunal bypass sleeve under conscious sedation: a case series. Surg Obes Relat Dis. 2012 Sep-Oct;8(5):e63-5.

111. Koehestanie P, Betzel B, Dogan K, Berends F, Janssen I, Aarts E, Groenen M, Wahab P. The feasibility of delivering a duodenal-jejunal bypass liner (endobarrier) endoscopically with patients under conscious sedation. Surg Endosc. 2014 Jan;28(1):325-30.

112. Heneghan HM, Cetin D, Navaneethan SD, Orzech N, Brethauer SA, Schauer PR. Effects of bariatric surgery on diabetic nephropathy after 5 years of follow-up. Surg Obes Relat Dis. 2013 Jan-Feb;9(1):7-14.

113. Hewitt S, Humerfelt S, Sovik TT, Aasheim ET, Risstad H, Kristinsson J, Mala T. Long-Term Improvements in Pulmonary Function 5 Years After Bariatric Surgery. Obes Surg. 2014 May;24(5):705-11.

114. Tschoner A, Sturm W, Gelsinger C, Ress C, Laimer M, Engl J, Laimer E, Muhlmann G, Mittermair R, Kaser $\mathrm{S}$, et al. Long-term effects of weight loss after bariatric surgery on functional and structural markers of atherosclerosis. Obesity. 2013 Oct;21(10):1960-5.

115. Zechmeister-Koss I, Huic M, Fischer S, for the European Network for Health Technology A. The DuodenalJejunal Bypass Liner for the Treatment of Type 2 Diabetes Mellitus and/or Obesity: a Systematic Review. Obes Surg. 2014 Feb;24(2):310-23. 


\section{Chapter 10 Valorization}


Chapter 10 


\section{VALORIZATION}

\section{Relevance of current thesis}

With the increasing prevalence of overweight and obesity, the health burden of obesity and its comorbidities is becoming bigger and bigger. ${ }^{1}$ Overweight is currently the fifth leading risk factor for death globally. The majority of people live in countries where overweight and obesity kill more people than underweight. Importantly, it is also starting to affect young adults and even children. In 2011, already 40 million children under the age of five were overweight. ${ }^{1}$

Importantly, obese patients are at risk of developing a range of life threatening diseases such as type 2 diabetes, nonalcoholic steatohepatitis, cardiovascular problems, and several types of cancer. ${ }^{2-4}$ As a result, obesity is associated with a markedly decrease in life expectancy. ${ }^{5,6}$ In addition, obesity leads to psychosocial problems and impairs healthrelated quality of life. ${ }^{7,8}$

Beyond the health-related problems caused by obesity, the epidemic imposes a considerable economic problem for societies. ${ }^{1,9}$ Medical costs of obesity and its related diseases add up to the costs of productivity loss, due to sick leave, decreased productivity while at work, disability, and premature mortality. ${ }^{10}$ of note, there is also a microeconomic burden, caused by increased sick leave, decreased income, higher unemployment rates, and increased costs of health care. ${ }^{11}$

For years, bariatric surgery, applied in combination with life style adaptations, has been in use to effectively reduce weight and improve obesity-related comorbidities. It is associated with a reduction in overall mortality and decreased incidence of the obesityrelated comorbidities. ${ }^{12-14}$ However, despite all beneficial effects, bariatric surgery is associated with complications. ${ }^{15-17}$ Therefore, less invasive techniques have been developed, ${ }^{18}$ such as the duodenal-jejunal bypass liner or DJBL.

The current thesis evaluates the effectiveness of the DJBL in treating obesity, type 2 diabetes, and nonalcoholic fatty liver disease. Our results indicate a positive effect of DJBL treatment on these diseases with a satisfactory risk/benefit ratio. Therefore, DJBL treatment should be considered as an effective noninvasive treatment option for obesity and its related diseases.

To gain more insight in mechanisms responsible for the improvement, we studied hormonal changes related to type 2 diabetes and satiety. In addition we investigated the possible role of the intestinal microbiota composition and the low grade systemic inflammation. We are the first to report on these data. Importantly, these data can 
possibly be extrapolated to bariatric surgical techniques excluding the proximal small intestine, such as the frequently used Roux-en-Y gastric bypass. Results like these are essential in the unraveling of the pathophysiology of obesity and its comorbidities and may lead to the development of new treatment strategies.

\section{Target group}

The target group of this thesis are investigators in the biomedical field will special interest in the effect of bariatric surgery, satiety, inflammation, type 2 diabetes, nonalcoholic fatty liver disease, and obesity. In addition, this thesis is of interest to bariatric surgeons, internal medicine doctors, diabetes nurses, and nutritional counselors. Next, pharmaceutical companies might be interested in the data presented in this thesis to develop new treatment strategies for obesity and related diseases. Also companies developing various strategies to treat obesity are likely to be interested. Hopefully in the end, patients will benefit from obtained knowledge of the pathophysiology of obesity and its comorbidities.

\section{Knowledge utilization}

First, this study is a valorization on itself by being a cooperative study between the developers of the DJBL and the university working group that made use of its experience in this field. The specific knowledge of the research group in the field of obesity and related diseases will be valorized by applying this knowledge in studies further identifying factors that drive the development of obesity, type 2 diabetes, and NAFLD with particular interest in the intestinal microbiota composition and inflammation. The anticipated results will be used to develop novel treatment strategies for obesity and its comorbidities. The research is expected to greatly decrease the long-term burden of obesity and its associated disorders to the economy, society, and health care.

\section{Innovation}

The described studies are the first evaluating the mechanisms responsible for the effectiveness of DJBL treatment and offer new insights in the applicability of duodenaljejunal exclusion. The data obtained, will be the basis for further studies and treatment modalities for obesity and its comorbidities. 


\section{REFERENCES}

1. World Health Organization World Wide Web Media Centre. Obesity and overweight Fact sheet $\mathrm{N}^{\circ} 311$. 2013.

2. Sjostrom LV. Morbidity of severely obese subjects. The American journal of clinical nutrition. 1992 Feb;55:508S-15S.

3. Donohoe CL, O'Farrell NJ, Doyle SL, Reynolds JV. The role of obesity in gastrointestinal cancer: evidence and opinion. Therapeutic advances in gastroenterology. 2014 Jan;7(1):38-50.

4. Pischon T, Nothlings U, Boeing H. Obesity and cancer. The Proceedings of the Nutrition Society. 2008 May;67(2):128-45.

5. Peeters A, Barendregt JJ, Willekens F, Mackenbach JP, Al Mamun A, Bonneux L, Nedcom tNE, Demography Compression of Morbidity Research G. Obesity in adulthood and its consequences for life expectancy: a life-table analysis. Annals of internal medicine. 2003 Jan 7;138(1):24-32.

6. Fontaine KR, Redden DT, Wang C, Westfall AO, Allison DB. Years of life lost due to obesity. JAMA. 2003 Jan 8;289(2):187-93.

7. Larsson U, Karlsson J, Sullivan M. Impact of overweight and obesity on health-related quality of life--a Swedish population study. Int J Obes Relat Metab Disord. 2002 Mar;26(3):417-24.

8. Fontaine KR, Barofsky I. Obesity and health-related quality of life. Obes Rev. 2001 Aug;2(3):173-82.

9. Wang YC, McPherson K, Marsh T, Gortmaker SL, Brown M. Health and economic burden of the projected obesity trends in the USA and the UK. Lancet. 2011 Aug 27;378(9793):815-25.

10. Hammond RA, Levine R. The economic impact of obesity in the United States. Diabetes, metabolic syndrome and obesity : targets and therapy. 2010 Aug;30(3):285-95.

11. Yach D, Stuckler D, Brownell KD. Epidemiologic and economic consequences of the global epidemics of obesity and diabetes. Nat Med. 2006 Jan;12(1):62-6.

12. Sjostrom L. Review of the key results from the Swedish Obese Subjects (SOS) trial - a prospective controlled intervention study of bariatric surgery. Journal of internal medicine. 2013 Mar;273(3):219-34.

13. Buchwald H, Estok R, Fahrbach K, Banel D, Jensen MD, Pories WJ, Bantle JP, Sledge I. Weight and type 2 diabetes after bariatric surgery: systematic review and meta-analysis. Am J Med. 2009 Mar;122(3):24856.

14. Rabl C, Campos GM. The impact of bariatric surgery on nonalcoholic steatohepatitis. Semin Liver Dis. 2012 Feb;32(1):80-91.

15. Buchwald H, Avidor Y, Braunwald E, Jensen MD, Pories W, Fahrbach K, Schoelles K. Bariatric surgery: a systematic review and meta-analysis. JAMA. 2004 Oct 13;292(14):1724-37.

16. Sjostrom L, Lindroos AK, Peltonen M, Torgerson J, Bouchard C, Carlsson B, Dahlgren S, Larsson B, Narbro $\mathrm{K}$, Sjostrom $\mathrm{CD}$, et al. Lifestyle, diabetes, and cardiovascular risk factors 10 years after bariatric surgery. $\mathrm{N}$ Engl J Med. 2004 Dec;351(26):2683-93.

17. Nguyen NT, Silver M, Robinson M, Needleman B, Hartley G, Cooney R, Catalano R, Dostal J, Sama D, Blankenship J, et al. Result of a national audit of bariatric surgery performed at academic centers: a 2004 University HealthSystem Consortium Benchmarking Project. Arch Surg. 2006 May;141(5):445-9.

18. Verdam FJ, Schouten R, Greve JW, Koek GH, Bouvy ND. An update on less invasive and endoscopic techniques mimicking the effect of bariatric surgery. Journal of obesity. 2012:597871. 



\section{Chapter 11}

Nederlandse Samenvatting 
Chapter 11 


\section{NEDERLANDSE SAMENVATTING}

Overgewicht wordt wereldwijd een steeds groter probleem. Het aantal mensen met overgewicht blijft toenemen. Dit is niet alleen het geval in de westerse samenleving, maar ook in landen zoals India is het percentage mensen met overgewicht de laatste jaren enorm gestegen en lijkt deze stijging voorlopig niet af te nemen.

Extreem overgewicht wordt in medische termen (morbide) obesitas genoemd. Obesitas gaat vaak gepaard met aandoeningen zoals type 2 suikerziekte (ook wel diabetes of ouderdomssuikerziekte genoemd), hart- en vaatziekten, en vette leverziekte. Deze aandoeningen zijn geassocieerd met obesitas en worden ook wel comorbiditeiten van obesitas genoemd. Ook het voorkomen van deze ziekten is de laatste jaren enorm toegenomen. Obesitas is daarmee niet langer alleen een probleem voor de patiënt, maar daarnaast meer en meer een probleem van de samenleving. Dientengevolge is de vraag naar behandelingen voor obesitas groter dan ooit.

De eerste stap in de behandeling van obesitas is het geven van leefstijladviezen zoals: 'meer bewegen en minder eten'. Echter, wanneer het effect hiervan niet toerijkend is, kan gekozen worden voor chirurgische oplossingen.

Chirurgie voor obesitas, ook wel bariatrische chirurgie genoemd, wordt al enkele decenia toegepast. De meest bekende voorbeelden van bariatrisch chirurgie zijn de maagband en de gastric bypass. Bariatrische chirurgie kan langdurig gewichtsverlies bewerkstelligen. Daarnaast heeft het een positief effect op de aan obesitas gerelateerde comorbiditeiten zoals diabetes en hart- en vaatziekten. In sommige gevallen kan bariatrische chirurgie gepaard gaan met complicaties die nadelig zijn voor de patiënt en die bovendien leiden tot hoge kosten. Daarom wordt gezocht naar minder ingrijpende behandelingen. Denk hierbij bijvoorbeeld aan de maagballon, die voornamelijk in de jaren '90 veel werd toegepast. Belangrijk lijkt echter het uitsluiten van een gedeelte van de dunne darm in plaats van het ingrijpen op niveau van de maag. Met dit als achtergrond gedachte is de Duodenal-Jejunal Bypass Liner (afgekort DJBL) ontwikkeld en op de markt gebracht. De DJBL bestaat uit een $60 \mathrm{~cm}$ lange flexibele teflon koker die endoscopisch, zoals bij een kijkonderzoek van de maag, in de dunne darm wordt geplaatst. Na zes maanden tot een jaar wordt deze koker door middel van eenzelfde kijkonderzoek weer verwijderd.

In Hoofdstuk 1 worden de achtergrond van obesitas, de comorbiditeiten evenals de verschillende behandelingen beschreven. Daarnaast wordt het concept van de DJBL behandeld. Het effect van de DJBL op overgewicht, type 2 diabetes, vette leverziekte, verzadiging, darmbacteriën en ontsteking zijn onderzocht en de resultaten hiervan zijn beschreven in de verdere hoofdstukken van dit proefschrift. 


\section{DJBL behandeling leidt tot gewichtsverlies en verbetering van type $\mathbf{2}$ diabetes gepaard gaand met hormonale veranderingen}

Hoofdstuk 2 is gericht op het effect van de DJBL op obesitas en type 2 diabetes. In samenwerking met het Rijnstate ziekenhuis in Arnhem en het Atrium Medisch Centrum in Heerlen is gevonden dat de behandeling met de DJBL gedurende een half jaar resulteert in gewichtsreductie en verbetering van de diabetes. Na het verwijderen van de DJBL blijft deze verbetering aanhouden. Daarnaast zijn de effecten van de DJBL sterker dan de effecten van een intensieve dieet-behandeling. Zo konden meer mensen in de DJBL-groep hun diabetes medicijnen afbouwen en waren de bloedsuikers beter in de groep die met de DJBL behandeld werd.

In Hoofdstuk 3 wordt dieper ingegaan op hormonen die een rol zouden kunnen spelen bij de verbetering van type 2 diabetes die de DJBL bewerkstelligt. Bij patiënten met diabetes is de suikerhuishouding, oftewel het glucosemetabolisme, gestoord. In het geval van type 2 diabetes is het glucosegehalte in het bloed van de patiënt verhoogd in reactie op verminderde gevoeligheid voor insuline. Insuline is een hormoon dat in de gezonde situatie zorgt voor de opname van glucose door weefsels. Zorgvuldige regulatie van de insuline uitscheiding waarborgt een lage glucosespiegel in het bloed. Wanneer insuline niet meer voldoende effectief is, ontstaat een verhoogde vraag naar insuline. Als de alvleesklier, het orgaan dat insuline produceert, niet meer kan voldoen aan deze verhoogde vraag en uitgeput raakt, leidt dat tot the hoge glucose waarden in het bloed, ook wel hyperglycemie genoemd. Deze hoge glucosewaarden in het bloed zijn slecht voor het lichaam.

In het tweede hoofdstuk is beschreven dat behandeling met de DJBL leidt tot verbetering van type 2 diabetes en een daling van het glucosegehalte in het bloed. Hormonen die hierbij een rol zouden kunnen spelen zijn: GLP-1 (voluit: glucagon-like peptide-1), glucagon en GIP (voluit: glucose-dependent insulinotrophic polypeptide). Het hormoon GLP-1 stimuleert de productie van insuline. Daarnaast zijn er aanwijzingen dat het de gevoeligheid voor insuline in de weefsels positief beïnvloedt. Verder remt GLP-1 de afgifte van glucagon. Dit hormoon stimuleert het vrijmaken van opgeslagen glucose uit bijvoorbeeld de lever. In het geval van diabetes, waarbij er een overschot aan glucose in het bloed aanwezig is, is het ongunstig om extra glucose uit de lever vrij te maken en daarmee het glucose niveau in het bloed verder te doen toenemen. Daarom is remming van de glucagon concentratie door een verhoogd GLP-1 gunstig. Het derde genoemde hormoon, GIP, kan in patiënten met diabetes zorgen voor extra glucagon. Het onderzoek liet zien dat na plaatsing van de DJBL de waarden van GLP-1 toenamen terwijl die van glucagon en GIP daalden. Deze veranderingen zouden kunnen bijdragen aan het positieve effect van de DJBL op type 2 diabetes. 
Om dieper in te gaan op hoe de DJBL gewichtsverlies bewerkstelligt, werden in Hoofdstuk 4 hormonen onderzocht die een rol spelen bij eetlust, zogenaamde verzadigings- en hongerhormonen. De meerderheid van de patiënten gaf na het plaatsen van de DJBL aan zich meer verzadigd te voelen. Daarnaast gaven alle patiënten aan minder te zijn gaan eten. In het afgenomen bloed werd na DJBL plaatsing een toename gevonden van het hormoon PYY (voluit: peptide YY), een hormoon dat in de darm aangemaakt wordt en zorgt voor een verzadigd gevoel. Dit zou deels de toename in het verzadigingsgevoel van de patiënten kunnen verklaren. Van ghreline, een hormoon dat door de maag gemaakt wordt als deze leeg is, is bekend dat het een honger gevoel kan geven. In onze patiënten zagen wij na het plaatsen van de DJBL het nuchtere ghreline omhoog gaan. Echter, na een maaltijd daalde het ghreline sterker. De waarden van leptine in het bloed, een verzadiginshormoon dat door vetcellen gemaakt wordt, nam af. Van leptine is bekend dat het verzadigende effect in patiënten met obesitas beperkt is en dat het met name interessant is als afspiegeling van de vet massa van het lichaam. CCK (voluit: cholecystokine) is net als PYY een verzadigingshormoon. De spiegels van dit hormoon daalden interessant genoeg na plaatsing van de DJBL. Kortom, patiënten behandeld met de DJBL geven aan zich meer verzadigd te voelen en minder te eten waarbij veranderingen in verzadigings hormonen mogelijk een belangrijke rol te spelen.

\section{DJBL behandeling verbetert niet-alcoholische vette leverziekte}

Hoofdstuk 5 is gericht op een andere ziekte geassocieerd met obesitas, namelijk nietalcoholische vette leverziekte. Deze leverziekte wordt in de Engelse literatuur nonalcoholic fatty liver disease genoemd en afgekort tot NAFLD. Wanneer NAFLD zich in het stadium bevindt waarin de ziekte beperkt is tot vervetting van de lever, is het een redelijk onschuldige ziekte. Echter wanneer dit stadium niet behandeld wordt, kan de ziekte verergeren tot NASH (voluit: niet-alcoholische steatohepatitis). In dit ernstigere stadium is er naast vervetting tevens sprake van ontsteking van de lever. Dit kan uiteindelijk zo ernstig worden dat de lever niet meer voldoende zijn werk kan doen en er leverfalen ontstaat. Het is daarom van belang om NAFLD in een vroeg stadium te behandelen. In dit hoofdstuk is onderzocht of de DJBL effectief is in het behandelen van NAFLD. Hiervoor zijn in het bloed van de patiënten markers bepaald die een indicatie geven over de aanwezigheid van NAFLD. Na het starten van de DJBL behandeling werd een daling van deze markers gezien, die grotendeels stabiel bleef tot zes maanden na het verwijderen van de DJBL. Dit suggereert een mogelijke verbetering van NAFLD, waarbij misschien zelfs progressie naar NASH voorkomen zou kunnen worden. 


\section{De rol van darmbacteriën in obesitas en het effect van de DJBL op de darmflora}

Verder onderzoek naar de ontwikkeling van obesitas is gerapporteerd in Hoofdstuk 6. Sinds enkele jaren wordt gedacht dat de samenstelling van darmbacteriën een rol speelt bij het ontstaan van obesitas. De bacteriële samenstelling in ontlasting van slanke personen is in deze studie vergeleken met de bacteriële samenstelling van de ontlasting van mensen met obesitas. De twee belangrijkste bacterie populaties in de menselijke darm zijn de Bacteroideten en de Firmicuten. Gevonden werd dat bij mensen met overgewicht de verhouding tussen deze populaties verstoord is, ten voordele van de Firmicuten. Deze bacteriën worden verantwoordelijk geacht voor het effectiever vrijmaken van energie uit voedsel. Bovendien werd een relatie gevonden tussen de mate van overgewicht, uitgedrukt in $\mathrm{kg} / \mathrm{m}^{2}$ oftewel $\mathrm{BMI}$, en de verhouding van de genoemde darmbacterie typen. Dit komt overeen met eerder proefdier en humaan onderzoek. Daarnaast werd er bij de obese mensen frequenter calprotectine in de ontlasting gevonden. Het eiwit calprotectine komt bij ontsteking vrij uit witte bloedcellen. Aanwezigheid van dit eiwit in de ontlasting kan duiden op ontsteking van de darm. Ook in het bloed van de obese mensen werd verhoogde ontstekings activiteit gevonden. Hiervoor werd de marker CRP (voluit: C-reactief proteïne) bepaald, een eiwit dat aanwezig is in het bloed als er in het lichaam sprake is van ontsteking. Kortom, de veranderde bacteriële samenstelling in mensen met obesitas lijkt samen te hangen met ontsteking in de darm en mogelijk verder in het lichaam. Dit suggereert dat de veranderde samenstelling van de darmbacteriën een ontstekingsbevorderend effect zou kunnen hebben. Gedacht wordt dat deze ontsteking, die in mensen met overgewicht laaggradig is, een belangrijke rol speelt in het ontstaan van de aan obesitas gerelateerde ziekten zoals type 2 diabetes en NAFLD. Belangrijk is dan ook te onderzoeken hoe de samenstelling van de darmbacteriën op een gunstige manier beïnvloed kan worden. Daarom is de laatste jaren wereldwijd veel onderzoek gedaan naar de mogelijke toepassing van pre- en probiotica of zelfs antibiotica in de strijd tegen obesitas en zijn comorbiditeiten.

In Hoofdstuk 7 is onderzocht of de DJBL leidt tot verbeteringen in de microbiota samenstelling van mensen met overgewicht. Gewichtsverlies en verbetering van type 2 diabetes gingen gepaard met veranderingen in de darmflora die bepaald werd in de ontlasting. Typen bacteriën die normaal gesproken voornamelijk in de dunne darm voorkomen werden na implantatie van de DJBL in grotere hoeveelheid teruggevonden in de ontlasting (welke met name de microbiota samenstelling in de dikke darm weerspiegelt). Een verklaring voor deze verschuiving zou kunnen zijn dat door de DJBL vertering van voedsel pas later in de darm van start kan gaan, immers verteringssappen zijn gedurende de eerste $60 \mathrm{~cm}$ van de dunnen darm gescheiden van het te verteren voedsel. Daarnaast werd een toename gezien van bacteriën uit een groep die doorgaans als gezondheid bevorderend worden beschouwd, te weten de Lactobacilli die we kennen van de zuivelproducten Activia en Yakult. Na explantatie van de DJBL bleven de gunstige 
effecten met betrekking tot gewicht en glucoseregulatie nog aanhouden, echter de microbiota samenstelling leek terug te gaan naar de oorspronkelijke samenstelling. Hierdoor ligt de verklaring voor de blijvend positieve effecten na verwijderen van de DJBL mogelijk niet bij de microbiota, maar worden deze gehandhaafd door andere nog onbekende mechanismen. Echter, deze laatste tests na uithalen van de DJBL zijn slechts uitgevoerd in een kleine groep mensen, waardoor verder onderzoek van meerwaarde zal zijn om hier met zekerheid iets over te kunnen zeggen.

\section{Het effect van de DJBL op ontsteking}

Al eerder kwam naar voren dat obesitas gepaard gaat met laaggradige ontsteking en dat juist deze minimale ontstekingsactiviteit een rol lijkt te spelen bij de aan obesitas gerelateerde comorbiditeiten zoals type 2 diabetes en NAFLD. Gezien het gunstige effect van DJBL behandeling op deze ziekten, zou een afname van de laaggradige ontsteking bij onze met de DJBL behandelde patiënten in de lijn der verwachting liggen. Om dit te onderzoeken zijn in Hoofdstuk 8 bloedmonsters afgenomen vooraf en op verschillende momenten tijdens de DJBL behandeling. Hierin zijn parameters bepaald die een indruk geven van de ontstekings status. Het al eerder genoemde CRP, een veel gebruikte klinische marker, werd bepaald. Daarnaast werden een tweetal cytokines bepaald, tumor necrosis factor alfa, ook wel TNF- $\alpha$ genoemd, en interleukine 6 (afgekort: IL-6). Cytokines zijn signaalstoffen van ons afweersysteem waarbij hogere waarden correleren met een hogere ontstekings activiteit. Tot slot werd MPO (voluit: myeloperoxidase), een onstekingsmediator die in eerder onderzoek gerelateerd bleek aan de aanwezigheid van $\mathrm{NASH}$, bepaald. Na implantatie van de DJBL werd een kortdurende stijging van de ontstekingsparameters in het bloed gezien. Dit kan het gevolg zijn van afgenomen voedselinname. Ook bij patiënten met anorexia wordt frequent een toegenomen ontstekingsactiviteit waargenomen. Een andere verklaring kan de reactie zijn op het 'vreemde lichaam', de DJBL. Zes maanden na inbrengen van de DJBL waren de ontstekingswaarden in het bloed vergelijkbaar met de waarden die vooraf aan DJBL plaatsing gevonden waren. Het is dus goed mogelijk dat langere behandeling met de DJBL een afname van de onstekingsparameters zal laten zien.

\section{Toekomstperspectief en conclusie}

In Hoofdstuk 9 staan de belangrijkste bevindingen uit dit proefschrift beschreven evenals het toekomstperspectief. Op niet al te lange termijn zullen resultaten beschikbaar komen over een langere behandelduur met de DJBL. Daarnaast zal inzicht verkregen worden in de mogelijkheid tot herimplantatie, dus het meermaals achter elkaar behandelen van een patiënt met de DJBL. Inmiddels is gebleken dat het niet langer nodig is om de procedure 
onder algehele narcose uit te voeren, zoals in de meeste van de door ons bestudeerde patiënten wel gebeurde, waarmee de risico's van narcose tot de verleden tijd behoren.

Interessant zou het zijn om verder onderzoek te verrichten naar het effect van DJBL behandeling op andere aan obesitas gerelateerde ziekten zoals diabetische oogziekte, slaap apneu syndroom en aderverkalking. Eveneens lijkt het van meerwaarde om de effecten van de DJBL te bestuderen in grotere groepen patiënten en onderzoek te verrichten waarin verschillende behandelstrategieën met elkaar vergeleken worden, zoals leefstijladviezen, medicamenteuze therapieën en bariatrische technieken.

Op basis van de in dit proefschrift beschreven resultaten en de actueel beschikbare literatuur, wordt geconcludeerd dat DJBL behandeling een plaats verdient tussen de conservatieve leefstijladviezen en invasieve bariatrische chirurgie, omdat het een veilige en effectieve methode is in de strijd tegen obesitas en zijn comorbiditeiten. 


\section{Appendix \\ Dankwoord}

Curriculum Vitae

List of Publications

Abbreviations 


\section{ABSTRACT}

\section{Background}

Promoveren in letterlijke zin is het behalen van de academische graad van doctor door het schrijven en publiekelijk verdedigen van een proefschrift. In werkelijkheid behelst promoveren een onderzoeksproject van veelal enkele jaren, met spreekwoordelijke pieken en dalen. Promoveren doet een promovendus echter gelukkig nooit alleen.

\section{Methods}

Met behulp van vele hardwerkende studenten, twee top verpleegkundigen en met steun van vele collega's, familie en vrienden, is bij tientallen gemotiveerde patiënten een uitgebreide set aan tests uitgevoerd. Dit allemaal onder de leiding van vier (co)promotoren.

\section{Results}

Ons onderzoek heeft geresulteerd tot deze thesis, verschillende publicaties, prijzen en (inter)nationale orale dan wel posterpresentaties. Daarnaast hebben er vele additionele activiteiten plaats gevonden, zoals labuitjes, kamerdiners, borrels, feestjes en winterbijscholingen, die het plezier in het werk significant hebben doen stijgen.

\section{Conclusion}

Vier jaar promoveren is niet niks, maar vele handen maken licht(er) werk. Gemotiveerde patiënten zijn een voorwaarde voor het doen slagen van een traject, evenals steun van naasten, lieve collega's en een goed promotie-team. De dank naar eenieder is dan ook groot. 


\section{DANKWOORD}

Allereerst natuurlijk veel lof voor alle patiënten die vrijwillig deel hebben genomen aan het onderzoek. Ze zijn onderworpen aan in totaal zo'n 300 maaltijdtollerantietesten, talloze urine- en ontlasting verzamelingen, ademtesten, vragenlijsten, biopten en wat al niet meer. Dankbaar ben ik dat ze bereid waren zich keer op keer in te zetten voor iets waar ze notabene zelf geen direct voordeel bij hadden.

Veel dank ook aan mijn vier-koppig promotie team. Allereerst Prof. dr. Buurman, beste Wim, meer dan eens heb ik je achter na moeten zitten omdat ik graag iets met je wilde overleggen. Echter, telkens was het de moeite meer dan waard. Dank voor het punctueel verbeteren van mijn abstracts, posters en manuscripten. Lang konden we samen nadenken over één enkele zin, een figuur of het best te gebruiken woord. Maar ook vele gespreken hebben we gevoerd over bijna alles tussen hemel en aarde. Natuurlijk wist jij altijd net iets beter het naadje van de kous, maar hopelijk heb ik andersom ook jou soms iets kunnen bijbrengen.

Daarnaast Prof. dr. Greve, beste Jan Willem, al vanaf de eerste keer dat ik met je mocht overleggen, over mijn SOEPEL die de effectiviteit van bariatrische chirurgie beschreef, was ik onder de indruk van je kennis. Dank voor de mogelijkheden die je me hebt gegeven om werkelijk alles te onderzoeken wat ik maar wilde en met de resultaten de hele wereld over te reizen, van New York tot New Delhi en van Istanbul tot Israel, niets was te gek. Ik voel me vereerd dat ik een van jouw promotie-telgen ben. In de toekomst hoop ik nog minstens net zoveel van je te mogen leren op chirurgisch vlak als ik reeds op wetenschappelijk vlak van je geleerd heb.

En natuurlijk Prof. dr. Bouvy, beste Nicole, jouw onuitputtelijke positiviteit en enthousiasme is voor eenieder een inspiratiebron. Dank voor je support, zowel ten aanzien van de klinische patiënt-gerelateerde zaken alswel met de stukken voor dit boekje. Fijn dat je inzet zijn vruchten heeft afgeworpen en dat ik je benoemd bent tot professor, het is je gegund.

Last but certainly not least, Dr. Rensen, beste Sander, hier voor je een van de weinige schrijfsels van mij die jij de afgelopen jaren niet hebt gelezen (uitzonderingen als boodschappenbriefjes daar gelaten). Met name de eerste stukken plozen we woord voor woord samen uit. Dank voor het nakijken van deze vele regels, je bereidheid om tijd voor me vrij te maken, het vertrouwen dat je altijd in me hebt gehad (toch?) en uiteraard de tip om naar Costa Rica op vakantie te gaan. Veel succes met je verdere AIO's en natuurlijk veel geluk met Petra en de stoere boys! 
Niet te onderschatten is ook de inzet van de twee top trialnurses Yvonne en Rochelle. Wat hebben we een bloed, zweet en tranen zitten in alle samples... En van Marjan, de diëtiste (en daarnaast fietsmaatje). Hartelijk dank voor jullie inzet voor de patiënten en dit boekje. Zonder jullie zou het nooit zo zijn geworden als het nu is. Enne Rochelle, onze welverdiende lunches, brunches, shopdates en asti-parties houden we erin hè?!

Mijn dank is uiteraard ook groot voor de vele studenten die hun steentje (of rots) bij hebben gedragen. Gideon, hoe vaak hebben we geen crisis overleg gehad? Noëlle, wat leuk dat je ook het bariatrisch onderzoek in bent gegaan. En natuurlijk CRP Hedwig (need I say more?), Beevendepee Bart, Stephanie, Runi, Mark, de ELISA-koningin Mandy en Tom.

Verder, de dames van de poli chirurgie onder leiding van Bernadette. Dank voor jullie interessse, flexibiliteit, maar vooral ook gezelligheid. Ook dank aan de verschillende secretaresses Sandra, Henriëtte, Tonneke en niet te vergeten Evelien. En natuurlijk het CTCM met in het bijzonder Carl en Inge. De dames (en heren) van de biobank mogen ook niet vergeten worden. Zo vaak heb ik jullie lastig moeten vallen, dank voor alle keren dat jullie voor mij de -80 in zijn gedoken. $\mathrm{MERCl}$ dat jullie er zijn! :)

Many thanks as well to the people from GI Dynamics, especially Michele, Ken, Andy, Stu, Karl, JC, Gerd, Sean, Alexander, and Aurora. Your interest, support, and enthusiasm really helped. Furthermore, thanks to the monitors and Hanta and Laura from Medpass. And to all my co-authors, with Dr. Carel le Roux in particular. En natuurlijk Parweez, ik mis onze bijna dagelijkse overleggen. Veel succes ook met je eigen boekje en opleiding, het was prettig om met jou samen te werken!

In addition, I would like to thank Prof. dr. E. Blaak, Prof. dr. A. Masclee, dr. B. van Ramshorst, Prof. dr. C. Stehouwer, and Prof. dr. F. Pattou for critically evaluating my thesis.

Dan is het nu tijd om de vele collega's te bedanken waarmee ik in de afgelopen jaren korte of lange duur heb samen mogen werken. Jullie hebben mijn tijd op het lab (en de vele momenten daarbuiten (lees: feestjes, borrels, labuitjes, diners, fietstochtjes, koffiemomentjes, ijsje-pauzes, lunches etc)) gemaakt tot een onvergetelijke! Steven (veel succes gewenst met jouw lab en het happy environment), CCK-koning Hadfouni, Joepie uhhh sorry Joep, Simone, Wolfje, Guyke (is het niet weer eens tijd voor een gezamenlijk congresje? Het was leuk!), Toine, Liliane, Dennis M, Ruben, van Wunniks, maatje Rubi, Maartje, Huntjens, JB, de altijd gezellige Irma, Dennis J, Milou, Lucske, Aart, sport-maatje Marlou (volgend jaar dan toch samen 150 van de AGR?!), Aron, Geertje, Iris, ELISAAnnemarie, mede skinny-bitch Froekje, gezelligheidsdier David, Joyce-Manyi, Sedigheh, Paul, Renske, Freek, Kimmetje, Sofia, Hans, Frank, Babs, Eveline, Kirsten en Kirsten, Kostanovic, mini mini ..... aka Kevin, Mechteld, de altijd-voor-iedereen-klaar-staande 
Dorkje, JZ, het high fat task force: Jacco en Tim, de transplantatie-groep: Eva, Snoe-ijs, Pieter (eerst mede-semi, later mede-onderzoeker en mede-AIOS (:)), fruitella Tim, de vaatboys: Mark, Rob, Yee Lai, Fabio en Ralph en de anderen van de UNS 40 kolonie: Wongie, IF (Leipzig was top he?), Tiara (later gepromoveerd tot carpool-maatje en nu diner-date), Lori, Givan (mede bariatrie mattie), Rutger, RJ en natuurlijk de nieuwkies die ik nog net heb mee gekregen: Frans, Anne-Claire, Kiran, Martine, Leontine en Selwyn.

Een aantal collega's wil ik in het bijzonder noemen. Allereerst mijn roomies van het eerste uur. Mama Kaatje, het woord mama slaat in dit geval niet alleen op het mooie ouderlijk paar van ons roomies gezinnetje dat je samen met Marc vormde, maar ook op het voorbeeld dat jij met jouw werk ethos voor velen bent. Gelukkig was er op het werk en in de avonduren ook nog af en toe tijd voor een goed gesprek (wat zouden we toch graag eens een vlieg zijn he?!) of een gezellig etentje met de girls en/of roomies. Dank hiervoor en ook voor je interesse, support en antwoorden op mijn vele vragen! Dan Bassie Boy, naast de kamer kleuter vooral een top collega! Alle pieken en dalen van mijn labtijd (en daarbuiten) heb je met me mee beleefd (of je nou wilde of niet...) Dank voor je hulp, gezelligheid, vriendschap en je schouder die ik meermaals nodig had (en voor Anja die hierbij meeleefde). Ik kan me niemand beters bedenken om het laatste stukje van m'n promotietraject mee te volbrengen, fijn dat jij mijn paranymf wil zijn! Dan Marcje, als er weer eens een raar soort schreeuw van links kwam, dan was dit meestal het begin van jouw dolle 5 minuten. Veel lol hebben we gehad als werkvriendjes! Fijn dat er in Amsterdam altijd een deur voor me open staat bij Casa di Marci en voor het zijn van toch wel een beetje mijn voorbeeld. Verder natuurlijk Niene-pien, jouw gezucht, gesteun en gekreun vulde regelmatig de kamer, afgewisseld met vlagen van totale uitzinnigheid en blijdschap. Je bent een geweldig en bijzonder mens en ik ben blij dat ik je als kamergenootje heb mogen leren kennen, fijn dat we elkaar nog steeds geregeld zien. En natuurlijk niet te vergeten, wanne-be roomie Houdini, we deelden niet eenzelfde onderzoekslijn en ook niet dezelfde kamer, maar des te meer daarbuiten! Lief en leed hebben we gedeeld tijdens de koffietjes, etentjes (in een restaurant of thuis op de bank, maar altijd met een glas wijn). Zoals jijzelf al reeds in jouw dankwoord aangaf, die moeten we erin houden! Daarnaast vond ik de 'paranymfen-promovenda-combi' bij jouw promotie erg voor herhaling vatbaar en vind ik het dan ook top dat ook jij naast mij voor de corona wilt staan. In dit rijtje horen ook de latere roomies. Fieliep, mijn mede obesitasonderzoeker, jammer dat je naar de kelder in Oslo bent vertrokken! En de dames met wie ik Bas de laatste maanden van mijn lab-tijd het leven zuur heb gemaakt met onze mode verhalen en verwarmings danwel raam-open-deur-dicht taferelen. Allereerst de temperamentvolle Inca, met jou als laser capture koningin in combinatie met je doorzettingsvermogen moet het onderzoek zeker een succes worden, ik heb er alle vertrouwen in! En Kimmie, roomie van het laatste uur, veel succes ook met jouw eigen protocollen, formulieren, statistiek en traject, het wordt wat! 
Daarnaast ook dank aan mijn, inmiddels alweer ex-, collega's in het VieCuri die mij na de lange tijd op het lab de terugkeer naar de kliniek hebben laten ervaren als een warm bad met veel gezelligheid, leermomenten en buiten-werktijdse-activiteiten. Met natuurlijk special thanks to the MCG $^{\circledR}$. En mijn huidige collega's in het Sittardse, die de laatste loodjes hebben meegekregen van dit boekje.

Graag wil ik ook mijn vrienden en vriendinnetjes danken voor hun steun, interesse en luisterend oor. Allereerst de mannen van de Zeeland gang: Jack, Rogier, Marçe, Bonnevits, Matt, Faaz en Dijkie, al hebben jullie niet veel van mijn promotietraject mee gekregen, mede door mijn chronische tijdgebrek, fijn dat we na al die jaren nog steeds vrienden zijn! En de geneeskunde-vriendinnetjes: Linda, Daniëlle, Debbie, Rianne en Ceciel, bedankt. Vrij verschillende karakters, maar wat voelt het vertrouwd als we weer eens samen zijn. Wanneer is het tijd voor Dublin 2.0? Daarnaast ook de Let's Dance! meiden: Rinske, Carla en Inge, heel erg bedankt en dank ook aan 'de vriendinnetjes van Philip': Loes en Gideon, Manon, Krista en Odin. Met name jullie hebben, samen met de andere 'Maastrichtenaren', het dubieuze voordeel gehad om mij nog wat vaker te zien, maar daarmee ook wat vaker mijn sores aan moeten horen. Bij deze beloof ik plechtig dat het niet meer zoveel over werk zal gaan of nou ja over mijn proefschrift dan.

In deze rij mogen natuurlijk mijn stiekem toch wel een beetje trotse ouders: Papa en Mama en broer(tje, ha ha) Bouke niet ontbreken. Voor jullie speelden mijn promotie zich, zowel letterlijk in afstand als figuurlijk qua inhoud, ver van jullie bed af (behalve dan het congres in New York, was leuk hè Bouke?). Desalniettemin heb ik jullie steun gevoeld! Evenals als van mijn verdere familie en schoonfamilie to be. Niet het minst dankbaar ben ik voor mijn zusje Janneke, een enkele lach van haar maakt alles relatief en de moeite waard.

Tot slot eeuwige dank aan Philip, mijn Flipster, mijn alles. Lieverd, deze laatste woorden zijn voor jou. Ik weet dat werk en privé bij jou bij voorkeur strikt gescheiden zijn... Toch bracht je het op om iedere keer (nou ja meestal dan) naar mijn uitgebreide verhalen te luisteren en me steeds weer met twee benen terug op de grond te zetten als ik weer eens doordraaide, op wat voor manier dan ook. Dank daarvoor en voor je onvoorwaardelijke steun en geduld. Het leven met jou is een feest en als er op de Olympische Spelen een onderdeel 'het goed hebben samen' zou zijn, dan zouden wij zeker gouden plak winnen. Ik hou van jou lieverd! Op naar nog meer vrije tijd om samen de wereld te ontdekken. :) 


\section{CURRICULUM VITAE}

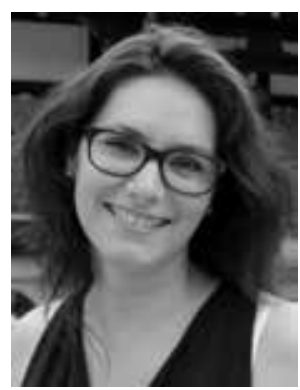

Charlotte de Jonge was born in Zierikzee, the Netherlands on the $10^{\text {th }}$ of September in 1985. After graduating from high school at the Regionale Scholengroep Professor Zeeman in June 2003, she attended medical school at the Maastricht University and obtained her medical degree with distinction in June 2009. As a medical student she went abroad to Tanzania, Belgium, and Nepal for international internships. During her senior year Charlotte followed a clinical and research elective at the Department of Surgery of the Atrium Medical Center, Heerlen. Subsequent to medical school she started her scientific career as a PhD-student at the Department of General Surgery of the Maastricht University Medical Center and the Atrium Medical Center Parkstad, under the supervision of Prof. dr. W.A. Buurman, dr. J.W.M. Greve, dr. S.S. Rensen, and dr. N.D. Bouvy. The work performed here, formed the basis of the current thesis and was presented at multiple national and international conferences and awarded with several prices. After 4 years, Charlotte started as a surgical resident at the VieCuri Medical Center Venlo. Recently, in July 2014, she started her surgical training program at the Orbis Medical Center SittardGeleen under supervision of dr. A.G.M. Hoofwijk. 


\section{LIST OF PUBLICATIONS}

F.J. Verdam, C. de Jonge, Y. Wils. EndoBarrier in de strijd tegen obesitas en diabetes. EADV Magazine. 2010 May;25(2):44-45.

Werkgroep Bariatrische Chirurgie: P.J. Daansen, A.J. Fogteloo, J.W. Greve, G.H. de Groot, I.M. Janssen, C. de Jonge, E.M. Mathus-Vliegen, M. Molag, H. Pijl, B. van Ramshorst, F.J. Verdam. Richtlijn Morbide Obesitas. Nederlandse Vereniging voor Heelkunde. 2011.

F.J. Verdam*, C. de Jonge*, J.W. Greve. Richtlijn voor de behandeling van morbide obesitas. Nederlands Tijdschrift voor Geneeskunde. 2012 May;156(23):A4630.

C. de Jonge, N.D. Bouvy. Foto van de maand: melena en kramp in de buik. Nederlands Tijdschrift voor Heelkunde. 2013 Mar;22(2):40.

F.J. Verdam, J.W. Dallinga, A. Driessen, C. de Jonge, E.J. Moonen, J.B. van Berkel, J. Luijk, N.D. Bouvy, W.A. Buurman, S.S. Rensen, J.W. Greve, F.J. van Schooten. Non-alcoholic steatohepatitis; a non-invasive diagnosis by analysis of exhaled breath. Journal of Hepatology. 2013 Mar;58(3):543-8.

C. de Jonge, S.S. Rensen, F.J. Verdam, R.P. Vincent, S.R. Bloom, W.A. Buurman, C.W. le Roux, N.C. Schaper, N.D. Bouvy, J.W. Greve. Endoscopic duodenal-jejunal bypass liner rapidly improves type 2 diabetes. Obesity Surgery. 2013 Sep;23(9):1354-60.

R.L. Blom, I.R. Steenbakkers, G. Lammering, R.F. Vliegen, E.J. Belgers, C. de Jonge, W.M. Schreurs, M. Nap, M.N. Sosef. PET/CT-based metabolic tumour volume for response prediction of neoadjuvant chemoradiotherapy in oesophageal carcinoma. European Journal of Nuclear Medicine and Molecular Imaging. 2013 Oct;40(10):1500-6.

C. de Jonge, S.S. Rensen, G.H. Koek, M.F. Joosten, W.A. Buurman, N.D. Bouvy, J.W. Greve. Endoscopic duodenal-jejunal bypass liner rapidly improves nonalcoholic fatty liver disease plasma parameters. Clinical Gastroenterology and Hepatology. 2013 Nov;11(11):1517-20.

C. de Jonge, S.S. Rensen, G.H. Koek, M.F. Joosten, W.A. Buurman, N.D. Bouvy, J.W. Greve. Endoscopic Duodenal-Jejunal Bypass Liner new treatment option for Nonalcoholic Fatty Liver Disease? Treatment Strategies Gastroenterology. 2013 Dec;1(2):40-41.

F.J. Verdam, S. Fuentes, C. de Jonge, E.G. Zoetendal, R. Erbil, J.W. Greve, W.A. Buurman, W.M. de Vos, S.S. Rensen. Human intestinal microbiota composition is associated with local and systemic inflammation in obesity. Obesity. 2013 Dec;21(12):E607-15. 
C. de Jonge, S.S. Rensen, H. D’Agnolo, N.D. Bouvy, W.A. Buurman, J.W. Greve. Six months of duodenal-jejunal exclusion does not lead to decreased systemic inflammation in obese subjects with type 2 diabetes. Obesity Surgery. 2014 Feb;24(2):337-41.

C. de Jonge*, P. Koehestanie*, F.J. Berends, I.M. Janssen, N.D. Bouvy, J.W. Greve. First long-term results of a multi-center, prospective, randomized, controlled trial of the endoscopic duodenal-jejunal bypass liner for the treatment of type 2 diabetes in obese subjects. Accepted in Annals of Surgery.

C. de Jonge, S.S. Rensen, F.J. Verdam, R.P. Vincent, S.R. Bloom, W.A. Buurman, C.W. le Roux, N.D. Bouvy, J.W. Greve. The impact of duodenal-jejunal exclusion on satiety hormones. Submitted.

F.M. Segers, F.J. Verdam, C. de Jonge, B. Boonen, A. Driessen, N.D. Bouvy, J.W. Greve, W.A. Buurman, S.S. Rensen. Activation of the alternative pathway of complement is associated with human nonalcoholic fatty liver disease. Submitted.

C. de Jonge, S. Fuentes, S.S. Rensen, W.A. Buurman, N.D. Bouvy, W.M. de Vos, J.W. Greve. The effect of the duodenal-jejunal bypass liner on gut microbiota composition. In preparation.

* shared first 


\section{ABBREVIATIONS}

A

ALT - alanine aminotransferase

AST - aspartate aminotransferase

AUC - area under the curve

\section{B}

$\mathrm{BMI}$ - body mass index

C

CCK - cholecystokinin

CK-18 - cytokeratin-18

CRP - c-reactive protein

\section{D}

DJBL - duodenal-jejunal bypass liner

\section{E}

ELISA - enzyme-linked immunosorbent assay

EWL - excess weight loss

\section{$\mathbf{F}$}

FFA - free fatty acids

\section{G}

Y-GT - gamma-glutamyltransferase

GIP - glucose-dependent insulinotropic polypeptide

GLP-1 - glucagon-like peptide-1

H

$\mathrm{HbA}_{1 \mathrm{c}}$ - glycated hemoglobin

HDL - high-density lipoprotein

HITChip - human intestinal tract chip

HOMA-IR - homeostasis model of

assessment of insulin resistance
I

IL-6 - interleukin-6

L

LDL - low-density lipoprotein

L-FABP - liver fatty acid binding protein

M

MPO - myeloperoxidase

MTT - meal tolerance test

N

NAFLD - non-alcoholic fatty liver disease

$\mathrm{NASH}$ - non-alcoholic steatohepatitis

$\mathbf{T}$

T2DM - type 2 diabetes

TERIS - trans-oral endoscopic restrictive implant system

TG - triglycerides

TOGA - transoral gastroplasty

P

PYY - peptide yy

$\mathbf{R}$

RDA - redundancy analysis

RYGB - roux-en-y gastric bypass

S

SEM - standard error of the mean

SD - standard deviation

SPSS - statistical package for social

sciences

SU - sulfonylurea derivates

T

TNF- $\alpha$ - tumor necrosis factor alpha 
Printing of this thesis was financially supported by:
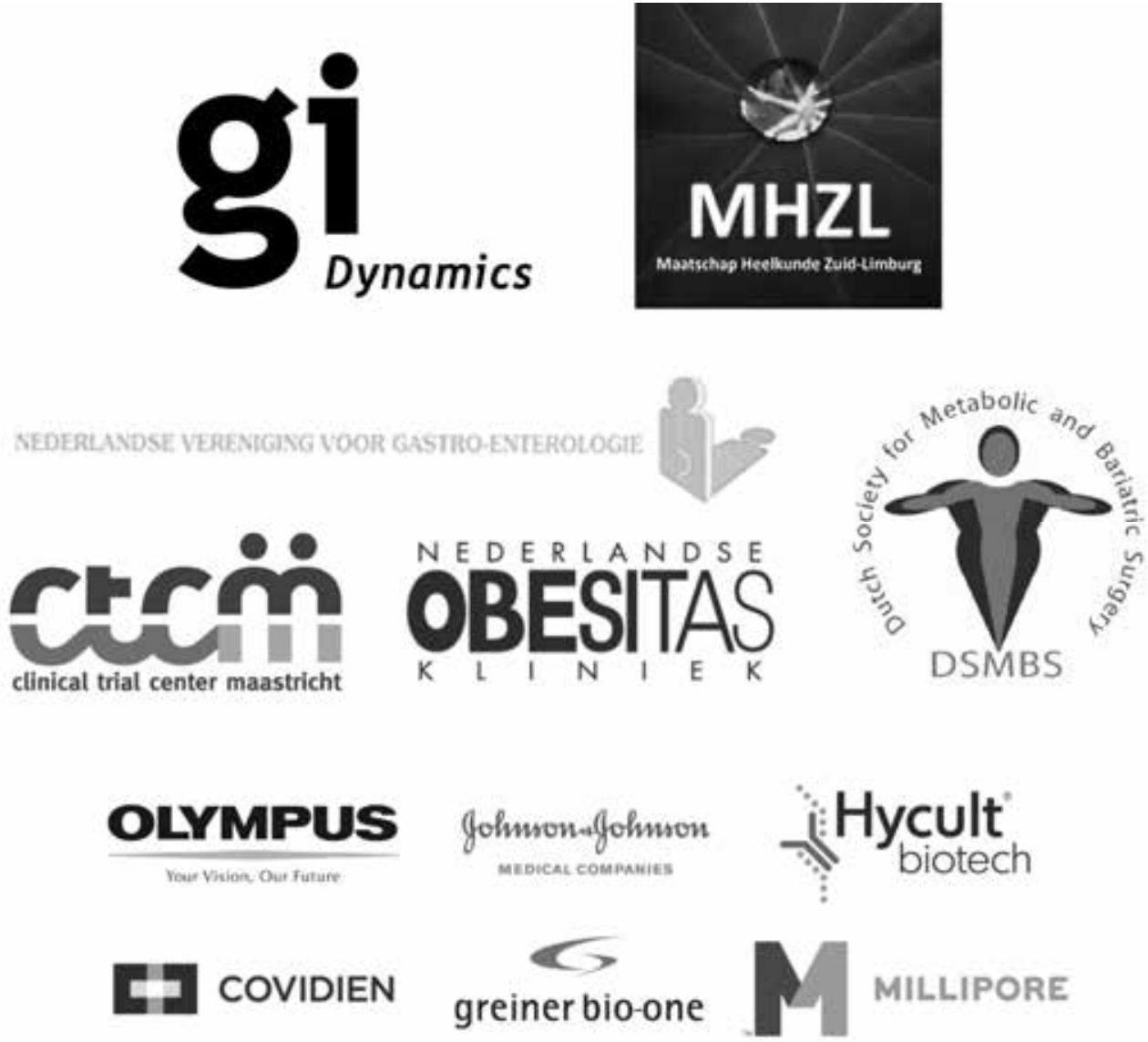

\section{Colofon}

Layout: Charlotte de Jonge

Printed by: Datawyse

ISBN: 978-90-9028444-6

(C) C. de Jonge, Maastricht 2014 
The Duodenal-Jejunal Bypass Liner is an Endoscopic bariatric technique. This thesis describes the effects on obesity and its comorbidities. In addition, possible mediating factors are adressed. 